Florida International University FIU Digital Commons

$5-27-2009$

\title{
The Development of an Optimized System of Narcotic and Explosive Contraband Mimics for Calibration and Training of Biological Detectors
}

Michael S. Macias

Florida International University, mmaci004@fiu.edu

DOI: $10.25148 /$ etd.FI09120807

Follow this and additional works at: https://digitalcommons.fiu.edu/etd

Part of the Chemistry Commons

\section{Recommended Citation}

Macias, Michael S., "The Development of an Optimized System of Narcotic and Explosive Contraband Mimics for Calibration and Training of Biological Detectors" (2009). FIU Electronic Theses and Dissertations. 123.

https://digitalcommons.fiu.edu/etd/123 


\title{
FLORIDA INTERNATIONAL UNIVERSITY
}

Miami, Florida

\section{THE DEVELOPMENT OF AN OPTIMIZED SYSTEM OF NARCOTIC AND EXPLOSIVE CONTRABAND MIMICS FOR CALIBRATION AND TRAINING OF BIOLOGICAL DETECTORS}

\author{
A dissertation submitted in partial fulfillment of the \\ requirements for the degree of \\ DOCTOR OF PHILOSOPHY \\ in \\ CHEMISTRY \\ by \\ Michael Salvador Macias
}

2009 
To: Dean Kenneth Furton

College of Arts and Sciences

This dissertation, written by Michael Salvador Macias, and entitled The Development of an Optimized System of Narcotic and Explosive Contraband Mimics for Calibration and Training of Biological Detectors, having been approved in respect to style and intellectual content, is referred to you for judgment.

We have read this dissertation and recommend that it be approved.

José Almirall

Yong Cai

Bruce McCord

De Etta Mills

Kenneth Furton, Major Professor

Date of Defense: May 27, 2009

The dissertation of Michael Salvador Macias is approved.

\begin{tabular}{r}
$\begin{array}{r}\text { Dean Kenneth Furton } \\
\text { College of Arts and Sciences }\end{array}$ \\
\hline Dean George Walker \\
University Graduate School
\end{tabular}

Florida International University, 2009 
(C) Copyright 2009 by Michael Salvador Macias

All rights reserved. 


\section{DEDICATION}

This dissertation is dedicated to my parents, Sal and Cindy, for their unwavering love, support, and empathy throughout my long and chaotic educational tenure. I doubt that I could have made it this far without their continual encouragement. 


\section{ACKNOWLEDGMENTS}

First, I would like to extend my gratitude to Dr. Kenneth Furton for his direction and friendship during my time at Florida International University. He was always willing to share his knowledge of chemistry and canine detection even though he could not always do so in a conventional manner. He instilled a desire to follow through with my goals so that I could succeed in the research field.

I want to thank Maiko Kusano, my roommate and closest friend during my time in Miami. She was always there to bounce ideas around, play the role of dictionary, spend time with away from school, and cook a never-ending buffet of international food. Maiko was a constant source of amusement both by her own doing and in response to my actions. I know that my time in Miami would have been less meaningful, less goofy and pounds lighter without her presence in my life.

I would like to thank the Furton research group for the interesting and always entertaining atmosphere that was our lab. In particular, I want to show my appreciation for Howard Holness who never complained at the constant questions that were thrown at him, the constant calls to ask for assistance, and the constant jokes that his wife will never be allowed to hear.

I would like to thank the faculty and staff of the Department of Chemistry \& Biochemistry. The knowledge that I gained through my coursework and instruction provided a sense of satisfaction for my choice of career.

I was honored with the assistance of an undergraduate researcher, Linda Calvo, who was always willing and eager to participate in my research. Linda helped with the early permeation studies, as well as playing a huge role in the development of the explosive 
tables found in the Appendix of this document. I wish to thank Linda for all of her help and constant vigilance in the face of such monotony.

I would especially like to thank Peter Nunez and the United States K9 Academy for his friendship and constant willingness to assist with the smallest details of my research. Pete was always around to answer questions, ensure canine teams were available to work with and buy lunch. He was instrumental in obtaining the results presented in this study.

The detection canine programs of the South Florida law enforcement departments have been particularly important to the success of my research. I would like to thank Mike Van Leer and the Florida Highway Patrol, Scott Silva and the Miami-Dade Police Department, Bill Swikehardt and the Coral Gables Police Department, Miami-Dade Corrections Department, the Miami Beach Police Department, the City of Miami Police Department, Sunny Isles Police Department, Homestead Police Department, Golden Beach Police Department, Sweetwater Police Department and Tony Guzman with Metro Dade K9 Service for participating in the field trials of my research.

Finally, I need to thank my family and friends for their support and making my time in Miami so worthwhile: Tony, David, Megan, Matt, Jenny, Davia, Shawn, Becca, Oliva, Lauryn, Jo Nell, Ben, Jessie, Paola, Jessica, and everyone else too numerable to mention. It was these people, with whom I've spent so much time at school, kayaking, playing volleyball and golf, bar hopping, and just goofing off in general.

This research was partially funded by the National Institute of Justice (2006-DN-BXK027), stipends from Florida International University's College of Arts and Science and Graduate Student Association, and was approved under IACUC 05-015 and 02-008 and IRB 080109-01. 


\section{ABSTRACT OF THE DISSERTATION \\ THE DEVELOPMENT OF AN OPTIMIZED SYSTEM OF NARCOTIC AND EXPLOSIVE CONTRABAND MIMICS FOR CALIBRATION AND TRAINING OF BIOLOGICAL DETECTORS by}

Michael Salvador Macias

Florida International University, 2009

Miami, Florida

Professor Kenneth Furton, Major Professor

Current commercially available mimics contain varying amounts of either the actual explosive/drug or the chemical compound of suspected interest by biological detectors. As a result, there is significant interest in determining the dominant chemical odor signatures of the mimics, often referred to as pseudos, particularly when compared to the genuine contraband material. This dissertation discusses results obtained from the analysis of drug and explosive headspace related to the odor profiles as recognized by trained detection canines. Analysis was performed through the use of headspace solid phase microextraction in conjunction with gas chromatography mass spectrometry (HSSPME-GC-MS). Upon determination of specific odors, field trials were held using a combination of the target odors with COMPS.

Piperonal was shown to be a dominant odor compound in the headspace of some ecstasy samples and a recognizable odor mimic by trained detection canines. It was also shown that detection canines could be imprinted on piperonal COMPS and correctly identify ecstasy samples at a threshold level of approximately 100ng/s. Isosafrole and/or MDP-2- 
$\mathrm{POH}$ show potential as training aid mimics for non-piperonal based MDMA. Acetic acid was shown to be dominant in the headspace of heroin samples and verified as a dominant odor in commercial vinegar samples; however, no common, secondary compound was detected in the headspace of either.

Because of the similarities detected within respective explosive classes, several compounds were chosen for explosive mimics. A single based smokeless powder with a detectable level of 2,4-dinitrotoluene, a double based smokeless powder with a detectable level of nitroglycerine, 2-ethyl-1-hexanol, DMNB, ethyl centralite and diphenylamine were shown to be accurate mimics for TNT-based explosives, NG-based explosives, plastic explosives, tagged explosives, and smokeless powders, respectively. The combination of these six odors represents a comprehensive explosive odor kit with positive results for imprint on detection canines.

As a proof of concept, the chemical compound PFTBA showed promise as a possible universal, non-target odor compound for comparison and calibration of detection canines and instrumentation.

In a comparison study of shape versus vibration odor theory, the detection of d-methyl benzoate and methyl benzoate was explored using canine detectors. While results did not overwhelmingly substantiate either theory, shape odor theory provides a better explanation of the canine and human subject responses. 


\section{TABLE OF CONTENTS}

CHAPTER

PAGE

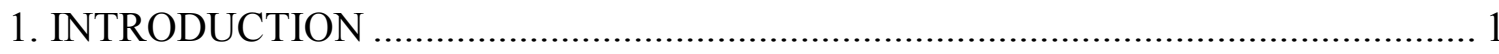

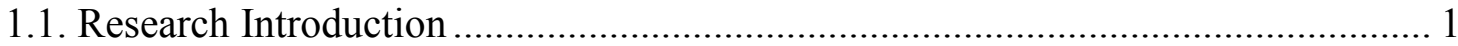

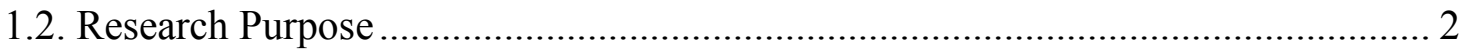

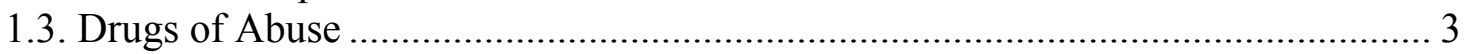

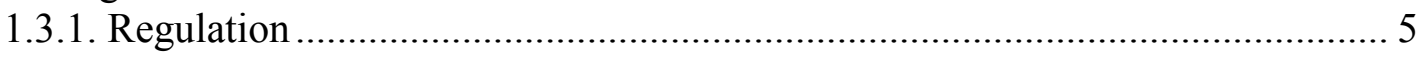

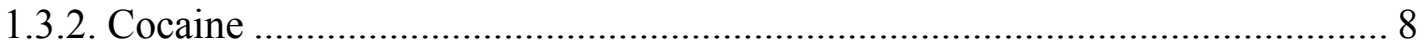

1.3.3. 3,4-Methylenedioxy-methamphetamine (MDMA),....................................... 9

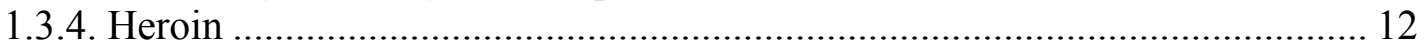

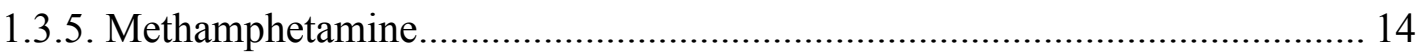

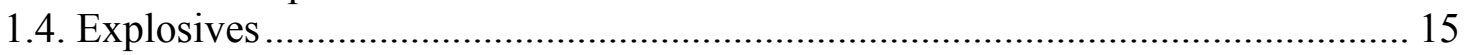

1.4.1. High vs. Low Explosives ...................................................................... 15

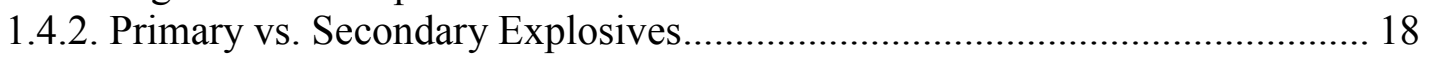

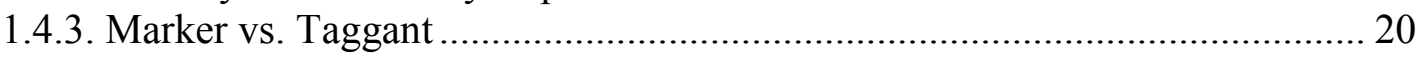

1.4.4. Chemical Groupings of Explosives ............................................................ 22

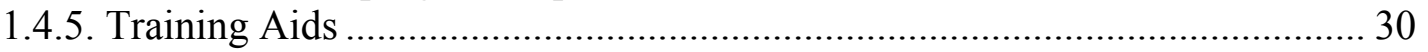

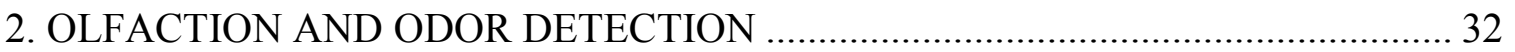

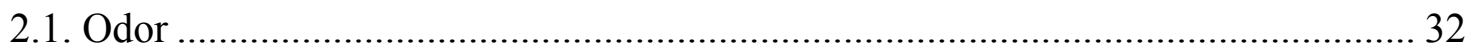

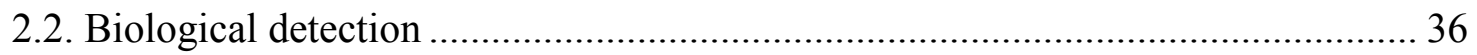

2.2.1. Canine (Canis familiaris) ........................................................................ 37

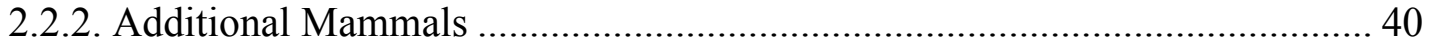

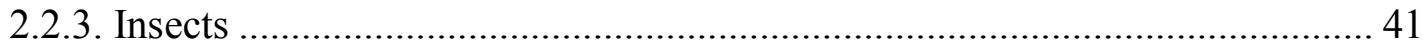

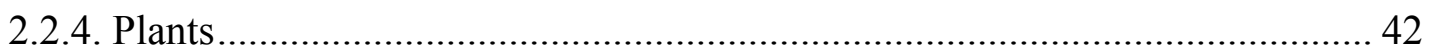

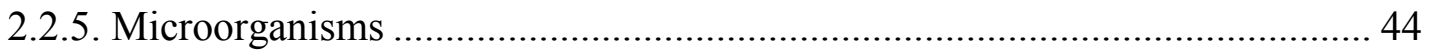

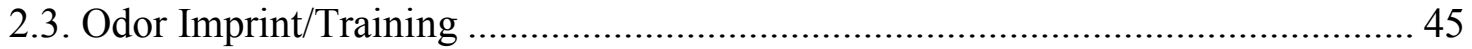

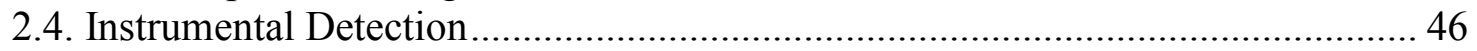

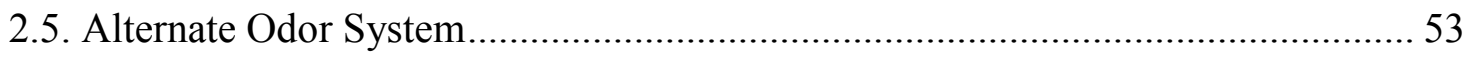

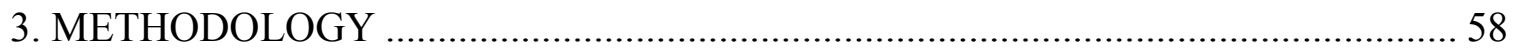

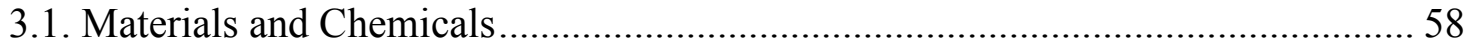

3.1.1. Chemicals, Drugs, Explosives, and Firearms …………………………......... 58

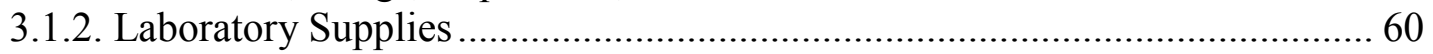

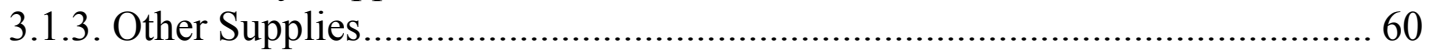

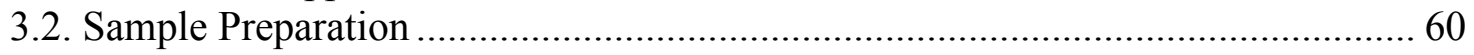

3.2.1. Headspace Sample Preparation ....................................................................... 60

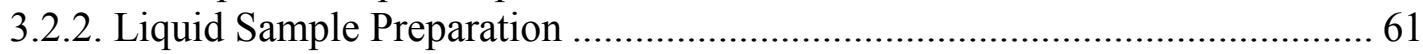

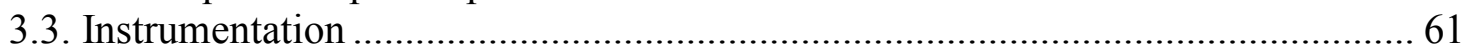

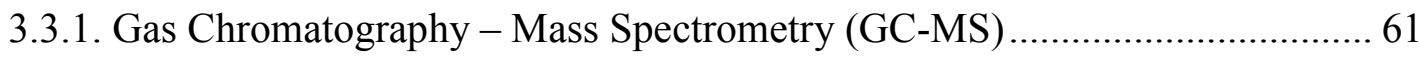

3.3.2. Liquid Chromatography - Mass Spectrometry (LC-MS) ................................. 63

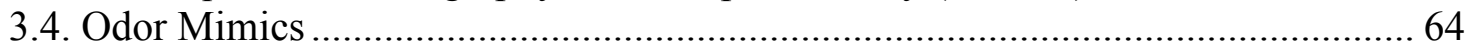

3.4.1. Controlled Odor Mimic Permeation System (COMPS) .................................... 64 


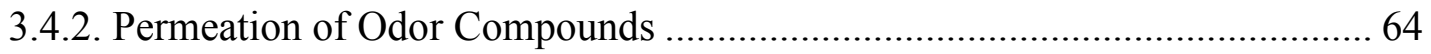

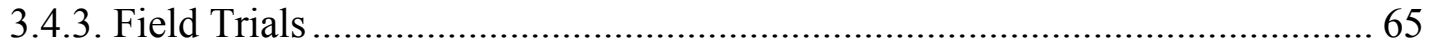

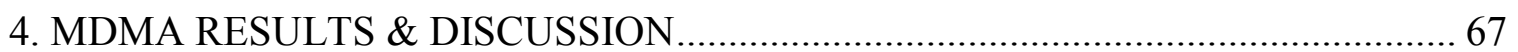

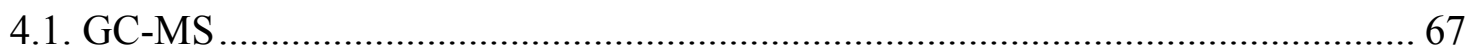

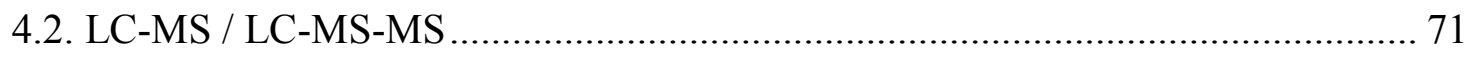

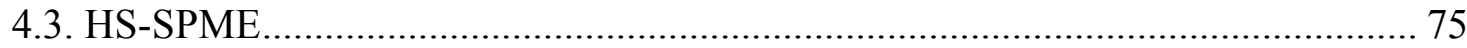

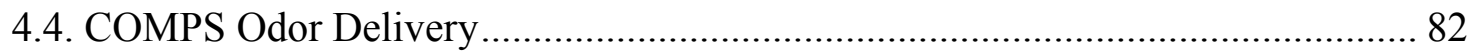

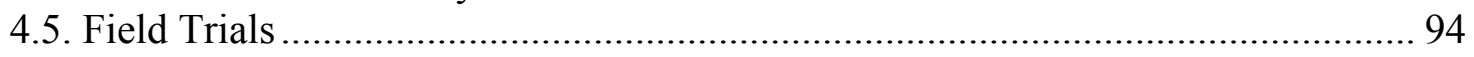

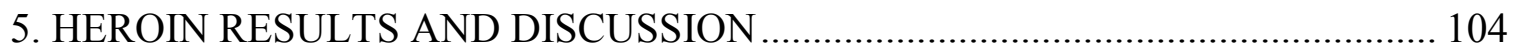

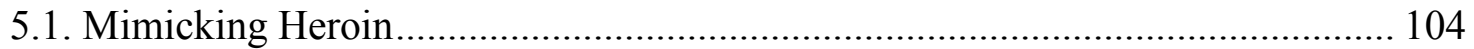

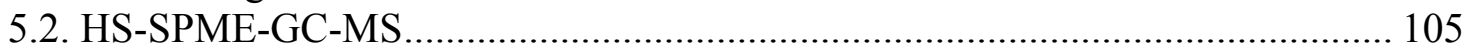

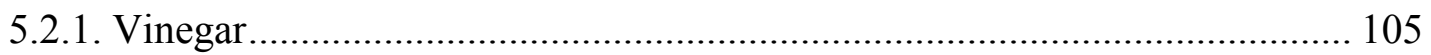

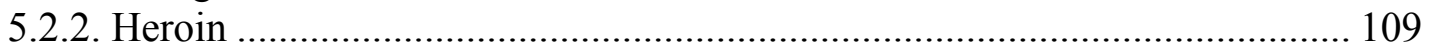

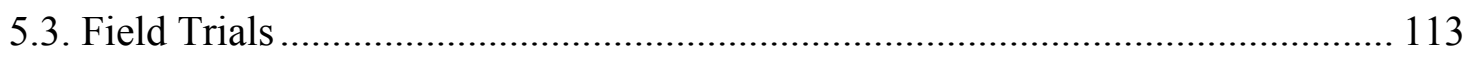

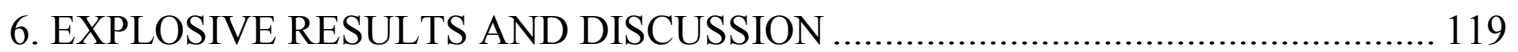

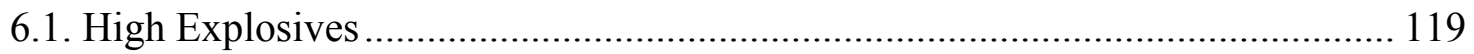

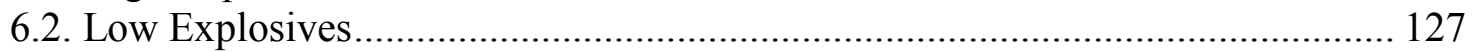

6.2.1. Single-Based Powder ............................................................................ 127

6.2.2. Double-Based Powders ............................................................................ 136

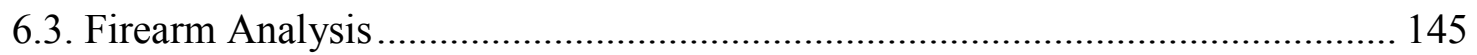

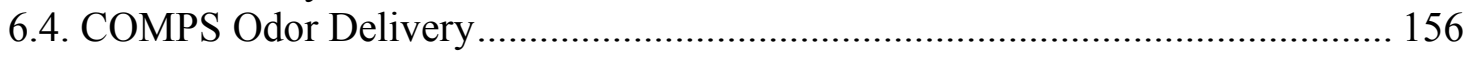

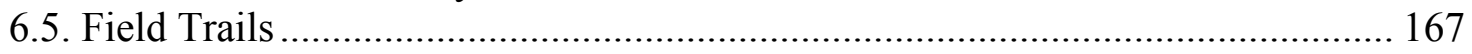

7. OLFACTION THEORY EXAMINATION AND RESULTS .................................. 173

8. CALIBRATION STANDARD EXPERIMENTATION AND RESULTS ................. 180

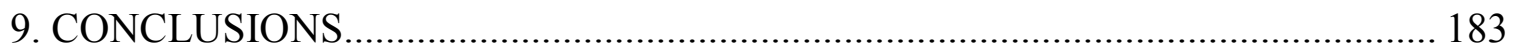

10. FUTURE WORK

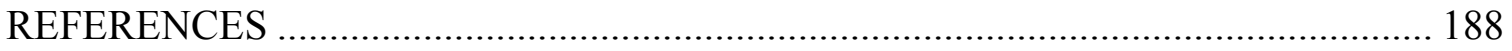

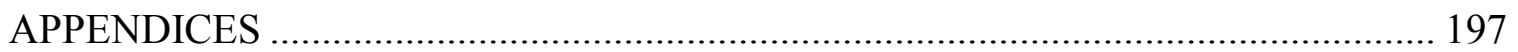

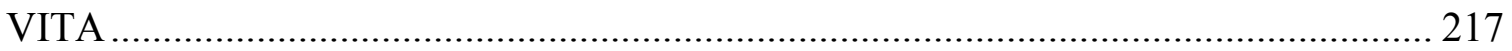




\section{LIST OF TABLES}

TABLE

PAGE

Table 1 - Drug class effects and examples........................................................... 4

Table 2 - CSA drug schedule characteristics and examples ...................................... 7

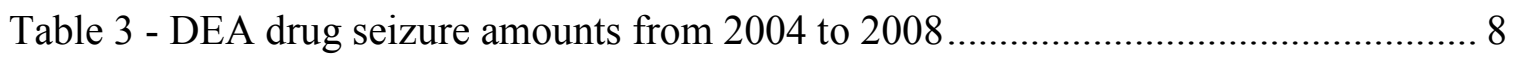

Table 4 - Examples of primary and secondary explosives ........................................ 19

Table 5 - Explosives grouped by chemical class .................................................... 23

Table 6 - Compositions of commercially available explosives (MSDS)........................ 31

Table 7 - Primary and secondary odor compounds for drugs \& explosives .................... 36

Table 8 - Comparisons between instrumental detectors and detection canines............... 52

Table 9 - Results of $1 \mathrm{mg} / \mathrm{mL}$ ecstasy solutions using GC-MS ................................... 71

Table 10 - Results of 10ppm ecstasy solutions using LC ....................................... 75

Table 11 - Summary of ecstasy headspace compounds ......................................... 81

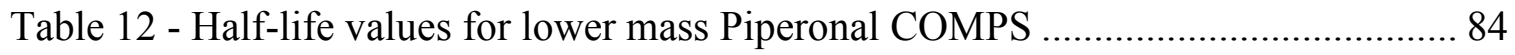

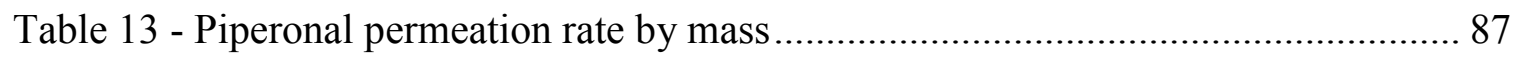

Table 14 - Piperonal permeation rate values by bag dimension ................................. 90

Table 15 - Piperonal permeation rate values by bag thickness .................................. 92

Table 16 - Piperonal permeation rate summary ..................................................... 94

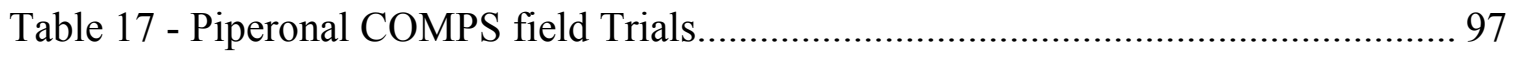

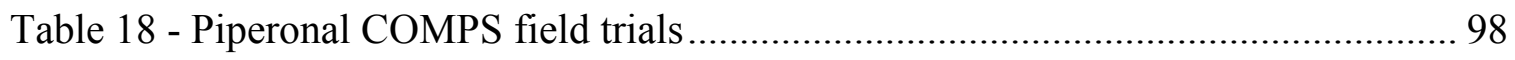

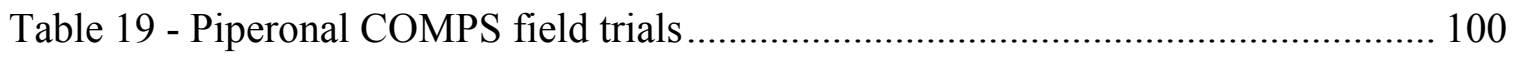

Table 20 - Summary of vinegar headspace compounds ......................................... 109

Table 21 - Summary of heroin and pseudo heroin headspace compounds .................... 112 
Table 22 - Heroin mimic field trials ....................................................................... 115

Table 23 - Heroin mimic field trials .................................................................. 116

Table 24 - Heroin mimic field trials .................................................................... 118

Table 25 - Summary of common high explosive headspace compounds ..................... 120

Table 26 - Summary of common single-based powder headspace compounds ............. 136

Table 27 - Summary of common double-based powder headspace compounds ............ 137

Table 28 - Explosive COMPS permeation rates in 2mil 3in x3in LDPE ..................... 166

Table 29 - Proofing results from IFRI explosive kit............................................... 169

Table 30 - Explosive testing after IFRI Explosive kit training .................................. 171

Table 31 - Results from canine reliability study of IFRI explosive kit ....................... 172

Table 32 - Field results from d-methyl benzoate odor recognition ............................. 176

Table 33 - Field results from PFTBA training ...................................................... 181 


\section{LIST OF FIGURES}

FIGURE

PAGE

Figure 1 - Chemical structures for common drugs of abuse ...................................... 5

Figure 2 - Synthesis of MDP-2-P intermediate from methylenedioxy starting

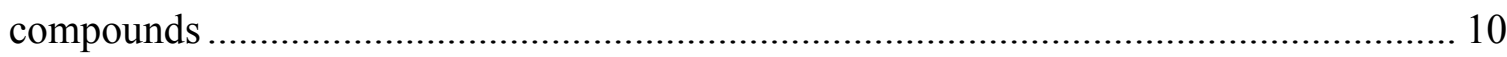

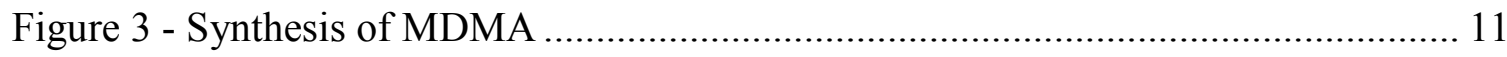

Figure 4 - Metabolism of heroin to morphine ......................................................... 12

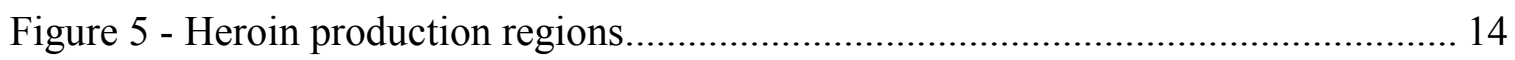

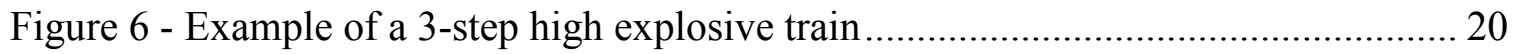

Figure 7 - Chemical structures for common explosive compounds ............................ 30

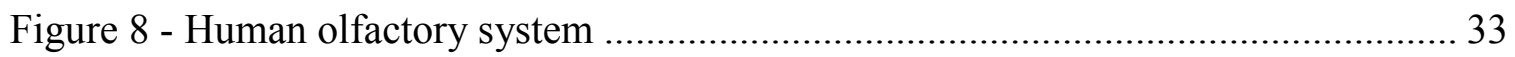

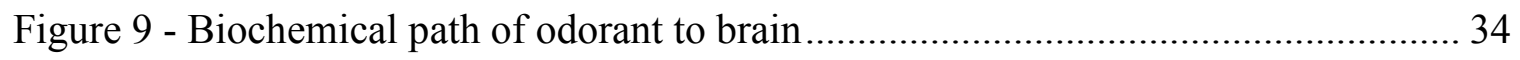

Figure 10 - Human and canine olfactory bulbs.................................................... 38

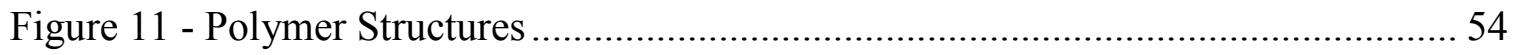

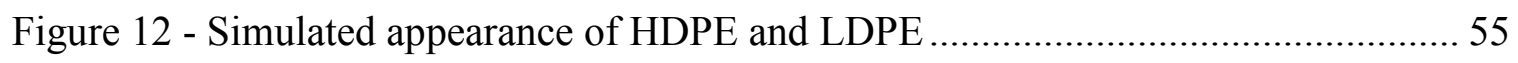

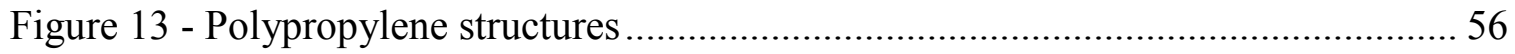

Figure 14 - Polypropylene polymer chains ....................................................... 57

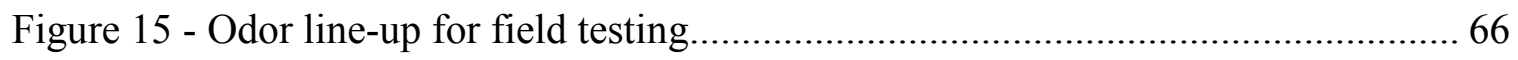

Figure 16 - Total ion chromatograms of $1000 \mu \mathrm{g} / \mathrm{mL}$ ecstasy solutions using GC .......... 68

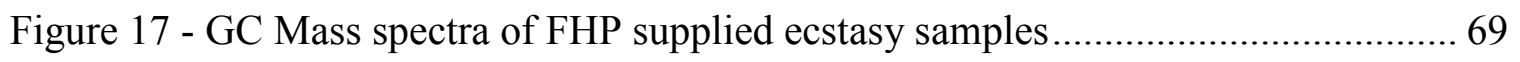

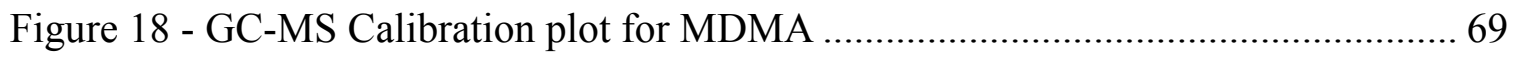

Figure 19 - GC-MS Calibration plot for caffeine .............................................. 70

Figure 20 - Total ion chromatograms of 10ppm ecstasy solutions using LC ................. 72 
Figure 21 - LC Mass spectra of FHP supplied ecstasy samples ................................. 73

Figure 22 - LC-MS Calibration plot for MDMA ..................................................... 74

Figure 23 - LC-MS Calibration plot for caffeine ................................................... 74

Figure 24 - Ecstasy Chromatograms using SPME-GC-MS showing most abundant

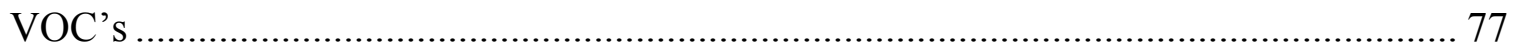

Figure 25 - Ecstasy Chromatograms using SPME-GC-MS showing most abundant

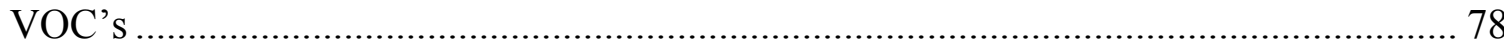

Figure 26 - Ecstasy Chromatograms using SPME-GC-MS showing most abundant

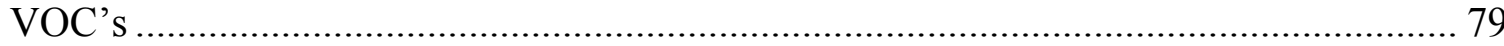

Figure 27 - Exponential relationship for piperonal permeation rate by mass ................. 84

Figure 28 - Linear relationship for piperonal permeation rate by mass for 3 in $\mathrm{x}$ 3in

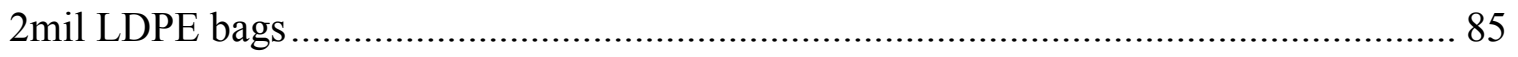

Figure 29 - Linear relationship for piperonal permeation rate by mass for 3in x 3in

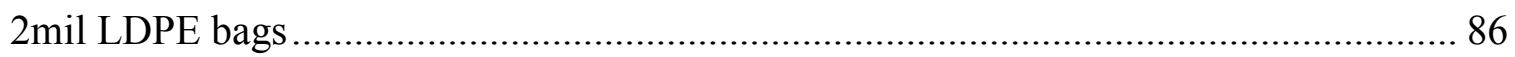

Figure 30 - Piperonal permeation rate in 3 in x 3 in 2 mil LDPE by initial mass .............. 88

Figure 31 - Plot of piperonal permeation rate by bag dimension ............................... 89

Figure 32 - Plot of piperonal permeation rate by bag area ....................................... 90

Figure 33 - Plot of piperonal permeation rate by polymer thickness........................... 91

Figure 34 - Plot of piperonal permeation rate by bag thickness ................................ 93

Figure 35 - Results of ecstasy testing on piperonal imprinted canines ......................... 96

Figure 36 - GC-MS chromatogram of three piperonal COMPS at different orders

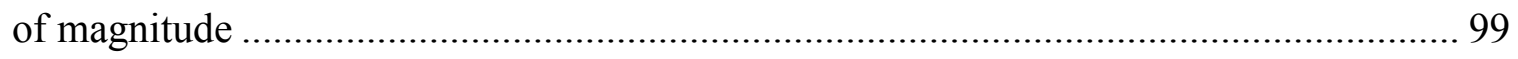

Figure 37 - Logarithmic plot of canine alert response vs. piperonal permeation rate .... 101 
Figure 38 - Results from canine repeatability study of piperonal COMPS 103

Figure 39 - Vinegar Chromatograms using SPME-GC-MS showing most abundant

VOC's

Figure 40 - Vinegar Chromatograms using SPME-GC-MS showing most abundant

VOC's

Figure 41 - Vinegar Chromatograms using SPME-GC-MS showing most abundant

VOC's 108

Figure 42 - Heroin chromatograms using SPME-GC-MS showing most abundant VOC's

Figure 43 - Pseudo heroin chromatograms using SPME-GC-MS showing most abundant VOC's

Figure 44 - TNT based high explosive chromatograms using SPME-GC-MS 121

Figure 45 - TNT based high explosive chromatograms using SPME-GC-MS 122

Figure 46 - TNT based high explosive chromatograms using SPME-GC-MS 123

Figure 47 - Plasticized high explosive chromatograms using SPME-GC-MS 124

Figure 48 - Plasticized high explosive chromatograms using SPME-GC-MS 125

Figure 49 - Plasticized high explosive chromatograms using SPME-GC-MS 126

Figure 50 - Hodgdon single based powder chromatograms using SPME-GC-MS ....... 128

Figure 51 - Hodgdon single based powder chromatograms using SPME-GC-MS ....... 129

Figure 52 - Hodgdon single based powder chromatograms using SPME-GC-MS ....... 130

Figure 53 - IMR single based powder chromatograms using SPME-GC-MS 131

Figure 54 - IMR single based powder chromatograms using SPME-GC-MS 132

Figure 55 - VihtaVuori single based powder chromatograms using SPME-GC-MS 133 
Figure 56 - VihtaVuori single based powder chromatograms using SPME-GC-MS .... 134

Figure 57 - VihtaVuori single based powder chromatograms using SPME-GC-MS ..... 135

Figure 58 - Hodgdon double based powder chromatograms using SPME-GC-MS ....... 138

Figure 59 - Hodgdon double based powder chromatograms using SPME-GC-MS ....... 139

Figure 60 - Hodgdon double based powder chromatograms using SPME-GC-MS ...... 140

Figure 61- Alliant double based powder chromatograms using SPME-GC-MS ........... 141

Figure 62 - Accurate Arms double based powder chromatograms using SPME-

GC-MS 142

Figure 63 - VihtaVuori double based powder chromatograms using SPME-GC-MS ... 143

Figure 64 - VihtaVuori double based powder chromatograms using SPME-GC-MS ... 144

Figure 65 - Firearm component chromatograms using SPME-GC-MS ...................... 147

Figure 66 - Firearm component chromatograms using SPME-GC-MS ....................... 148

Figure 67 - Firearm component chromatograms using SPME-GC-MS ....................... 149

Figure 68 - Gun cleaner chromatograms using SPME-GC-MS ............................... 150

Figure 69 - Firearm oil chromatograms using SPME-GC-MS ................................ 151

Figure 70 - Oil chromatograms using SPME-GC-MS ......................................... 152

Figure 71 - Oil chromatograms using SPME-GC-MS ......................................... 153

Figure 72 - Burned powder chromatograms using SPME-GC-MS showing most

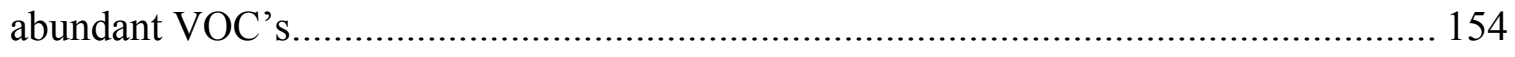

Figure 73 - Detected levels of 2,4-dinitrotoluene ............................................... 158

Figure 74 - Ethyl centralite permeation rate 2mil 3in x 3in LDPE............................. 160

Figure 75 - Diphenylamine permeation rate 2mil 3in x 3in LDPE............................ 161

Figure 76 - DMNB permeation rate 2mil 3in x 3in LDPE ....................................... 162 
Figure 77 - 2-Ethyl-1-hexanol permeation rate 2mil 3in x 3in LDPE .......................... 163

Figure 78 - Single based smokeless powder permeation rate 2mil 3in x 3in LDPE ...... 164

Figure 79 - Double based smokeless powder permeation rate 2mil 3in x 3in LDPE ..... 165

Figure 80 - Field test results from smokeless powder imprint.................................. 168

Figure 81 - Dose-response curve for methyl benzoate .......................................... 175

Figure 82 - Results from methyl benzoate isotope comparison trials with human

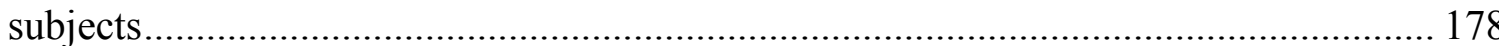




\section{INTRODUCTION}

\subsection{Research Introduction}

Biologic detection training and instrument calibration requires specific odors to ensure reliable results in the field. Yet the use of the actual substances is fraught with challenges. As an alternative to training on actual explosives and controlled substances, many agencies choose to apply mimics in place of the real contraband, avoiding complicated Drug Enforcement Administration (DEA) and Bureau of Alcohol, Tobacco, Firearm and Explosive (ATF) regulations and paperwork. Current commercially available mimics contain varying amounts of either the actual explosive/drug or the chemical compound of suspected interest by biological detectors. As a result, there is substantial interest in determining the dominant chemical odor signatures of the mimics, often referred to as pseudos, particularly when compared to the genuine contraband material.

In previous studies the ability of solid phase micro extraction (SPME) to extract volatiles from the headspace of forensic samples has been used in conjunction with gas chromatography - mass spectrometry (GC-MS) [1-5]. The odor chemicals present in the headspace of actual explosive and drug contraband parent compounds can be compared with those observed emanating from the mimic training aids. The identified chemicals

were used for the development of improved calibration aids for instrumental and biological detectors. 


\subsection{Research Purpose}

The goal of my research is to develop a standardized method for detection of contraband without the necessity of said contraband. This ability would widen the world of contraband detection by biological detectors beyond that of governmental agencies, and it would also allow for a universal standard to be used. Allowing for the forensic field to expand into the general community promotes the efforts of the forensic scientists while allowing the common person to comprehend and appreciate the design and optimization of the techniques that are used. The comprehension is beneficial because, ultimately, it is the common person serving as jurors who make the decisions based on the presented evidence.

The current study will present the differences and commonalities between chemical odor signatures of real contraband with that of contraband-mimic training aids as a method for demonstrating reliability in calibration of biological and instrumental detection. Solid phase micro extraction in conjunction with gas chromatography - mass spectrometry is used to analyze the headspace of the various compounds. Field trials conducted as double blind tests are used to determine biological detector interest in the observed odors and to evaluate the reliability of the mimicked scent. The expected results will describe a system of odor mimic of explosive and drugs that can be used as training/calibration devices for biologic/instrumental detectors. 


\subsection{Drugs of Abuse}

A drug is any xenobiotic (foreign chemical) that brings about a change in biologic function through pharmacological reactions within the body. There are five main classes of drugs grouped according to their pharmacodynamic effects (i.e. actions of the drug on the body): depressants, stimulants, psychedelics (hallucinogens and dissociative anesthetics), narcotic analgesic (opioids), and anabolic steroids (Table 1) [6]. Depressants are classified as such because they decrease cognitive function and reduce stimulatory response time. Stimulants are the opposite of depressants in that they increase respiration, heart rate, and electrical and chemical processes in the body. Psychedelics cause alterations in perception and mood. Narcotic analgesics cause euphoria like stimulants, but they also cause decrease in heart rate and respiration. Anabolic steroids speed up naturally occurring muscle development with the side effects of heart problems, liver problems, and increased rage. The most common drugs of abuse include: cocaine, marijuana, 3,4-methylenedioxy-methamphetamine (Ecstasy), heroin, methamphetamine, gamma-hydroxybutyrate (GHB), lysergic acid diethylamide (LSD), psilocybin, and phencyclidine (PCP). Examples of these can be seen in Figure 1. More information about these drugs can be found in Appendix I. 
Table 1 - Drug class effects and examples

\begin{tabular}{|c|c|c|}
\hline Category & Effects & Examples \\
\hline Depressants & 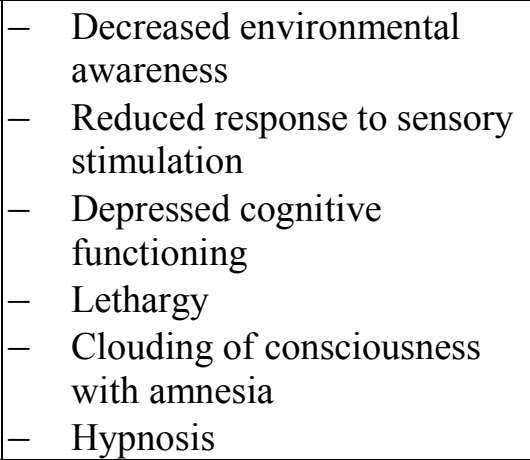 & $\begin{array}{ll}- & \text { Alcohol } \\
- & \text { Benzodiazepines } \\
- & \text { Barbiturates } \\
- & \text { Quaaludes } \\
- & \text { GHB }\end{array}$ \\
\hline Stimulants & 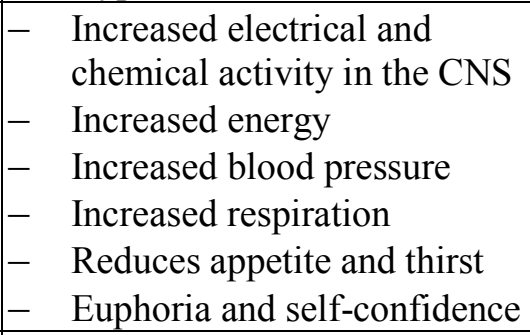 & $\begin{array}{ll}- & \text { Caffeine } \\
- & \text { Nicotine } \\
- & \text { Cocaine } \\
- & \text { Amphetamines / } \\
& \text { Methamphetamines }\end{array}$ \\
\hline Psychedelics & 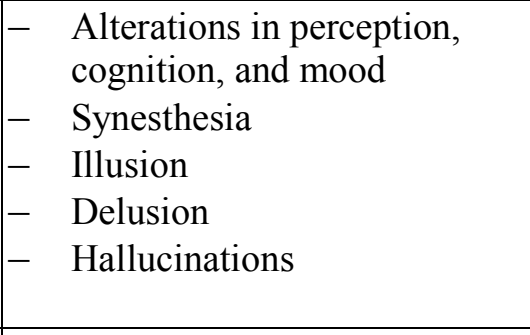 & $\begin{array}{ll}- & \text { LSD } \\
- & \text { Psilocybin } \\
- & \text { Mescaline } \\
- & \text { Cannabinols } \\
& \text { (Marijuana) } \\
- & \text { MDMA } \\
- & \text { Phencyclidine (PCP) } \\
\end{array}$ \\
\hline Narcotic Analgesic & $\begin{array}{ll}- & \text { Analgesia } \\
- & \text { Euphoria } \\
- & \text { Sedation } \\
- & \text { Respiratory depression } \\
- & \text { Antitussive } \\
- & \text { Bradycardia } \\
\end{array}$ & $\begin{array}{ll}- & \text { Opium } \\
- & \text { Morphine } \\
- & \text { Heroin } \\
- & \text { Codeine } \\
- & \text { Oxycodone }\end{array}$ \\
\hline Anabolic Steroids & $\begin{array}{ll}- & \text { Muscle development } \\
- & \text { Acne } \\
- & \text { Liver disorders } \\
- & \text { Heart problems } \\
- & \text { Aggression } \\
- & \text { Androgenic effects }\end{array}$ & $\begin{array}{ll}- & \text { Testosterone } \\
- & \text { Fluoxymesterone } \\
- & \text { Oxymetholone } \\
- & \text { Stanozolol }\end{array}$ \\
\hline
\end{tabular}


<smiles>COC(=O)C1CC2CCC(C1)N2C</smiles>

Cocaine<smiles>CC(=O)OC1=CCC2C3Cc4ccc(OC(C)=O)c5c4C2(CC1)C3O5</smiles>

Heroin

THC<smiles>CNC(C)Cc1ccccc1</smiles>

Methamphetamine<smiles>CNC(C)Cc1ccc2c(c1)OCO2</smiles>

MDMA

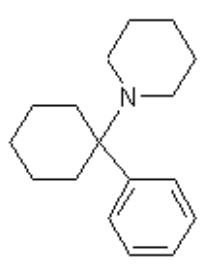

PCP<smiles>CN1CC(C(N)=O)C=C2c3cccc4[nH]cc(c34)C[C@H]21</smiles>

LSD

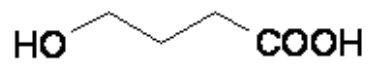

GHB

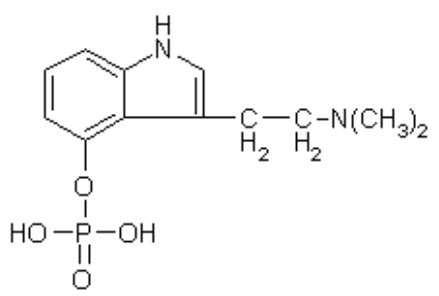

Psilocybin

Figure 1 - Chemical structures for common drugs of abuse

\subsubsection{Regulation}

Drugs that have been in constant use throughout history include cannabis, opium, coca, tea, coffee, tobacco, and plants that yield alcohol; however, the control, regulation, and policing of illicit substances has only been a public issue for several decades. By the late $19^{\text {th }}$ century, physicians understood the psychosis inducing effects of certain drugs; however, it took another couple of decades before regulations of these drugs began. In the United States alone, several attempts (both successful and unsuccessful) have been made 
to control the spread and/or consumption of various illicit drugs. Some of these attempts include: The Pure Food and Drug Act (1906), The Opium Exclusion Act (1909), The Harrison Narcotic Act (1914), the Eighteenth Amendment: Alcohol Prohibition (1918), and The Comprehensive Drug Abuse Prevention and Control Act (1970) [7-9].

Beginning in 1970, the Comprehensive Drug Abuse Prevention and Control Act replaced the Harrison Narcotic Act as the foundation of federal control of illicit substances. Title II of this law, the Controlled Substances Act (CSA), is the legal foundation of narcotics enforcement in the United States [10]. The CSA regulates the manufacture and distribution of drugs, and places all drugs into one of five categories. These categories, or schedules, are based upon multiple considerations: the drug's actual or relative potential for abuse, scientific evidence of the drug's pharmacological effects, state of current scientific knowledge regarding the substance, history and current pattern of abuse, scope duration and significance of abuse, risk to public health, physical and psychological dependence liability, current accepted medical use, and whether the substance is an immediate precursor of a substance that is already controlled (Table 2). The CSA provides a platform where substances can be controlled (added to a schedule), decontrolled (removed from schedule), or rescheduled (transferred from one schedule to another). 
Table 2 - CSA drug schedule characteristics and examples

\begin{tabular}{|c|c|c|}
\hline Assignment & Characteristics & Examples \\
\hline Schedule I & 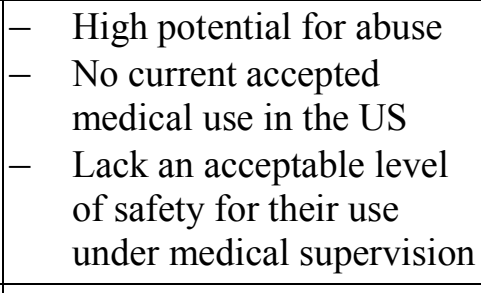 & $\begin{array}{ll}- & \text { Heroin } \\
- & \text { Marijuana } \\
- & \text { MDMA } \\
- & \text { Hashish } \\
- & \text { Methaqualone (quaaludes) } \\
- & \text { LSD } \\
\end{array}$ \\
\hline Schedule II & 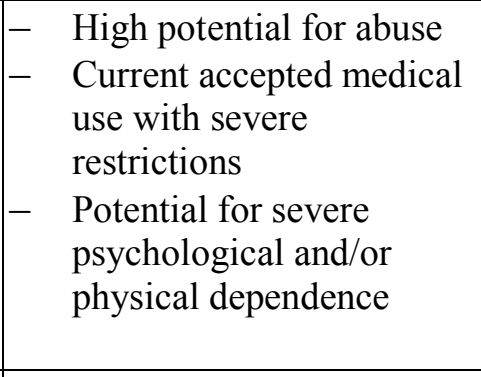 & $\begin{array}{ll}- & \text { Opium, opiates (morphine, } \\
\text { codeine, oxycodone) } \\
- & \text { Cocaine } \\
- & \text { Phencyclidine (PCP) } \\
- & \text { Amphetamines } \\
- & \text { Fast-acting barbiturates } \\
& \text { (amo- seco- and pento- } \\
\text { barbital) }\end{array}$ \\
\hline Schedule III & 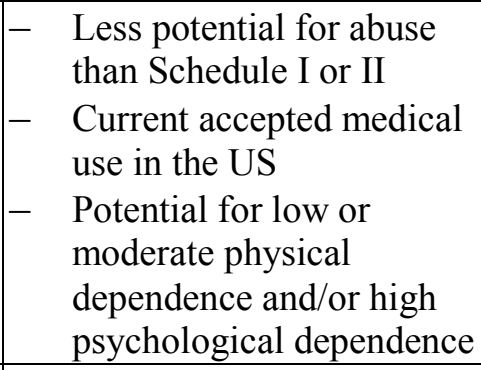 & 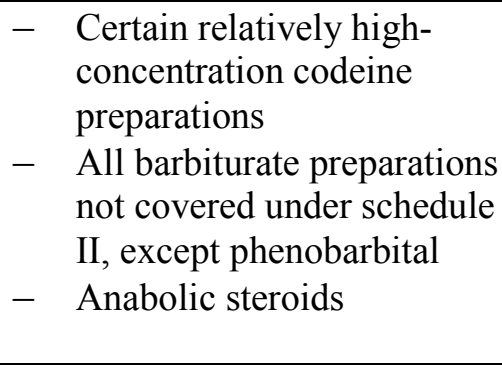 \\
\hline Schedule IV & 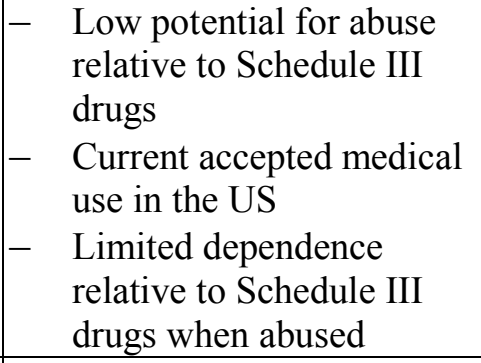 & $\begin{aligned}- & \text { Propoxyphene (Darvon) } \\
- & \text { Phenobarbital } \\
- & \text { Tranquilizers such as } \\
& \text { Meprobamate (Miltown), } \\
& \text { diazepam (Valium), } \\
& \text { chlordiazepoxide (Librium) }\end{aligned}$ \\
\hline Schedule V & 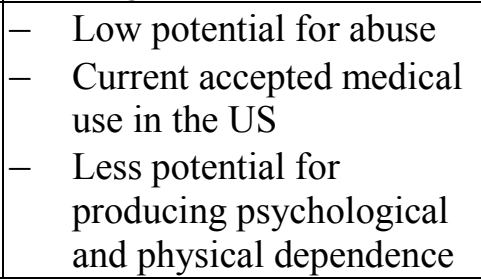 & $\begin{array}{l}\text { Opiate drug (codeine) } \\
\text { mixtures of low } \\
\text { concentration, such as } \\
\text { inhalers or cough } \\
\text { medicines }\end{array}$ \\
\hline
\end{tabular}

The most commonly abused illicit drugs primarily fall into Schedules I or II and constitute the most widely seized drugs by law-enforcement agencies. The larger and more frequent the seizure of illicit drugs, the higher the interest for the development of 
new and/or improved detection systems of the drugs. The increased interest helps determine which drugs to include within the canine training regimens. The DEA seizure amounts for the highest interest drugs from 2004-2008 are given in Table 3.

Table 3 - DEA drug seizure amounts from 2004 to 2008 [11]

\begin{tabular}{|c|c|c|c|c|c|}
\hline $\begin{array}{l}\text { Calendar } \\
\text { Year }\end{array}$ & $\begin{array}{l}\text { Cocaine } \\
\text { (kg) }\end{array}$ & $\begin{array}{l}\text { Heroin } \\
\text { (kg) }\end{array}$ & $\begin{array}{l}\text { Marijuana } \\
\text { (kg) }\end{array}$ & $\begin{array}{c}\text { Methamphetamine } \\
(\mathrm{kg})\end{array}$ & $\begin{array}{l}\text { Hallucinogens } \\
\text { (dosage units) }\end{array}$ \\
\hline 2008 & $49,823.3$ & 598.6 & $660,969.2$ & $1,540.4$ & $9,199,693$ \\
\hline 2007 & 96,713 & 625 & 356,472 & 1,086 & $5,636,305$ \\
\hline 2006 & 69,826 & 805 & 322,438 & 1,711 & $4,606,277$ \\
\hline 2005 & 118,311 & 640 & 283,344 & 2,161 & $8,881,321$ \\
\hline 2004 & 117,854 & 672 & 265,813 & 1,659 & $2,261,706$ \\
\hline
\end{tabular}

\subsubsection{Cocaine}

The coca plant has been used by inhabitants of the Andes for thousands of years, but cocaine was first separated from the plant in the late $19^{\text {th }}$ century by the German scientist, Albert Nieman $[10,13]$. There are two pharmacodynamic effects that cocaine has on the body: (1) artificially stimulation of the release of neurotransmitters such as dopamine, serotonin, and norepinephrine; (2) interference of the normal reuptake of the neurotransmitters. These two effects are what give the prolonged sense of the drug high and the euphoric feelings associated with that high. Because of its potential for abuse, the Harrison Narcotic Act of 1914 was the first step to governmental regulation of cocaine. It is presented as either white powder or in the freebase form (commonly known as crack). The powder form (cocaine hydrochloride) is the salt form of the drug and is typically 
snorted through the nasal passage. It can also be dissolved in water and injected. The freebase form of cocaine is a crystal that is obtained via liquid-liquid extraction from the salt form. Because of its insolubility in water and stability at vaporization temperatures, the freebase form of cocaine is smoked.

\subsubsection{3,4-Methylenedioxy-methamphetamine (MDMA)}

3,4-Methylenedioxy-methamphetamine was first developed in 1914 by the German company E. Merck as a precursor for other therapeutic drugs [10,13]. The first medical tests were conducted by the U.S. Army in 1953 for application as a psychological warfare agent. Abuse in the United States is believed to have originated on the western coast sometime in the 1960 's. While it is traditionally taken in pill form (commonly known as Ecstasy), the drug is also available in powder and liquid forms. There is a plethora of published processes for the chemical synthesis of MDMA (Figure 2 and Figure 3) which include the dissolving metal reduction $(\mathrm{Al} / \mathrm{HgCl} 2)$, the cyanoborohydride reduction $(\mathrm{NaBH} 3 \mathrm{CN})$, the borohydride reduction in low temperature $(\mathrm{NaBH} 4)$, the Leuckart reaction and the safrole bromination $[14,15]$. Most of these processes begin with a methylenedioxy compound such as safrole, isosafrole, or piperonal, all of which are commercially available, or 3,4-methylenedioxypheny-2-propanone (MDP-2-P), which is a controlled substance. 
$\underline{\text { Isosafrole }}$

(l)

$\underline{\text { Piperonal }}$

政

Figure 2 - Synthesis of MDP-2-P intermediate from methylenedioxy starting compounds

MDMA has a two stage effect (similar to amphetamines): (1) it causes serotonin to be released into the brain causing an increased sense of euphoria and (2) blocks the reuptake process causing the serotonin to remain in the synapses longer than normal exaggerating the euphoric effect. The two-stage effect depletes the available serotonin levels. It is widely agreed that the reduction in serotonin levels occur, but there is not agreement as to the severity of the effect. The physical effects include increased body temperature, blood pressure, and heart rate, while the psychological effects include warm feelings and an increased openness towards strangers. Many people fall prey to heat stroke and dehydration from overexertion while on MDMA. As a result of increased interest and usage, the distribution of this drug has increased in metropolitan and suburban areas across the country. MDMA is one of the top controlled substances most identified in crime labs, and it is the most recent drug to be added to law enforcement detection canine training regimens. 
Dissolving Metal Reduction $\left(\mathrm{Al} / \mathrm{HgCl}_{2}\right)$

$\prod_{\mathrm{O}}^{\longrightarrow}+\mathrm{CH}_{3} \mathrm{NH}_{2} \stackrel{\mathrm{Al} / \mathrm{HgCl}_{2}}{\longrightarrow}$ MDMA

3,4-MDP-2-P

Cyanoborohydride Reduction $\left(\mathrm{NaBH}_{3} \underline{\mathrm{CN}}\right)$

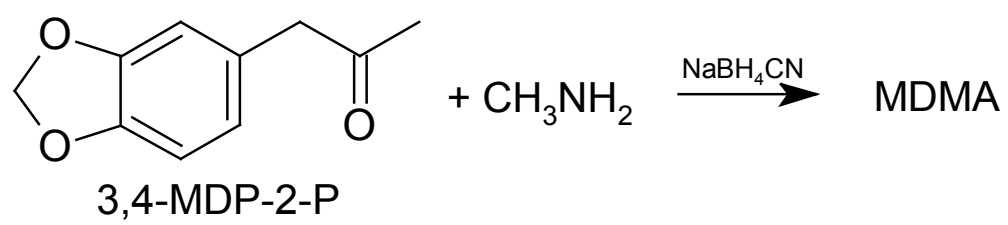

$\underline{\text { Borohydride Reduction in low temperature }\left(\mathrm{NaBH}_{4}\right)}$

$\prod_{\mathrm{O}}^{\longrightarrow}+\mathrm{CH}_{3} \mathrm{NH}_{2} \underset{-20^{\circ} \mathrm{C}}{\stackrel{\mathrm{NaBH}_{4}}{\longrightarrow}}$ MDMA

3,4-MDP-2-P

$\underline{\text { Leuckart Reaction }}$

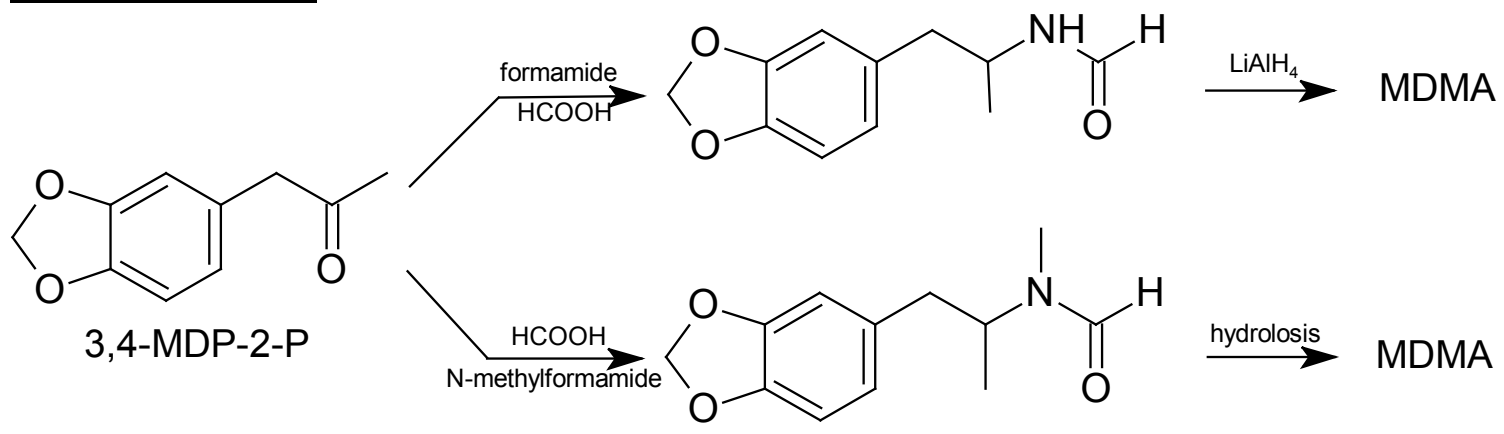

$\underline{\text { Safrole Bromination }}$<smiles>C=CCc1ccc2c(c1)OCO2</smiles>

Figure 3 - Synthesis of MDMA 


\subsubsection{Heroin}

Heroin is a derivative of morphine, which is itself extracted from opium. Opium was first used for medicinal purposes over the last 9000 years by the Assyrians, followed by the Sumerians, the Greeks, across Africa and Europe, and eventually reaching China $[10,13]$. Morphine, with accepted medical use as a treatment for pain, was first isolated as the main active substance of opium in 1803 by the German pharmacist, F.W. Serturner $[13,16]$. Morphine reacts with the body by increasing the release of endorphins and prolonging their effect. Following that discovery, diacetylmorphine (heroin) was first synthesized in the late 1800's by the English chemist, Alder Wright by combining morphine with acetic anhydride and heating [10]. Heroin itself has no effect on the body, but it is quite lipid soluble and quickly passes through the blood/brain barrier before metabolizing into morphine (Figure 4).

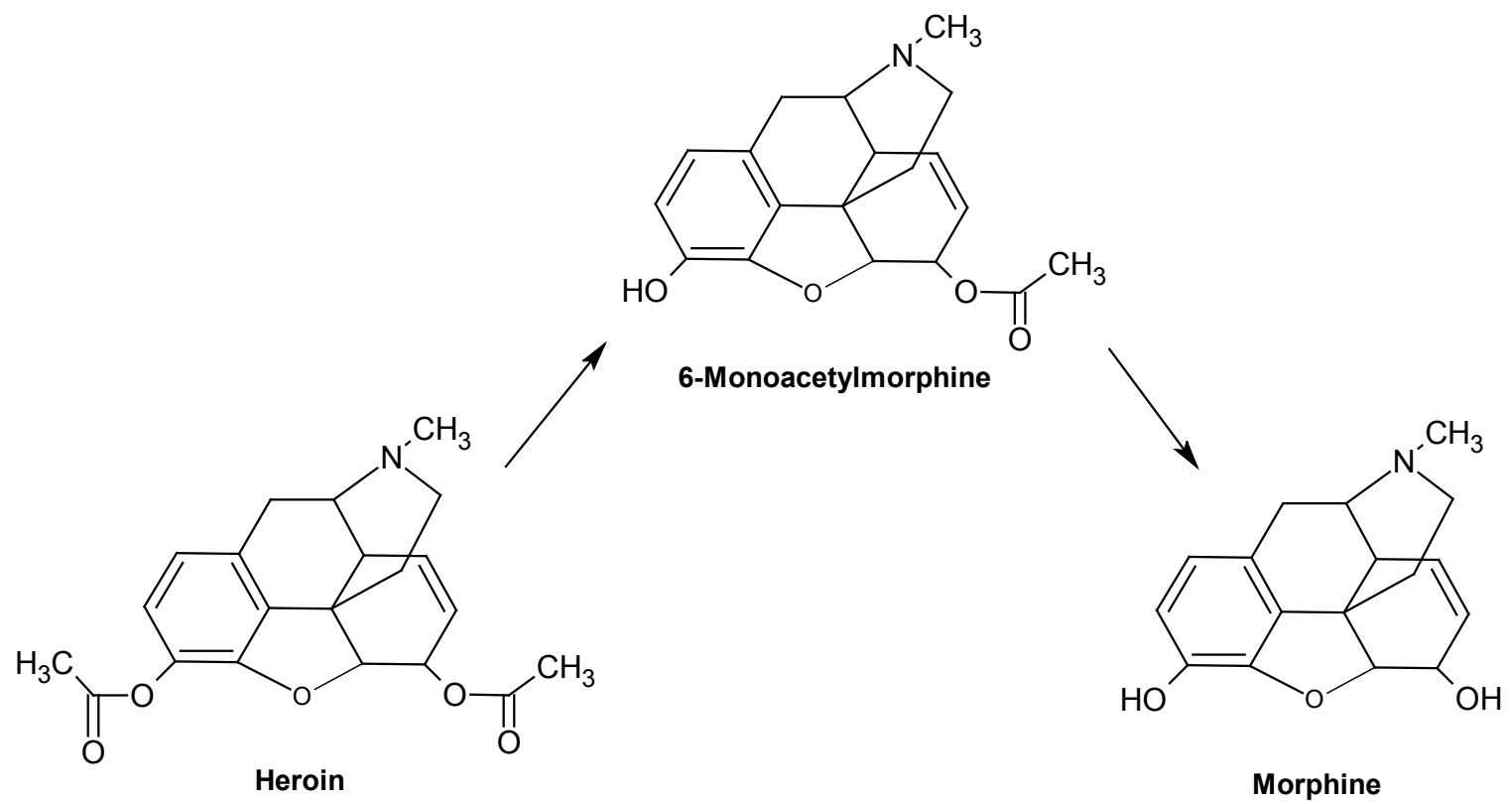

Figure 4 - Metabolism of heroin to morphine 
There are several versions of heroin available depending on how far the manufacturing process proceeds. The first version was described above. Heroin \#2 (heroin base) is precipitated out of an aqueous solution of the first step heroin with the addition of sodium carbonate. Heroin \#3 (used for smoking) is produced by mixing dry heroin base with hydrochloric acid to form heroin hydrochloride. Heroin \#4 (used for snorting and injection) is created by dissolving heroin base in ethyl ether and combining with hydrochloric acid and ethanol to form purified white crystals. Black tar heroin is created by skipping the purification processes and resulting in a much lower purity than the other versions $(30-60 \%$ vs. $85-90 \%)$ [10].

Studies have reported that the headspace of many fresh, well stored, and/or well preserved samples of heroin possess remnants of the various solvents used in manufacturing process (e.g. acetone, diethyl ether, methyl isobutyl ketone, methyl ethyl ketone, ethyl acetate) $[17,18]$. The solvents that are used differ depending on the region of origin of the heroin (Figure 5).

The effects of heroin include drowsiness, pain reduction, euphoria, loss of coordination, papillary constriction, and slow speech. Heroin is administered through injection (intravenously, intramuscularly, and subcutaneously), insufflation, and inhalation. Injection is the preferred method for consistent users because of the speed of the onset of effects; however, if potency is more than $20 \%$, snorting is an effective method. 


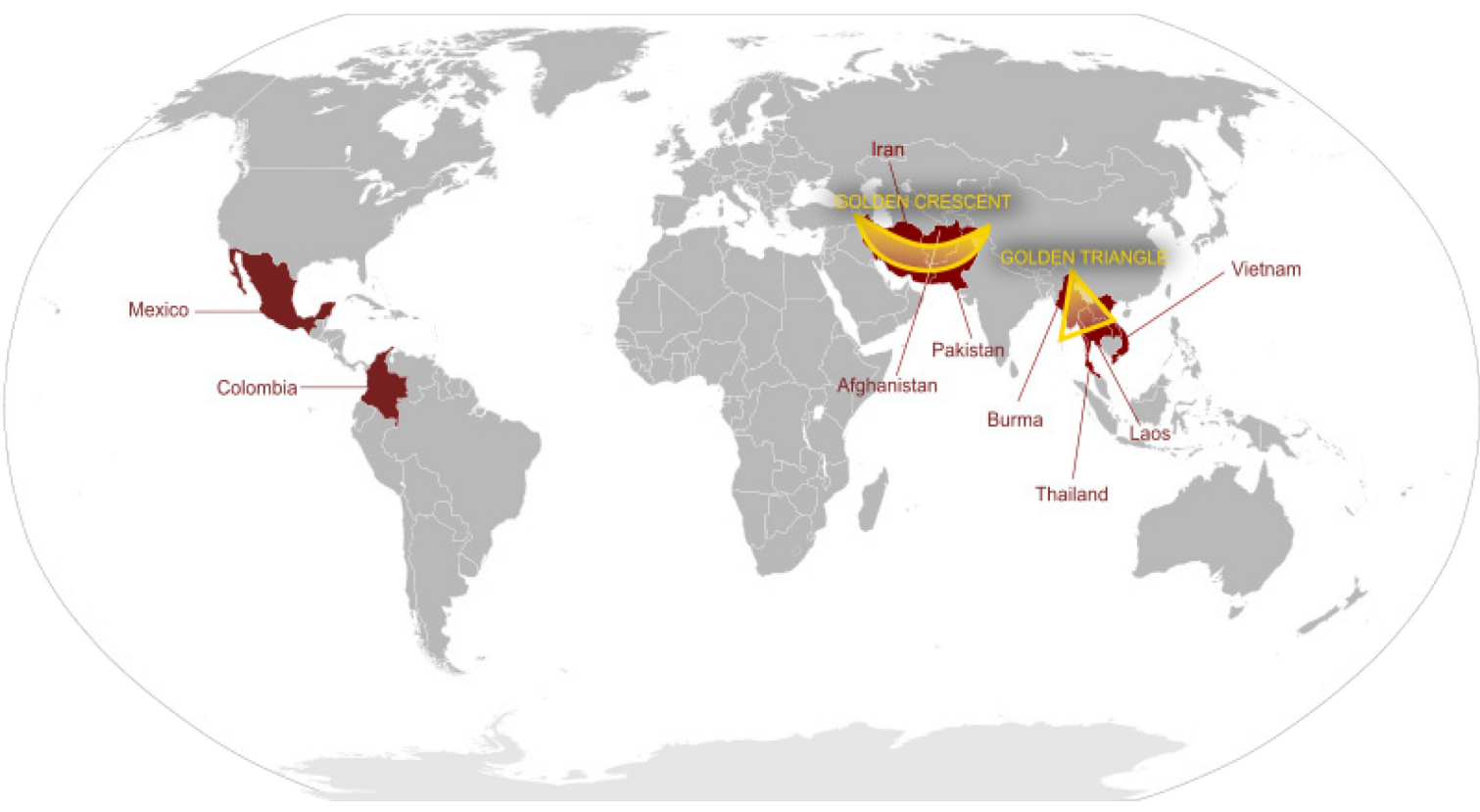

Figure 5 - Heroin production regions

1: Mexico/South America 2: Southwest Asia - "Golden Crescent"

3: Southeast Asia - "Golden Triangle" [19]

\subsubsection{Methamphetamine}

Amphetamines were first created in Germany in the late $19^{\text {th }}$ century [10]. The medicinal properties of amphetamines include dilation of bronchial passages, relief of fatigue, increase in energy levels, suppression of appetite, and reduced necessity for sleep. Because of its stimulating effects, amphetamines were used to help asthmatics and to keep troops alert in war times. The abuse of amphetamines became severe and widespread so restrictions were enacted by the Controlled Substances Act of 1970 . Today, the vast majority of illicit amphetamine is of the more potent form, methamphetamine. Clandestine labs utilize ephedrine and pseudoephedrine as the base ingredient in the production of methamphetamine [10]. Amphetamine administration includes insufflation, inhalation, oral consumption, and injection. One of the most 
baffling aspect to amphetamine use is the calming effect it has on children (in therapeutic dosages) while the opposite is true for adults [20].

\subsection{Explosives}

An explosive is a chemically unstable material which produces an explosion, detonation, or deflagration of material into more stable substances through the release of heat and gas. There are several ways in which explosives may be classified: primary vs. secondary explosives, high vs. low explosives, commercial vs. industrial explosives, and according to chemical structure $[3,21]$.

\subsubsection{High vs. Low Explosives}

\section{$\underline{\text { High Explosive }}$}

A high explosive is a compound material in which the combustible and oxidizer are bonded molecularly. Upon activation, the chemical reaction zone advances at a supersonic rate with respect to the undisturbed material (i.e. detonation) [22]. High explosives require initiation by blasting caps or agents of a similar kind. When the cap is detonated, it delivers a sharp shock to the explosive causing both the explosive and oxidizer molecular bonds to break. The breaking of these bonds causes a shock wave that propagates through the explosive accelerating it outward. The damage caused by a high explosive is the result of the blast pressure wave instead as compared to the containment of gases seen with low explosives. Examples of high explosives include aromatic nitrates, nitramines, and nitrate esters (further discussion in section 1.4.4). 


\section{Low Explosive}

A low explosive is classified by the subsonic rate of advance of the chemical reaction zone into the unreacted explosive with respect to the undisturbed material [22]. This is referred to as deflagration, a fast combustion reaction driven by the transfer of heat as opposed to a shock wave. Low explosives are distributed in mixtures of one or more energetic materials, plasticizers, stabilizers, and inorganic additives. Plasticizers are used to improve processing characteristics, stabilizers are used to increase shelf life (i.e. storage length), and the inorganic additives improve ignitability, reduce muzzle flash, and make them safer to handle. Examples of these types of publically available explosives include: black powder, flash powder, and smokeless powder.

\section{Black Powder (BP)}

Considered the oldest propellant, the Chinese are given credit for black powder's conception/invention several millennia ago $[23,24]$. Black powder is comprised of a physical combination of fuel (sulfur and charcoal) and oxidizer (potassium nitrate, $\mathrm{KNO}_{3}$ ). There are many applications for $\mathrm{BP}$ including muzzle loading firearms, fireworks, motor propellant for model rockets, blasting for mining companies, and various military reasons. $\mathrm{BP}$ is found to retain its energetic properties indefinitely, assuming proper packaging and storage.

\section{Flash Powder (FP)}

Flash powders are primarily, and almost exclusively, used in pyrotechnic displays. FP is comprised of an oxidizer (sodium nitrate, potassium nitrate, potassium chlorate, or 
potassium perchlorate) in conjunction with fuel (sulfur and charcoal) and metal ions for color or effect (aluminum or magnesium) [25]. FP is considered the most sensitive (i.e. most easily initiated) of all low explosives and can reach detonation velocities in some instances.

\section{Smokeless Powder (SP)}

Smokeless powders are most commonly found as the propellant in firearm ammunition, but they are also commonly used as the propellant in improvised explosive devices (IED) [26]. Although SPs are referred to as "smokeless," a white smoke is produced; however, this white smoke is minimal in comparison to the large amount of black smoke produced by black powders. There are three classifications of SPs which are grouped according to the energetic(s) contained within: single based, double based, and triple based. All single based powders possess the energetic nitrocellulose (NC). Some manufacturers of single based powders incorporate the secondary energetic 2,4-dinitrotoluene (2,4-DNT). Double based powders possess two energetics, NC and nitroglycerine (NG). Triple based powders possess three energetics, NC, NG, and nitroguanidine (NQ) or, in some cases, trinitrotoluene (TNT). Triple based powders are not commercially available and are only sanctioned for military use. Smokeless powders also contain other components such as stabilizers, burn-rate modifiers, flash suppressants, and graphite for reduced sensitivity to ignition. Stabilizers help counter the effect of nitric acid during decomposition. Two common stabilizers are diphenylamine and 1,3-diethyl-1,3-diphenylurea (ethyl centralite). 


\subsubsection{Primary vs. Secondary Explosives}

\section{Primary Explosive}

High explosives can be separated into two groups: primary high explosive or secondary high explosive. Primary explosives are highly sensitive to initiation through the action of mechanical shock, direct contact with flame or electric spark, and friction, regardless of confinement. Primary explosives differ from secondary explosives in that they undergo a rapid transition from burning to detonation. The detonation velocities of these types of explosives exist in the range of $3500 \mathrm{~m} / \mathrm{s}$ to $5500 \mathrm{~m} / \mathrm{s}$ (Table 4). Examples of primary explosives include lead azide, lead styphnate, and triacetone triperoxide (additional information in section 1.4.4.6). Primary explosives are used to transmit the detonation to less sensitive explosives, such as secondary explosives.

\section{$\underline{\text { Secondary Explosive }}$}

Secondary explosives are relatively insensitive when compared to primary explosives. Secondary explosives are not readily detonated by heat or shock, but initiation can be accomplished through the detonation of a primary explosive. Initiation is usually handled in an explosive series referred to as an explosive train. The detonation velocities of these types of explosives exist in the range of $5500 \mathrm{~m} / \mathrm{s}$ to $9200 \mathrm{~m} / \mathrm{s}$ (Table 4). Examples of secondary explosives include trinitrotoluene (TNT), pentaerythritol tetranitrate (PETN), and cyclonite (RDX). 
Table 4 - Examples of primary and secondary explosives [27-30]

\begin{tabular}{|c|c|c|c|c|}
\hline & Explosive & $\begin{array}{c}\text { Molecular } \\
\text { Weight } \\
\text { (g/mol) }\end{array}$ & $\begin{array}{c}\text { Detonation } \\
\text { Velocities } \\
(\mathrm{m} / \mathrm{s})\end{array}$ & $\begin{array}{c}\text { Vapor } \\
\text { Pressure } \\
\left(\text { Torr@25 } 25^{\circ} \mathrm{C}\right. \\
\end{array}$ \\
\hline \multicolumn{5}{|c|}{ Primary Explosives } \\
\hline \multirow[t]{3}{*}{ TATP } & Triacetone Triperoxide & 222 & 5300 & $3.7 \times 10^{-1} *$ \\
\hline & Lead Styphnate & 468 & 5200 & \\
\hline & Lead Azide & 291 & 4500 & \\
\hline \multicolumn{5}{|c|}{ Secondary Explosives } \\
\hline HMX & $\begin{array}{c}\text { Tetranitro- } \\
\text { tetrazacyclooctane }\end{array}$ & 296 & 9110 & $1.6 \times 10^{-13} *$ \\
\hline RDX & Trinitro-triazacyclohexane & 222 & 8440 & $1.4 \times 10^{-9}$ \\
\hline PETN & Pentaerythritol Tetranitrate & 316 & 8300 & $3.8 \times 10^{-10}$ \\
\hline Tetryl & Tetranitro- $N$-methylamine & 287 & 7900 & $5.7 \times 10^{-9}$ \\
\hline EGDN & Ethylene Glycol Dinitrate & 152 & 7800 & $2.8 \times 10^{-2}$ \\
\hline $\mathrm{NG}$ & Trinitroglycerin & 227 & 7750 & $2.4 \times 10^{-5}$ \\
\hline $\mathrm{NC}$ & Nitrocellulose & 327 & 7300 & N/A \\
\hline TNT & 2,4,6-Trinitrotoluene & 227 & 6850 & $3.0 \times 10^{-6}$ \\
\hline
\end{tabular}

\section{Explosive Train}

Explosive trains can be classified as either low or high depending on the last explosive in the series. Low explosive trains usually only require a two-step process; pipe bombs are one such example. In pipe bombs, a safety fuse is inserted into the pipe at one end and is ignited by a match (or electric spark) at the other end. The safety fuse puts the flame (or charge) to the SP which produces gases that cause the pipe to explode. Typically, high explosive trains have more steps than low explosive trains: detonator, booster, and main charge (Figure 6). In some cases, the detonator can be connected directly to the main 
charge if the shock wave created by the detonator is powerful enough to detonate the main charge. In many cases, the main charge is not sensitive enough, thus a booster is used to increase the shock wave applied to the main charge. Primary explosives are generally used for detonators; whereas, boosters and main charges are usually secondary explosives.

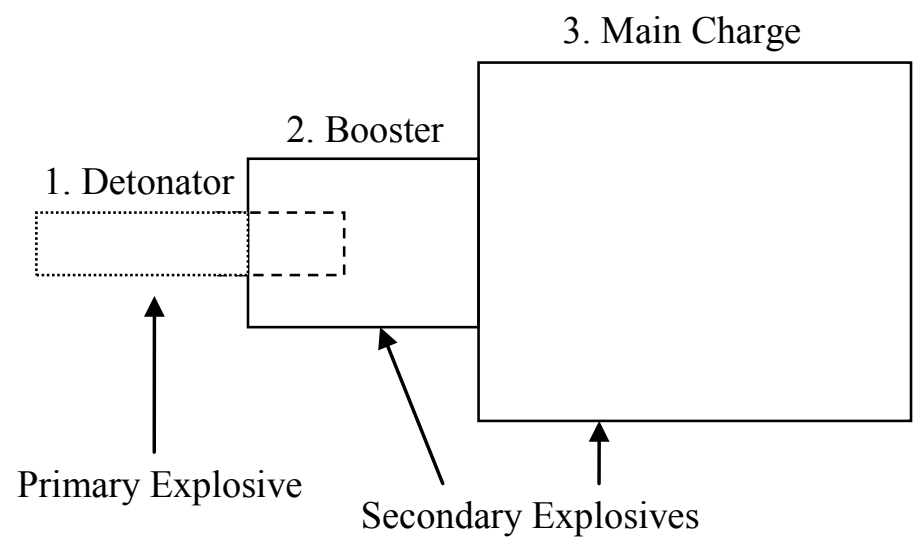

Figure 6 - Example of a 3-step high explosive train

\subsubsection{Marker vs. Taggant}

The terms marker and taggant are used interchangeably and describe coded materials that are added to substances by manufacturers to enhance detectability by investigators. When used in explosives, a marker (also referred to as detection taggant) aids in the detection of explosive materials pre-blast, whereas a taggant (also referred to as identification taggant) aids in the identification and tracking of explosive materials to source in post-blast scenarios. 
There are two approaches for markers (detection taggants): active and passive. An active marker continuously emits a signal (chemical vapor, light, sound, radiowaves, or radioactive emissions); a passive marker has to be probed in order to be detected (such as a fluorescent dye). The most common and useful markers in explosive scenarios are active vapor markers [23]. The four ICAO (International Civil Aviation Organization) approved active vapor markers used in high explosives are 2,3-dimethyl-2,3-dinitobutane (DMNB), ethylene glycol dinitrate (EDGN), ortho-mononitrotoluene (o-MNT), and paramononitrotoluene ( $p$-MNT) [31]. Of these, DMNB is the most commonly used.

Taggants (identification taggants) are coded materials that manufacturers add to provide information that can be interpreted by investigators at a later stage in the use of the product. There are two categories for taggants (Class I and II) which can be further broken down into four sub-categories (physical, spectroscopic, chemical, and isotopic) depending on the method of analysis. Class I taggants are resistant to countermeasures that are incorporated by the manufacturer to hinder detection and prevention while Class II taggants may be susceptible to countermeasures and/or destruction by an explosion. Taggants have also been used to combat counterfeiting in applications such as animal feed, perfume, personal hygiene products, and gasoline [23]. Currently, Switzerland is the only country that adds taggants to explosives.

Ideal explosive markers and taggants possess similar characteristics. These characteristics include the following: no real or perceived health or safety risks, forensic applicability and utility for law enforcement, chemical and physical compatibility with explosive, no 
adverse effect on explosive, no adverse environmental impact or contamination, low cost, no viable countermeasures, easy to read/detect, and appropriate lifetime.

\subsubsection{Chemical Groupings of Explosives}

Classification by chemical groups is a third common method of identification, especially for research purposes. Chemical classification is accomplished by assigning explosives into the following classes based upon the chemical constituents: organic nitrates (which includes aliphatic nitros and aromatic nitros), nitrate esters, nitramines, inorganic salts, and peroxides [3,27]. Table 5 lists common explosives examples for each chemical group. Examples of their chemical structures can be seen in Figure 7.

\subsubsection{Aliphatic Nitrate}

Aliphatic nitrates are straight chain (aliphatic) alkanes with carbon-nitro moieties (C$\mathrm{NO}_{2}$ ). There are six basic groups of aliphatic nitrates: primary, secondary, tertiary nitroalkanes, terminal and internal gem-dinitroalkanes, and trinitromethyl compounds.

\section{Nitromethane}

Although not usually regarded as an explosive, this clear, volatile liquid can propagate its own detonation with a strong enough initiator. When used in combination with ammonium nitrate, a more powerful explosive than ANFO can be created [29]. Another common (and costly) combination is to mix nitromethane with aluminum powder. 
Table 5 - Explosives grouped by chemical class

\begin{tabular}{|c|c|c|c|c|}
\hline $\begin{array}{c}\text { Chemical } \\
\text { class }\end{array}$ & & Explosive & $\begin{array}{c}\text { Mol. Wt. } \\
\text { (amu) }\end{array}$ & Formula \\
\hline \multirow{2}{*}{$\begin{array}{l}\text { Aliphatic } \\
\text { nitrate }\end{array}$} & & Nitromethane & 61 & $\mathrm{CH}_{3} \mathrm{NO}_{2}$ \\
\hline & DMNB & $\begin{array}{l}\text { 2,3-Dimethyl- } \\
\text { dinitrobutane }\end{array}$ & 176 & $\mathrm{C}_{6} \mathrm{H}_{12} \mathrm{~N}_{2} \mathrm{O}_{4}$ \\
\hline \multirow{5}{*}{$\begin{array}{l}\text { Aromatic } \\
\text { nitrate }\end{array}$} & $o-\mathrm{MNT}$ & 2-Nitrotoluene & 137 & $\mathrm{C}_{7} \mathrm{H}_{7} \mathrm{NO}_{2}$ \\
\hline & $p$-MNT & 4-Nitrotoluene & 137 & $\mathrm{C}_{7} \mathrm{H}_{7} \mathrm{NO}_{2}$ \\
\hline & DNT & 2,4-Dinitrotoluene & 182 & $\mathrm{C}_{7} \mathrm{H}_{6} \mathrm{~N}_{2} \mathrm{O}_{4}$ \\
\hline & TNT & 2,4,6-Trinitrotoluene & 227 & $\mathrm{C}_{7} \mathrm{H}_{5} \mathrm{~N}_{3} \mathrm{O}_{6}$ \\
\hline & $\begin{array}{c}\text { Picric } \\
\text { acid }\end{array}$ & 2,4,6-Trinitrophenol & 229 & $\mathrm{C}_{6} \mathrm{H}_{3} \mathrm{~N}_{3} \mathrm{O}_{7}$ \\
\hline \multirow{4}{*}{ Nitramine } & Tetryl & $\begin{array}{l}\text { Tetranitro- } N- \\
\text { methylamine }\end{array}$ & 287 & $\mathrm{C}_{7} \mathrm{H}_{5} \mathrm{~N}_{5} \mathrm{O}_{8}$ \\
\hline & $\mathrm{RDX}$ & $\begin{array}{l}\text { Trinitro- } \\
\text { triazacyclohexane }\end{array}$ & 222 & $\mathrm{C}_{3} \mathrm{H}_{6} \mathrm{~N}_{6} \mathrm{O}_{6}$ \\
\hline & HMX & $\begin{array}{l}\text { Tetranitro- } \\
\text { tetrazacyclooctane }\end{array}$ & 296 & $\mathrm{C}_{4} \mathrm{H}_{8} \mathrm{~N}_{8} \mathrm{O}_{8}$ \\
\hline & CL20 & $\begin{array}{c}\text { Hexanitro- } \\
\text { hexaazaisowurzitane }\end{array}$ & 438 & $\mathrm{C}_{6} \mathrm{H}_{6} \mathrm{~N}_{12} \mathrm{O}_{12}$ \\
\hline \multirow{4}{*}{$\begin{array}{l}\text { Nitrate } \\
\text { ester }\end{array}$} & EGDN & $\begin{array}{l}\text { Ethylene Glycol } \\
\text { Dinitrate }\end{array}$ & 152 & $\mathrm{C}_{2} \mathrm{H}_{4} \mathrm{~N}_{2} \mathrm{O}_{4}$ \\
\hline & NG & Trinitroglycerin & 227 & $\mathrm{C}_{4} \mathrm{H}_{5} \mathrm{~N}_{3} \mathrm{O}_{9}$ \\
\hline & PETN & $\begin{array}{l}\text { Pentaerythritol } \\
\text { Tetranitrate }\end{array}$ & 314 & $\mathrm{C}_{5} \mathrm{H}_{8} \mathrm{~N}_{4} \mathrm{O}_{12}$ \\
\hline & $\mathrm{NC}$ & Nitrocellulose & 327 & {$\left[\mathrm{C}_{6} \mathrm{H}_{7} \mathrm{~N}_{3} \mathrm{O}_{11}\right]_{n}$} \\
\hline $\begin{array}{l}\text { Inorganic } \\
\text { Salt }\end{array}$ & AN & Ammonium nitrate & 80 & $\mathrm{NH}_{4} \mathrm{NO}_{3}$ \\
\hline \multirow{2}{*}{ Peroxide } & TATP & Triacetone Triperoxide & 222 & $\mathrm{C}_{3} \mathrm{H}_{6} \mathrm{O}_{6}$ \\
\hline & HMTD & $\begin{array}{l}\text { Hexamethylene } \\
\text { Triperoxide Diamine }\end{array}$ & 208 & $\mathrm{C}_{6} \mathrm{H}_{12} \mathrm{~N}_{2} \mathrm{O}_{6}$ \\
\hline
\end{tabular}




\section{2,3-Dimethyl-2,3-dinitrobutane (DMNB)}

2,3-Dimethyl-2,3-dinitrobutane is most often used as a marker in secondary high explosives. It is an ideal marker because of a sufficient shelf life, low level of toxicity (as compared to the high explosives it is marking), and because it does not affect explosive characteristics (such as stability) [23]. Additionally, there is no known industrial application which offers little chance that the compound will be present in any background, thereby causing a false identification.

\subsubsection{Aromatic Nitrate}

Aromatic nitrates are cyclic alkanes (benzene rings) with carbon-nitro moieties $\left(\mathrm{C}-\mathrm{NO}_{2}\right)$. There are several isomers depending on the position of the $\mathrm{C}-\mathrm{NO}_{2}$ group(s).

\section{2,4,6-Trinitrotoluene (TNT)}

2,4,6-Trinitrotoluene was first prepared by Wilbrand in 1863, but the pure form of TNT was not achieved until 1880 by Hepp [28]. In pure form, TNT is a pale yellow, crystalline solid that is compatible in combination with other explosives (e.g. Pentolite - 50/50 TNT/PETN, Amatol - TNT/AN, Cyclotol - 75/25 RDX/TNT, Composition B - 60/40 RDX/TNT/wax). TNT is both a military explosive and used extensively in munitions and demolition charges. It can also be found in some triple base smokeless powders. Due to TNT's high level of chemical and thermal stability, GC methods are appropriate analysis techniques. One of the biggest drawbacks to TNT is the leaching of dinitrotoluene (DNT) and TNT isomers during storage. The leaching can lead to premature detonation as well as contamination of adjacent explosives/matrices (see Table 25 in section 6.1). 


\section{2,4-Dinitrotoluene (2,4-DNT)}

2,4-Dinitrotoluene is not considered an explosive, so is not used in that capacity. However, it is added to some smokeless powders (primarily single base) as an additional fuel source. The vapor pressure of $2,4-\mathrm{DNT}$ is higher than TNT $\left(2.1 \times 10^{-4}\right.$ torr vs $5.8 \times 10^{-6}$ torr, respectively [32]), and it is often found in the headspace of TNT samples.

\subsubsection{Nitramines}

Nitramines are one form of the nitrogen-nitro group $\left(\mathrm{N}-\mathrm{NO}_{2}\right)$ bonded compounds (along with nitramides and nitrimines). Nitramines can be divided into two groups: primary and secondary depending on the presence of an acidic hydrogen $\left(\mathrm{N} H \mathrm{NO}_{2}\right)$ [29]. Because of the energetic nature of the $\mathrm{N}-\mathrm{NO}_{2}$ groups, secondary nitramines are some of the most powerful explosives and, as a result, are often chosen for military applications over aromatic nitrate groups.

\section{$\underline{1,3,5-\text { Trinitro-1,3,5-triazacyclohexane (RDX) }}$}

1,3,5-Trinitro-1,3,5-triazacyclohexane (also referred to as RDX, hexagen, cyclonite, and cyclotrimethylenetrinitramine) was first prepared for use in medical applications by Henning in 1899. Herz first demonstrated its explosive capability in 1920; however, it was not until the early 1940's that a continuous production method was developed. Brockman has been credited for manufacturing a synthetic route for pure RDX (a white, crystalline solid), referred to as Type A RDX [28]. RDX is the main component of C-4 or "plastic explosive," but is also used in some detonation cords and blasting caps. RDX is 
the preferential explosive in military munitions because of the stability and long shelf life. During chemical synthesis, HMX can be produced as a by-product.

\section{$\underline{1,3,5,7-T e t r a n i t r o-1,3,5,7-t e t r a z a c y c l o o c t a n e}$ (HMX)}

1,3,5,7-Tetranitro-1,3,5,7-tetrazacyclooctane (also referred to as HMX, octagen, and cyclotetramethylenetetranitraminen) is a by-product of the chemical formation of Type B RDX. The synthetic path, developed by Bachmann, yields an 8-12\% impurity level which is used in the development of HMX [33]. HMX is a white, crystalline solid that comes in four forms $(\alpha, \beta, \gamma$, and $\delta)$ differentiated by density and sensitivity to impact [28]. It is the $\beta$-form that is used as a secondary explosive. HMX is superior to RDX in chemical stability and ignition temperature as well as slightly inferior in explosive power and cost of production. HMX is strictly used by the military.

\subsubsection{Nitrate Esters}

Nitrate esters are characterized by carbon-oxygen-nitro group bondings $\left(\mathrm{C}-\mathrm{O}-\mathrm{NO}_{2}\right)$ where the nitro group is bonded to the oxygen atom. As a group, nitrate esters are among the most powerful explosives. In general, these explosives are more sensitive to shock and friction than other C-nitro and $\mathrm{N}$-nitro explosive compounds. One downside to nitrate esters is the release of nitric acid during decomposition making long-term storage impractical. 


\section{Nitrocellulose (NC)}

Nitrocellulose was discovered separately around 1846 by Schönbein and Böttger. Stability improvements and detonation properties were explored by Abel and his assistant, Brown, in 1865 and 1868, respectively [28]. Used as a generic term to describe a family of compounds, nitrocellulose is formed from a nitration of the polymer, cellulose, to form "fluffy" white solids. One of the major explosive applications is its use as the base energetic in all smokeless powders. As a polymer, NC has an extremely low volatility, which makes GC an unsuitable analysis method.

\section{Nitroglycerine (NG)}

Nitroglycerine (trinitroglycerin) was first discovered as a powerful, yet extremely sensitive, explosive by Sobrero in 1846 [34]. NG is an oily liquid that varies in color from clear to milky to amber depending on age and presence of moisture. During decomposition, red fumes will appear indicating increased danger. Often, the liquid was frozen to decrease sensitivity thus increasing safety for transport. Real notoriety came from Alfred Nobel's use of nitroglycerine in dynamite in 1866 [34]. Nobel demonstrated that allowing the NG to adsorb onto an inert matrix (such as clay) created a safer method of application. More recently, it has been shown that dissolving NG in nitrocellulose creates a rubbery gel substance which improves the explosive's resistance to water as seen in double base smokeless powders. Additionally, NG has medical applications for coronary ailments [35]. 


\section{Ethylene Glycol Dinitrate (EDGN)}

Ethylene glycol dinitrate is a viscous oil that ranges in color from pale yellow to colorless. It is more stable and less sensitive to impact than $\mathrm{NG}$, but it is also more volatile [29]. EGDN is mainly used as a plasticizing agent in combination with NG (or to replace NG) in dynamites to reduce freezing point, but it has also been used as a marker in plastic explosives [30].

\section{$\underline{\text { Pentaerythritol Tetranitrate (PETN) }}$}

Pentaerythritol tetranitrate was first prepared in 1864 but was not commercially available until just before World War II [28]. PETN appears as colorless, crystalline solid that is insoluble in water, only slightly soluble in some organics, and completely soluble in other organics. It is considered the most stable nitrate ester and prolonged storage does not seem to affect the potency of the explosive. PETN is most commonly used as the explosive component in detonation cord, but it can also be found in blasting caps and boosters. In its pure form, PETN is extremely sensitive to friction and impact, thus it is mixed with plasticized $\mathrm{NC}$ to form polymer bonded explosives (PBXs). For military use, PETN has been largely replaced by RDX.

\subsubsection{Inorganic Salts}

Inorganic salts can be formed through combination of heavily oxygenated anions (nitrates, chlorates, perchlorates) in combination with cations such as ammonium, sodium, or potassium. While inorganic salts are not explosive on their own, they can be used in combination with other compounds to make explosive binary mixtures. One of 
the most common inorganic salts is ammonium nitrate (AN). First developed in 1654 by Glauber, AN was not considered an explosive until after World War II [28]. Because AN is available and easy to acquire, it is currently one of the most widely used materials in the manufacture of explosives. The color ranges from white to buff-brown depending on purity [22]. The most common form is small compressed pellets referred to as prills. One of the most recognizable examples of AN being used as an explosive is in combination with fuel oil to form ANFO. Along with the possible explosive capability, AN is commonly used in fertilizers.

\subsubsection{Peroxides}

Peroxide explosives are produced through a reaction of acetone and peroxide involving a strong acid. They are high explosives with explosive strength comparable to TNT. Peroxides are ideally used as primary explosives due to their extreme sensitivity to initiation by heat, vibrational shock, flame, or electrical charge.

\section{$\underline{\text { Triacetone Triperoxide (TATP) }}$}

Triacetone triperoxide was first prepared by German chemists late in the $19^{\text {th }}$ century [36]. It presents itself as white crystals that are sensitive to UV light (the crystals turn brown in color after UV exposure). Recent years have shown an increase in use because it is popular with terrorists $[37,38]$. Because of the absence of nitro groups and metallic elements, explosive devices that include TATP are not detectable by standard methods. Infrared/Raman spectroscopy and mass spectrometry coupled with gas chromatography have been the most successful methods for identification [39]. 


\section{Hexamethylene Triperoxide Diamine (HMTD)}

Hexamethylene triperoxide diamine was first synthesized in the early 1880's [40]. It is less sensitive to shock initiation than TATP, but it has been used in terrorist bombings [41].

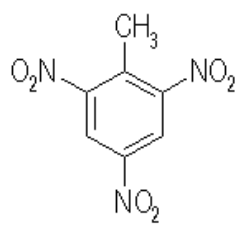

TNT<smiles>Cc1ccc([N+](=O)[O-])cc1CO</smiles>

DNT<smiles>COCCON</smiles>

EGDN<smiles>COOCCON(O)O[N+](=O)[O-]</smiles>

NG<smiles>O=[N+]([O-])N1CN([N+](=O)[O-])CN([N+](=O)[O-])C1</smiles>

RDX

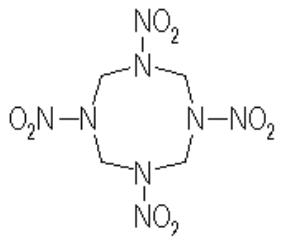

HMX

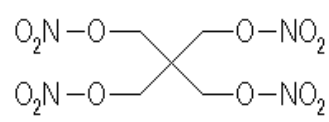

PETN

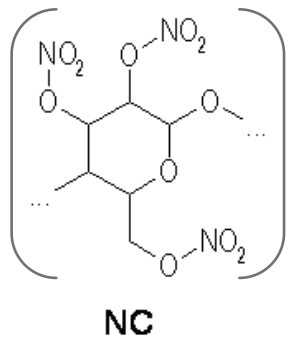

Figure 7 - Chemical structures for common explosive compounds

\subsubsection{Training Aids}

Currently, explosive detection canine training utilizes numerous examples of several types of explosives (i.e. TNT-based, RDX-based, PETN-based, etc.). A typical training kit includes $20+$ explosive samples. Since many of the explosives that are manufactured posses similar active ingredients, it makes sense that the training aids can be reduced to reflect these similarities. Table 6 lists common explosive groups from a comprehensive 
listing of commercially available explosives. More information about these explosives is found in Appendix II.

Table 6 - Compositions of commercially available explosives (MSDS)

\begin{tabular}{|c|c|c|}
\hline Major Component & Number of Explosives & \% of Total \\
\hline TNT & 15 & $8 \%$ \\
\hline Plasticized PETN only & 9 & $5 \%$ \\
\hline Plasticized RDX only & 75 & $40 \%$ \\
\hline AN & 78 & $42 \%$ \\
\hline Other & 10 & $5 \%$ \\
\hline
\end{tabular}




\section{OLFACTION AND ODOR DETECTION}

\subsection{Odor}

Odor detection has become a focused area of research in recent years because of its importance to the forensic, law enforcement, and legal communities. It has been explored with both biological and instrumental detectors with the most common applications in arson (ignitable liquid residue), drug, explosive, currency, cadaver, and human scent detection [29].

\section{Odor Chemistry}

An odor is a volatilized chemical compound which humans and other animals perceive through the sense of olfaction [42]. The perception of an odor is considered a two step process: the physiological step and the psychological step. The physiological step is the stimulation of the receptors in the nose by the stimuli (odorants). The psychological step is where the odorants are processed by the region of the brain responsible for smell. The biological system responsible for this odor perception process is referred to as the olfactory system (Figure 8 and Figure 9). The olfactory system is comprised of the olfactory epithelium, olfactory receptors, olfactory nerves, glomeruli, mitral cells, and olfactory bulbs. 


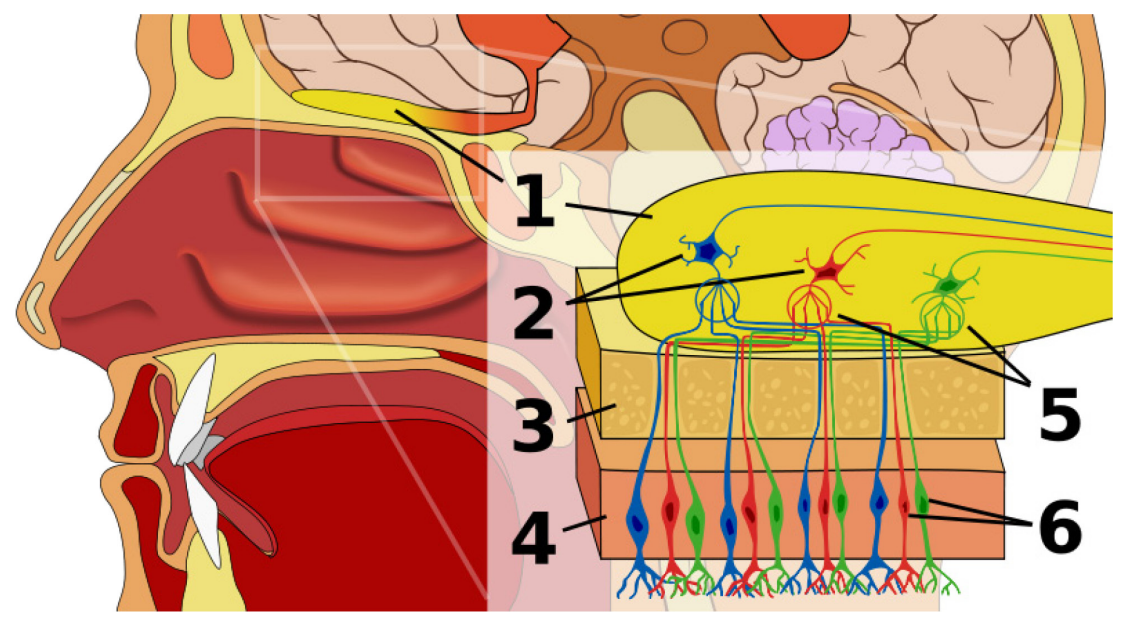

Figure 8 - Human olfactory system

(1: Olfactory bulb 2: Mitral cells 3: Bone 4: Olfactory Epithelium

5: Glomeruli 6: Olfactory receptor cells) [43]

As odorants enter the nasal cavity, they are absorbed into the mucus layer and are passed through the cell membrane via a transfer protein and receptor protein. As the odorants move into the cells, they come into contact with the olfactory epithelium, the tissue that houses the olfactory receptors. The receptors are the first step in the creation of a nerve impulse that is transmitted to the brain. In vertebrates, the olfactory receptors are located in the cilia of the olfactory sensory neurons [44]. In contrast, the olfactory receptors of insects are located on the antennae [45]. The odor impulse travels along the olfactory nerve culminating at a nerve cluster (glomerulus) within the olfactory bulb of the brain. Each glomerulus receives multiple impulses that express the olfactory receptor interpretation of similar odor particles. The signal is then transmitted by mitral cells from the glomeruli to the piriform cortex (olfactory cortex) for signal interpretation. 


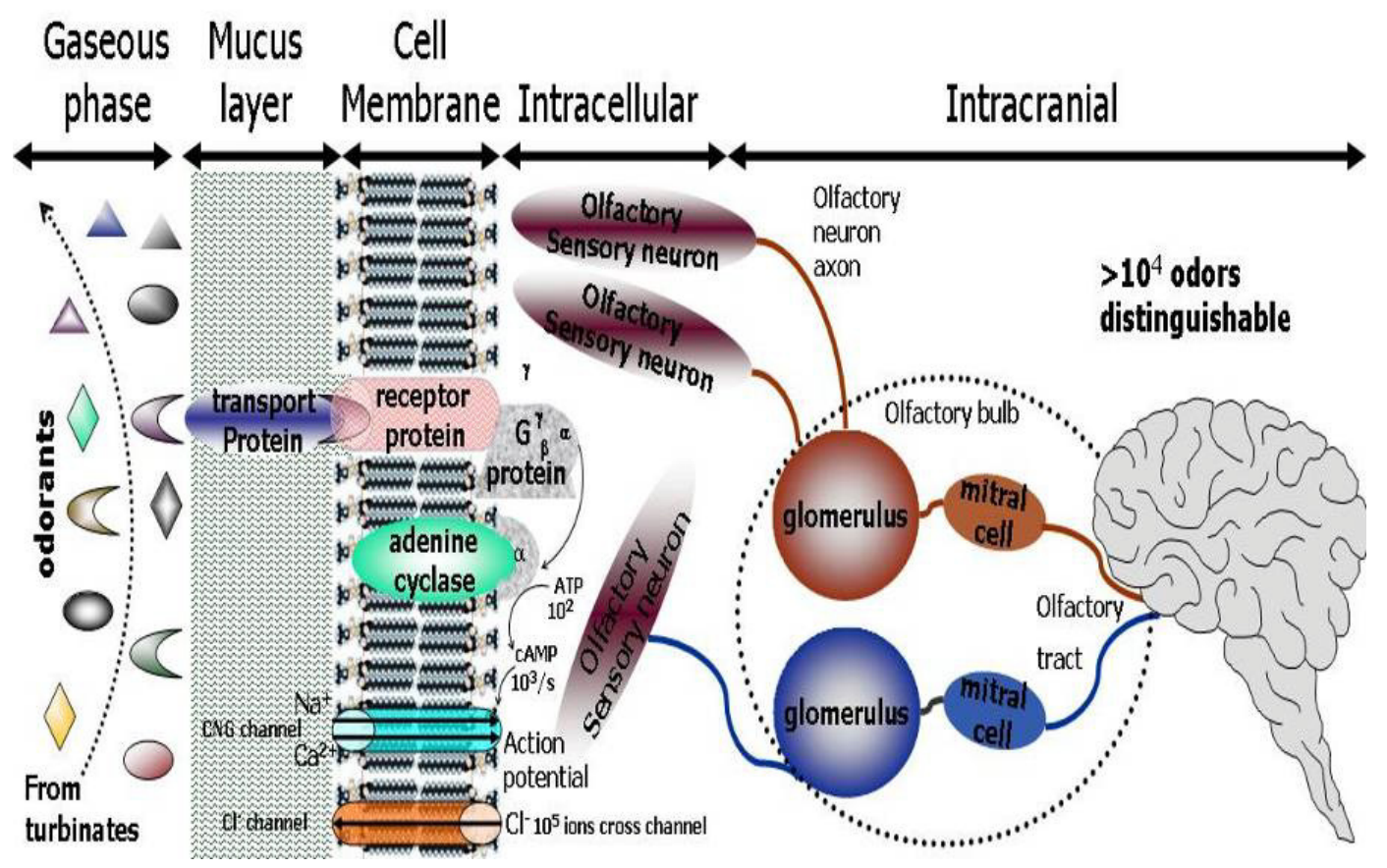

Figure 9 - Biochemical path of odorant to brain [32] (adapted from Fig 1)

Johnson et al. was able to map neural activity in the glomerular region of the olfactory bulbs of rats upon presentation of different chemical function group stimuli [46]. The study reported that while one functional group yields a specific pattern of activity in the olfactory bulb, a different functional group's activity in the olfactory bulb had a different pattern. In addition, a measurable change in the response was noted due to changes in the number of carbons (i.e. the length/size of the functional group).

\section{$\underline{\text { Odor Movement }}$}

The path (or movement) of odor particles through air is greatly dependent upon the surrounding environment. As the odor leaves the source, it expands from the size of the source to an indefinite size dependent on concentration of the source, air current velocity 
and direction, temperature, and the simplest path. The pattern of odor that escapes is referred to as the scent cone because the shape of the odor plume emanating from the source outward is approximately cone shaped [47].

In many cases, the scent cone of a compound has been shown to be comprised of the volatile organic compounds (VOCs) that are present in the sample instead of the actual parent compound $[1,2,48]$. For example, methyl benzoate has been shown to be the dominant odor signature in the headspace analysis of cocaine and the compound to which biologic detectors alert $[2,48,49]$. A list of other illicit drug and explosive compounds and their dominant odors can be seen in Table 7. 
Table 7 - Primary and secondary odor compounds for drugs \& explosives [1,3-5,50-55]

\begin{tabular}{|c|c|c|c|c|}
\hline $\begin{array}{l}\text { Forensic } \\
\text { Specimen }\end{array}$ & Target Item & $\begin{array}{l}\text { Headspace } \\
\text { Components }\end{array}$ & Primary Odor & $\begin{array}{l}\text { Secondary } \\
\text { Odor }\end{array}$ \\
\hline \multirow{5}{*}{ Drugs } & Cocaine & $\begin{array}{l}\text { Methyl Benzoate } \\
\text { Benzoic Acid }\end{array}$ & $\begin{array}{l}\text { Methyl } \\
\text { Benzoate }\end{array}$ & Benzoic Acid \\
\hline & Heroin & Acetic Acid & NA & NA \\
\hline & $\begin{array}{l}\text { Meth- } \\
\text { amphetamine }\end{array}$ & $\begin{array}{c}\text { Benzaldehyde } \\
\text { Methamphetamine } \\
\text { P2P }\end{array}$ & Benzaldehyde & $\begin{array}{l}\text { 1-Phenyl-1,2- } \\
\text { propanedione } \\
\text { 3-Phenyl-3- } \\
\text { buten-2-one }\end{array}$ \\
\hline & $\begin{array}{l}\text { 3,4-Methylene } \\
\text { dioxymeth- } \\
\text { amphetamine }\end{array}$ & $\begin{array}{l}\text { Piperonal } \\
\text { MDP2P }\end{array}$ & Piperonal & Benzoic Acid \\
\hline & Marijuana & $\begin{array}{c}\text { Polycyclic Aromatic } \\
\text { Hydrocarbons }\end{array}$ & $\begin{array}{c}\beta-\text { Pinene } \\
\text { Caryophyllene }\end{array}$ & $\begin{array}{l}\text { Limoene } \\
\text { Myrcene }\end{array}$ \\
\hline \multirow{3}{*}{ Explosives } & $\begin{array}{l}\text { TNT \& Cast } \\
\text { Explosives }\end{array}$ & $\begin{array}{l}\text { 2,4-Dinitrotoluene } \\
\text { 2,4,6-Trinitrotoluene } \\
\text { 1,3-Dinitrobenzene }\end{array}$ & $\begin{array}{l}\text { 2,4-Dinitro- } \\
\text { toluene }\end{array}$ & $\begin{array}{l}\text { Smokeless } \\
\text { Powders }\end{array}$ \\
\hline & $\begin{array}{l}\text { Polymer Bonded } \\
\text { Explosives }\end{array}$ & $\begin{array}{l}\text { 2-Ethyl-1-hexanol } \\
\text { 2,3-Dimethyl-2,3 } \\
\text {-dinitrobutane } \\
\text { Cyclohexanone }\end{array}$ & $\begin{array}{l}\text { 2-Ethyl-1- } \\
\text { hexanol }\end{array}$ & $\begin{array}{l}\text { Smokeless } \\
\text { Powders }\end{array}$ \\
\hline & Smokeless Powder & $\begin{array}{l}\text { 2,4-Dinitrotoluene } \\
\text { 2,6-Dinitrotoluene } \\
\text { Ethyl Centralite } \\
\text { Diphenylamine } \\
\text { Trinitroglycerin } \\
\text { (double based) }\end{array}$ & $\begin{array}{l}\text { 2,4-Dinitro- } \\
\text { Toluene }\end{array}$ & $\begin{array}{l}\text { Smokeless } \\
\text { Powders }\end{array}$ \\
\hline
\end{tabular}

\subsection{Biological detection}

Odor detection has been explored utilizing a variety of biologic detectors. While canines are still the most publically recognized and utilized detectors, experiments have included 
other mammalian species, insects, plants, and microorganisms. Each of these is discussed in more detail below.

\subsubsection{Canine (Canis familiaris)}

Biologic detectors can be traced back thousands of years through the use of dogs for hunting purposes. Since the mid-twentieth century, the military has incorporated doghandler teams for the detection of explosives while civilian use has commonly included the tracking of individuals and the location of victims of disasters, drugs, and explosives $[2,27]$. Recent years has seen the applications for a dog's olfaction ability expand into the detection of accelerants, guns, pipeline leaks, gold ore, contraband food, mold, and individual human scent [5,56-60]. Detector-dog response is one of the major forensic applications involved with odor detection studies, both for the determination of the chemical signature of individual odors to which these canines are actually alerting and whether or not there is a common element within different items to support the use of contraband mimics.

With respect olfaction, dogs are considered macrosmatic because they rely almost completely on their sense of smell over their other senses [61,62]. Humans are considered microsmatic because the human sense of smell is much less developed and as a species, humans rely heavily on other senses such as vision. The increased significance for the sense of smell over the other senses can be attributed to the size of the olfactory bulbs in the canine brain. The olfactory bulbs of dogs are much larger in size than humans and comprise a larger percentage of the total brain mass (Figure 10). Quignon et al. 
demonstrated that the dog olfactory receptor repertoire appears to be around $30 \%$ larger than in humans [63]. In addition, out of the total 661 olfactory receptor genetic sequences that have been characterized in dogs, only $18 \%$ are predicted to be some form of pseudogene (i.e. genes that serve no function [64]) which is a much lower percentage of pseudogenes than seen in humans $(63 \%)$. Olfactory receptors constitute the largest gene family in vertebrates and include around 900 genes in human and 1,500 genes in the mouse [63].

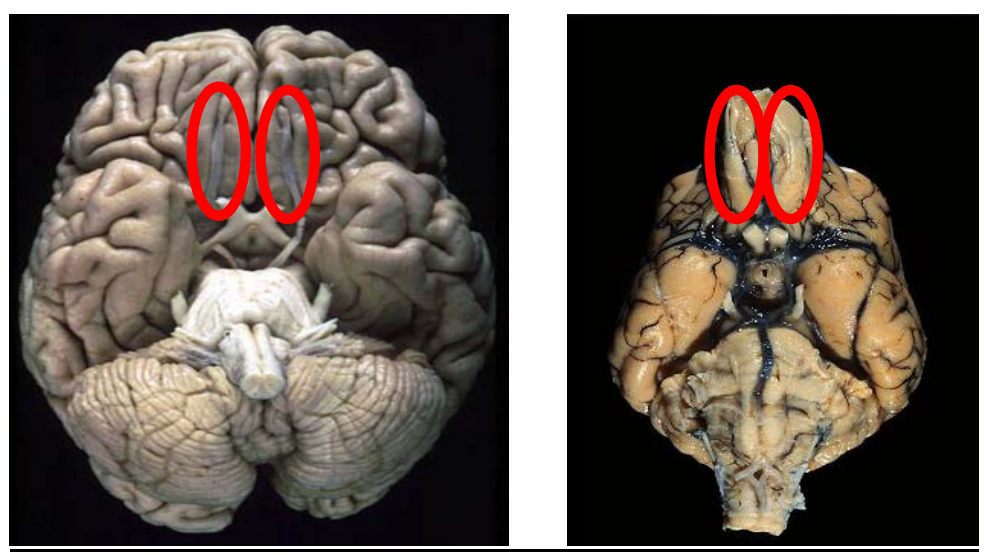

Figure 10 - Human and canine olfactory bulbs [32]

The canine detection system is the biological process of inhaling odorants followed by nerve-impulse interpretation of the odorants, considered to be a dynamic system that occurs in less than one second. Due to the orientation of its nose (i.e. air is inhaled from the front and exhaled through side slits) a canine's sniffing frequency is around $5 \mathrm{~Hz}$, which is approximately 300 breaths per minute [65]. This volume of air inhaled through the canine nose is around $60 \mathrm{~mL} / \mathrm{s}$ [66]. At a frequency of $5 \mathrm{~Hz}$, this totals $300 \mathrm{~mL}$ of air sampled each second. The dynamics of the breathing combined with the large olfactory 
system, give the canine its ability to search and identify odors quickly and efficiently. Because of these factors, a canine's olfactory sensitivity can be as high as fifty to onehundred times that over a human's olfactory sensitivity.

\section{$\underline{\text { Previous Research }}$}

Lorenzo et al. reported on the success of piperonal recognition by ecstasy-trained detection canines $[1,48]$. The success is explained by the reported dominant presence of piperonal in the headspace of 3,4-methylenedioxymethamphetamin (MDMA) based drugs, such as ecstasy $[1,14,15,48,67]$. Lorenzo conjectured that canines trained upon piperonal would correctly alert to MDMA based drugs because of the canine recognition of the compound piperonal.

Furton et al. showed that the chemical compound methyl benzoate is a dominant presence in the headspace of samples of cocaine (base and salt varieties) using SPME-GC-MS. Methyl benzoate was spiked onto circulated currency, and field trials were conducted to assess the recognition of methyl benzoate with trained drug canines. The conclusion was that methyl benzoate is an accurate and reliable training aid mimic for cocaine [2].

Harper et al. explored the potential for universal training aid mimics for common explosives $[3,68]$. The studies concluded that the chemicals present in the vapor headspace of explosive materials were not necessarily the parent explosives; however, several compounds, such as 2,4-dinitrotoluene and 2,3-dimethyl-2,3-dinitrobutane, were identified using SPME-GC-MS and SPME-GC-ECD as dominant across particular 
explosive species. Field tests with trained explosive canines verified canine recognition of these common volatile compounds. It was also determined that there was no common compound in smokeless powders that could be used for universal training purposes.

Several studies from Auburn University have been conducted to ascertain the major odors found smokeless powders that are most identified by trained canines [69-71]. Initial instrumental examination of the volatile components of the powders returned four major odor components: acetone, toluene, nitroglycerine, and limonene. Of the various tests with the canines, the mixture of acetone, toluene, and limonene was more readily identified by the canine detectors as having a similar odor to that of the smokeless powders.

\subsubsection{Additional Mammals}

$\underline{\text { Rats }}$

Interest in other animals that possess highly discriminating olfactory systems as potential odor detectors has led to experimentation with rats. Experiments with the Common Brown Rat (Rattus norvegicus) demonstrated that rats can learn to exhibit unique alerting behaviors upon identification of a variety of odors [72]. Other studies with the African Giant Pouched Rat (Cricetomys gambianus) demonstrated that the use of rats to evaluate land mine risk is a very promising mine-detection method [73]. The benefits of rats include their small size allowing them to squeeze into small areas that dogs cannot, the reduced expense, and the relative ease to acquire and maintain the animals. A female rat can have pups every few months (up to 10 pups per litter with up to 4 litters per year), 
thus it may be easy to breed selectively for behavioral performance. Unlike dogs, rats are relatively unaffected by the presence of humans and by social bonds with specific humans. The lack of attachment between the detector and the handler may reduce the dependency of the animals while trying to maintain consistent performance during long periods of repetitive work. Finally, rats have the potential to be used in ways that other animals cannot due to social and political constraints.

\section{$\underline{\text { Pig (Sus scrofa domestica) }}$}

Although there is little documentation on the use of pigs for the location of land mines, pigs are thought to locate odors more accurately than dogs, and their use to find truffles is well known [74]. In comparison to dogs, pigs are calm and relaxed animals and their focus is on eating and sleeping. Pigs are motivated to find the target (e.g. the mine) because they will be rewarded by food, whereas a dog may be more motivated by social rewards from the handler. Experimental tests have shown that only female pigs are suited for the job as male pig are harder to train because of their increased aggressive tendencies $[75]$.

\subsubsection{Insects}

\section{Parasitic Wasp (Microplitis croceipes)}

Parasitic wasps utilize chemical cues to help forage for food and locate hosts. Several studies demonstrated that these wasps are able to learn and detect a range of chemicals that are outside their natural foraging encounters [76,77]. Upon successful detection of the conditioned odors, wasps demonstrated characteristic behavior associated with the 
location of food or host. Among the proven conditioned chemicals is the compound 2,4DNT, an odor associated with TNT (section 1.4.4.2).

\section{Honeybee (Apis mellifera)}

The use of honeybees has been investigated to determine whether trained foraging bees can reliably and inexpensively search wide areas for the presence of the chemical signatures associated with landmines, drugs, and even decomposing bodies [77-80]. Through both inhalation and the branched body hairs, honeybees can sample all media (air, soil, water and vegetation) and all chemical forms (gaseous, liquid and particulate) [77-80]. The training is accomplished through odor imprint/association with their hive, and an alert is signaled by the congregation of the bees in a specific area of recognized odor in the field. The advantage for the use of bees in land mine detection is that thousands of bees can be trained within a very short time to search a field for explosives while avoiding direct contact with any mines. The disadvantage of using bees is that they do not fly at night, during heavy rain, cold weather, or wind. Additionally, a major difficulty exists in tracking the bees beyond a few meters when in areas other than open fields, such as dense forests. The use of small scale (half size of a grain of rice) radiofrequency tracking tags and a LIDAR (light detection and ranging) system have been investigated to help map out exploration areas of the bees $[79,80]$.

\subsubsection{Plants}

Plants possess certain advantages that are not seen in other biologic detectors such as the lack of a required training program. On the other hand, detection of target compounds is 
often related to growth and may take days or weeks (vs. instantaneous indication from animals) to demonstrate results.

\section{Thale Cress (Arabidopsis thaliana)}

Aresa (a Danish plant biotechnology company) has developed a genetically modified plant, thale cress (Arabidopsis thaliana), which changes color from green to red when growing on or in the proximity of landmines [81]. Because the explosive material within the landmines releases nitrogen dioxide $\left(\mathrm{NO}_{2}\right)$ into the soil, it is absorbed by the plant. Absorption of $\mathrm{NO}_{2}$ starts the production of a red compound which causes the leaves of the plant to turn red.

\section{Tobacco (Nicotiana tabacum)}

Studies have shown that the use of genetically modified tobacco plants (Nicotiana tabacum) can be used in combination with fluorescence for the detection of nitroaromatic compounds [82]. The plants are modified to express a green fluorescent protein (GFP) when in the presence of a specific inducer. A field spectrometer and imaging system was used to determine if the fluorescence of the spiked plants was detectable and separable from controls and naturally fluorescent plants.

\section{$\underline{\text { Chlorophyll Circuit }}$}

Research at Colorado State University has explored the use a synthetic "de-greening circuit" that produces rapid chlorophyll loss (i.e. color change from green to white) in the presence of specific target materials. Additionally, these synthetically "de-greened," 
white plants will "re-green" upon removal of the specific inducer, allowing for an easily re-settable reporter system for plants [83].

\subsubsection{Microorganisms}

\section{$\underline{\text { Yeast (Saccharomyces cerevisiae) }}$}

Through the implantation of a specific rat olfactory protein that detects DNT, researchers at Temple University have engineered yeast (Saccharomyces cerevisiae) for the detection of 2,4-DNT [84]. Activation of the rat olfactory protein increases the production of the intracellular messenger, cAMP (cyclic adenosine monophosphate), which then triggers the production of GFP. The GFP levels were analyzed by fluorescence microscopy. Provided that the correct mammalian olfactory receptor protein is utilized, any odorant can be detected. Potential applications of this yeast range from diagnostics that are associated with the odor of bodily fluids to industrial process monitoring.

\section{Algae (Dictyosphaerium chlorelloides)}

A new genetic method has been developed for the detection of contaminants based on the use of two different algal genotypes: a sensitive genotype to obtain sensitivity and a resistant mutant to obtain specificity. Researchers have tested this method with the detection of TNT using a wild-type microalgae strain (Dictyosphaerium chlorelloides) as the sensitive organism and a TNT-resistant mutant strain [85]. It was observed that the resistant mutants always exhibited a significantly higher maximal fluorescence value in the presence of TNT than the wild-type cells. The algal biosensors offer potential use as an early warning system for the detection of contaminants. 


\subsection{Odor Imprint/Training}

Some of the more debated points for use of biologic detectors have to do with odor imprint, training procedure, olfactory memory, and training context. One example has to do with the initial imprint of a detection canine on multiple target odors (i.e. multiple types of drugs or multiple types of explosives). The ongoing debate is whether the odors should be first presented as a group and later separated into individual odors, or should the target odors be kept separate for the length of the training. Variations in canine training play a large role in the level of odor recognition by the canines. For example, ecstasy pills taken from different batches can possess different concentrations of the active ingredient MDMA which can result in lower thresholds of piperonal (the identified odor for canine recognition $[1,48])$. As recently shown, samples from three separate batches of ecstasy pills were comprised of $34 \%, 21 \%$ and $8 \%$ of MDMA, respectively [86].

Blais et al. has experimented with reconditioning training based on early olfactory experiences [87]. Two groups of rats were exposed to odors for the first twenty days after birth; one group's odor was aniseed and the other's was water. At day forty, both groups were training to the two month mark in a Y-maze for eighty percent recognition of aniseed odor. Finally, the ease of reconditioning training to the aniseed odor was tested at the 5, 6, 7, 8, and 9 month interval. The results showed that the group of rats that had been exposure to the aniseed odor did not require reconditioning while the control group did. The study's conclusion supports the theory that early exposure to olfactory stimuli can aid in future training processes. 
Gazit et al. demonstrated the "context shift effect" of stimulus-response training using "highly trained explosives detection dogs" [88]. The "context shift effect" is a reduction in performance of a learned stimulus-response-reinforcer relationship (i.e. alerting to specific odors) from one context to another. The potential difficulty of achieving the same success in a conditioned stimulus response is attributed to the environment change that is perceived by the subject. The reported results suggest that extinction training (i.e. a repetitious non-alert response) is context dependent. Thus, a learned behavior will not extend past the specific context used during the extinction training. Further, once the extinction behavior is learned, it will be difficult to overcome in the specific context to which it was developed. The "context shift effect" is the reason many biologic trainers incorporate many situations, areas, and contexts in their training regimens. One criticism of this study was the researchers' definition of a "similar" path. The identification of "similar" was based on visual appearance by the experimenters. It has previously been said that canines rely much more on their olfactory capabilities than visual, therefore, a visually "similar" path to humans may not be perceived as olfactoraly similar to canines.

\subsection{Instrumental Detection}

Instrumental techniques encompass a wide range of instruments from large-scale, immobile instruments to small, field portable instruments. Instrumentation can be used for sampling, separation and identification of analytes. While most sampling may be done in the field, sample preparation and analysis is often performed in a laboratory setting. 


\section{$\underline{\text { Solid Phase Micro Extraction (SPME) }}$}

Solid phase micro extraction is a non-exhaustive method for extracting the volatile organic compounds in the headspace of a sample by combining isolation and preconcentration of the analytes of interest. SPME is accomplished in two steps: adsorption of analytes from the headspace of the sample onto the coating of the fiber followed by desorption of the analytes from the fiber into the analytical instrument. The amount of analyte extracted by the coating is determined by the partition coefficient of the volatile analyte between the sample and fiber coating. SPME can be performed as an equilibrium extraction or a pre-equilibrium extraction depending on the amount analyte necessary for analysis. SPME offers fast, simple, reusable, and economic sampling without the need for solvents or complicated apparatus. Because of this, SPME sampling can be performed in the field by nonscientists and sent to the lab for analysis. SPME has been used in conjunction with gas chromatography for samples of all types including drugs, explosives, human scent, arson, pesticides, etc [2,89-92].

\section{$\underline{\text { Gas Chromatography (GC) }}$}

Gas chromatography provides a combination of high-resolution, reproducibility, ease of use and quick analysis for volatile samples. Several detectors are commonly used in conjunction with gas chromatography including mass spectrometry and electron capture devices. 


\section{Liquid Chromatography (LC)}

Liquid chromatography provides a quick analysis for samples in solution, regardless of analyte volatility. Therefore, thermally labile compounds are easily analyzed. Mass spectrometry is commonly used as the detection technique in conjunction with liquid chromatography.

\section{Mass Spectrometer (MS)}

A mass spectrometer with electron ionization (EI) is the most common detector encountered in drug and explosives analysis. Unfortunately, samples of the same chemical class, such as nitrate esters, can sometimes yield similar spectra from an EI source. In these cases, chemical ionization (CI) can be used in compliment as it provides more information about molecular weight. Further sensitivity and selectivity can be accomplished by coupling MS with MS for the analysis of product ions.

\section{Electron Capture Device (ECD)}

The electron capture device is a highly sensitive detector based on the relative ability of compounds to capture electrons; these are typically electronegative species such as organic nitro- compounds, nitramines, and nitrate esters. The affinity for negative moieties makes ECD a good detector to be used in conjunction with chromatography for explosive samples. 


\section{Field Portable Instrumentation}

There is a large demand for field portable instrumentation that yields fast and reliable analysis. The application for portable instruments exists for explosive detection (e.g. mine field), drug detection (clandestine lab chemicals), and biologic weapons. Since the canine nose has yielded such reliable and proven results, it is common for field-portable detection devices to be referred to as electronic noses.

The current "gold standard" for portable detection is ion mobility spectrometry (IMS) which offers fast and sensitive detection [93,94]. With IMS, sample ions are formed and injected into an electric field. Separation is based on mobility of ion clusters down a drift tube at atmospheric pressure. The resulting plasmagram is based on ion current by drift time. It is currently used by many police departments for fast detection of drugs and airport security for fast detection of explosives and explosive residue.

To maximize the detectable uses for IMS, Perr et al. created a SPME interface so that volatile compounds emanating from explosives (such as detection taggants) could be sampled [95]. Using this technology, Joshi et al. and Lai et al. have demonstrated extremely low detection limits for drug and explosive related odors [96,97]. The limit of detection using SPME-IMS for diphenylamine, ethyl centraltie, DMNB, and piperonal was determined to be $0.12 \mathrm{ng}, 1.2 \mathrm{ng}, 1.61 \mathrm{ng}$, and $0.45 \mathrm{ng}$, respectively. One drawback to the SPME-IMS interface was the need for separate interfaces for varying fibers (i.e. the interface is not considered robust). Further experimentation has been performed by 
Guerra et al. using a novel planar SPME device which negates the need for varying fiber interfaces [98]. This geometry $(\sim 65-70 \mu \mathrm{m}$ thick) increases the surface area and volume which enhances analyte recovery. In addition, the equilibrium sampling is reduced from 10hr with the PDMS fiber to 40min with the planar PDMS.

Another example of sensitive technology is the use of fluorescent polymers that have the ability to bind specifically to target compounds [99]. The primary flaw of this technique is that it is limited to a single analyte. Other examples of current technology include sensor arrays, metal oxide semiconductor sensors, fast speed GC columns, surface acoustic wave detector (SAW), and microelectromechanical sensors (MEMS) [99-103].

The detection limits of instrumentation (i.e. sensitivity) have been shown to reach subnanogram levels (e.g. 0.45ng of piperonal using SPME-IMS) [96,97]. The detection limits for a dog's olfactory ability are greatly dependent upon the training that dog has received. Dogs that train on small amounts of substance may not recognize the odor signature of large quantities. Similarly, dogs that train on large quantities of substance may not alert to the signature of small quantities. Johnson demonstrated the sensitivity of the canine nose is dependent upon the target compound [104]. The reported detection limits ( $\sim 50 \%$ alert response) of explosive odor compounds such as 2,4-DNT and DMNB by trained canines were in the 500ppt range (part per trillion). The reported detection limits for NG and methyl benzoate by trained canines were in the of 10ppb range (part per billion). Furton et al. demonstrated that a dog's olfactory recognition range of methyl benzoate spiked on circulated currency is comparable to that of humans [2]. 
For the most part, the sensitivity of instrumentation is superior; however, the ability for selectivity in highly complex search zones is superior for canines. Combined with the fast speed of detection and the mobility of the canine, this selectivity demonstrates the heretofore claimed superiority of canines in the field. At the same time, there are drawbacks to using dogs versus an instrumental technique (found in Table 8) [27]. Depending on the training technique, the possibility of handler influence can cause the dog to falter during detection whereas instrument operator error is less of a factor in the detection function. The environment can have a large bearing on the ability of the canine to detect odors. Extreme temperatures can adversely affect the canine's ability to search (i.e. heat-induced time-limit or reduced odor availability in cold temperatures). Even in the best situations, a canine's ability to work is governed by its biological needs and limits. Depending on the instrumental technique, reduced odor availability (as seen in colder temperatures) may also limit the usefulness of a volatile compound detector; however, as long as proper upkeep is maintained, an instrument can be run under most environmental conditions. In many scenarios, the comprehensive benefits of the canine detector are equal to or better than an instrumental counterpart. 
Table 8 - Comparisons between instrumental detectors and detection canines

\begin{tabular}{|c|c|c|}
\hline Aspect & Instrument & Canine \\
\hline Operation Time & $24 \mathrm{~h} /$ day (theoretical) & $8 \mathrm{~h} /$ day \\
\hline I.D. of target & $\begin{array}{l}\text { Presumptive I.D. possible (limited by } \\
\text { selectivity factors) }\end{array}$ & $\begin{array}{l}\text { Not trained to I.D. with different } \\
\text { alerts }\end{array}$ \\
\hline $\begin{array}{l}\text { Operator/handler } \\
\text { influence }\end{array}$ & Less of a factor & A potential factor \\
\hline $\begin{array}{l}\text { Environmental } \\
\text { conditions }\end{array}$ & Less affected & $\begin{array}{l}\text { May adversely affect (i.e. high } \\
\text { temperatures) }\end{array}$ \\
\hline $\begin{array}{l}\text { State of scientific } \\
\text { knowledge }\end{array}$ & Relatively mature & Late emerging \\
\hline Courtroom acceptance & Generally unchallenged & Sometimes challenged \\
\hline$L O D$ & $\begin{array}{l}\text { Compound dependent } \\
\text { (sub-nanogram levels) }\end{array}$ & $\begin{array}{l}\text { Compound dependent } \\
\text { (nanogram levels) }\end{array}$ \\
\hline Selectivity & Sometimes problematic & Very good \\
\hline Mobility & Limited to operator & Very versatile \\
\hline $\begin{array}{l}\text { Overall speed of } \\
\text { detection }\end{array}$ & Area dependant & Generally faster \\
\hline Scent to source & Difficult with present technology & Natural and quick \\
\hline Intrusiveness & $\begin{array}{l}\text { Variable (apprehensiveness not } \\
\text { uncommon) }\end{array}$ & $\begin{array}{l}\text { Often innocuous (breed } \\
\text { dependent) }\end{array}$ \\
\hline Initial cost & ca. $\$ 45000$ & ca. $\$ 6000$ \\
\hline $\begin{array}{l}\text { Annual cost (excluding } \\
\text { personnel) }\end{array}$ & ca. $\$ 4000$ (service contract) & ca. $\$ 2000$ (vet and food bill) \\
\hline Calibration standards & Can be run simultaneously & Run individually \\
\hline Re-calibrations & Daily to weekly & Daily to weekly \\
\hline Performance issues & Electronics: mechanical & Disease conditions \\
\hline
\end{tabular}




\subsection{Alternate Odor System}

\section{$\underline{\text { Odor Mimic }}$}

An alternate odor system is created through the use of comparable methods and materials to simulate training and testing conditions. The resulting product is referred to as an "odor mimic." An "odor mimic" is an imitation or simulative that is similar in functionality to that of the actual compound or compounds. Mimics can be used in place of a training aid and/or calibration standard for biologic and instrumental detectors. Often, mimics are incorrectly referred to as "pseudo aids," or simply "pseudos". A pseudo is a product that resembles or is related to the actual compound in functionality, but it is not necessarily an odor imitation. Mimics are used across many disciplines including: arson, drugs, explosives, human scent, mold, and cadavers.

After determination of the appropriate simulant and creation of the odor mimic, presentation to biologic and instrumental detectors is considered. The optimal presentation method is dependent upon the physical form of the chemical compounds that comprise the odor mimic (i.e. large solid form, powder form, liquid form). The most widely used containers include paint cans, scent boxes, scent cages, PVC pipes, permeation tubes, and polymers.

\section{$\underline{\text { Polymers }}$}

Polyethylene

Polyethylene is the most commonly encountered polymer used to date. Among its many commercial uses include items such as grocery bags, shampoo bottles, children's toys, 
and even bullet proof vests. The simplest structure of all commercial polymers, polyethylene, is comprised of a long chain of carbon atoms with two hydrogen atoms attached to each carbon atom (Figure 11). The structure is referred to as a linear polyethylene or high-density polyethylene (HDPE).

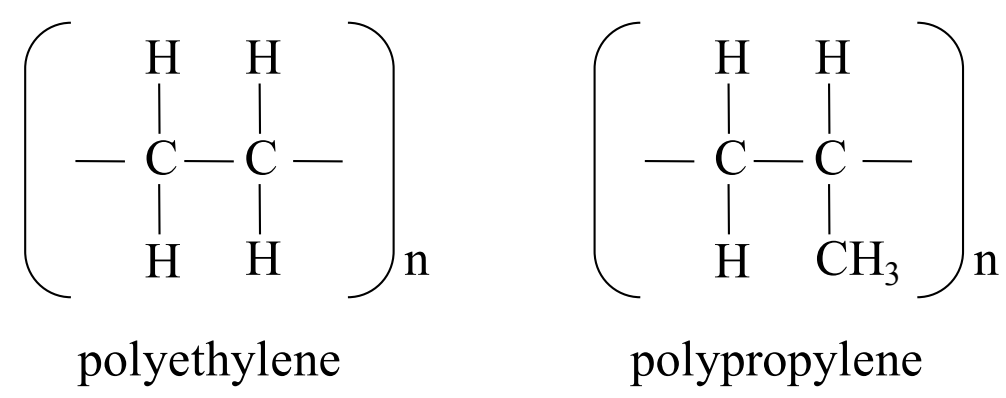

Figure 11 - Polymer Structures

Within this simple structure, variations/mutations can occur. One mutation consists of the substitution of additional polyethylene chains in place of the hydrogens (Figure 12). Referred to as branching, the substitution occurs in low-density polyethylene (LDPE). LDPE has a lower tensile strength and higher ductility than HDPE. While linear polyethylene offers a more rigid structure (i.e. it is much stronger), branched polyethylene is less expensive and easier to make than linear polyethylene. 


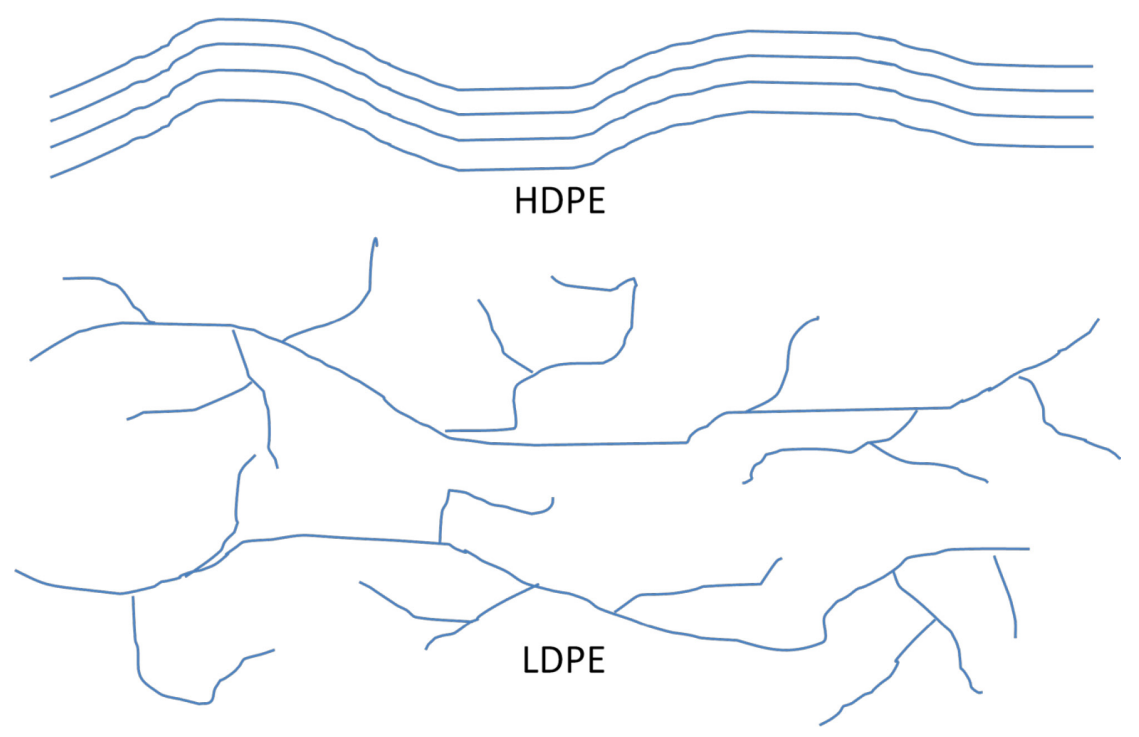

Figure 12 - Simulated appearance of HDPE and LDPE

Polypropylene

Polypropylene is a versatile polymer that serves as both a plastic and as a fiber. As a plastic it is used to make things such as dishwasher-safe food containers. Polypropylene does not melt below $160^{\circ} \mathrm{C}$, unlike polyethylene which anneals at $100^{\circ} \mathrm{C}$ causing dishes to warp in a dishwasher. As a fiber, polypropylene is used to make indoor-outdoor carpeting. Because it is easy to color and resistant to water, it is often seen around pools and miniature-golf courses.

Structurally, polypropylene is comprised of a carbon backbone with methyl groups attached at alternating carbon atoms. Depending on the orientation of the methyl group, the tacticity (rigidity) of polypropylene is affected. The most commonly used polypropylene is isotactic, meaning that all the methyl groups are arranged on the same 
side of the chain. Polypropylene can also present as atactic, meaning that the methyl groups are randomly arranged on both sides of the chain (Figure 13).

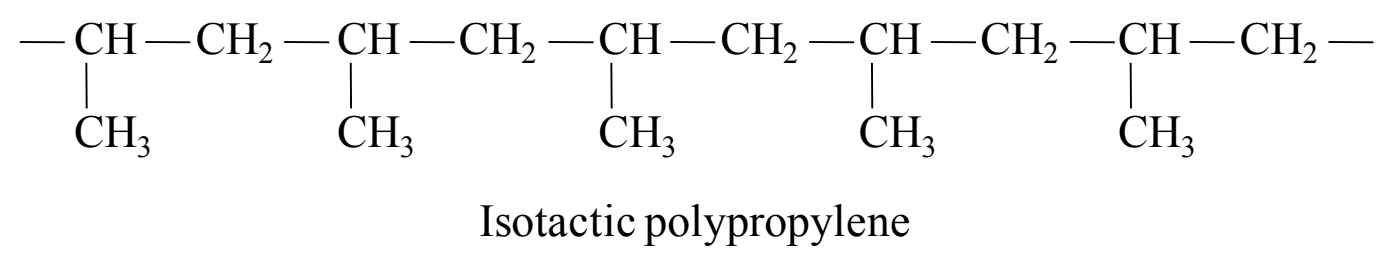<smiles>CCC(C)CC(C)CC(C)CC(C)CC(C)C</smiles>

Atactic polypropylene

Figure 13 - Polypropylene structures

Certain synthesis processes can form polymers that contain sections of both isotactic and atactic polypropylenes in the same polymer chain (Figure 14). In this polymer, alignment of the isotactic blocks forms crystals which are held together by soft rubbery tethers of atactic polypropylene. Conversely, the hard isotactic blocks add strength to the rubbery atactic material together resulting in a polymer that is rubbery and makes a good elastomer. 


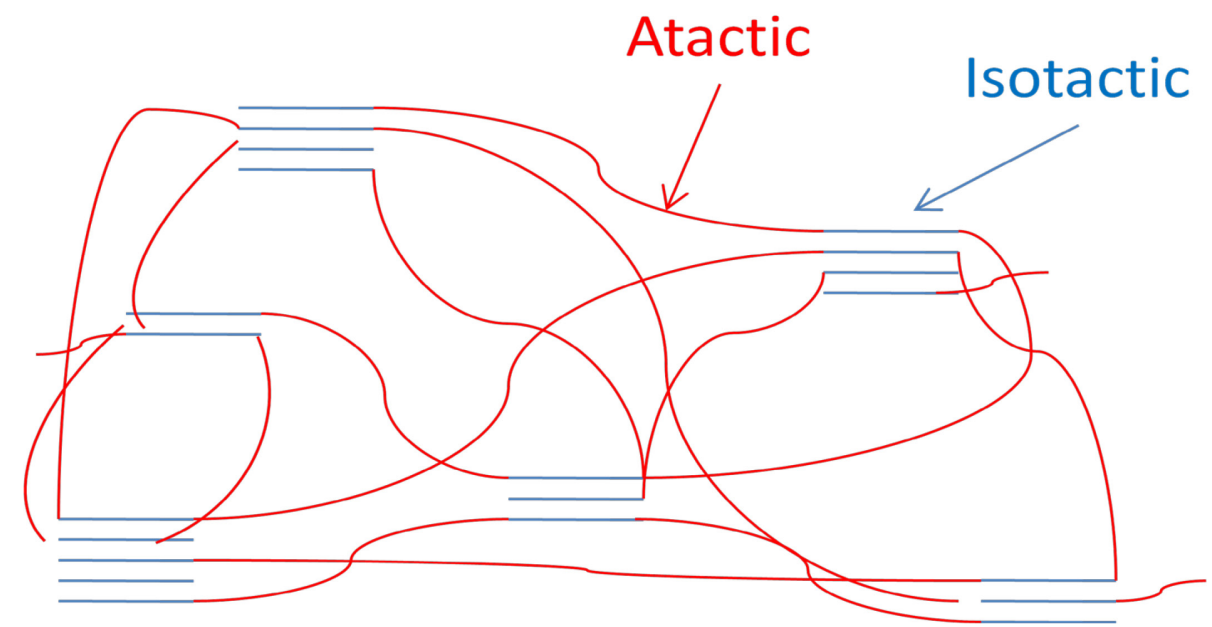

Figure 14 - Polypropylene polymer chains

\section{Controlled odor mimic permeation system (COMPS)}

The creation of a controlled odor mimic permeation system has been researched and evaluated in order to determine an optimized method for odor delivery [68]. These devices incorporate a polymer matrix for delivery of the target odor. The polymer matrix allows for the presentation of the odor mimic with a reliable and measurable delivery of the target odor. The use of COMPS devices should allow for the creation of better training aids that are safer, easier to acquire, and more consistent than currently available. Overall, the use of COMPS will lead to improvements in the performance and standardization of biological and instrumental stand-off detection of targets. 


\section{METHODOLOGY}

\subsection{Materials and Chemicals}

\subsubsection{Chemicals, Drugs, Explosives, and Firearms}

Piperonal, isosafrole, caffeine, acetic acid, salicylic acid, diphenylamine, ethyl centralite, 2,4-dinitrotoluene, 2,3-dimethly-2,3-dinitrobutane, and 2-ethyl-1-hexanol were obtained from Sigma Aldrich (St. Louis, MO). Optima grade solvents (acetonitrile, methylene chloride, methanol, and water) were purchased from Fischer Scientific (Pittsburgh, PA). Drug standards were obtained from Ceilliant (Round Rock, TX) and Restek (Bellefonte, PA) including: 3,4-methylenedioxymethamphetamine, methamphetamine hydrochloride, 3,4-methylenedioxyethamphetamine, 3,4-methylenedioxyphenyl-2-propanone, and 1(3,4-methylenedioxyphenyl)-propan-2-ol. Explosive standards were obtained from Cerilliant including: nitrobenzene, 1,3-dinitrobenzene, 1,3,5-trinitrobenzene, 2nitrotoluene, 3-nitrotoluene, 4-nitrotoluene, 2,4-dinitrotoluene, 2,6-dinitrotoluene, 2,4,6trinitrotoluene, 1,3,5-trinitro-1,3,5-triazacyclohexane (RDX), 1,3,5,7-tetranitro-1,3,5,7tetrazacyclooctane (HMX), Tetryl, ethylene glycol dinitrate, nitroglycerine, and pentaerythritol tetranitrate.

Drug samples were provided by local and state law enforcement agencies, including Miami Dade Police Department (MDPD) Narcotics K9 Unit, Coral Gables Police Department (CGPD), Florida Highway Patrol Contraband Interdiction Program (FHPCIP) K9 Division, and US-K9 Academy and Police Dog Training Center. 
Explosive samples were provided by local and state law enforcement agencies, including Miami Dade Police Department (MDPD) Bomb Squad, Florida International University Police Department (FIUPD) K9 Unit, Palm Beach County Sheriff's Office (PBSO) Bomb Squad and K9 Division, and US-K9 Academy and Police Dog Training Center. Single based smokeless powders including: Hodgdon's H1000, Varget, Retumbo, H4350, H4831, and H4831SC; IMR's 3031, 4064, 4831, and 4895; VihtaVuor's VV110, VV140, VV150, VV160, VV165, and VV170 were purchased from local outdoor \& hunting stores and donated by local gun-range patrons. Double based smokeless powders including: Hodgdon's H110, H414, Clays, BL-C(2), and Lil' Gun; Alliant's Reloader 15 and Red Dot; Accurate Arms' AA2230 and AA2520; VihtaVuori's VV350, VV530, VV540, and VV560 were purchased from local outdoor \& hunting stores and donated by local gun-range patrons.

Used ammunition rounds of various calibers, live ammunition rounds of various calibers, various models of firearms and firearm components (Raven 25cal, Kel-Tec 9mm, Taurus .38 , Beretta .32 , and loaded gun magazines), and a variety of oils and solvents (HD-30 motor oil, WD-40 lubricant, sewing machine oil, 3-in-1 Oil, Tetra gun oil, gun lubrication oil, bore cleaner, and powder solvent) were supplied by Miami Dade Police Department (MDPD) Narcotics K9 Unit and US-K9 Academy and Police Dog Training Center.

Various forms of commercial vinegar (Publix Distilled White Vinegar, Publix Red Wine Vinegar, Publix Balsamic Vinegar, Musselman's Distilled White Vinegar, and Heinz Apple Cider Vinegar) were purchased at local grocery stores. 


\subsubsection{Laboratory Supplies}

The $70 \mu \mathrm{m}$ StableFlex ${ }^{\mathrm{TM}} \quad$ Carbowax ${ }^{\circledR} /$ Divinylbenzene $\quad(\mathrm{CW} / \mathrm{DVB})$ solid phase microextraction (SPME) fibers, SPME fiber holders for manual sampling, headspace vials (10ml, and 40ml) fitted with phenolic plastic caps and a PTFE/silicon septum, and clear ABC auto-sampler vials (2ml) with PTFE/silicone lined caps were purchased from Supelco (Bellefonte, PA). Red-rubber, sleeve-stopper septa $(11 \mathrm{~mm})$ were purchased from Wheaton (Millville, NJ).

\subsubsection{Other Supplies}

Quart and gallon sized steel paint cans were obtained from All American Containers (Miami, FL). Metal electrical junction boxes, 4" x 4" x 2", were purchased from local hardware stores. Sigma Pseudo ${ }^{\mathrm{TM}}$ Scent Cages were purchased from Sigma Aldrich (St. Louis, MO). Sterile cotton gauze, 2" x 2", was purchased from Independent Medical Coop (Daytona Beach, FL). Polymer, heat-seal bags were obtained in 1.5mil, 2.0mil, 3.0mil and 4.0mil low density polyethylene and 2.0mil high density polypropylene from Veripak (Atlanta, GA). Heat sealed, aluminized bags (5.75" x 6" and 6" x 5.5") were purchased from Kapak (St Louis, MN) and Ted Pella, Inc. (Redding, CA), respectively. Tea candles were purchased from local retail stores.

\subsection{Sample Preparation}

\subsubsection{Headspace Sample Preparation}

Small amounts of samples $₫ 5 \mathrm{~g}$ or $\leq 10 \mathrm{~mL}$ ) were placed inside $10 \mathrm{ml}$ glass vials and capped with Silica/PTFE septa. The headspace of each sample was sampled through 
insertion of the SPME fiber through the septum. The fiber was exposed approximately $1 \mathrm{~cm}$ to $2 \mathrm{~cm}$ above the sample within the closed vial for the sample specific adsorption time immediately prior to GC analysis. Large amounts of samples, or bulk samples, (10g to $75 \mathrm{~g}$ ) were placed inside quart or gallon sized, steel paint cans. Using a $3 / 16$ " drill bit, a hole was drilled into the paint can lids and fitted with a $11 \mathrm{~mm}$ red-rubber septum. As before, a SPME fiber was inserted through the septum and exposed approximately 3 in to 6in (depending on the size of the can) above the sample within the closed paint can for the sample specific adsorption time immediately prior to GC analysis.

\subsubsection{Liquid Sample Preparation}

Liquid samples were created by diluting the pure sample to the appropriate concentration with the selected solvent. The solution concentration varied depending on the nature of the sample (pure or convoluted) and the instrument in use. Because of the sensitivity of the detector, GC-MS analysis utilized a much higher concentration of solution than the LC-MS. If necessary, the solid samples were ground into a powder using a mortar and pestle prior to dilution. The solutions were placed into $2 \mathrm{ml}$ auto-sample vials which were then placed into the GC or LC auto-sample tray for analysis.

\subsection{Instrumentation}

\subsubsection{Gas Chromatography - Mass Spectrometry (GC-MS)}

An Agilent 6890N Gas Chromatograph was used in combination with the Agilent 5973N

Quadrupole Mass Selective Detector running Agilent Technologies MSD Productivity ChemStation software (Revision D.03.00 SP1). The GC was fitted with a HP5 30m long 
$\mathrm{x} 0.25 \mathrm{~mm}$ inner diameter column with a $25 \mu \mathrm{m}$ thick stationary phase that was obtained from Agilent. For sample analysis, the GC-MS parameters were set as follows:

- $\mathrm{GC}$

- Injection port temperature of $235^{\circ} \mathrm{C}$

- $2 \mathrm{~mm}$ inner diameter liner

○ Oven Program

- $40^{\circ} \mathrm{C}$ hold for 5 minutes

- $10^{\circ} \mathrm{C} / \mathrm{min}$ ramp to $280^{\circ} \mathrm{C}$

- 1 minute hold at $280^{\circ} \mathrm{C}$

- Carrier gas - Helium at a flow rate of $1.0 \mathrm{ml} / \mathrm{min}$

- Transfer line temperature of $280^{\circ} \mathrm{C}$

- MS

- Source temperature of $230^{\circ} \mathrm{C}$

- MS Quad temperature of $150^{\circ} \mathrm{C}$

- Electron Ionization (EI)

- Full scan range $\mathrm{m} / \mathrm{z} 35-350$

- Excitation voltage of $70 \mathrm{eV}$

- 5 minute solvent delay

Liquid samples were analyzed with the auto-injector (Agilent 7683B Series). The injection method included a pre- and post-wash cleaning of the injection syringe in the sample solvent. Post headspace sample collection, the SPME fiber was set to $3 \mathrm{~cm}$ and inserted into the split/splitless injection port of the GC for a $5 \mathrm{~min}$ desorption period. 


\subsubsection{Liquid Chromatography - Mass Spectrometry (LC-MS)}

The Varian ProStar Liquid Chromatography system was used in combination with the Varian Ion Trap Mass Spectrometer Model 500-MS running Varian's MS Workstation software (Version 6). The Varian ProStar liquid chromatography system was comprised of an auto-injector (Varian Model 230) connected in sequence with two solvent delivery modules (Varian Model 210). The LC column was fitted with a Pursuit XRs 3 C18 $100 \mathrm{~mm}$ long x $2.0 \mathrm{~mm}$ wide column obtained from Varian. For sample analysis, the LCMS parameters were set as follows:

- LC

○ Injection volume of $10 \mu \mathrm{L}$

○ Mobile Phase - 45:55 Aqueous:Organic Isocratic

- Aqueous - 2mM Ammonium Acetate with 1\% Formic Acid

- Organic - 50/50 Acetonitrile/Methanol

- Flow rate of $0.2 \mathrm{~mL} / \mathrm{min}$

- Column Temp of $25^{\circ} \mathrm{C}$

- MS

○ Nebulizer gas - Nitrogen at 25psi

○ Drying gas - Nitrogen at $15 \mathrm{psi}, 350^{\circ} \mathrm{C}$

- Electrospray Ionization in positive mode (ESI+)

- Full scan range $\mathrm{m} / \mathrm{z}$ 50-300

- Needle voltage of $5000 \mathrm{~V}$

- Capillary voltage of $40 \mathrm{~V}$

- RF loading of $61 \%$ 
- Ionization chamber at $50^{\circ} \mathrm{C}$

\subsection{Odor Mimics}

\subsubsection{Controlled Odor Mimic Permeation System (COMPS)}

The chemical compounds used as odor mimic were prepared for presentation to canines according to the physical appearance of the compounds. Solid compounds were weighed to various amounts and heat sealed within a polymer bags. Liquid compounds were spiked onto 2in x 2in sterile gauze pads and heat sealed within LDPE bags. The solid amounts varied from $5 \mathrm{mg}$ to $2 \mathrm{~g}$ and liquid amounts varied from $1 \mathrm{~mL}$ to $5 \mathrm{~mL}$. The polymer bags that were used included 3in x 3in 1.5mil, 2mil, 3mil, 4mil LDPE and 2mil HDPP. The COMPS device was then heat sealed and stored within an aluminized Kapak bag. Negative controls were created by with blank media (i.e. blank gauze, empty polymer bags, and blank tea candles).

\subsubsection{Permeation of Odor Compounds}

Once the COMPS were prepared, they were monitored (weighed) over the course of twenty-one days to determine the mass loss per time, i.e. the permeation rate through the polymer bags. At the conclusion of the weighing process, the data was plotted as mass vs. time. Each sample was made-up in triplicate for statistical purposes. The plotted results of average mass loss vs. time in days allowed for a calculation of permeation rate and half-life for each odor compounds through the polymer bags. Empty bags were also heat sealed and kept in the same environment to use as control samples. These controls 
(blanks) were made in triplicate blanks were kept and monitored concurrently to maintain a baseline.

\subsubsection{Field Trials}

Field trials were performed with trained and certified local law enforcement explosive detection canine teams and drug detection canine teams. The odor aids were presented to the canines in metal scent/electrical boxes, Sigma Pseudo ${ }^{\mathrm{TM}}$ Scent Cages, or quart paint cans. Prior to use, the presentation vessels were cleaned with soap, rinsed with water, and placed in an oven set to $110^{\circ} \mathrm{C}$ for a minimum of 12 hours. After preparation, the odor samples were presented to the canines in an "odor line-up" by placing the samples on the floor approximately one meter apart (Figure 15). The handlers were instructed to work with their detection canines to detail each sample in the line-up utilizing their normal search pattern. The handlers had no previous knowledge of the compounds or order of placement in the line-up. Additionally, there was no marking on the containers to indicate the contents. A positive control and negative control were included in the odor line-ups. The positive control was an actual explosive sample provided by the police agency at the time of testing. The negative control was an object from the ambient environment used for the trial.

Forty-three certified drug detection canines and twenty certified explosive detection canines participated in this study. Field test attendance varied from three to ten canines at any given test. For data collection, analysis, and result reporting purposes, each canine 
was assigned an individual three digit identification code. The code system also groups the canine teams into the explosive or drug detection category.

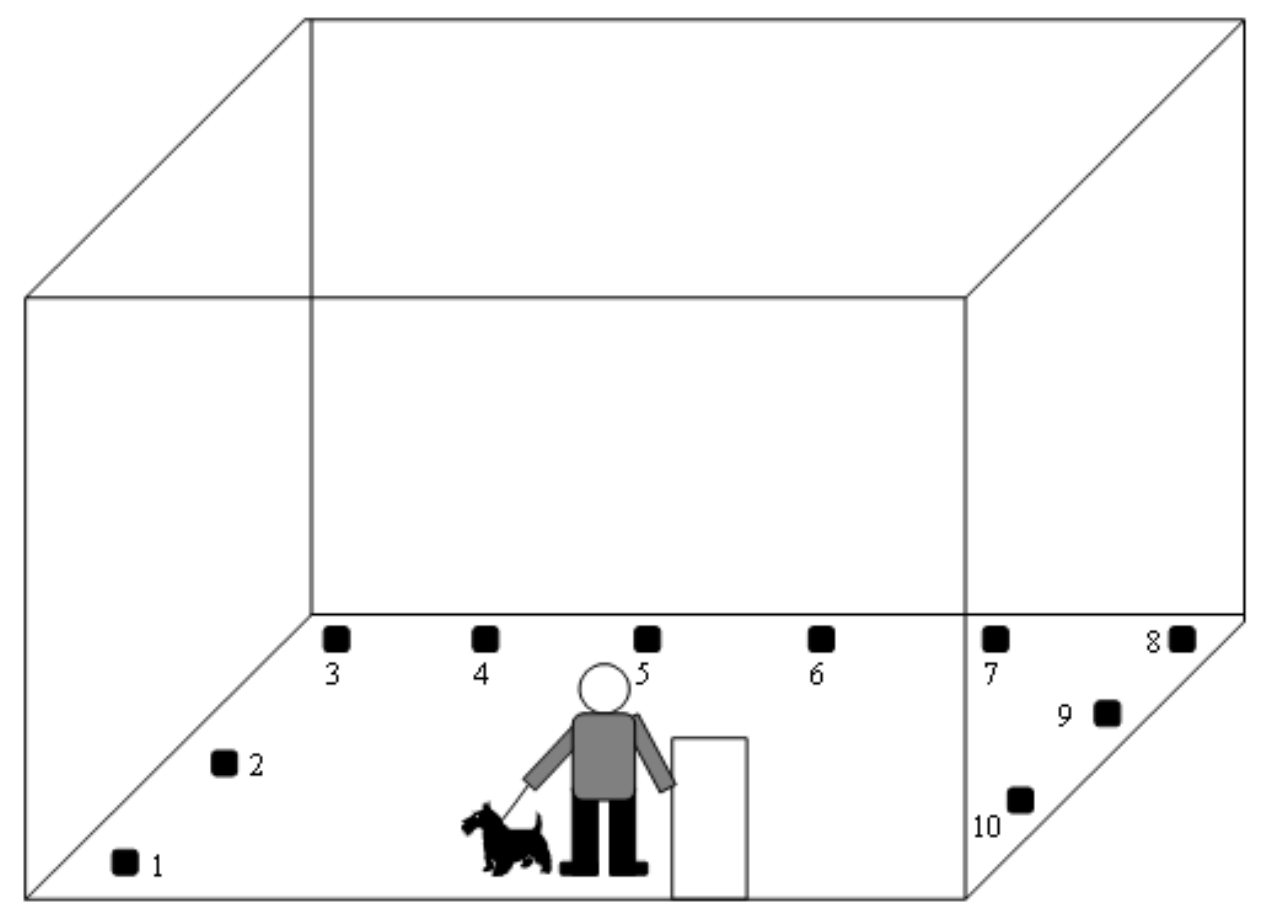

Figure 15 - Odor line-up for field testing 


\section{MDMA RESULTS \& DISCUSSION}

\subsection{GC-MS}

For liquid analysis, a $1000 \mathrm{ug} / \mathrm{mL}$ solution was created in methanol based upon the initial weight of the crushed ecstasy pills. The weights were as follows: $0.217 \mathrm{~g}, 0.247 \mathrm{~g}$, and $0.122 \mathrm{~g}$ for samples FHP Ecstasy \#1, \#2, and \#3, respectively. The age of the pills decreases from FHP Ecstasy \#1 through FHP Ecstasy \#3. Since the stock solutions were based on the total masses of the pills, they were made at a high concentration. Depending on the synthesis process and how much the product has been cut, the actual MDMA present in each pill can vary. The total ion chromatograms for the ecstasy samples and for the standard solutions of MDMA and caffeine are shown in Figure 16. The mass spectra for these same samples are shown in Figure 17.

The presence of MDMA was identified in the total ion chromatograms based on a retention time comparison to a standard solution (Figure 16). Additionally, the identification was confirmed by the dominant ion peaks at 58 and 135 and the molecular ion peak at 193 in the mass spectra (Figure 17). Caffeine was also identified in the third ecstasy sample (FHP \#3) based on a retention time comparison with the standard solution and the 194 ion.

Calibration plots were created from the analysis of various standard solutions of MDMA and caffeine. The concentrations of the standard solutions were $10 \mathrm{ug} / \mathrm{mL}, 25 \mathrm{ug} / \mathrm{mL}$, $50 \mathrm{ug} / \mathrm{mL}, 100 \mathrm{ug} / \mathrm{mL}$, and 250ug/mL. These plots are shown in Figure 18 and Figure 19. 


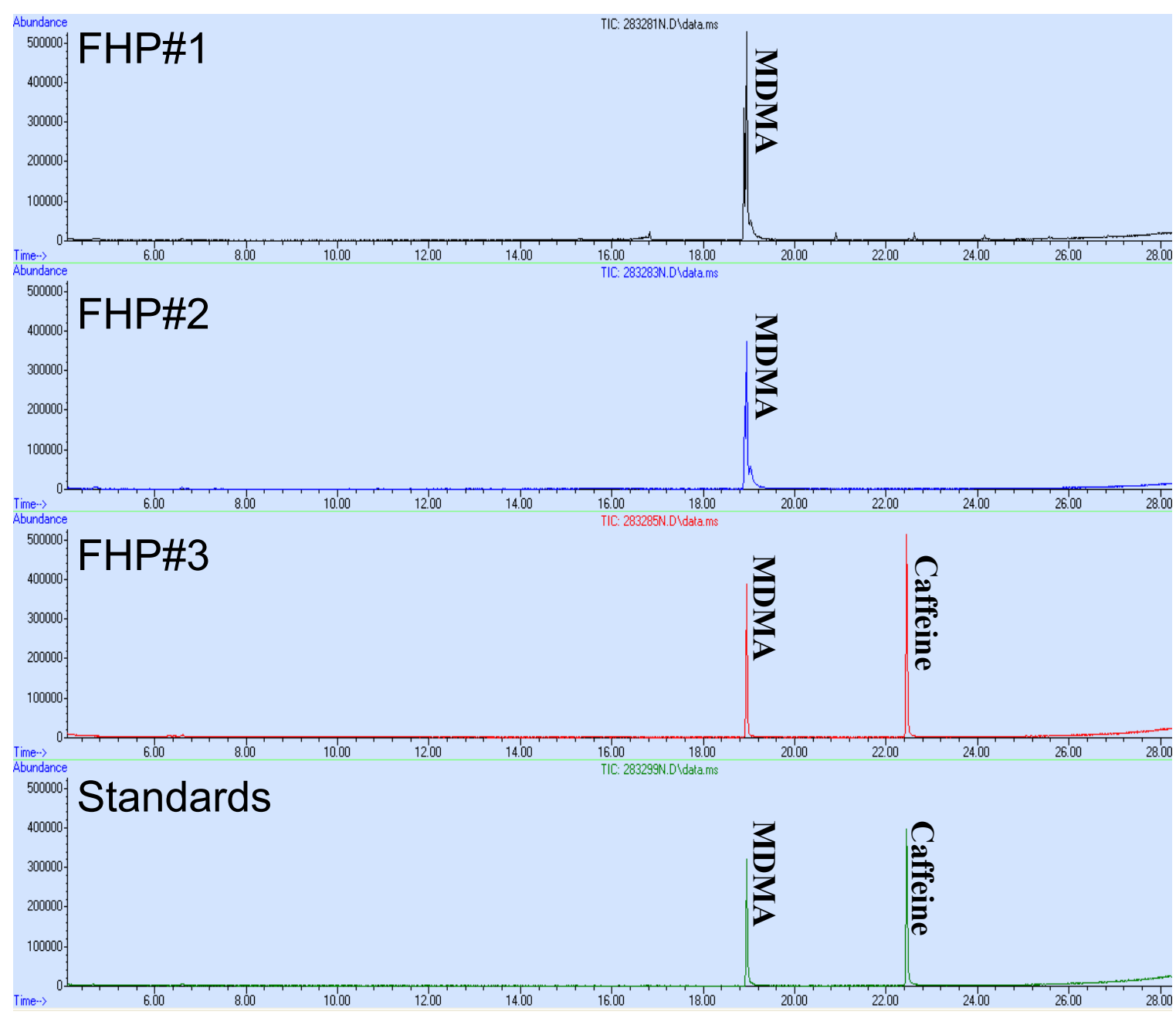

Figure 16 - Total ion chromatograms of $1000 \mu \mathrm{g} / \mathrm{mL}$ ecstasy solutions using GC

A high correlation $\left(\mathrm{r}^{2}>0.99\right)$ between the concentration of the standard solution $(\mathrm{ppm})$ and the abundance value of the signal from the GC-MS analysis is shown. 

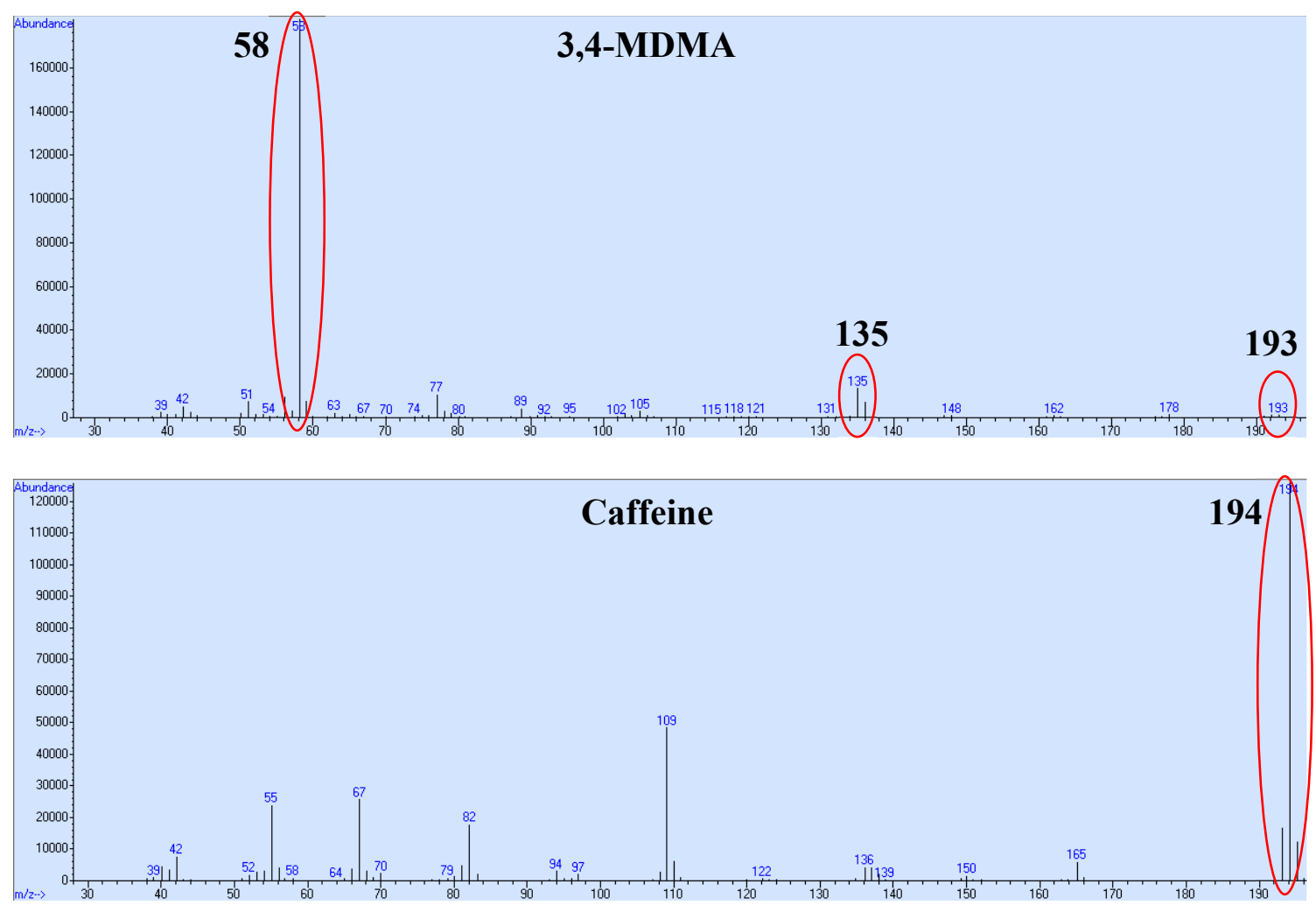

Figure 17 - GC Mass spectra of FHP supplied ecstasy samples

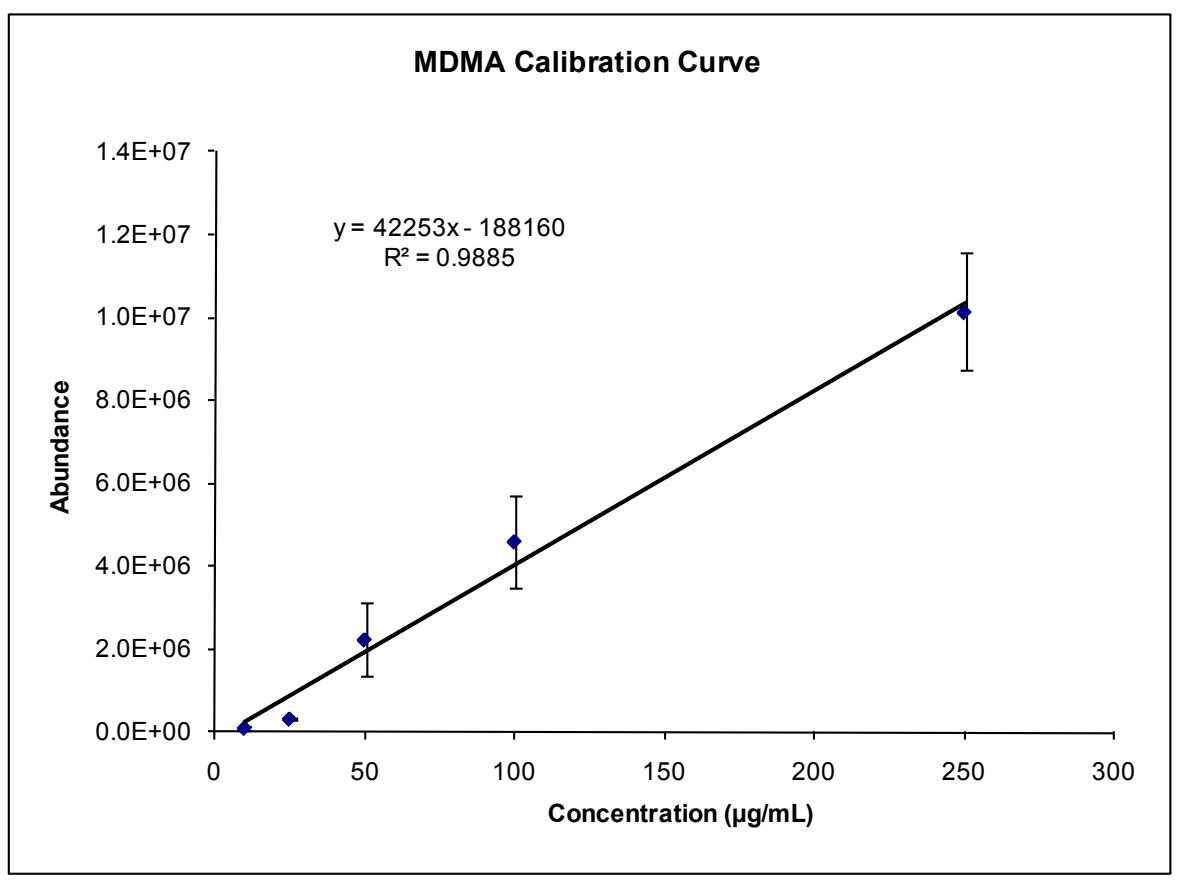

Figure 18 - GC-MS Calibration plot for MDMA 


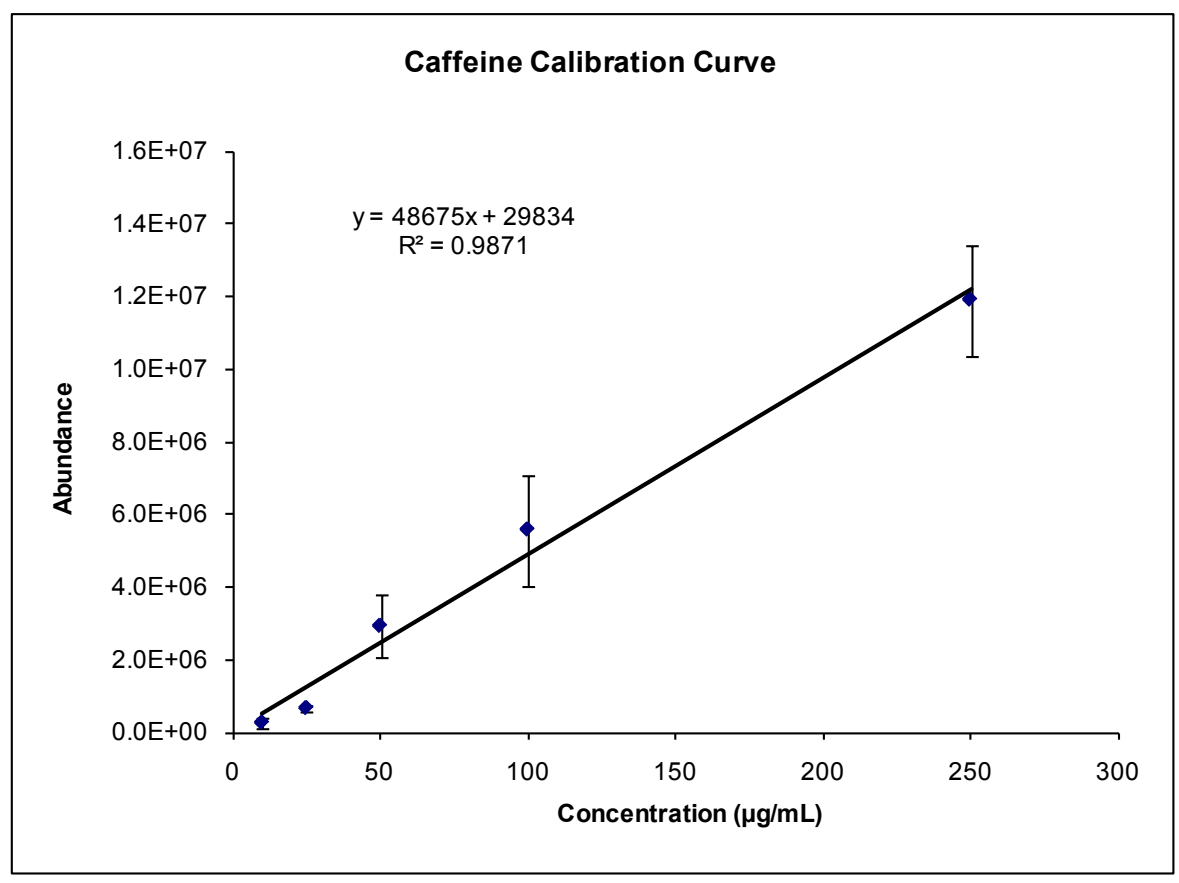

Figure 19 - GC-MS Calibration plot for caffeine

The percentage of both MDMA and caffeine present in the ecstasy samples were calculated from the calibration curves; these results are shown in Table 9. There is a noticeable difference in the amount of MDMA present in the three samples (i.e. batches) of pills. The percentage of MDMA present decreases as the age of the pills decreases. The reduction in detectable MDMA is attributed to continual cutting of the drug with other chemicals (such as caffeine) by the drug suppliers/manufacturers in an attempt to stretch the product for increased profit. In the most recent batch of pills, a higher percentage of caffeine was detected over that of the active ingredient, MDMA using GCMS analysis. 
Table 9 - Results of $1 \mathrm{mg} / \mathrm{mL}$ ecstasy solutions using GC-MS

\begin{tabular}{|c|c|c|c|c|}
\hline \multirow{2}{*}{ Sample } & \multicolumn{2}{|c|}{ MDMA } & \multicolumn{2}{c|}{ Caffeine } \\
\cline { 2 - 5 } & Concentration & $\%$ of Pill (W/W) & Concentration & $\%$ of Pill \\
\hline FHP Ex 1 & $337 \mathrm{ug} / \mathrm{mL}$ & $35 \%$ & - & - \\
\hline FHP Ex 2 & $217 \mathrm{ug} / \mathrm{mL}$ & $22 \%$ & - & - \\
\hline FHP Ex 3 & $66 \mathrm{ug} / \mathrm{mL}$ & $7 \%$ & $171 \mathrm{ug} / \mathrm{mL}$ & $17 \%$ \\
\hline
\end{tabular}

\subsection{LC-MS / LC-MS-MS}

For LC analysis, the $1000 \mathrm{ug} / \mathrm{mL}$ stock solutions were diluted to $10 \mathrm{ug} / \mathrm{mL}$ using a buffer solution $(2 \mathrm{mM}$ ammonium acetate at $1 \%$ formic acid). Again, a higher than normal concentration for this analysis method was used to ensure detection since the actual MDMA concentration in the pills was unknown. The total ion chromatograms for the ecstasy samples and a standard solution of MDMA and caffeine are shown in Figure 20 and the extracted ion profiles for the samples are shown in Figure 21.

Similar to the results reported from the liquid sample analysis by GC-MS, MDMA was found to be present in all three samples of ecstasy. The presence of MDMA was confirmed based on a retention time comparison of the samples to the standard solution (Figure 20). In addition, the extracted ion profile of the 194 ion yielded characteristic ion peaks of 163 and the molecular ion peak at $194\left[\mathrm{M}+\mathrm{H}^{+}\right]$seen in the MDMA standard (Figure 21). Caffeine was also identified in the last ecstasy sample (FHP \#3) based on a retention time comparison and the extracted ion profile of the 195 ion $\left[\mathrm{M}+\mathrm{H}^{+}\right]$. 


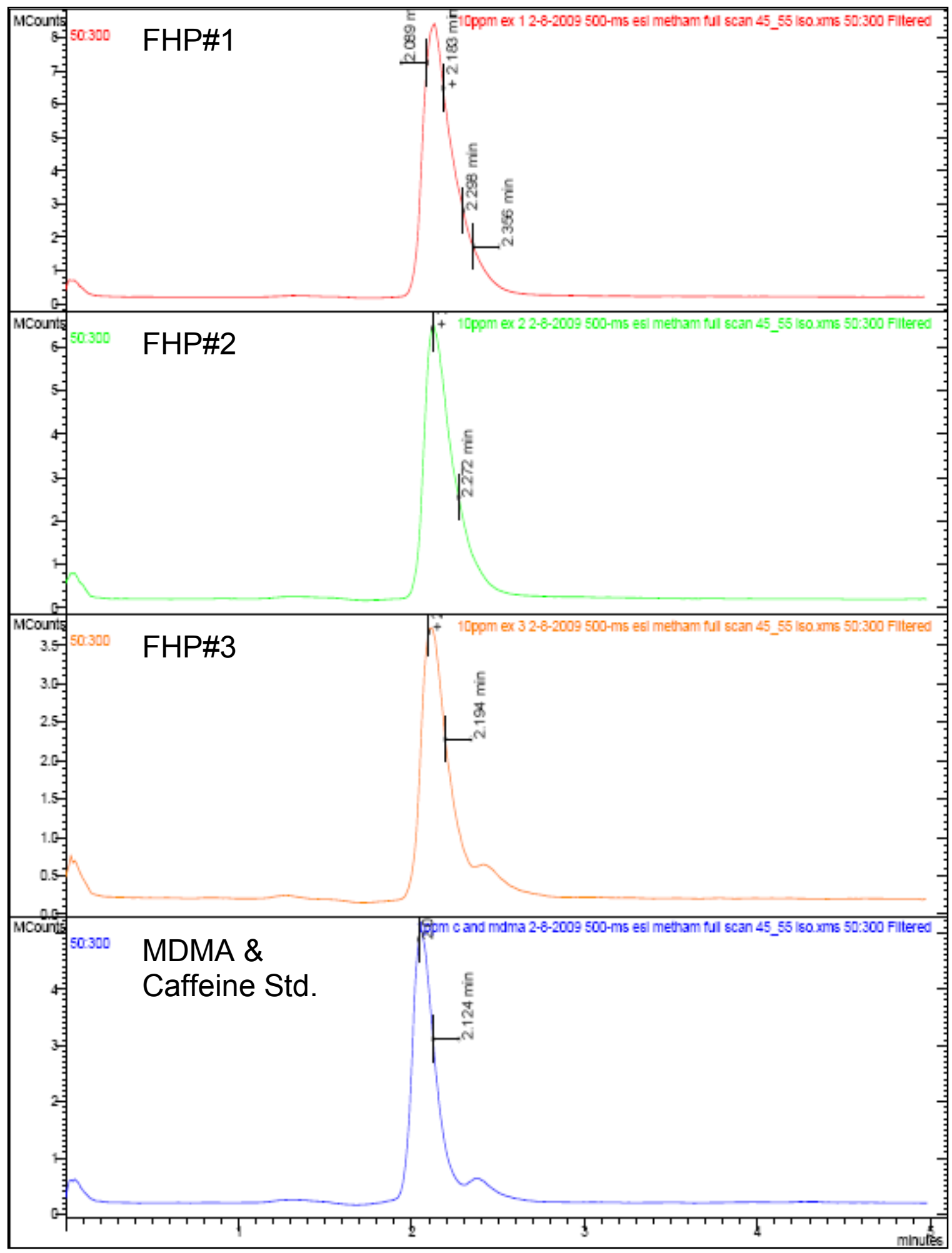

Figure 20 - Total ion chromatograms of 10ppm ecstasy solutions using LC 


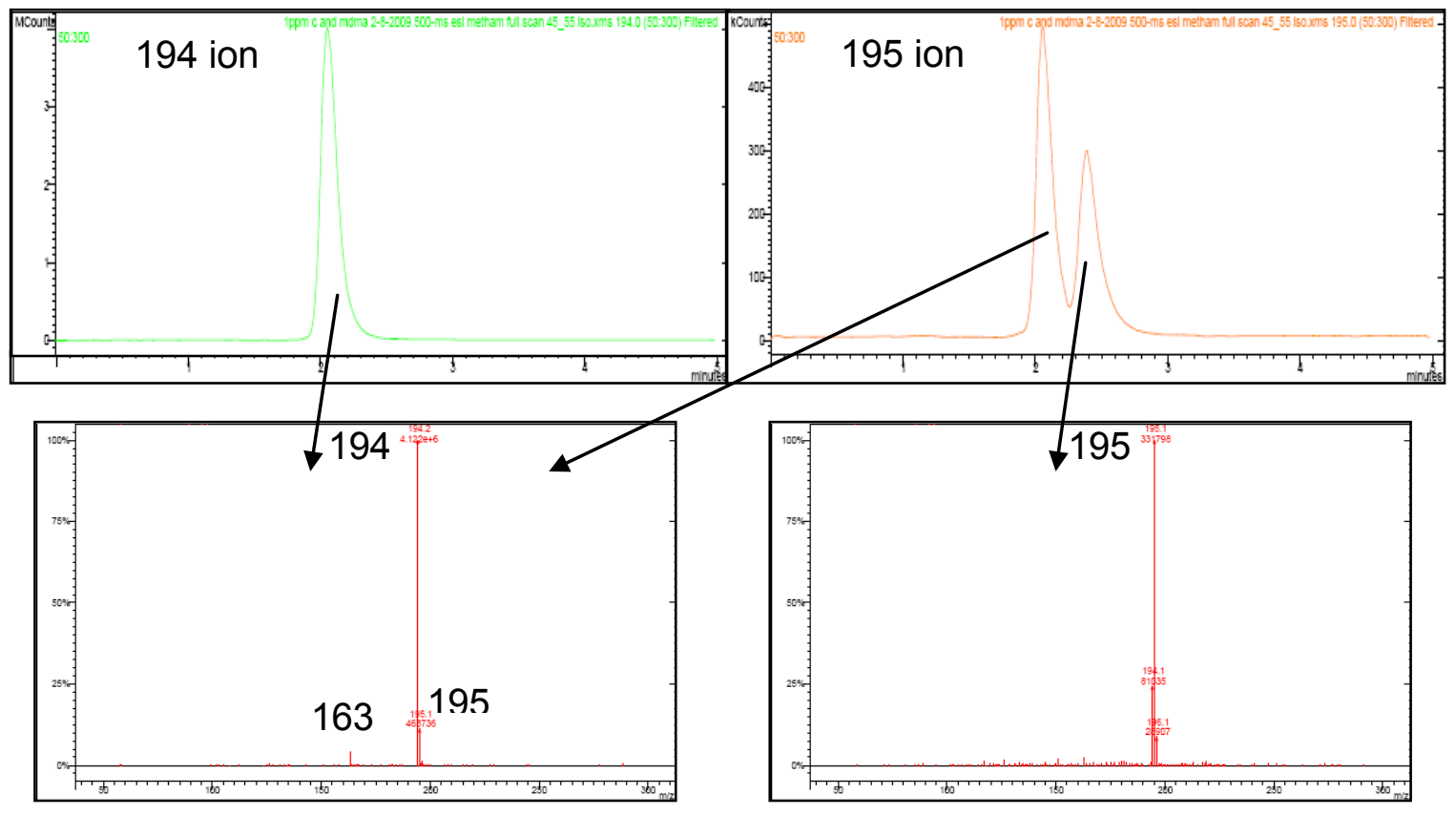

Figure 21 - LC Mass spectra of FHP supplied ecstasy samples

Calibration plots for standard solutions of MDMA and caffeine were produced using solutions with concentrations of $0.05 \mathrm{ug} / \mathrm{mL}, 0.1 \mathrm{ug} / \mathrm{mL}, 0.5 \mathrm{ug} / \mathrm{mL}$, and $1.0 \mathrm{ug} / \mathrm{mL}$. These plots are shown in Figure 22 and Figure 23.

Using the calibration curves, the percentage of MDMA and caffeine present in the pills could be calculated (Table 10). As seen with the GC-MS results (section 4.1), the percentage of MDMA present in the pills decreases as the age of the pills decreases. Again, with the most recent batch of pills (FHP \#3), a higher percentage of caffeine was detected than MDMA (10\% vs. $8 \%)$. 


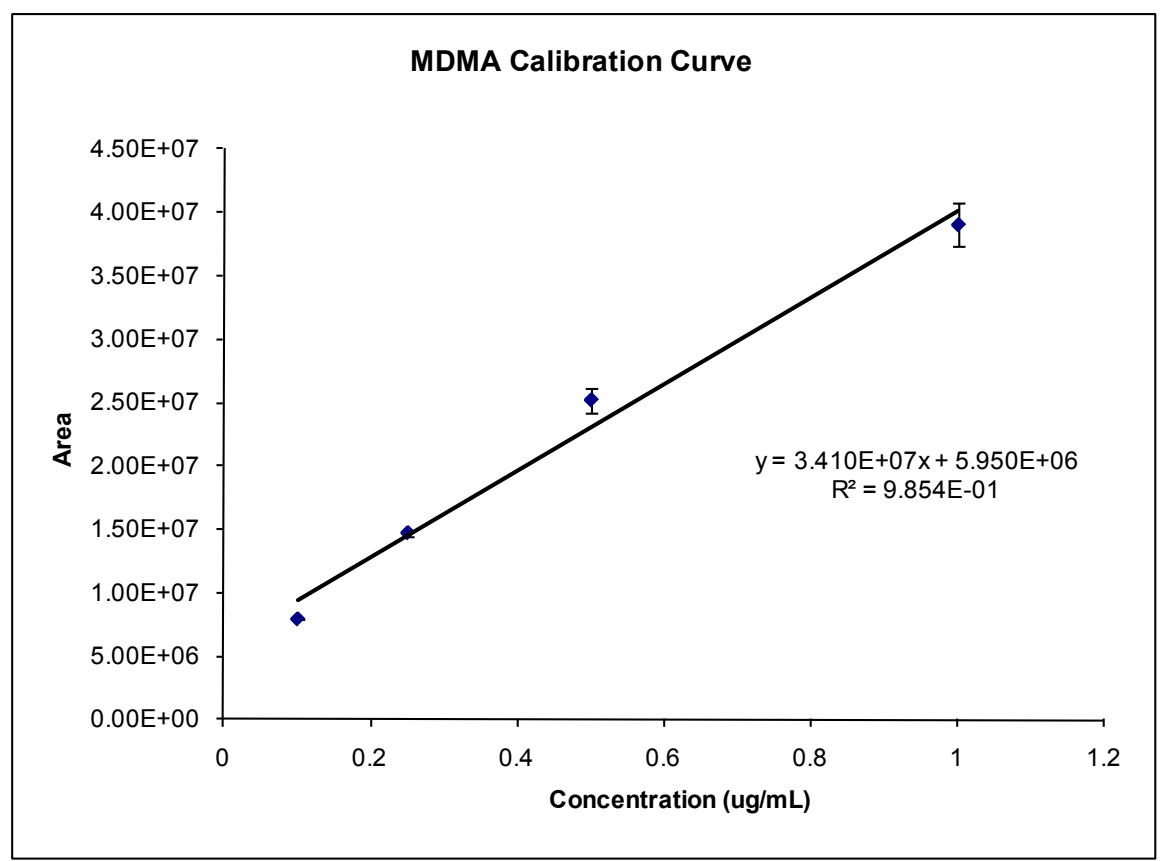

Figure 22 - LC-MS Calibration plot for MDMA

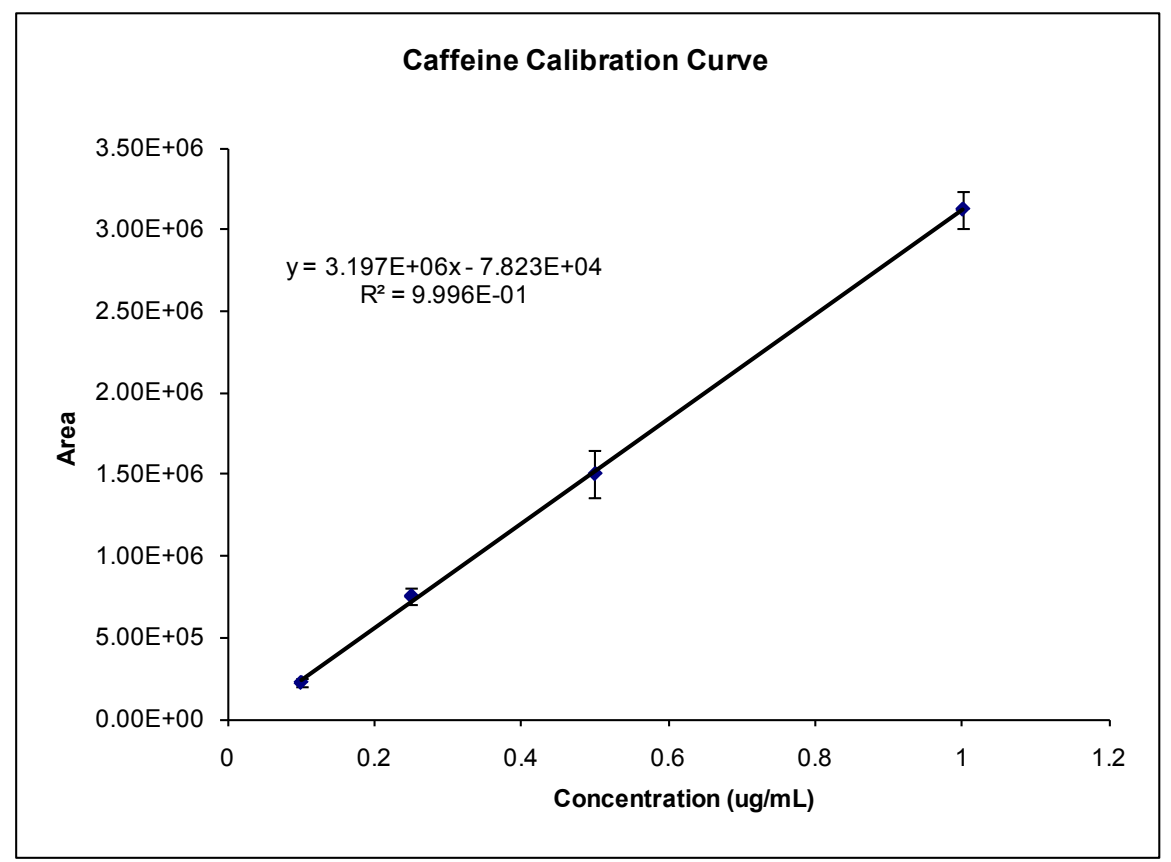

Figure 23 - LC-MS Calibration plot for caffeine 
Table 10 - Results of 10ppm ecstasy solutions using LC

\begin{tabular}{|c|c|c|c|c|}
\hline \multirow{2}{*}{ Sample } & \multicolumn{2}{|c|}{ MIDA } & \multicolumn{2}{c|}{ Caffeine } \\
\cline { 2 - 5 } & Concentration & $\%$ of Pill (W/W) & Concentration & $\%$ of Pill \\
\hline FHP Ex 1 & $25 \mathrm{ug} / \mathrm{mL}$ & $25 \%$ & - & - \\
\hline FHP Ex 2 & $15 \mathrm{ug} / \mathrm{mL}$ & $17 \%$ & - & - \\
\hline FHP Ex 3 & $8 \mathrm{ug} / \mathrm{mL}$ & $8 \%$ & $10 \mathrm{ug} / \mathrm{mL}$ & $10 \%$ \\
\hline
\end{tabular}

Both methods of analysis, GC and LC, demonstrated similar final results for the determination of the ecstasy pill compositions. There is a distinct decrease in the concentration of MDMA from FHP Ecstasy $\# 1$ to $\# 2$ to \#3. This is important because a reduction in MDMA levels can have an adverse effect on the odor profiles of the samples (i.e. less MDMA translates into lower availability of detectable odor compounds). A reduced level of MDMA makes it more difficult for identification by detection systems (biologic and instrumental). The two methods yielded similar identification and quantification of the components of the MDMA tablets; however, the LC-MS method proved superior to the GC-MS method due to the significantly faster chromatographic analysis time of 5 minutes versus 30 minutes, respectively. The results of the ecstasy solution analysis pose two questions: (1) do detection systems require a reduced threshold for training/calibration and (2) are additional compounds are needed to supplement previously proven methods.

\subsection{HS-SPME}

Previous research has reported on the success of piperonal recognition by ecstasy trained detection canines $[1,39]$. The success is explained by the reported dominant presence of 
piperonal in the headspace of 3,4-methylenedioxymethamphetamin (MDMA) based drugs, such as ecstasy $[1,14,15,39,79]$. The synthesis process that supports this was discussed in section 1.3.3. Samples of ecstasy were supplied by local law enforcement agencies and training schools including the Florida Highway Patrol (FHP) and the US-K9 Academy and Police Dog Training Center. These samples were analyzed using HSSPME-GC-MS to determine the dominant headspace components in the odor profile. These chromatograms are shown in Figure 24 - Figure 26. A summary of the headspace compounds of the ecstasy samples is given in Table 11. 


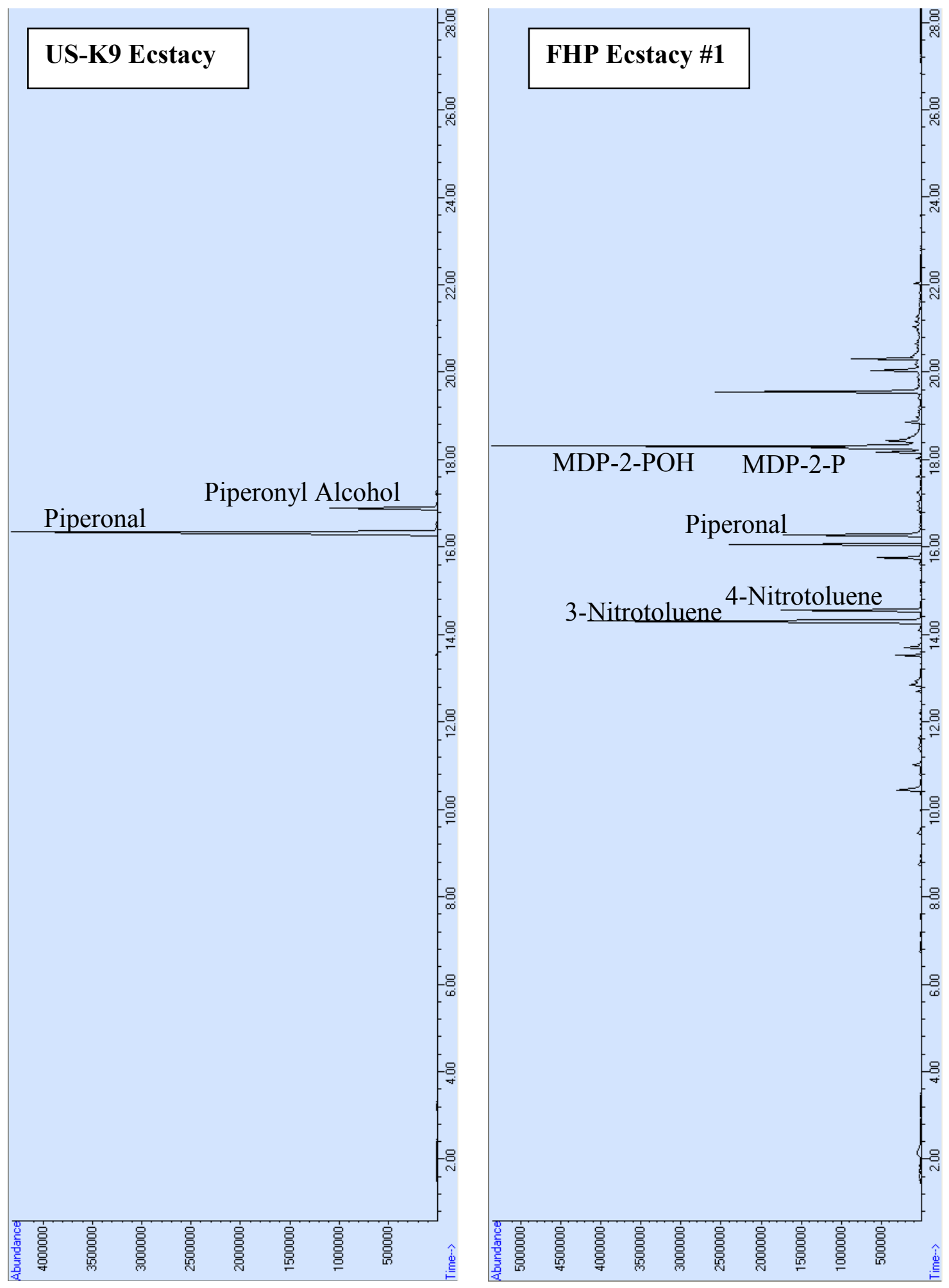

Figure 24 - Ecstasy Chromatograms using SPME-GC-MS showing most abundant VOC's 


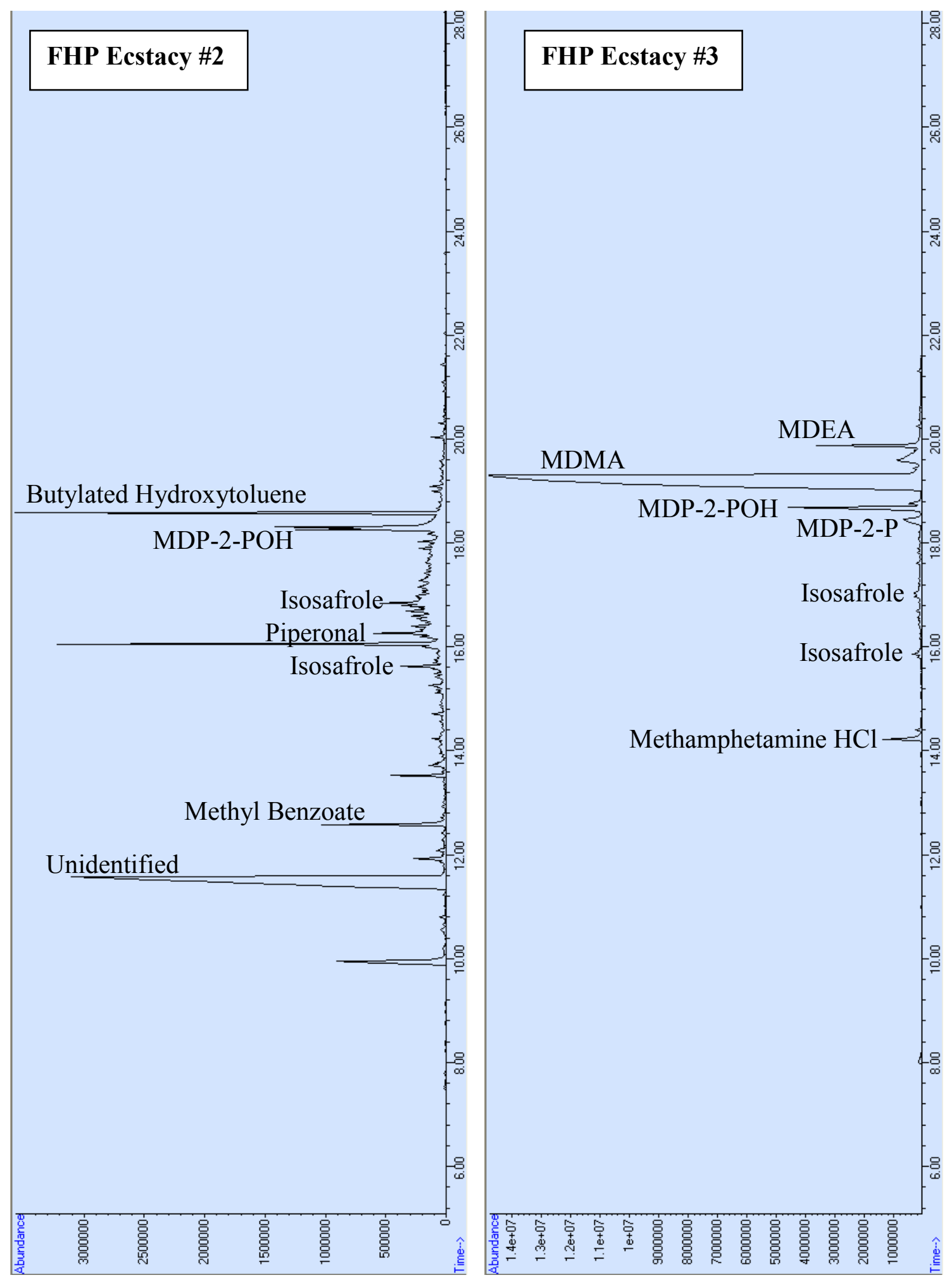

Figure 25 - Ecstasy Chromatograms using SPME-GC-MS showing most abundant VOC's 


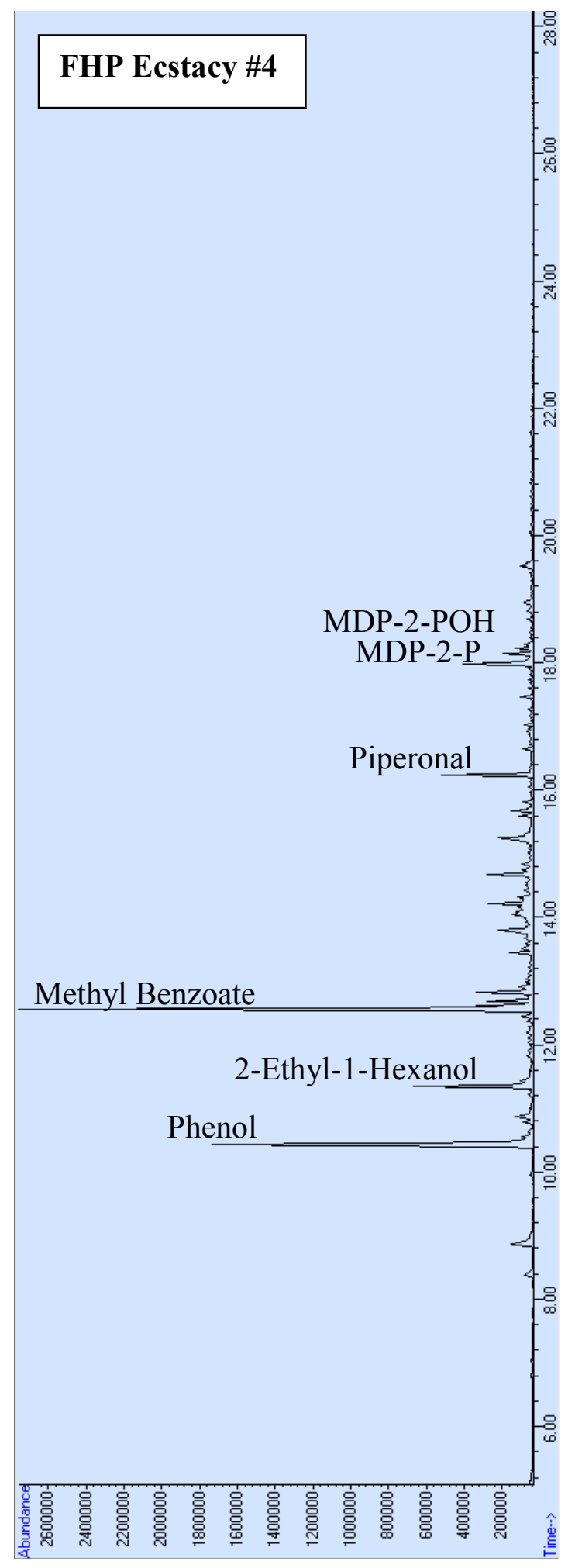

Figure 26 - Ecstasy Chromatograms using SPME-GC-MS showing most abundant VOC's 
No single compound was detected in every ecstasy sample; the parent compound MDMA was only detected in one sample of ecstasy (FHP \#3). It is believed that this has to do with the relative "freshness" of that drug sample (a few months) as compared to the other samples (which were reported to be several years old). Piperonal was detected in great abundance in one ecstasy sample (US-K9) and at reduced levels in three other ecstasy samples (FHP \#1, FHP \#2, and FHP \#4). Piperonal was not detected at all in one sample of ecstasy (FHP \#3). Among the samples tested, several other compounds were detected which are related to and/or similar in structure to piperonal and MDMA. These compounds include piperonyl alcohol (US-K9), 1-(3,4-methylenedioxyphenyl)-2propanol (FHP \#1, FHP \#2, FHP \#3, and FHP \#4), 3,4-methyelenedioxyphenyl-2propanone (FHP \#1, FHP \#3, and FHP \#4), methamphetamine hydrochloride (FHP \#3), 3,4-methylenedioxyethylamine (FHP \#3), and isosafrole (FHP \#2 and FHP \#3). 3,4Methyelenedioxyphenyl-2-propanone (MDP-2-P) is an immediate precursor in the manufacture of MDMA by several synthetic routes (Figure 3). Because MDP-2-P is a controlled chemical substance, it is not considered a good universal training aid for MDMA. Isosafrole is one of the starting compounds like piperonal and safrole used in the production of MDMA (Figure 2). Isosafrole is naturally found in the oil of star anise [105]. It is similar to safrole which can be found naturally in sassafras, nutmeg, ginger and cinnamon. Isosafrole is also used in the production of perfumes and pesticides but is not currently produced in the U.S. [105,106]. 1-(3,4-Methylenedioxyphenyl)-2-propanol (MDP-2-POH) is a by-product that develops during MDMA manufacture from the reduction and bromination synthetic routes. Isosafrole and MDP-2-POH are uncontrolled chemical compounds which offer potential as additional training aids for MDMA; 
however, they are monitored for the purchase and sale of significant quantities. The detection of methamphetamine in the headspace of ecstasy sample FHP \#3 is important since this is a drug generally included in training regimes of law enforcement agencies even if MDMA is not included. The significance being that dogs trained on methamphetamine may alter to MDMA samples such as sample 3 due to the presence of methamphetamine.

Table 11 - Summary of ecstasy headspace compounds

\begin{tabular}{|c|ccccc|}
\hline Detected Compound & US K-9 & FHP \#1 & FHP \#2 & FHP \#3 & FHP \#4 \\
\hline Methamphetamine HCl & & & & & \\
\hline Isosafrole & & & & & \\
\hline Piperonal & $\mathrm{X}$ & $\mathrm{X}$ & $\mathrm{X}$ & & $\mathrm{X}$ \\
\hline Piperonyl Alcohol & $\mathrm{X}$ & & & & \\
\hline MDP-2-POH & & $\mathrm{X}$ & $\mathrm{X}$ & $\mathrm{X}$ & $\mathrm{X}$ \\
\hline MDP-2-P & & $\mathrm{X}$ & & $\mathrm{X}$ & $\mathrm{X}$ \\
\hline MDMA & & & & $\mathrm{X}$ & \\
\hline MDEA & & & & $\mathrm{X}$ & \\
\hline
\end{tabular}

Methyl benzoate was detected in the headspace of two samples of ecstasy (FHP \#2 and FH \#4). Methyl benzoate is known to exist in great abundance in the headspace of cocaine, and as a result is used for training purposes with detection canines $[5,39,40]$. Prior to sampling, the ecstasy was stored in close proximity to several large samples of cocaine which may have led to cross contamination. As with most street drugs, ecstasy is often cut with additional compounds to stretch the quantity for sale. Both explanations 
offer possible sources for the detection of methyl benzoate. Two compounds (3nitrotoluene and 4-nitrotoluene) known to exist in the headspace of TNT were also detected in one sample of ecstasy (FHP \#1). Again, storage prior to sampling may have been the cause.

\subsection{COMPS Odor Delivery}

Following the determination of piperonal as a dominant odor compound in the headspace of MDMA based drugs (section 4.3), the next step was to develop an optimized odor delivery system. COMPS devices were prepared in several variations/combinations: masses ranging from $11 \mathrm{mg}$ to $2 \mathrm{~g}$, LDPE and HDPP polymer chemistries, polymer bag thickness (1.5mil, 2mil, 3mil, and 4mil), and polymer bag dimensions (1 in $\mathrm{x} 1$ in, 1 in $\mathrm{x}$ 2 in, 1 in $x 3$ in, 2 in $x$ 2in, 2 in $x 3$ in, and 3 in $x$ in). Since all polymer bags were acquired with the dimensions of 3 in $x$ in, the other sizes had to be created. The adjustment in size was accomplished by heat-sealing the bags to the appropriate dimensions prior to application of the sample. Since piperonal is a solid compound, each sample of piperonal was weighed out and heat-sealed directly into the polymer bag.

Once the COMPS were prepared, they were monitored (weighed) over the course of twenty-one days to determine the mass loss per time, i.e. the permeation rate through the polymer bags. Triplicate blanks were kept and monitored concurrently to maintain a baseline. At the conclusion of the weighing process, the data was plotted as Mass (grams) vs. Time (days). 
At lower starting amounts, such as in the $11 \mathrm{mg}$ COMPS, the permeation rate is best represented as an exponential decay (Figure 27). The exponential relationship is first order with respect to the rate of the mass decay of the COMPS. Using this relationship, a half-life value is derived by converting the equation for the exponential decay into a linear format (see Equation 1 and Equation 2). The half life equation is derived through the rearrangement of Equation 2 for the decay (permeation) of one half of the mass. The final equation for half life determination is given in Equation 3. The half-life values calculated from the best-fit exponential equations in Figure 27 are given in Table 12.

Equation 1- Exponential equation

$$
y=y_{0} e^{-k x}
$$

Equation 2 - Linear equation

$$
\operatorname{Ln}\left(y_{n}\right)=-k x+\operatorname{Ln}\left(y_{0}\right)
$$

Equation 3 - Half-life equation

$$
T_{1 / 2}=\frac{0.693}{k}
$$




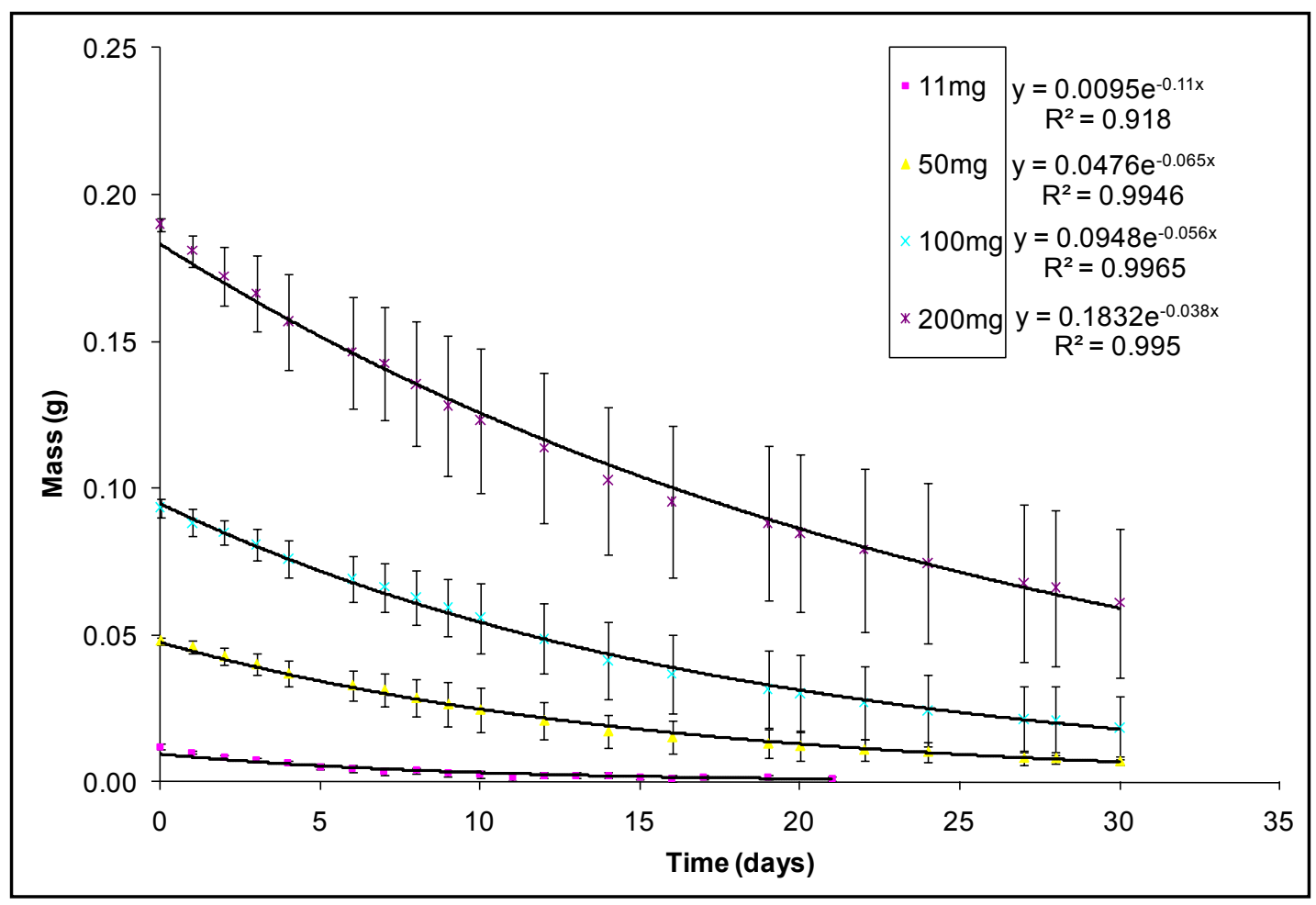

Figure 27 - Exponential relationship for piperonal permeation rate by mass for 3in x 3in 2mil LDPE bags

Table 12 - Half-life values for lower mass Piperonal COMPS

\begin{tabular}{|c|c|}
\hline Mass (mg) & Half-life (days) \\
\hline 11 & 6.3 \\
50 & 10.0 \\
100 & 12.4 \\
200 & 18.2 \\
\hline
\end{tabular}

At higher starting amounts, such as the 2000mg COMPS, the permeation rate is best represented linearly. This is demonstrated in Figure 28 where the correlation values are greater than 0.99 . 


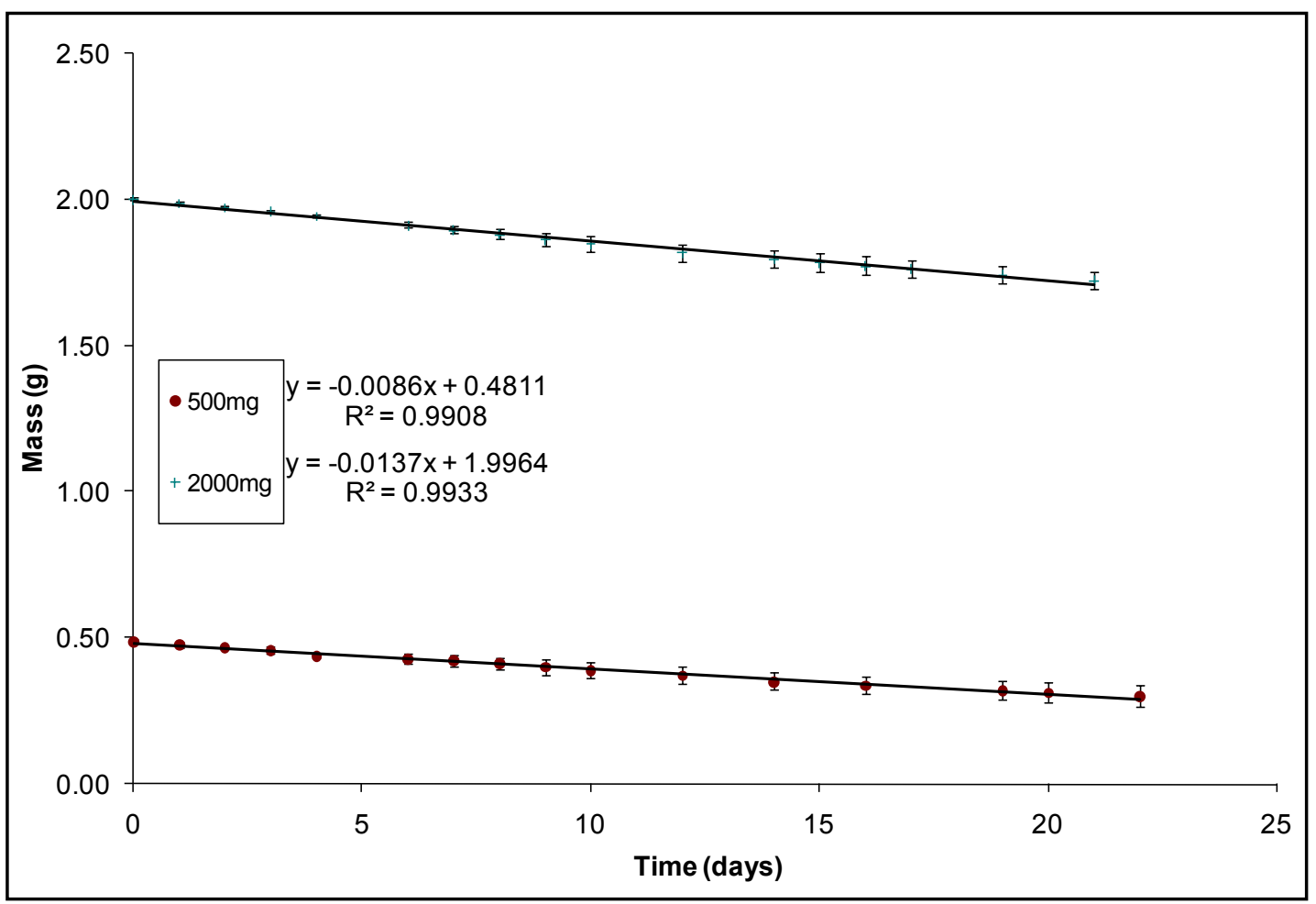

Figure 28 - Linear relationship for piperonal permeation rate by mass for 3 in $x$ 3in 2 mil LDPE bags

During the current study, the COMPS samples were utilized up to seven days after creation. A highly correlated linear-fit application was applied to the first ten days. The magnitude of the slope for the best-fit line is the value of permeation rate in grams per day $(\mathrm{g} / \mathrm{d})$ which was converted to a permeation rate in nanograms per second $(\mathrm{ng} / \mathrm{sec})$. Figure 29 shows the relationship between mass and time for a range of masses. Each sample was heat-sealed within 3in x 3in 2mil LDPE bags. 


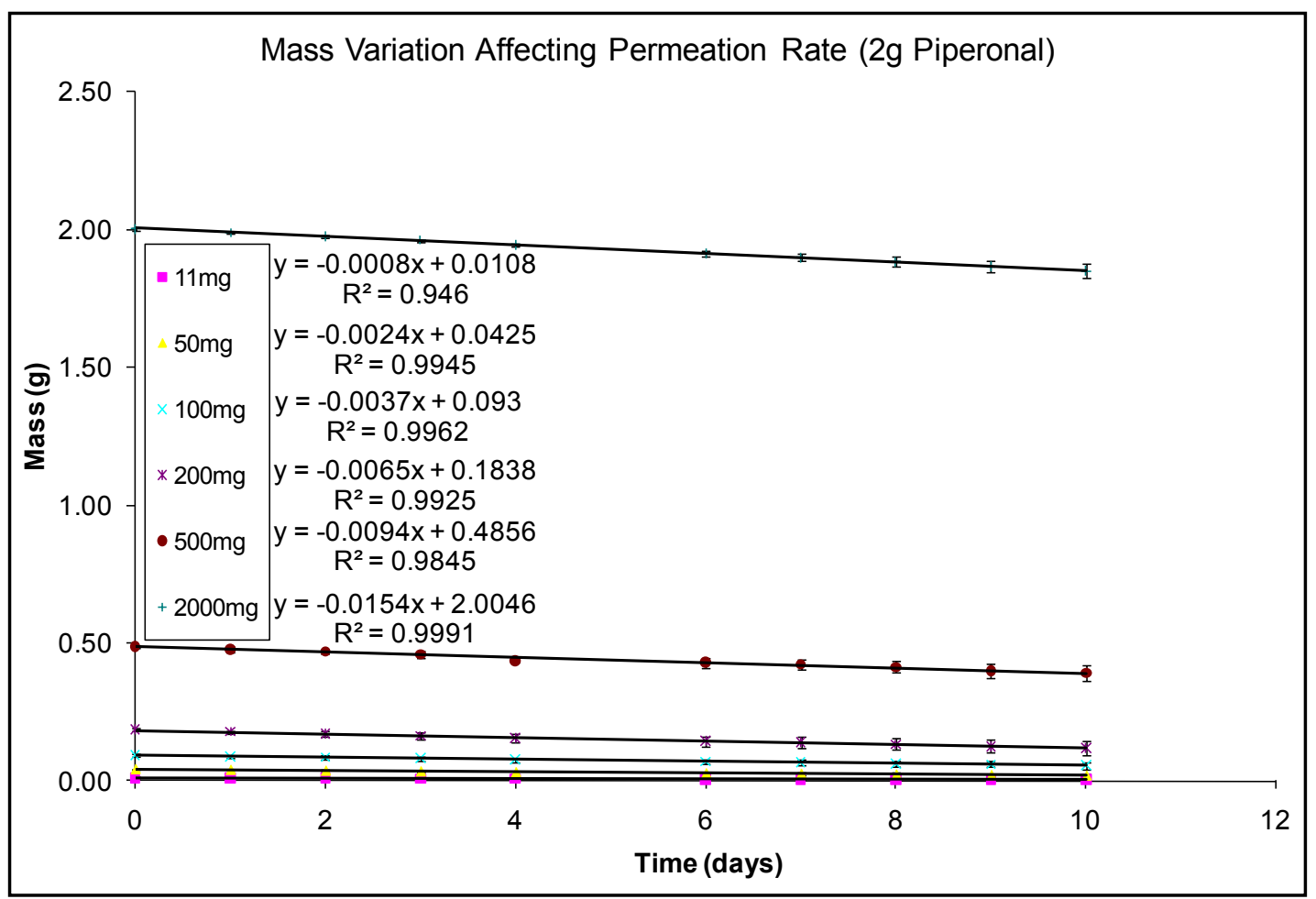

Figure 29 - Linear relationship for piperonal permeation rate by mass for 3 in $x$ 3in 2 mil LDPE bags

The permeation rate was affected by the initial amount of material sealed within the COMPS devices (Table 13). The larger the starting mass, the faster the permeation rate (178ng/sec for 2000mg COMPS); conversely, the lower the starting mass, the slower the permeation rate $(9 \mathrm{ng} / \mathrm{sec}$ for $11 \mathrm{mg}$ COMPS). 
Table 13 - Piperonal permeation rate by mass

\begin{tabular}{|c|c|}
\hline Mass (mg) & $\begin{array}{c}\text { Permeation Rate } \\
\text { (ng/sec) }\end{array}$ \\
\hline 11 & $9 \pm 1$ \\
50 & $28 \pm 1$ \\
100 & $43 \pm 1$ \\
200 & $75 \pm 2$ \\
500 & $109 \pm 5$ \\
2000 & $178 \pm 2$ \\
\hline
\end{tabular}

A direct comparison of permeation rate vs. starting mass is shown in Figure 30. An exponential relationship exists between the initial mass of the piperonal in the COMPS and the permeation rate for the first half life. The plot of these two conditions yields the exponential equation that can be used to calculate the permeation rate for piperonal COMPS of varying masses. 


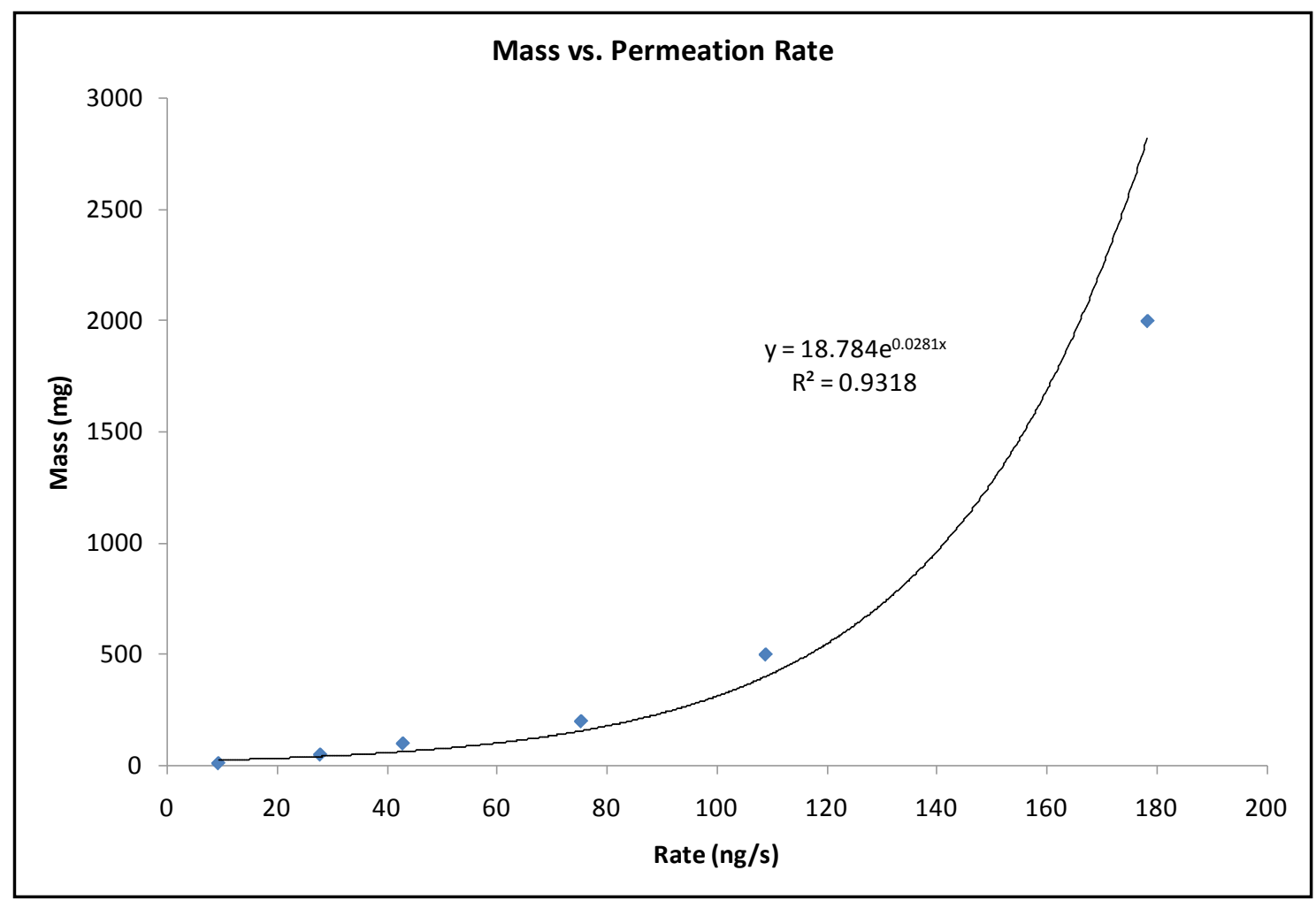

Figure 30 - Piperonal permeation rate in 3in x 3in 2mil LDPE by initial mass

As with any absolute container, there is maximum permeation rate available that is dependent upon the relationship between the analyte of interest and the membrane chemistry. The exponential relationship of the higher masses to permeation rate suggests that the maximum permeation potential for the 3in x 3in 2mil LDPE bags is substantially affected by the amount of piperonal present.

Figure 31 represents the plotted data of Mass (grams) vs. Time (days) for a variation in bag dimension: 1 in $x$ 1in, 1 in $x 2$ in, 1 in $x 3$ in, 2 in $x 2$ in, and 2 in $x$ in. For each sample, $2 \mathrm{~g}$ of piperonal was heat-sealed within 1.5mil LDPE bags. 


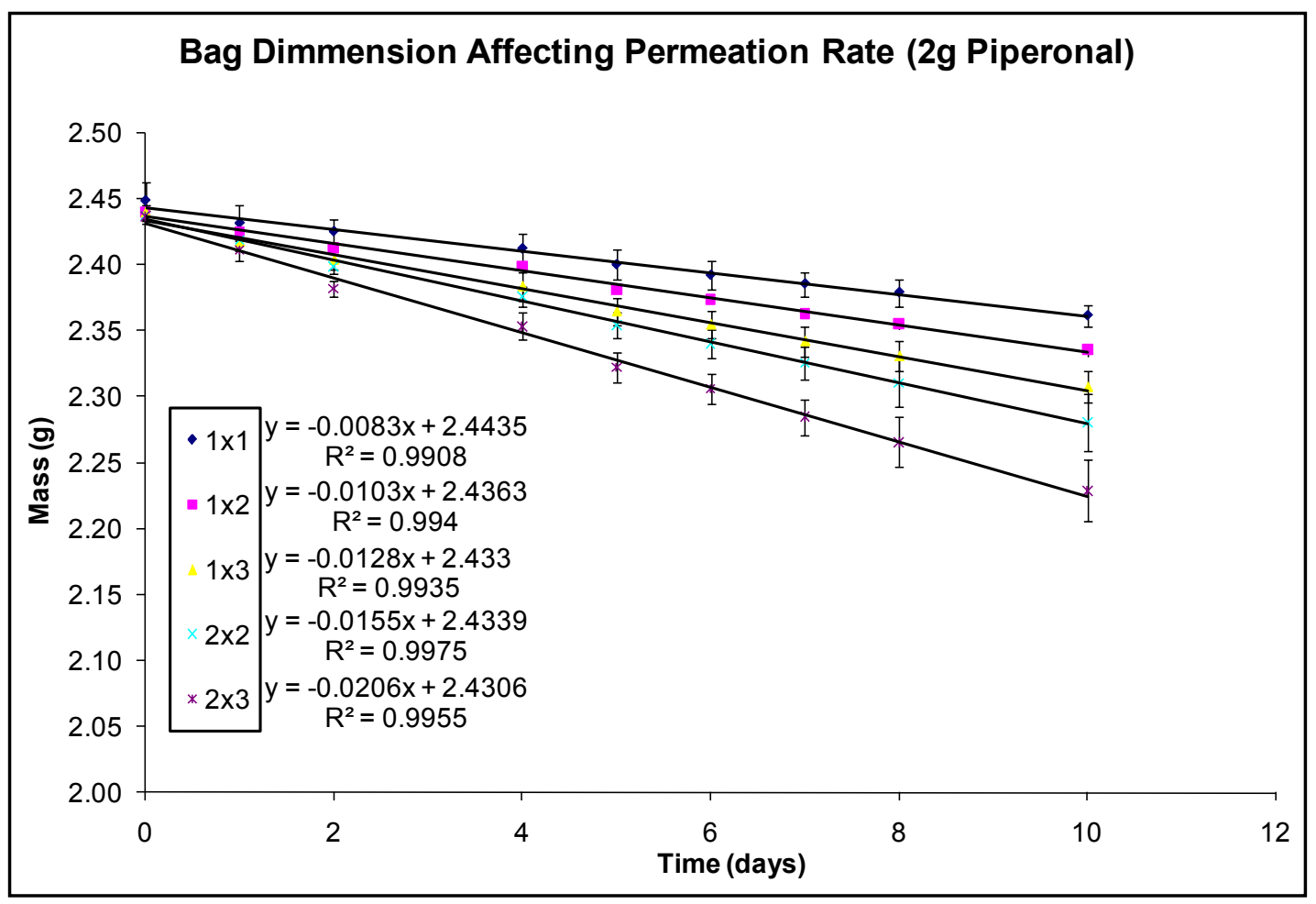

Figure 31 - Plot of piperonal permeation rate by bag dimension

As expected, the permeation rate is affected by the dimensions of the COMPS device (Table 14). The larger the area of the COMPS device, the faster the permeation rate (238ng/sec for $2 \times 3 \mathrm{bag}$ ); conversely, the smaller the area, the slower the permeation rate (96ng/sec for 1x1 bag). Adjustment of the COMPS area offers a second element of control for the creation of COMPS devices. "Don't do anything that affects anything, unless it turns out you were supposed to do it, in which case, for the love of God, don't not do it!" 
Table 14 - Piperonal permeation rate values by bag dimension

\begin{tabular}{|c|c|c|}
\hline $\begin{array}{c}\text { Dimension } \\
(\text { in } \mathrm{x} \text { in })\end{array}$ & $\begin{array}{c}\text { Area } \\
\left(\mathrm{in}^{2}\right)\end{array}$ & $\begin{array}{c}\text { Permeation Rate } \\
(\mathrm{ng} / \mathrm{sec})\end{array}$ \\
\hline $1 \times 1$ & 1 & $96 \pm 3$ \\
$1 \times 2$ & 2 & $119 \pm 3$ \\
$1 \times 3$ & 3 & $149 \pm 5$ \\
$2 \times 2$ & 4 & $179 \pm 3$ \\
$2 \times 3$ & 6 & $238 \pm 6$ \\
\hline
\end{tabular}

The relationship between permeation rate and bag area (Figure 32) is shown to have a highly correlated linearity $\left(r^{2}>0.99\right)$. Logically, the permeation rate will continue to increase as the bag size increases.

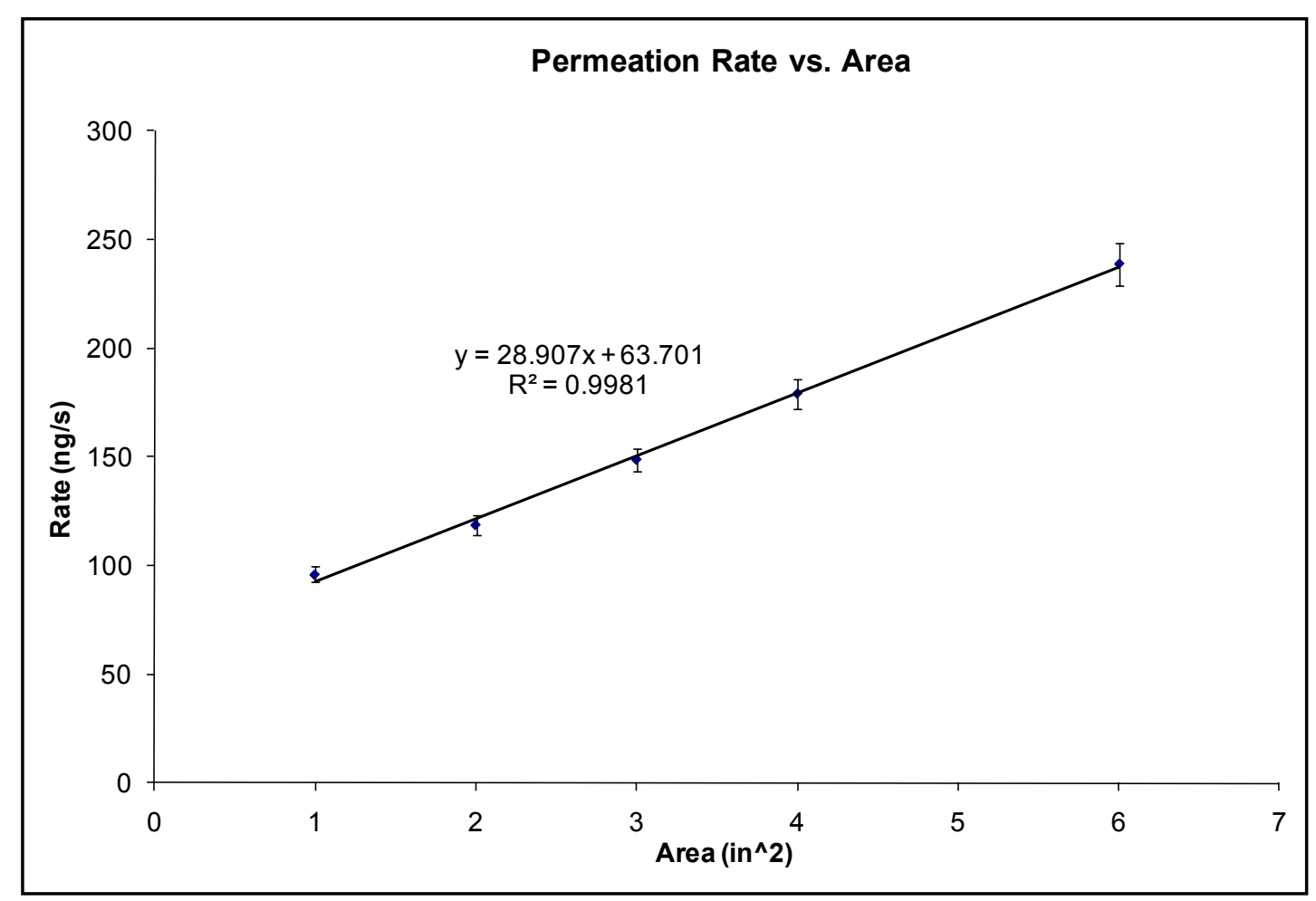

Figure 32 - Plot of piperonal permeation rate by bag area 
Figure 33 represents the plotted data of Mass (grams) vs. Time (days) for a variation in bag thickness: 1.5mil LDPE, 2mil LDPE, 3mil LDPE, and 4mil LDPE, and 2mil HDPP. For each sample, $2 \mathrm{~g}$ of piperonal was heat-sealed within 3 in $\mathrm{x}$ 3in bags.

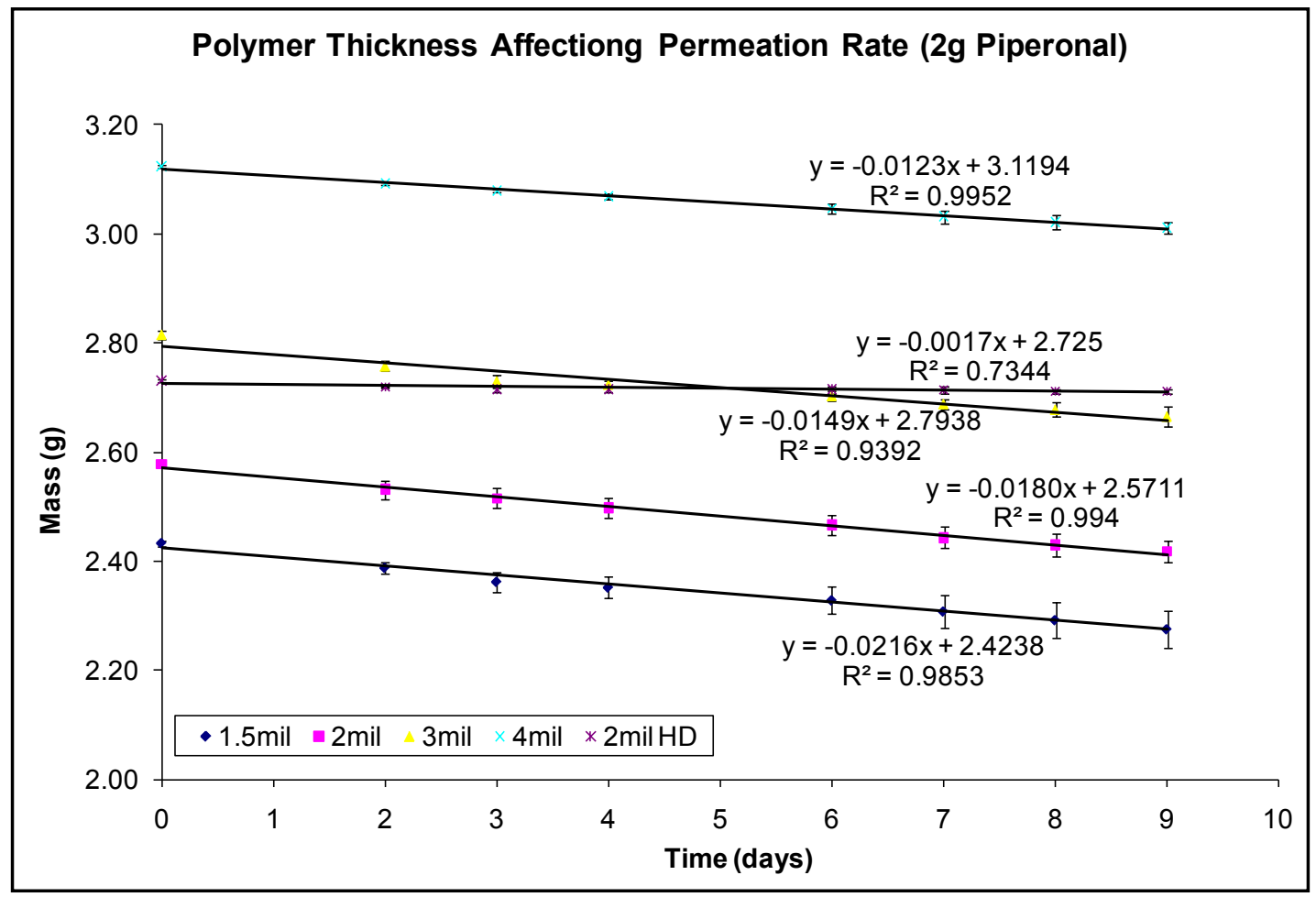

Figure 33 - Plot of piperonal permeation rate by polymer thickness

As expected, the permeation rate is affected by the thickness of the LDPE bags (Table 15). The thinner the polymer bag, the faster the permeation rate $(250 \mathrm{ng} / \mathrm{sec}$ for $1.5 \mathrm{mil}$ bag); conversely, the thicker the polymer bag, the slower the permeation rate $(142 \mathrm{ng} / \mathrm{sec}$ for 4 mil bag). The low density form means that there is less organization to the polyethylene structure because of branching (see section 2.5). This branching creates gaps, and the larger gaps, the easier it is for the compounds to pass through the polymer. Thicker polyethylene does not necessarily equate to a more structured form, but it does 
provide a thicker weave of polyethylene branches through which the compound must pass. The increased time the compound spends passing though the polymer matrix reduces the permeation rate of the compound. Permeation through the HDPP bag was substantially lower than the thickest LDPE bags (19ng/sec vs. $142 \mathrm{ng} / \mathrm{s})$. The reduction in permeation rate can be explained though the nature of a high density polymer and the polypropylene structure. The rigidity of the isotactic blocks found in polypropylene coupled with the high linearity characteristic of the high density form greatly reduces the available openings the compound to pass through resulting in a slower permeation rate.

\section{Table 15 - Piperonal permeation rate values by bag thickness}

\begin{tabular}{|c|c|}
\hline $\begin{array}{c}\text { Bag Thickness } \\
\text { (mil) }\end{array}$ & $\begin{array}{c}\text { Permeation Rate } \\
\text { (ng/sec) }\end{array}$ \\
\hline 1.5 & $250 \pm 10$ \\
2 & $208 \pm 6$ \\
3 & $173 \pm 18$ \\
4 & $142 \pm 4$ \\
HD (2mil) & $19 \pm 5$ \\
\hline
\end{tabular}

The relationship between permeation rate and bag thickness (Figure 34) is shown to be highly correlated exponential $\left(r^{2}>0.98\right)$. The plot shows an exponentially, inverse relationship between permeation rate and bag thickness. The inverse relationship is to be expected since the decreased path length of thinner mediums should allow for a faster permeation of the compound. 


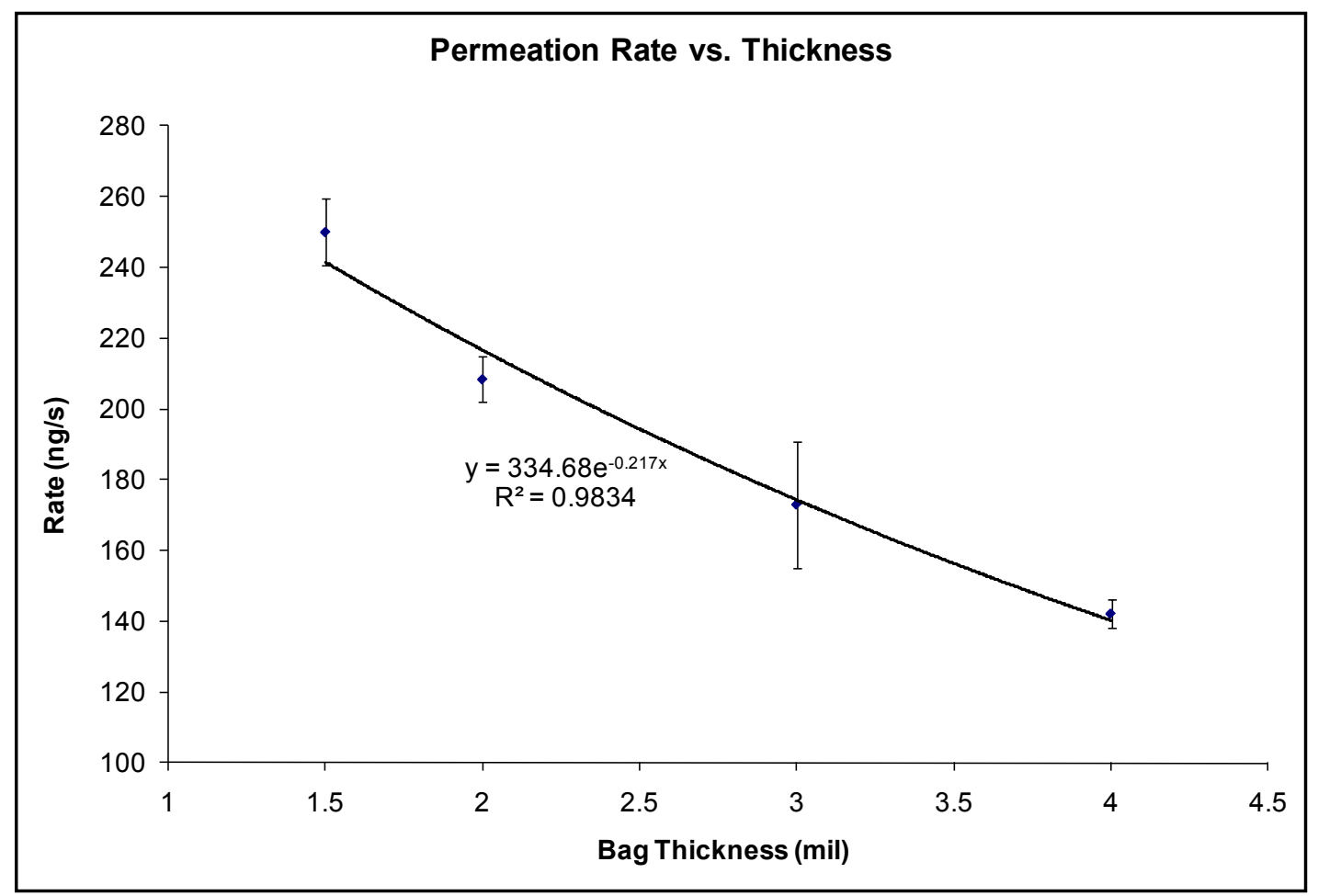

Figure 34 - Plot of piperonal permeation rate by bag thickness

A summary of the permeation rates of the piperonal COMPS is given in Table 16 . Utilization of this table will help with the selection of training aids that have permeation rates at different orders of magnitude for threshold testing purposes. 
Table 16 - Piperonal permeation rate summary

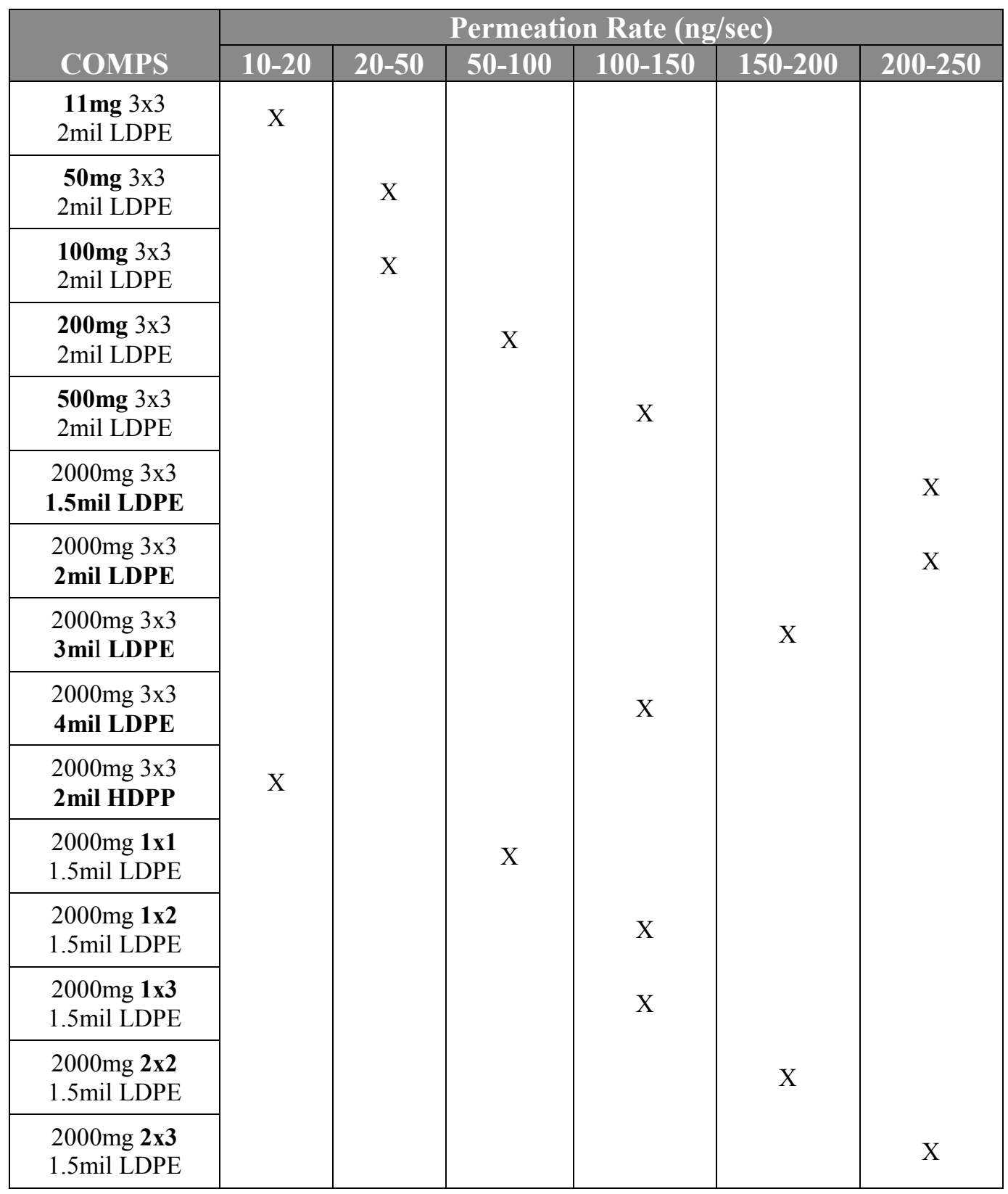

\subsection{Field Trials}

It has been shown that dogs trained to alert to ecstasy will also alert to piperonal [1]. In order to confirm the reliability and accuracy of piperonal as a training aid, "new canines" 
were imprinted on piperonal and then tested with ecstasy samples. The term "new canine" refers to canines that were not exposed to any type of drug sample prior to or during the piperonal training process. The training consisted of 2 sessions a day for 5-15 days (depending on the training agency) using $50 \mathrm{~g}$ of a piperonal training aid $(1: 10$, piperonal: matrix). The testing phase consisted of a double-blind line-up using $25 \mathrm{~g}$ of blank matrix, $50 \mathrm{~g}$ of the piperonal aid, and $30 \mathrm{~g}$ of ecstasy tablets. For the line-up, each sample was placed in a separate scent box/electrical box along a wall. The handlers were instructed to have their canines sample the odor in each box and identify a response of alert, no-alert, or extended interest. The results of these tests are given in Figure 35. $100 \%$ of the canines ( 24 of 24$)$ correctly identified the positive control $(50 \mathrm{~g}$ of piperonal aid) to which they had been trained. Ninety-six percent of the canines (23 of 24) gave a final alert response to the ecstasy tablets after demonstrating their ability to identify the piperonal correctly. The single canine that did not alert to the ecstasy showed extended interest in the sample, but did not give a final response. 


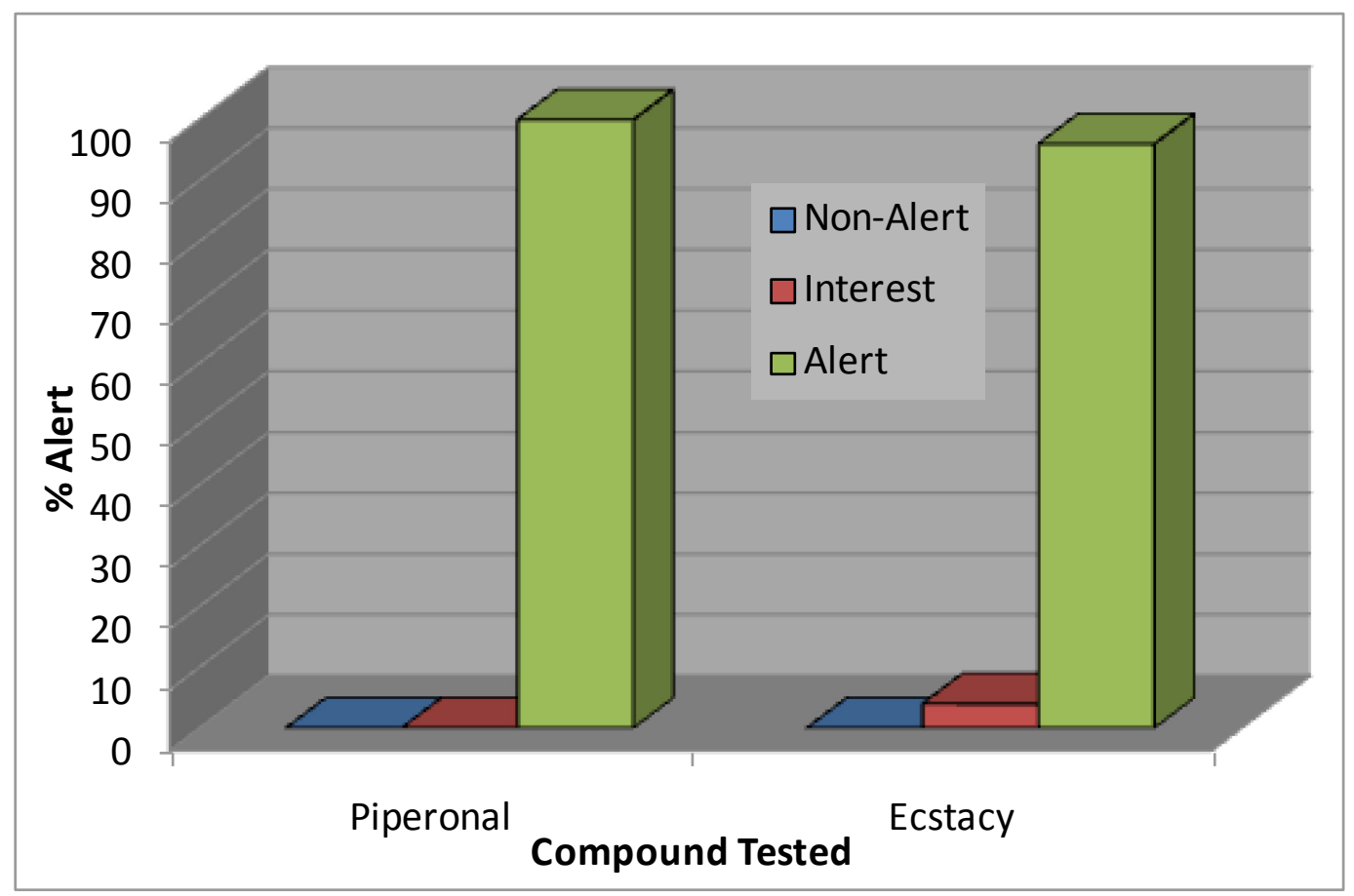

Figure 35 - Results of ecstasy testing on piperonal imprinted canines $(n=24)$

After demonstration of piperonal's capability for reliable MDMA mimicry (e.g. ecstasy), field tests were held to help determine the canine's absolute threshold of detection. The absolute threshold is the minimum intensity of a stimulus that is detected by a [42]. In the case of odor, this is considered the minimum concentration of vapor. Absolute threshold is commonly referred to as LOD for instrumental detection. Table 17 shows field results for the first round of double blind field tests of piperonal COMPS presented in Sigma Pseudo $^{\mathrm{TM}}$ Scent Cages. The canines that participated in this trial were certified drug dogs whose training and certification included detection of ecstasy tablets. The COMPS were created by spiking a 600ppt (part-per-thousand) piperonal solution in acetonitrile onto sterile gauze. The spiked gauze sat for $20 \mathrm{~min}$ to allow for the evaporation of the acetonitrile. Afterwards, the samples were sealed within 3in x 3 in 2 mil LDPE bags and 
then heat sealed within aluminized Kapak bags for transport. As shown in Table 17, 60\% (3/5) of the dogs alerted to the COMPS devices that possessed $80 \mathrm{mg}$ and $120 \mathrm{mg}$ of piperonal. For those same COMPS, $100 \%$ of the canines showed at least some interest even though all did not give a final response. No interest or final response alerts were seen for any of the other piperonal samples. Based on these results, the lower limit of detection of piperonal for this group of canines is between $40 \mathrm{mg}$ and $80 \mathrm{mg}$.

Table 17 - Piperonal COMPS field Trials

Piperonal solutions spiked onto gauze, sealed in 2 mil LDPE, presented in Sigma Pseudo Cages

\begin{tabular}{|c|c|c|c|c|}
\hline Content & No Alert & Interest & Alert & $\%$ Alert \\
\hline Silica Blank & $115,116,117,118,119$ & - & - & 0 \\
\hline 10g Piperonal Silica (10\%) & $115,116,117,118,119$ & - & - & 0 \\
\hline 5g Piperonal Silica (10\%) & $115,116,117,118,119$ & - & - & 0 \\
\hline Blank COMPS & $115,116,117,118,119$ & - & - & 0 \\
\hline $120 \mathrm{mg}$ in COMPS & - & 116,119 & $115,117,118$ & $60 \%$ \\
\hline 80mg in COMPS & - & 115,116 & $117,118,119$ & $60 \%$ \\
\hline $40 \mathrm{mg}$ in COMPS & $115,116,117,118,119$ & - & - & 0 \\
\hline 20mg in COMPS & $115,116,117,118,119$ & - & - & 0 \\
\hline
\end{tabular}

The results for the second round of field tests for the absolute threshold of piperonal detection are given in Table 18. The COMPS were created by sealing pure piperonal within 3 in $x$ 3in 2 mil LDPE bags. While there was at least interest shown in every 
piperonal sample, the only full response alerts occurred with the 5mg sample $(4 / 4,100 \%)$ and the $25 \mathrm{mg}$ piperonal sample $(1 / 4,25 \%)$. The absolute threshold of detection for piperonal is different for this second set of trials as compared to the first set of trials. Since the sensitivity of the canine nose is dependent upon the training it receives, inconsistent training from variations in available drug training aids between agencies, along with natural differences in sensitivity inherent to biological specimens, may result in the threshold variation $[104,107]$.

Table 18 - Piperonal COMPS field trials

Solid piperonal, sealed in 2mil LDPE, presented in Sigma Pseudo Cages

\begin{tabular}{|c|c|c|c|c|}
\hline Content & No Alert & Interest & Alert & $\%$ Alert \\
\hline $\begin{array}{c}\text { 5mg Pip } \\
\text { 2mil LDPE in Electrical Box }\end{array}$ & - & - & $132,133,134,135$ & $100 \%$ \\
\hline $\begin{array}{c}\text { 10mg Pip } \\
\text { 2mil LDPE in Electrical Box }\end{array}$ & 132,134 & 133,135 & - & $0 \%$ \\
\hline $\begin{array}{c}\mathbf{2 5 m g ~ P i p ~} \\
\text { 2mil LDPE in Electrical Box }\end{array}$ & 134 & 132,135 & 133 & $25 \%$ \\
\hline $\begin{array}{c}\text { Blank } \\
\text { 2mil LDPE in Electrical Box }\end{array}$ & $132,133,134,135$ & - & - & $0 \%$ \\
\hline $\begin{array}{c}\mathbf{5 0 m g} \text { Pip } \\
\text { 2mil LDPE in Electrical Box }\end{array}$ & $133,134,135$ & 132 & - & $0 \%$ \\
\hline $\begin{array}{c}\mathbf{7 5 m g} \text { Pip } \\
\text { 2mil LDPE in Electrical Box }\end{array}$ & $132,133,134$ & 135 & - & $0 \%$ \\
\hline $\begin{array}{c}\mathbf{1 0 0 m g} \text { Pip } \\
\text { 2mil LDPE in Electrical Box }\end{array}$ & $133,134,135$ & 132 & - & $0 \%$ \\
\hline
\end{tabular}

In order to determine the field threshold levels of piperonal dogs trained to detect ecstasy, piperonal COMPS were prepared at several different orders of magnitude in permeation of the target odorant. Based on the piperonal permeation results from section 4.4, samples with $10 \mathrm{ng} / \mathrm{sec}, 100 \mathrm{ng} / \mathrm{sec}$, and $1000 \mathrm{ng} / \mathrm{sec}$ permeation rates were selected. The 3 in x 3 in 
2mil HDPP with $2 \mathrm{~g}$ was used for the $10 \mathrm{ng} / \mathrm{sec}$ sample and the 3 in $\mathrm{x}$ 3in 1.5mil LDPE with 500mg was used for the 100ng/sec sample. Since no COMPS aid yielded a permeation rate of $1000 \mathrm{ng} / \mathrm{sec}$, five 3 in $x$ in $1.5 \mathrm{mil}$ LDPE with $2 \mathrm{~g}$ were used in combination $(5 \times 200 \mathrm{ng} / \mathrm{sec})$. To verify the available odor emanating from the COMPS, each permeation amount was sampled in a one quart paint can for 30 minutes using SPME. The GC-MS chromatogram shown in Figure 36 clearly displays the substantial difference in piperonal vapor between the three COMPS devices.

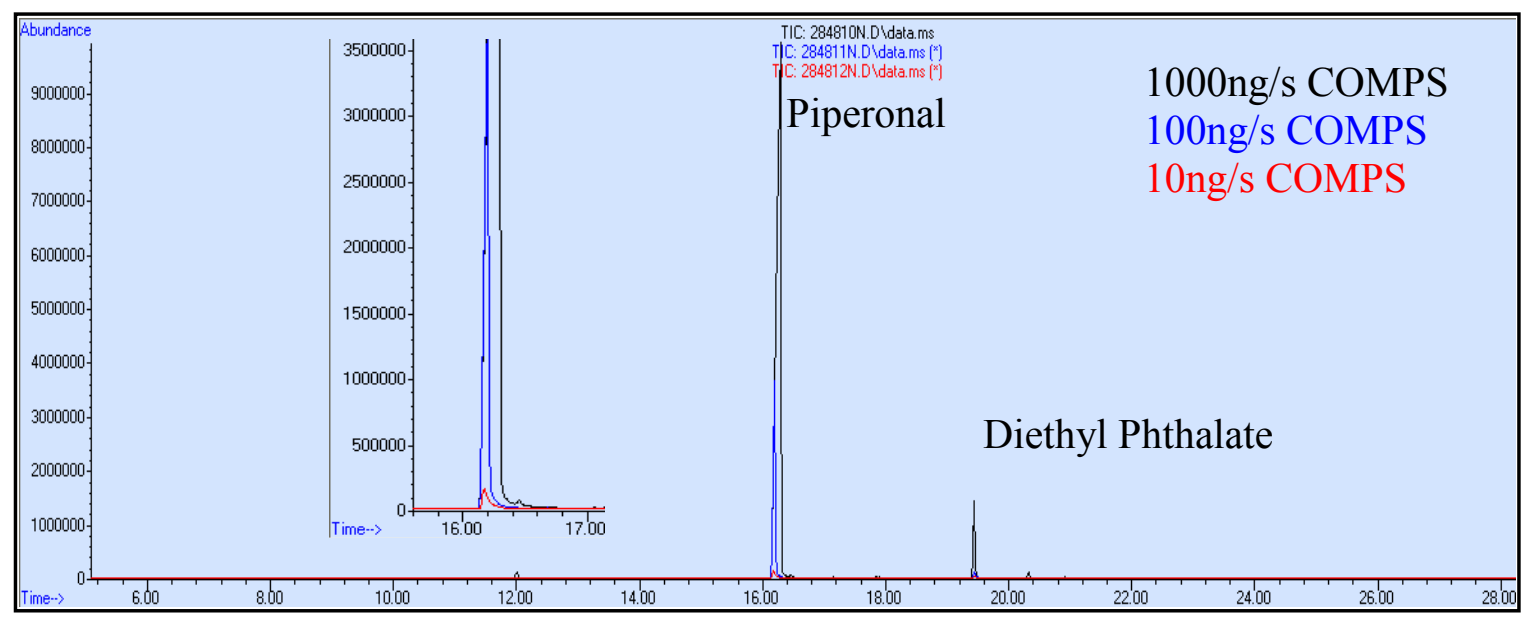

Figure 36 - GC-MS chromatogram of three piperonal COMPS at different orders of magnitude

Next, the three COMPS devices were used in field tests with trained Ecstasy (MDMA) canines. The results of the canine field trials using the three COMPS are given in Table 19. 
Table 19 - Piperonal COMPS field trials

Solid piperonal, sealed in 2mil LDPE, presented in Sigma Pseudo Cages

\begin{tabular}{|c|c|c|c|c|}
\hline Content & No Alert & Interest & Alert & $\%$ Alert \\
\hline $\begin{array}{c}\text { Blank } \\
\text { 3" x 3"LDPE in } \\
\text { Sigma Scent Cage }\end{array}$ & $\begin{array}{c}101,106,109, \\
111,114,115, \\
122,125,127, \\
128,130,136, \\
137,138,140, \\
141\end{array}$ & 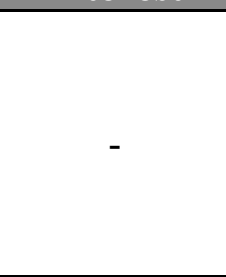 & & $0 \%$ \\
\hline $\begin{array}{c}\mathbf{1 0 n g} / \mathbf{s e c} \\
2 \mathrm{~g} \text { in } 3 " \times 3 " 2 \mathrm{mil} \mathrm{HDPP} \text { in } \\
\text { Sigma Scent Cage }\end{array}$ & $\begin{array}{l}101,111,114, \\
115,125,127, \\
128,130,137, \\
138,140,141 \\
\end{array}$ & - & $\begin{array}{c}106,109,122 \\
136\end{array}$ & $25 \%$ \\
\hline $\begin{array}{c}\mathbf{1 0 0 n g} / \mathbf{s e c} \\
\text { 500mg in 3"x3" } 1.5 \mathrm{mil} \\
\text { LDPE in } \\
\text { Sigma Scent Cage } \\
\end{array}$ & $\begin{array}{l}109,111,114, \\
125,128,130, \\
138,140,141\end{array}$ & - & $\begin{array}{l}101,106,115, \\
122,127,136, \\
137\end{array}$ & $44 \%$ \\
\hline $\begin{array}{c}\mathbf{1 0 0 0 n g / \mathbf { s e c }} \\
2 \mathrm{~g} \text { in 3"x3" } 1.5 \mathrm{mil} \text { LDPE in } \\
\text { Sigma Scent Cage }\end{array}$ & 138 & $114,125,127$ & $\begin{array}{l}101,106,109, \\
111,115,122, \\
128,130,136, \\
137,140,141 \\
\end{array}$ & $75 \%$ \\
\hline
\end{tabular}

A logarithmic plot was created utilizing the percent of alert and the permeation rate (Figure 37). A biological dose-response curve is demonstrated by the permeation rate of piperonal plotted against the behavioral response of the canine. The results suggest that a dose-response relationship exists between the permeation rate of piperonal and a positive alert response from trained detector canines. The effective dose for $50 \%$ of the canines tested (i.e. $\mathrm{ED}_{50}$ ) is approximately $100 \mathrm{ng} / \mathrm{s}$. The results suggest that while some dogs' noses are sensitive enough to detect smaller levels of piperonal $(10 \mathrm{ng} / \mathrm{s})$; the majority lies above the $100 \mathrm{ng} / \mathrm{s}$. 


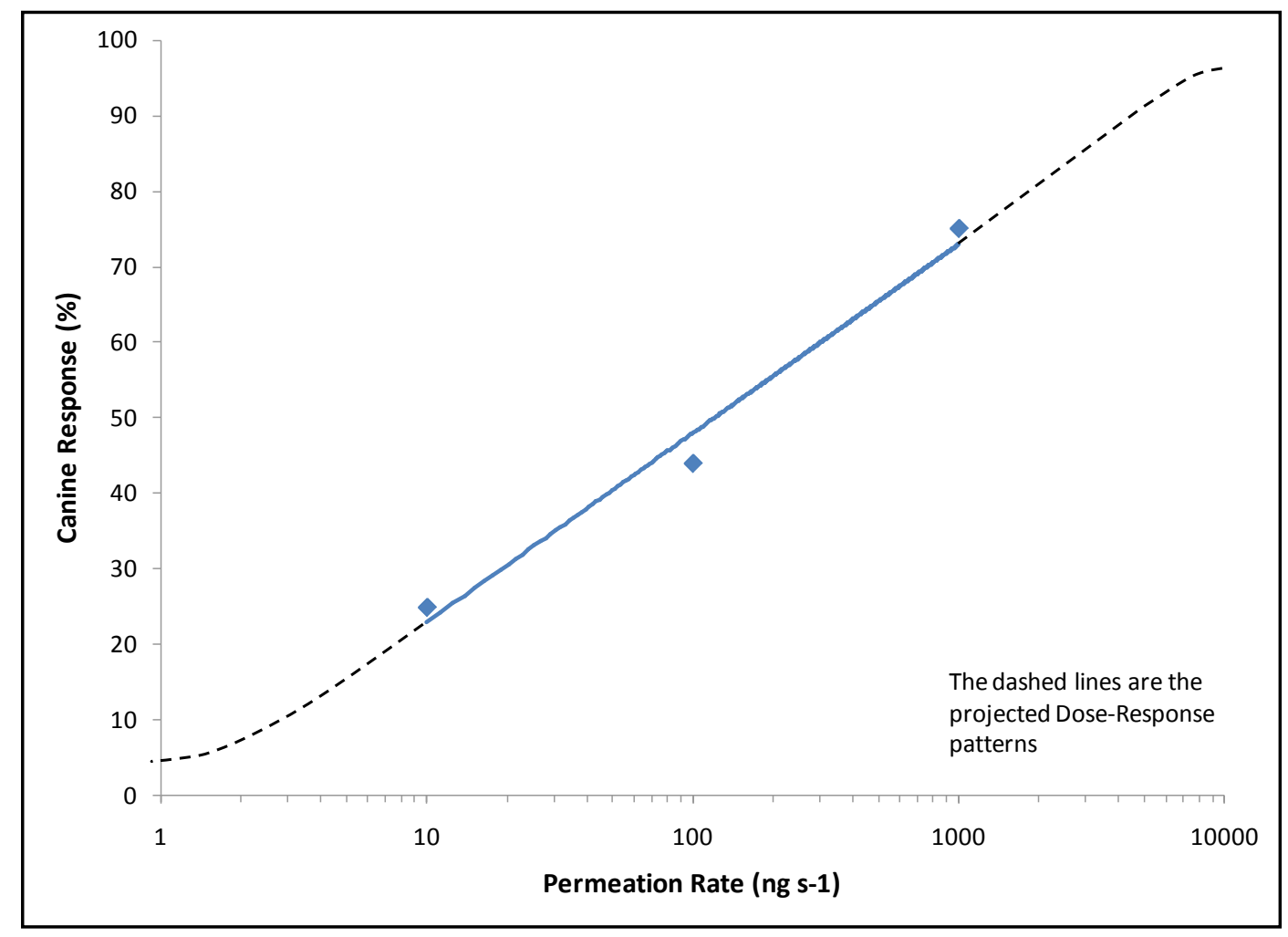

Figure 37 - Logarithmic plot of canine alert response vs. piperonal permeation rate

The permeation rate of the COMPS devices is based on the amount of compound lost per second; however, the actual amount of odor that is available for presentation is dependent upon the distance between the sample and the detector. Increased distance between the detector and sample yields greater effects of diffusion and advection. Typically, the canine's sample distance occurs at 2 to 3 inches eliminating significant effects of diffusion and advection. Macias et al. conjectured that using a SPME-IMS closed static system as a model for the amount of piperonal odor available from the $100 \mathrm{ng} / \mathrm{s}$ COMPS [107], allows for an approximation to be made for the LOD of the canine nose. Based on the instrumental model, a 1 second sampling time of the 100ng/s COMPS yields an LOD 
of approximately 1 ng of piperonal necessary to reach threshold levels of detection (50\% recognition, Figure 37) as compared to the LOD of the SPME-IMS system at 2ng.

In order to determine the reliability of the canine responses to the COMPS used in the threshold study, each aid was tested 5 times with 5 different trained and certified canines (Canine 109, 111, 131, 144, and 145). The results are given in Figure 38. The field detection results shown in (a), (b), and (c) were for canines that were trained using training aids confirmed to contain piperonal in their headspace. Consistent detection was observed for $55-75 \%$ of detector dogs tested at the $10 \mathrm{ng} / \mathrm{sec}$ level, increasing to nearly $100 \%$ for the $1000 \mathrm{ng} / \mathrm{sec}$ piperonal COMPS. In contrast, the results shown in (d) \& (e) are for dogs trained with MDMA tablets later determined not to contain piperonal as a major volatile organic compound (VOC). Most of these dogs did not alert to any of the piperonal COMPs used regardless of the permeation rate.

Canines 109, 111, and 131 had also been exposed to pure piperonal during initial training scenarios whereas Canines 144 and 145 had not been exposed to pure piperonal. The results demonstrate that recognition of the piperonal odor is highly dependent upon training aids employed. The results also demonstrate that more than one training aids may be required for the complete detection of street MDMA samples due to the variability in the VOCs present in street samples that may be chosen for training purposes. 

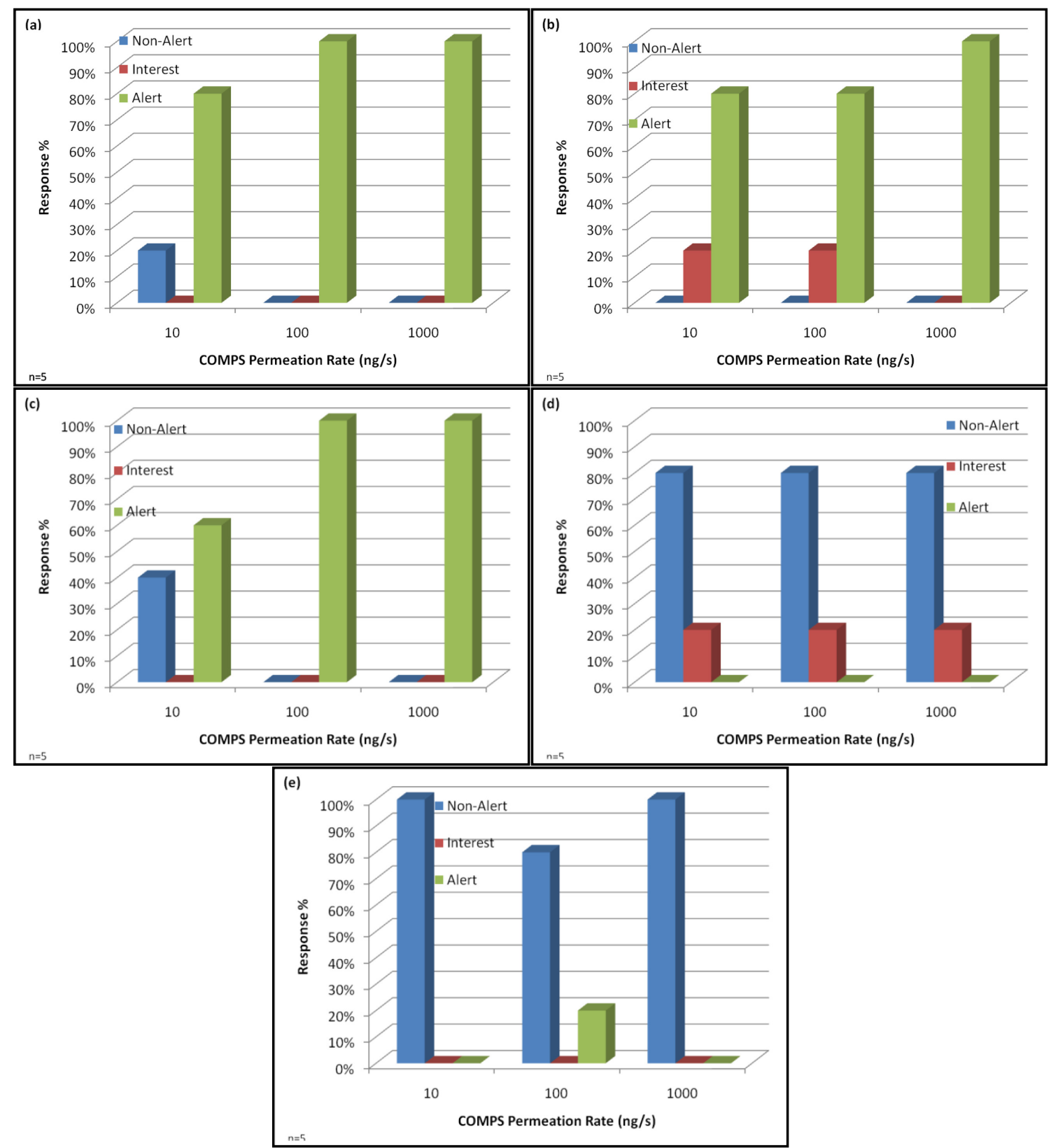

Figure 38 - Results from canine repeatability study of piperonal COMPS

(a) Canine 109 (b) Canine 111 (c) Canine 131 (d) Canine 144 (e) Canine 145 


\section{HEROIN RESULTS AND DISCUSSION}

\subsection{Mimicking Heroin}

Previous research has shown acetic acid to be a major contributor in the headspace of heroin $[18,19]$. The acetic acid seen in the headspace of heroin is a result of deacetylation process of heroin to morphine. While this might seem to offer a simple solution for odor training purposes, the issue is not so easily resolved. Acetic acid is also the major ingredient found in vinegar $[108,109]$. The acetic acid is a direct result of the fermentation process (denaturation process) of ethyl alcohol with ethyl acetate. The final outcome of the least complex vinegar, white distilled vinegar (glacial vinegar), contains traces of ethyl acetate, residual ethyl alcohol, and acetic acid. The amount of acetic acid ranges from a $5 \%$ solution for table vinegar to an $18 \%$ solution for pickling processes $(\mathrm{v} / \mathrm{v})$. Training compounds need to be representative of the actual sample of interest (i.e. heroin) and distinguishable from common, everyday items (i.e. vinegar); thus, the use of acetic acid as a single training compound may not be sufficient.

There are three approaches that could help establish the significance of this problem. The first is to determine whether all vinegars possess a common secondary compound to help distinguish them from pure acetic acid. The second method would be to determine if there is a secondary compound common in heroin samples that could be used in combination with acetic acid to help distinguish them from other sources of acetic acid, such as vinegar. The last method would be to test whether training upon a lower percentage solution of acetic acid, while confirming no alert to $5 \%$ solution or higher, would be sufficient for heroin detection training. 


\subsection{HS-SPME-GC-MS}

\subsubsection{Vinegar}

The vinegars used in this study included two samples of white distilled vinegar, one sample of red wine vinegar, one sample of balsamic vinegar, and one sample of apple cider vinegar; all vinegar samples were obtained from local grocery stores. The odor compounds of each vinegar sample were found through headspace sampling and analysis with HS-SPME-GC-MS. The profiles are shown in Figure 39 - Figure 41. A summary of the identified compounds is shown in Table 20.

Acetic acid was the only odor compound detected in all vinegar samples, reaffirming the findings from of other studies $[108,109]$. The balsamic and apple cider vinegars had six compounds that were common between them: acetic acid, 3-hydroxy-2-butanone, 3methyl-butanoic acid, phenylethyl alcohol, diethyl ester butanedioic acid, and 2phenylethyl ester acetic Acid. Also, three of the five vinegar samples possessed 3-mehtylbutanoic acid. Only one compound, acetic acid, was detected in the headspace of the two white distilled vinegars. As a result, there was not a common secondary compound detected in all of the various vinegar samples. 


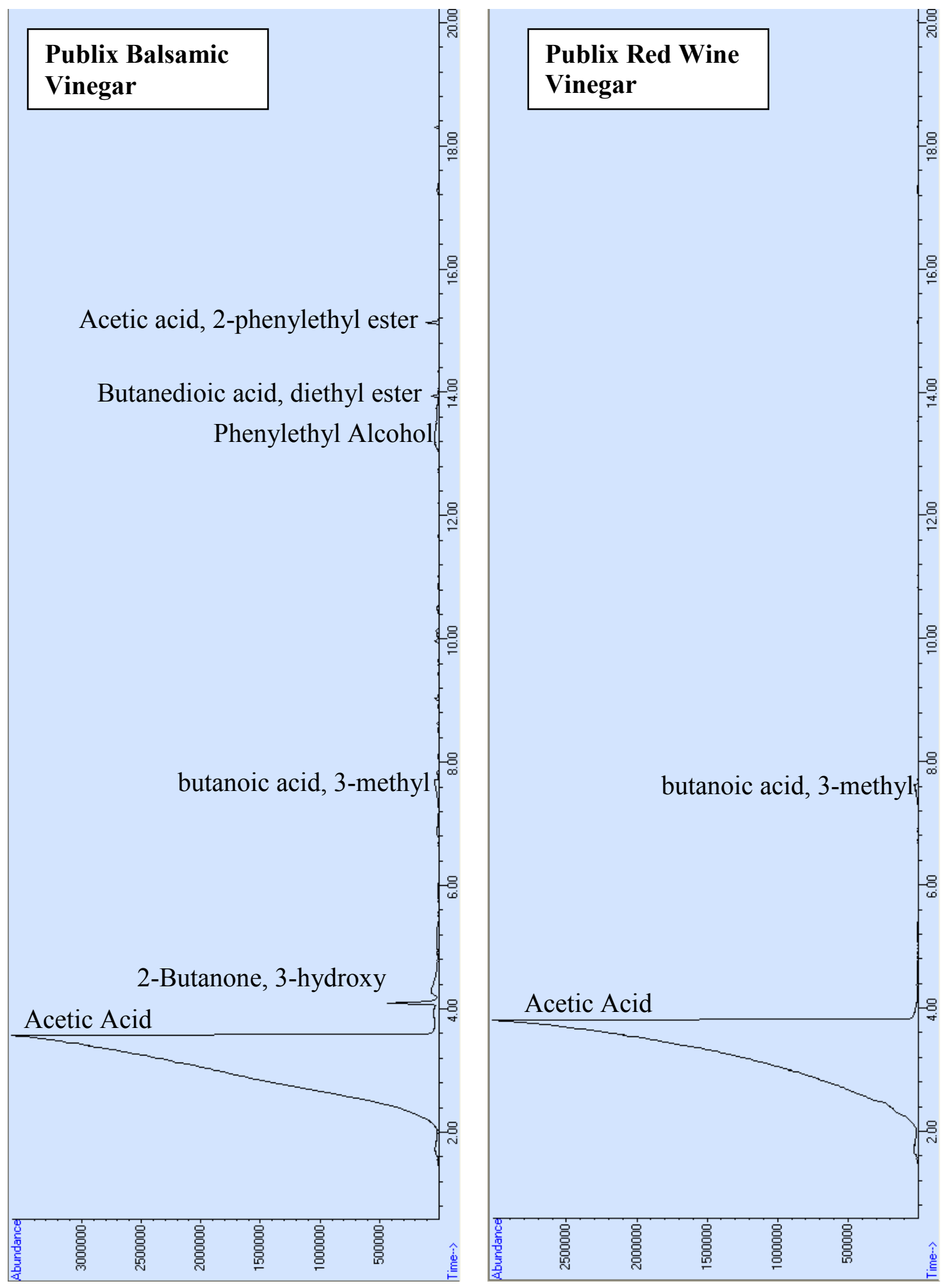

Figure 39 - Vinegar Chromatograms using SPME-GC-MS showing most abundant VOC's 


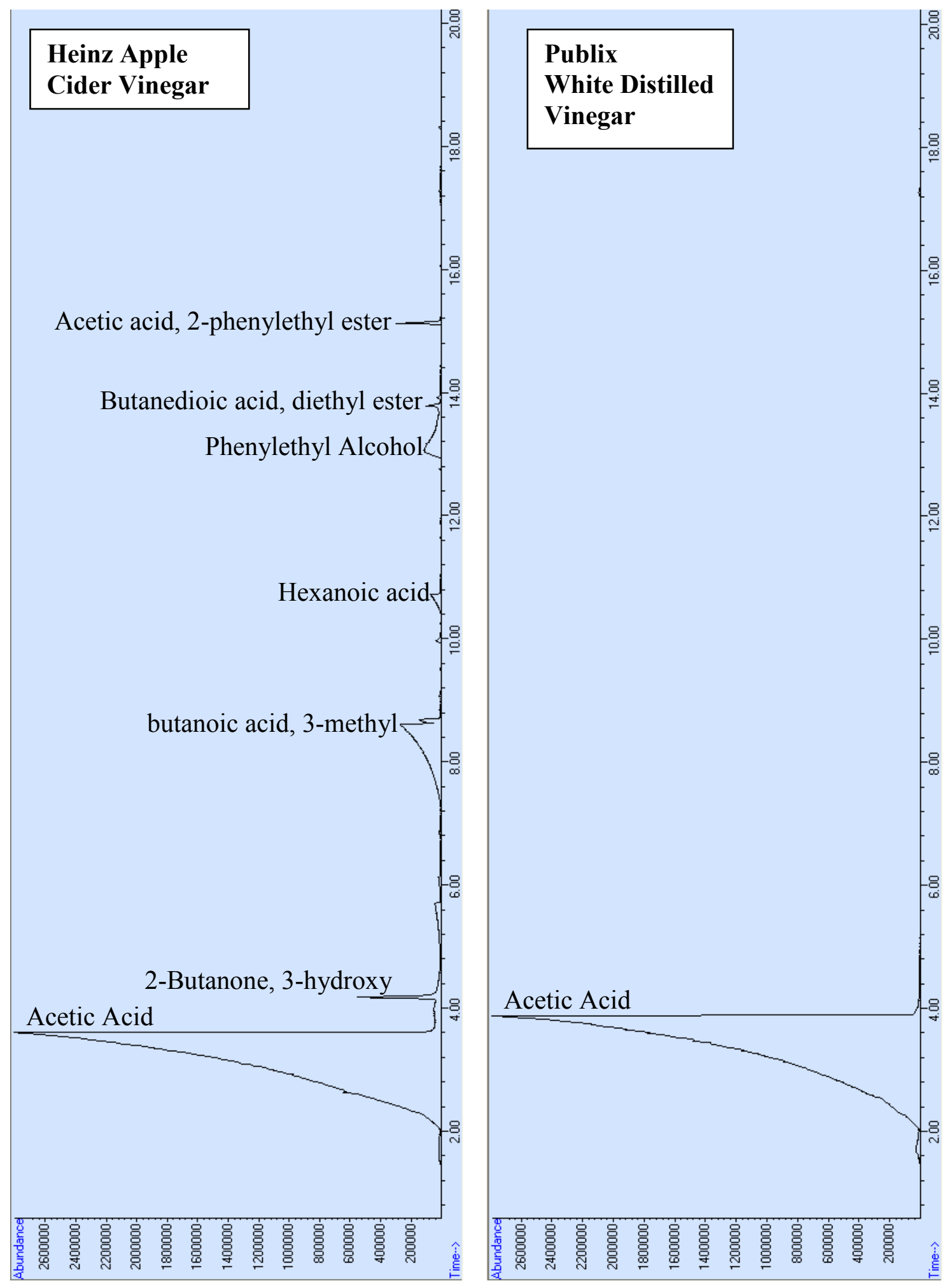

Figure 40 - Vinegar Chromatograms using SPME-GC-MS showing most abundant VOC's 


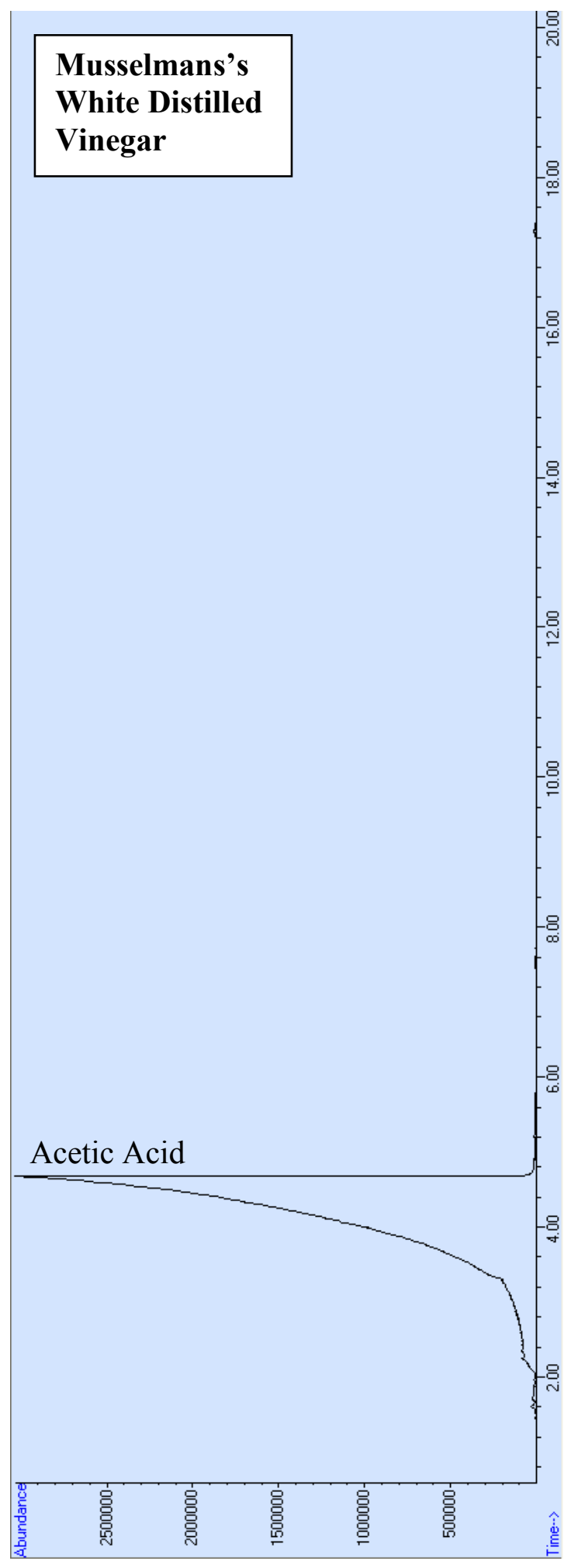

Figure 41 - Vinegar Chromatograms using SPME-GC-MS showing most abundant VOC's 
Table 20 - Summary of vinegar headspace compounds

\begin{tabular}{|c|ccccc|}
\hline $\begin{array}{c}\text { Detected } \\
\text { Compound }\end{array}$ & $\begin{array}{c}\text { Publix } \\
\text { Balsamic }\end{array}$ & $\begin{array}{c}\text { Publix } \\
\text { Red } \\
\text { Wine }\end{array}$ & $\begin{array}{c}\text { Heinz } \\
\text { Apple } \\
\text { Cider }\end{array}$ & $\begin{array}{c}\text { Musselman's } \\
\text { White } \\
\text { Distilled }\end{array}$ & $\begin{array}{c}\text { Publix } \\
\text { White } \\
\text { Distilled }\end{array}$ \\
\hline Acetic Acid & $\mathrm{X}$ & $\mathrm{X}$ & $\mathrm{X}$ & $\mathrm{X}$ & $\mathrm{X}$ \\
\hline 3-Hydroxy-2-butanone & $\mathrm{X}$ & & $\mathrm{X}$ & & \\
\hline 3-Methyl-butanoic Acid & $\mathrm{X}$ & $\mathrm{X}$ & $\mathrm{X}$ & \\
\hline Hexanoic Acid & & & $\mathrm{X}$ & \\
\hline $\begin{array}{c}\text { Phenylethyl Alcohol } \\
\begin{array}{c}\text { Diethyl ester } \\
\text { butanedioic Acid }\end{array}\end{array}$ & $\mathrm{X}$ & & $\mathrm{X}$ & \\
\hline $\begin{array}{c}\text { 2-Phenylethyl ester } \\
\text { acetic Acid }\end{array}$ & $\mathrm{X}$ & & $\mathrm{X}$ & \\
\hline
\end{tabular}

\subsubsection{Heroin}

The heroin samples and the commercial pseudo heroin sample used in this study were obtained from local law enforcement agencies and training schools including Florida Highway Patrol (FHP) and the US-K9 Academy and Police Dog Training Center. The Sigma Pseudo ${ }^{\mathrm{TM}}$ Narcotic Scent Heroin formulation, Canine Training Aid was purchased from Sigma Aldrich. The odor compounds of each sample were found through headspace sampling and analysis with HS-SPME-GC-MS. The profiles are shown in Figure 42 and Figure 43. A summary of the identified compounds is shown in Table 21. 


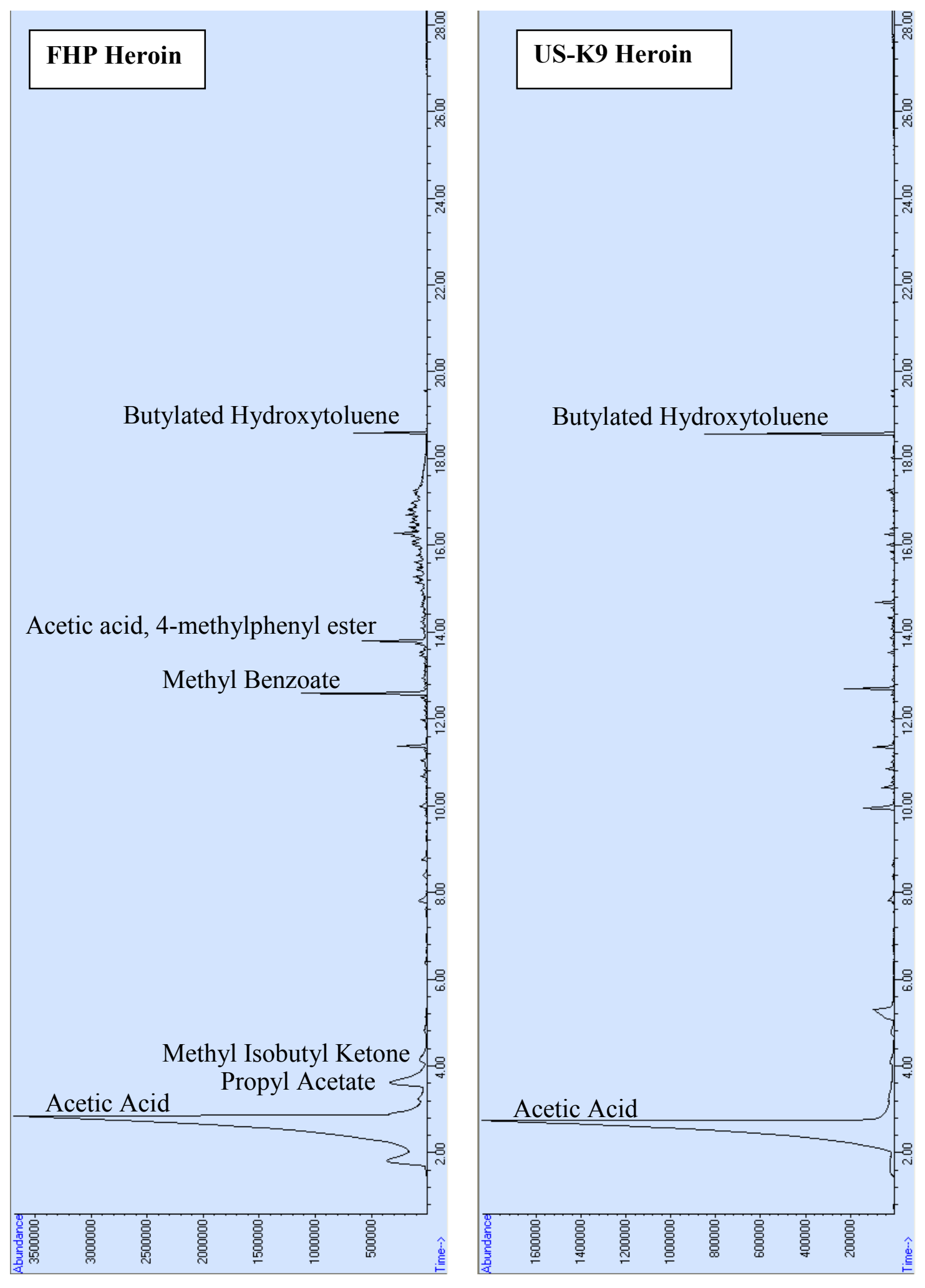

Figure 42 - Heroin chromatograms using SPME-GC-MS showing most abundant VOC's 


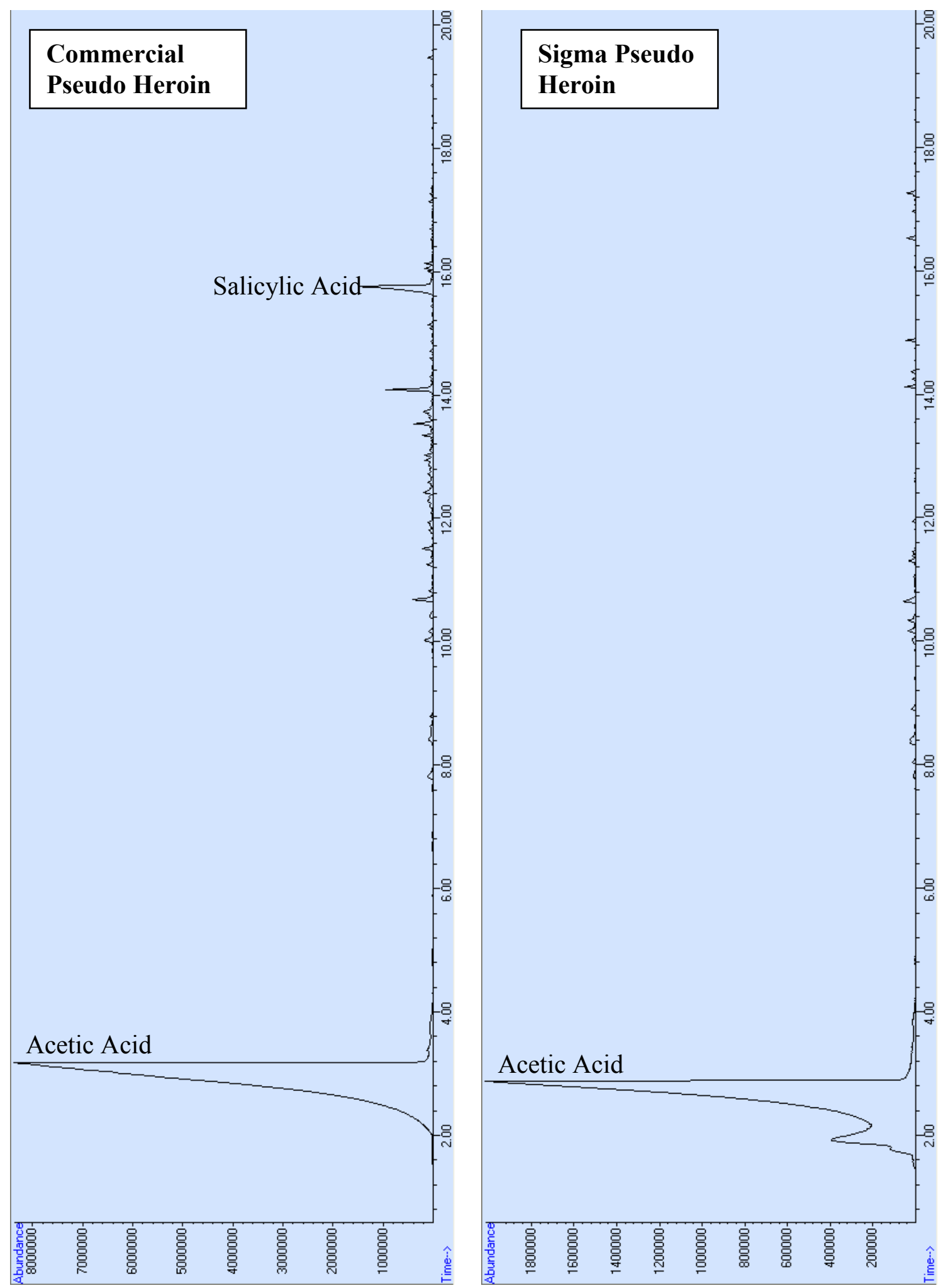

Figure 43 - Pseudo heroin chromatograms using SPME-GC-MS showing most abundant VOC's 
Acetic acid was detected in both samples of heroin, the commercial pseudo heroin, and was the sole compound detected in the Sigma Pseudo ${ }^{\mathrm{TM}}$ Narcotic Scent Heroin. Salicylic acid was the second most abundant compound detected within the headspace of the "commercial pseudo heroin"; however, salicylic acid was not detected within the heroin samples and has not been reported in previous studies. The solvent, methyl isobutyl ketone, was detected at a low level in one heroin sample (FHP). Methyl isobutyl ketone is one of the solvents used during certain production process of heroin $[17,18]$. Besides the acetic acid, there were no common compounds detected across all the heroin samples.

Table 21 - Summary of heroin and pseudo heroin headspace compounds

\begin{tabular}{|c|cccc|}
\hline $\begin{array}{c}\text { Headspace } \\
\text { Compounds }\end{array}$ & $\begin{array}{c}\text { FHP } \\
\text { Heroin }\end{array}$ & $\begin{array}{c}\text { US-K9 } \\
\text { Heroin }\end{array}$ & $\begin{array}{c}\text { Commercial } \\
\text { Pseudo Heroin }\end{array}$ & $\begin{array}{c}\text { Sigma Pseudo } \\
\text { Heroin }\end{array}$ \\
\hline Acetic Acid & $\mathrm{X}$ & $\mathrm{X}$ & $\mathrm{X}$ & $\mathrm{X}$ \\
\hline Propyl Acetate & $\mathrm{X}$ & & \\
\hline $\begin{array}{c}\text { Methyl } \\
\text { Isobutyl Ketone }\end{array}$ & $\mathrm{X}$ & & \\
\hline $\begin{array}{c}\text { 4-Methyl-phenyl } \\
\text { Ester Acetic acid }\end{array}$ & $\mathrm{X}$ & $\mathrm{X}$ & $\mathrm{X}$ \\
\hline $\begin{array}{c}\text { Butylated } \\
\text { Hydroxytoluene }\end{array}$ & $\mathrm{X}$ & $\mathrm{X}$ & \\
\hline \begin{tabular}{c} 
Salicylic Acid \\
\hline
\end{tabular} & & & $\mathrm{X}$ \\
\hline
\end{tabular}

Methyl benzoate was detected in the headspace of one sample of heroin (FHP heroin). Prior to sampling, the heroin was stored in close proximity to several bulk samples of cocaine which may have led to cross contamination. Alternatively, heroin has been known to be cut with additional compounds to stretch the quantity of the drug sold. While 
both explanations offer possible sources for the detection of methyl benzoate, the cross contamination is the most likely choice.

There was no secondary compound detected in either the vinegar samples or the heroin samples that might help distinguish one group from the other for detection training purposes. Additional sampling must be conducted to confirm the results of the current study. As previously mentioned, a variety of solvents are used during the manufacture process depending upon the region of origin (section 1.3.4). The use of one or several of these solvents in combination with acetic acid may offer the best heroin mimic for training purposes while maintaining an appropriate level of distinction from other sources of acetic acid. Acetone would be a poor solvent choice to incorporate into a heroin training aid because it is utilized in the production of peroxide explosives. The presence of acetone in the manufacturing process of peroxide explosives makes it a potential headspace component of this class of explosive. If a canine were trained to acetone, an alert could mean heroin, but it could also mean TATP. Further evaluation and field testing of the possible mimicry options will be addressed in section 5.3.

"Nothing is impossible, not if you can imagine it. That's what being a scientist is all about!"

\subsection{Field Trials}

The results for the first set of field tests using heroin mimics are given in Table 22. The mimics were mixtures of salicylic acid to acetic acid created at $10 \%, 25 \%, 50 \%, 75 \%$ and 
$90 \%$ concentrations. Each solution was spiked onto an inert matrix (tea candle) and then placed in electrical boxes for presentation to the canine teams. At the day of testing, the canines demonstrated their ability to recognize and alert to the odor of a $28 \mathrm{~g}$ sample of heroin. Of the five mixture combinations, only two of the mixtures had a better than $50 \%$ alert percentage by the trained drug canines: the $10 \%$ mixture and the $50 \%$ mixture. The other mixtures were of little interest to the canines. The exception is Canine 128; Canine 128 alerted to 3 of the 5 mixtures and showed extended interest in the other two. There are two reasons that this may have occurred: (1) the canine uses a single odor (i.e. acetic acid) to identify heroin and/or (2) the heroin being used for training purposes possesses a strong acetic acid smell. The data from Canine 131 was omitted from the alert percentage calculation. The data was omitted because the canine was extremely winded and not focused on the task at hand. It should also be noted that Canine 101 alerted to one of the blanks in addition to the mimics. While this may demonstrate the canine's inability to distinguish between a blank and odor sample, it is more likely due to the handler initiation. At the time of testing, the handler inadvertently cued the canine to alert to the blank sample. This error is countered by the non-alert response given for the second blank. 
Table 22 - Heroin mimic field trials

Solutions of salicylic acid and acetic acid spiked onto tea candles, presented in an electrical box

\begin{tabular}{|c|c|c|c|c|}
\hline Content & No Alert & Interest & Alert & $\%$ Alert \\
\hline $\begin{array}{c}\mathbf{1 0 \%} \text { Solution } \\
\text { Inert Matrix in Electrical Box }\end{array}$ & 129,131 & 111,130 & $\begin{array}{c}101,109,127 \\
128\end{array}$ & $57 \%$ \\
\hline $\begin{array}{c}\mathbf{2 5 \%} \text { Solution } \\
\text { Inert Matrix in Electrical Box }\end{array}$ & $\begin{array}{l}109,111,127 \\
129,130,131\end{array}$ & 128 & 101 & $14 \%$ \\
\hline $\begin{array}{c}\text { Blank } \\
\text { Inert Matrix in Electrical Box }\end{array}$ & $\begin{array}{c}109,111,127 \\
128,129,130 \\
131\end{array}$ & - & 101 & $14 \%$ \\
\hline $\begin{array}{c}\mathbf{5 0 \%} \text { Solution } \\
\text { Inert Matrix in Electrical Box }\end{array}$ & 129,131 & 111,127 & $\begin{array}{c}101,109,128 \\
130\end{array}$ & $57 \%$ \\
\hline $\begin{array}{c}\mathbf{7 5 \%} \text { Solution } \\
\text { Inert Matrix in Electrical Box }\end{array}$ & $\begin{array}{l}101,111,127 \\
129,130,131\end{array}$ & 109 & 128 & $14 \%$ \\
\hline $\begin{array}{c}\text { Blank } \\
\text { Inert Matrix in Electrical Box }\end{array}$ & $\begin{array}{c}101,109,111 \\
127,128,129 \\
130,131\end{array}$ & - & - & $0 \%$ \\
\hline $\begin{array}{c}\mathbf{9 0 \%} \text { Solution } \\
\text { Inert Matrix in Electrical Box }\end{array}$ & $\begin{array}{l}101,109,111 \\
129,130,131\end{array}$ & 127,128 & - & $0 \%$ \\
\hline
\end{tabular}

To access the results from the first round of heroin mimic testing, a second round was planned. For the second set of field tests the following samples were prepared: pure acetic acid, pure salicylic acid, distilled vinegar, heroin and the two solutions from the first round of field testing (10\% and 50\%). Each sample was spiked onto sterile gauze pads and placed in electrical boxes for presentation to the canine teams. The results of the canine response for this set of samples are given in Table 23. On this occasion, a 32g sample of heroin was used with $100 \%$ (14 of 14) of the canines correctly identifying and alerting. As expected, none of the canines ( 0 of 14$)$ showed interest in pure acetic acid or pure salicylic acid samples. It is believed that the pure substances were too highly 
concentrated for recognition by the canines. While it might be expected that canines would not alert to the distilled vinegar sample, it is not completely unreasonable since the odors of the heroin and vinegar are similar (i.e. acetic acid). For this round of field trials, $0 \%$ of the canines $(0$ of 14$)$ alerted to the $10 \%$ salicylic acid to acetic acid mixture. As previously seen, approximately $50 \%$ of the canines ( 6 of 14 ) alerted to the $50 \%$ salicylic acid to acetic acid mixture.

Table 23 - Heroin mimic field trials

Each sample was spiked onto gauze, presented in electrical box

\begin{tabular}{|c|c|c|c|c|}
\hline Content & No Alert & Interest & $\overline{\text { Alert }}$ & $\%$ Alert \\
\hline $\begin{array}{c}\text { 1g Acetic Acid } \\
\text { on gauze in Electrical Box }\end{array}$ & $\begin{array}{c}106,109,111,113, \\
114,127,128,131, \\
132,133,134,135, \\
136,137\end{array}$ & - & - & $0 \%$ \\
\hline $\begin{array}{c}\text { 1g Salicylic Acid } \\
\text { on gauze in Electrical Box }\end{array}$ & $\begin{array}{c}106,109,111,113, \\
114,127,128,131, \\
132,133,135,136, \\
137\end{array}$ & 134 & - & $0 \%$ \\
\hline $\begin{array}{c}\text { Blank } \\
\text { on gauze in Electrical Box }\end{array}$ & $\begin{array}{c}106,109,111,113, \\
114,127,128,131, \\
132,133,134,135, \\
136,137\end{array}$ & - & - & $0 \%$ \\
\hline $\begin{array}{c}\text { 32g Heroin } \\
\text { in Electrical Box }\end{array}$ & - & - & $\begin{array}{c}106,109,111, \\
113,114,127, \\
128,131,132, \\
133,134,135, \\
136,137\end{array}$ & $100 \%$ \\
\hline $\begin{array}{l}\text { 1g Distilled Vinegar } \\
\text { on gauze in Electrical Box }\end{array}$ & $\begin{array}{c}106,109,111,113, \\
114,127,128,131 \\
134,136,137\end{array}$ & - & $132,133,135$ & $21 \%$ \\
\hline $\begin{array}{c}\mathbf{5 0 \%} \text { Solution } \\
\text { on gauze in Electrical Box }\end{array}$ & $\begin{array}{c}109,127,128,136 \\
137\end{array}$ & $\begin{array}{c}106,111 \\
132\end{array}$ & $\begin{array}{l}113,114,131 \\
133,134,135\end{array}$ & $43 \%$ \\
\hline $\begin{array}{l}\mathbf{1 0 \%} \text { Solution } \\
\text { 2mil LDPE in Electrical } \\
\text { Box }\end{array}$ & $\begin{array}{c}109,114,127,128 \\
131,136,137\end{array}$ & 106,111 & - & $0 \%$ \\
\hline
\end{tabular}


One of the previously mention scenarios for heroin mimic training incorporated a diluted acetic acid concentration below $5 \%(\mathrm{v} / \mathrm{v})$. The choice to use a less than $5 \%$ acetic acid mixture was to prevent possible false alerts on vinegar (know to be as low as $5 \%$ acetic acid concentration). Dilutions of acetic acid were created to $0.01 \%, 0.1 \%$ and $1 \%$ concentrations. These solutions were spiked onto sterile gauze and placed in electrical boxes for presentation to the canines. The results from these samples (given in Table 24) yielded unanimous results. None of the canines ( 0 of 17) alerted to or showed interest in the acetic acid dilutions. Two conclusions can be taken from this round of results: (1) the percentage of acetic acid is still incorrect to accurately mimic heroin for recognition by the canines or (2) the odor profile of heroin as recognized by detector canines is more complex than the lone compound, acetic acid. 
Table 24 - Heroin mimic field trials

Dilutions of acetic acid spiked onto gauze, presented in electrical boxes

\begin{tabular}{|c|c|c|c|c|}
\hline Content & No Alert & Interest & Alert & $\%$ Alert \\
\hline $\begin{array}{l}\mathbf{5 m L ~ 0 . 0 1 \% ~ A c e t i c ~ A c i d ~} \\
\text { on gauze in gallon paint can }\end{array}$ & $\begin{array}{c}101,106,109,111,114, \\
115,122,125,127,128, \\
130,136,137,138,139, \\
140,141\end{array}$ & - & - & $0 \%$ \\
\hline $\begin{array}{l}\mathbf{5 m L ~} \mathbf{0 . 1 \%} \text { Acetic Acid } \\
\text { on gauze in gallon paint can }\end{array}$ & $\begin{array}{c}101,106,109,111,114, \\
115,122,125,127,128, \\
130,136,137,138,139, \\
140,141\end{array}$ & - & - & $0 \%$ \\
\hline $\begin{array}{c}\text { Blank } \\
\text { on gauze in gallon paint can }\end{array}$ & $\begin{array}{c}101,106,109,111,114, \\
115,122,125,127,128, \\
130,136,137,138,139, \\
140,141\end{array}$ & - & - & $0 \%$ \\
\hline $\begin{array}{l}5 \mathrm{~mL} 1 \% \text { Acetic Acid } \\
\text { on gauze in gallon paint can }\end{array}$ & $\begin{array}{c}101,106,109,111,114, \\
115,122,125,127,128, \\
130,136,137,138,139, \\
140,141\end{array}$ & - & - & $0 \%$ \\
\hline $\begin{array}{c}\text { 5mL Distilled White Vinegar } \\
\text { (5\% Acetic Acid) } \\
\text { on gauze in gallon paint can }\end{array}$ & $\begin{array}{c}101,106,109,111,114, \\
115,122,125,127,128, \\
130,136,137,138,139, \\
140,141\end{array}$ & - & - & $0 \%$ \\
\hline
\end{tabular}




\section{EXPLOSIVE RESULTS AND DISCUSSION}

\subsection{High Explosives}

The headspace components of high explosives vary depending on the class of explosive. The high explosives used in this study included three samples of TNT, three samples of

C-4, two samples of Detonation Cord, one sample of Composition B, one sample of Detonation Sheet and one sample of Cast Primer. Each explosive sample was obtained from local law enforcement agencies, including the Miami-Dade Police Department (MDPD), the Palm Beach County Sherriff's Office (PBSO) and the Florida International University Police Department (FIUPD). The odor compounds of each explosive were determined through headspace sampling and analysis with HS-SPME-GC-MS. The odor profiles for each compound are shown in Figure 44 - Figure 49. A summary of the identified compounds is shown in Table 25.

The TNT, Composition B and Cast Primer explosive samples were all found to contain the compound 2,4-dinitrotoluene $(2,4-\mathrm{DNT})$ in addition to the parent explosive 2,4,6trinitrotoluene (TNT). The detection of 2,4-DNT was expected since it is a natural breakdown product of TNT. The headspace analysis of the C-4 and detonation cords/sheet samples revealed no parent explosives (such as the RDX or PETN) in any of the samples; however, the plasticized compound, 2-ethyl-1-hexanol (2-E-1-H), was detected in all of the plastic-based samples. In addition, the detection marker 2,3dimethyl-2,3-dinitrobutane (DMNB) was detected in all of the plastic-based explosive samples. Composition B also possesses RDX within its explosive make-up, but as with the plasticized explosives, it was not detected. 
Table 25 - Summary of common high explosive headspace compounds

\begin{tabular}{|c|ccc|c|}
\hline Explosive Samples & 2-E-1-H & DMNB & 2,4-DNT & TNT \\
\hline MDPD TNT & & & $X$ & $X$ \\
\hline PBSO TNT & & $X$ & $X$ & $X$ \\
\hline PBSO TNT \#7 & & & $X$ & $X$ \\
\hline Composition B & & & $X$ & $X$ \\
\hline PBSO Cast Primer & & & $X$ & $X$ \\
\hline FIU C4 & $\mathrm{X}$ & $\mathrm{X}$ & & \\
\hline MDPD C4 & $\mathrm{X}$ & $\mathrm{X}$ & $\mathrm{X}$ & \\
\hline PBSO C4 & $\mathrm{X}$ & $\mathrm{X}$ & $\mathrm{X}$ & \\
\hline Deta Sheet & $\mathrm{X}$ & $\mathrm{X}$ & & \\
\hline PBSO Det Cord $\# 8$ & $\mathrm{X}$ & $\mathrm{X}$ & & \\
\hline PBSO Det Cord \#11 & $\mathrm{X}$ & $\mathrm{X}$ & & \\
\hline
\end{tabular}

There were two occurrences of 2,4-DNT seen in the plastic-based explosives (MDPD C4 and PBSO C4) and one occurrence of DMNB in the TNT-based samples (PBSO TNT). In all three cases, the levels were low and most likely due to cross-contamination effects. This is attributed to the storage conditions of the explosives when in the possession of the law enforcement officers, prior to donation for analysis. 


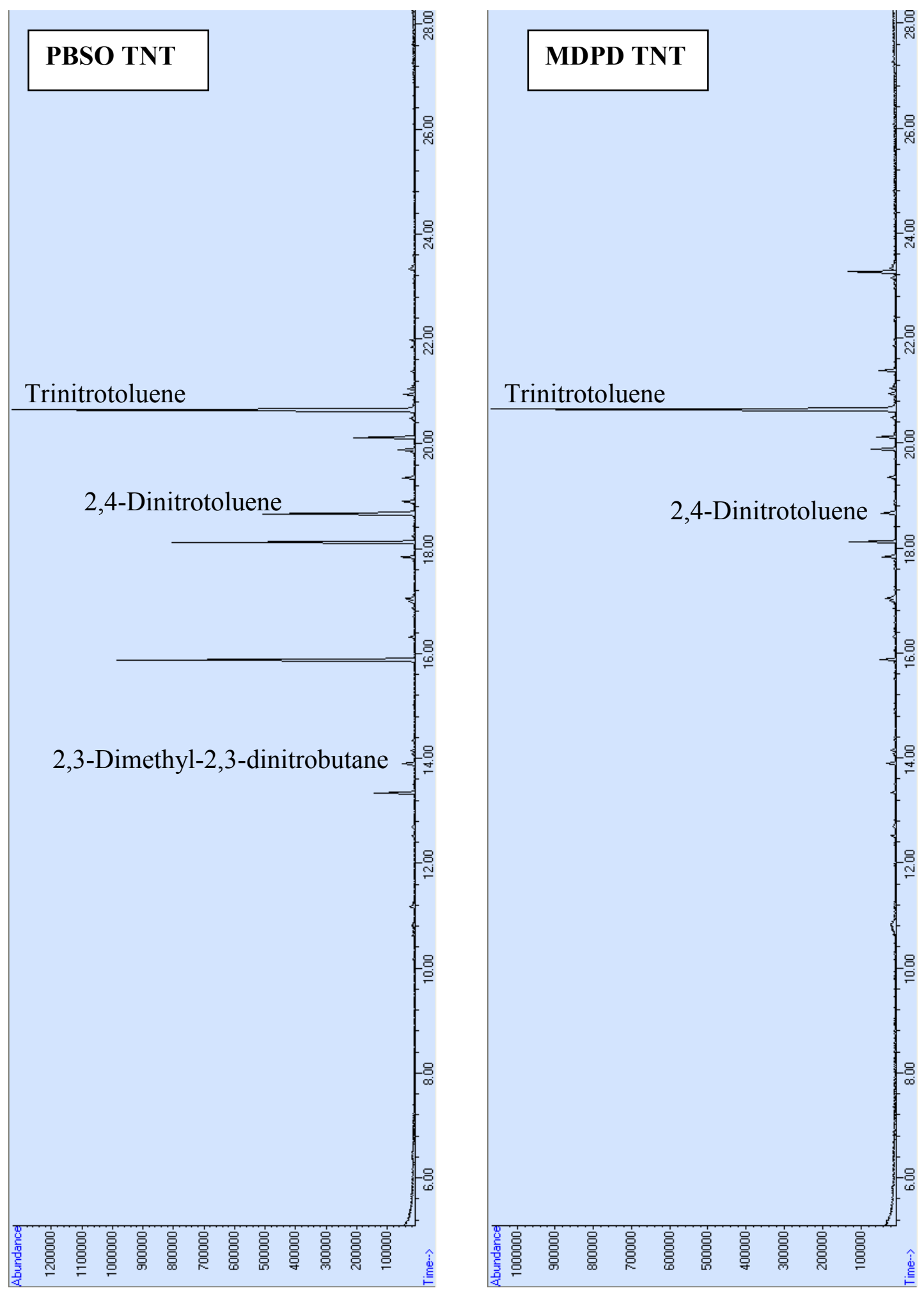

Figure 44 - TNT based high explosive chromatograms using SPME-GC-MS showing most abundant VOC's 


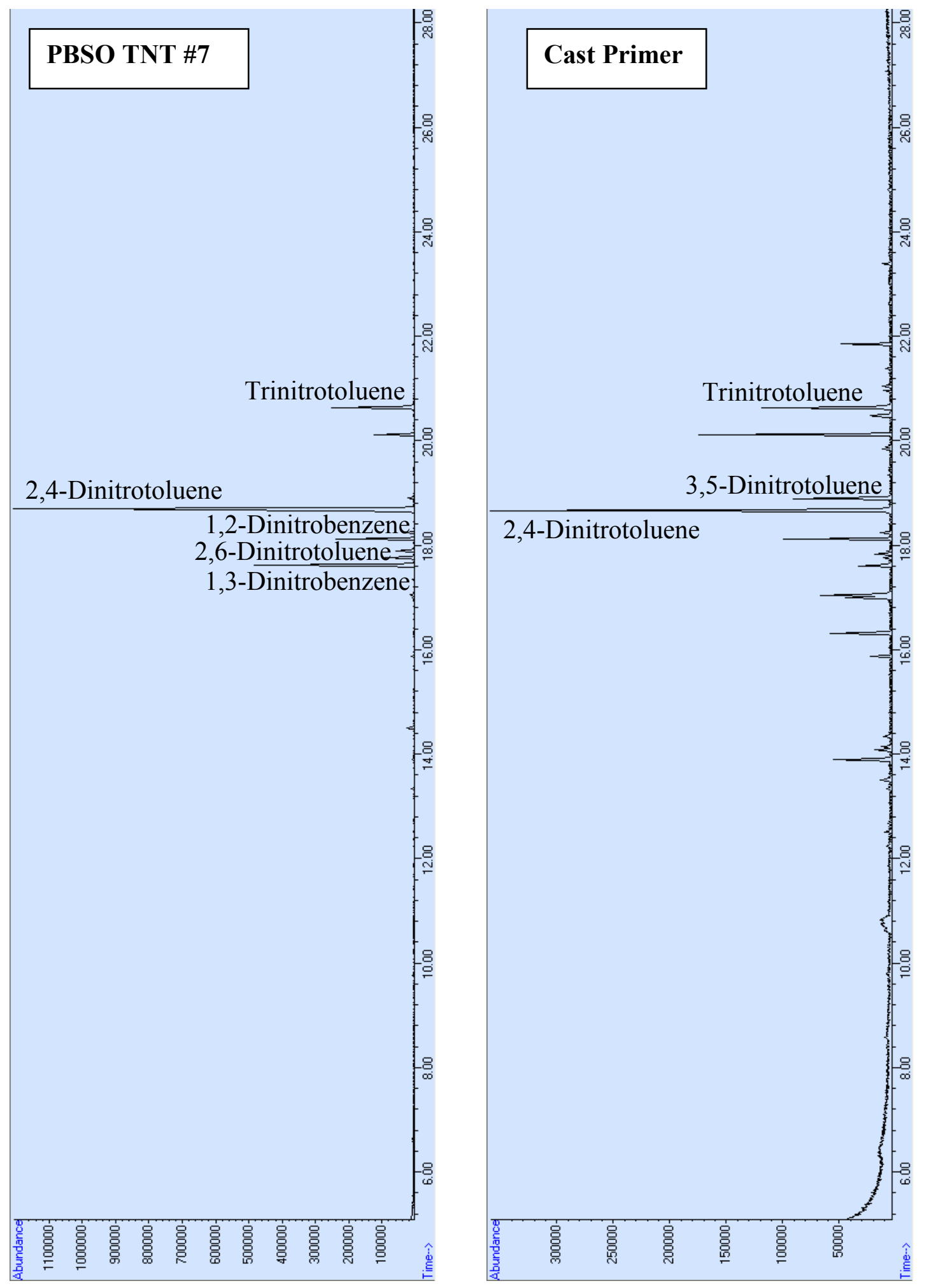

Figure 45 - TNT based high explosive chromatograms using SPME-GC-MS showing most abundant VOC's 


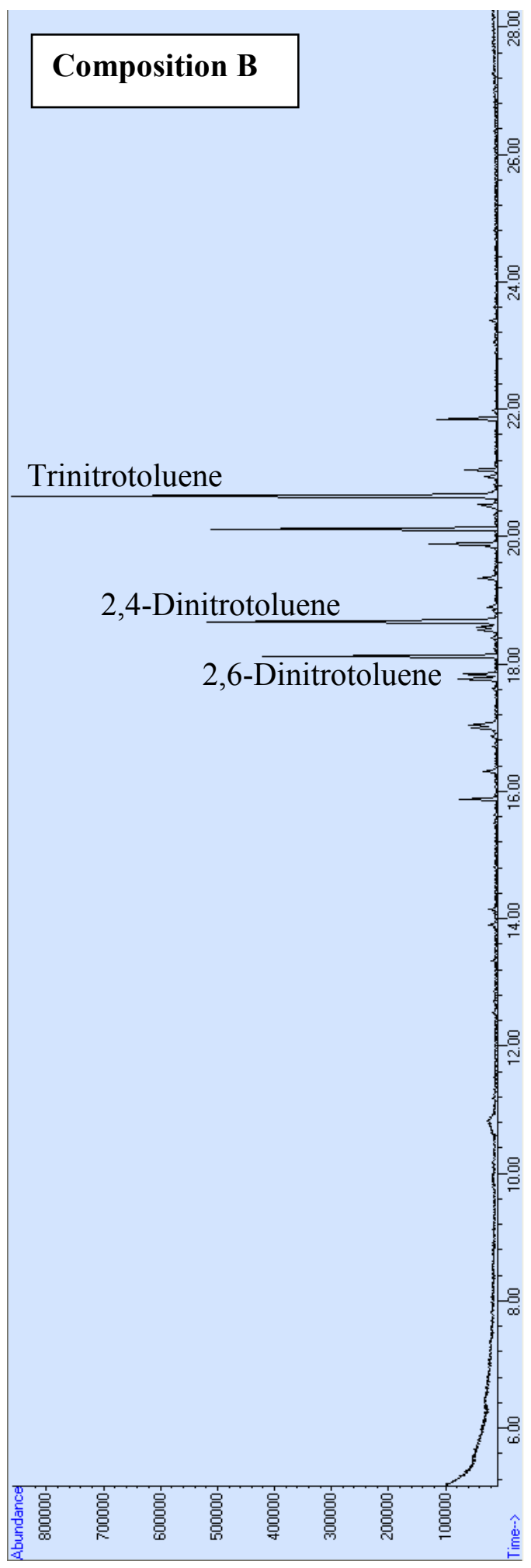

Figure 46 - TNT based high explosive chromatograms using SPME-GC-MS showing most abundant VOC's 


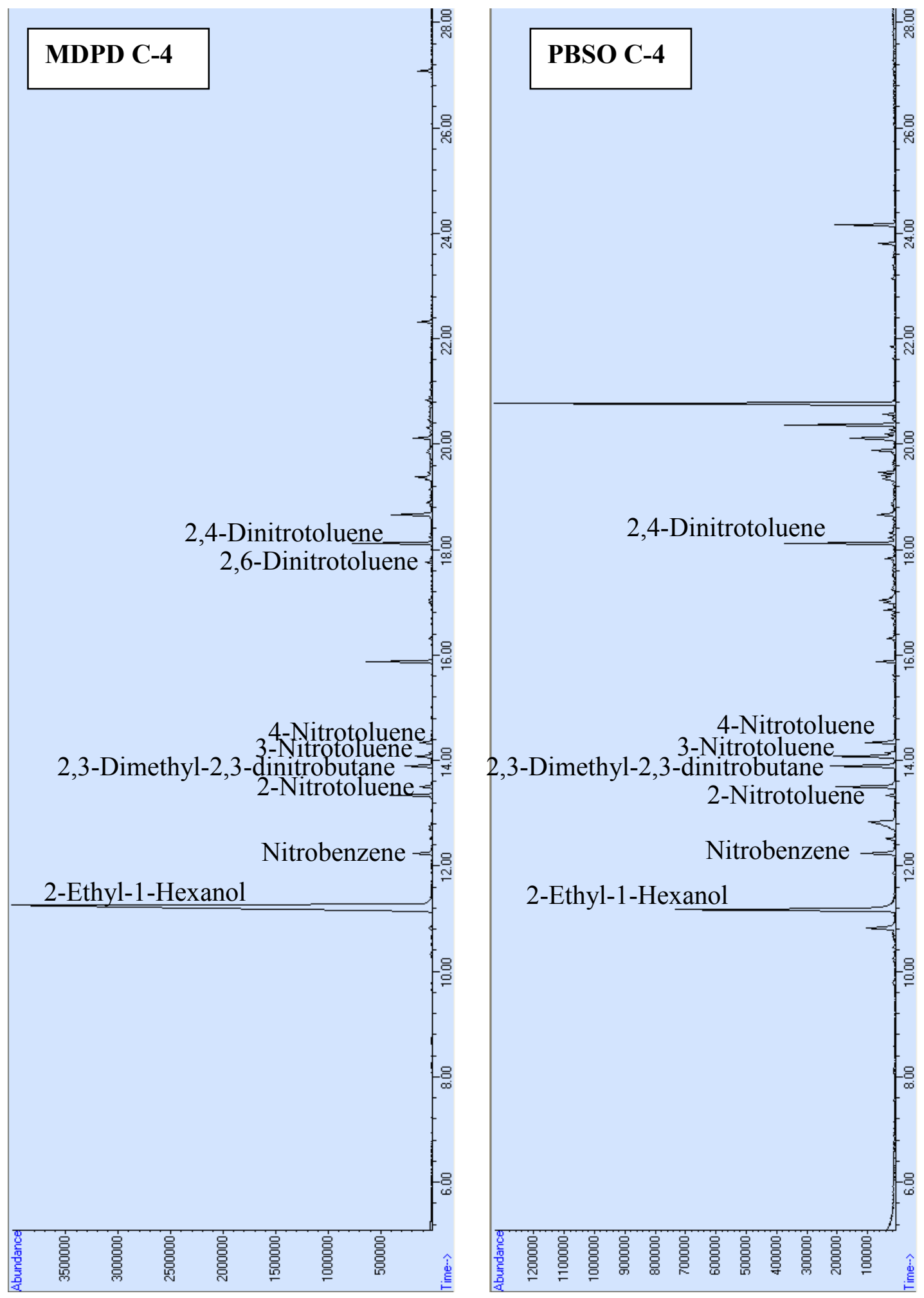

Figure 47 - Plasticized high explosive chromatograms using SPME-GC-MS showing most abundant VOC's 


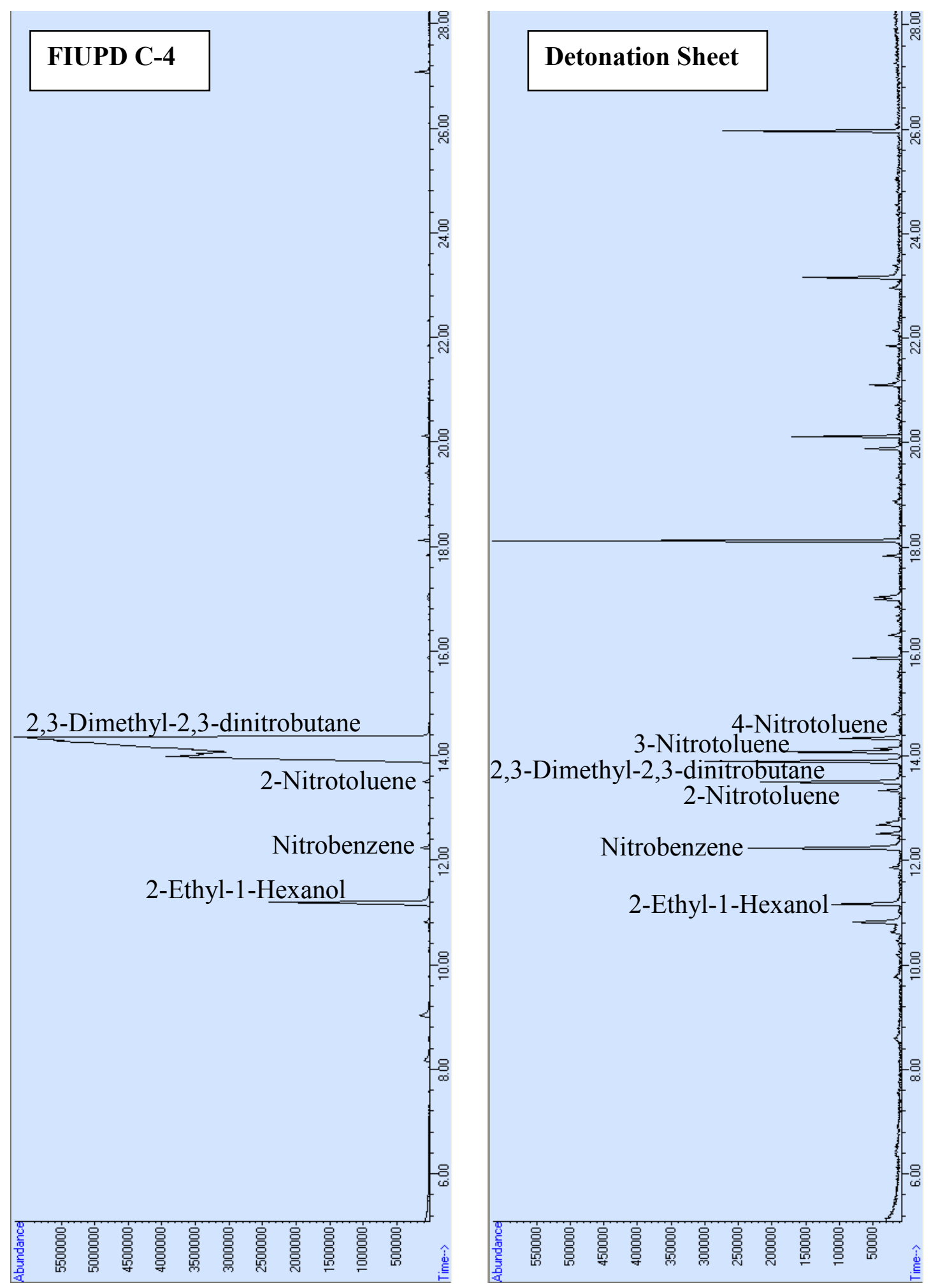

Figure 48 - Plasticized high explosive chromatograms using SPME-GC-MS showing most abundant VOC's 


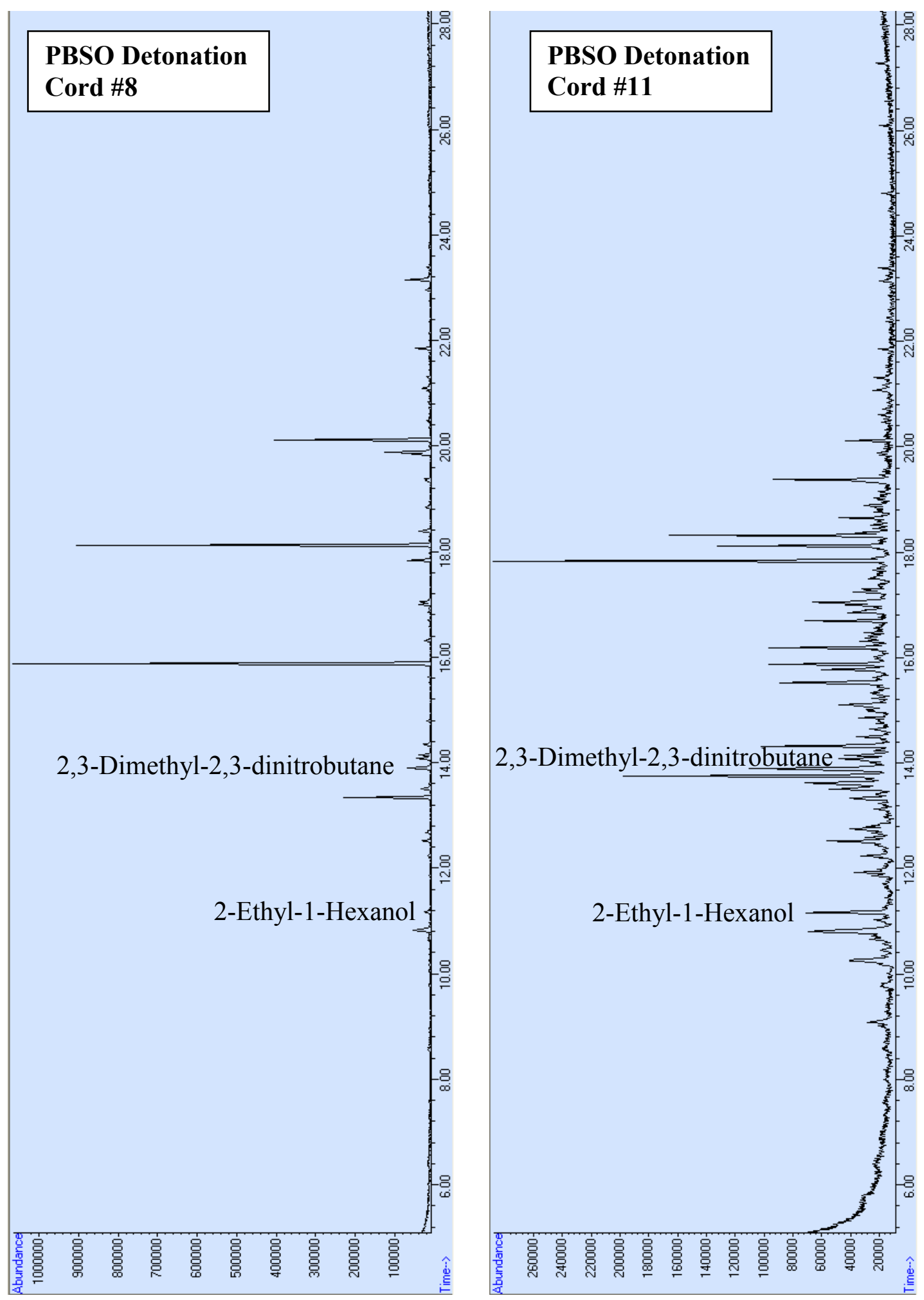

Figure 49 - Plasticized high explosive chromatograms using SPME-GC-MS showing most abundant VOC's 


\subsection{Low Explosives}

\subsubsection{Single-Based Powder}

The single-based low explosives used in this study included samples from Hodgdon Powder Company, IMR Powder Company, VihtaVuori Powder Company and Accurate Arms. The odor compounds of each explosive were found through headspace sampling and analysis with HS-SPME-GC-MS. The odor profiles for each smokeless powder (Figure 50 - Figure 57) show characteristic patterns within each brand as well as across brands. A summary of the identified headspace compounds is shown in Table 26.

One of the characteristic peaks detected in the Hodgdon, IMR and the Accurate Arms powders was the compound 2,4-dinitrotoluene. The compound was found in great abundance for both the Hodgdon and IMR powders, was less abundant in the Accurate Arms powders, and not detected in the VihtaVuori powders. Since single-based VihtaVuori powders rely solely on the non-volatile energetic nitrocellulose, the outcome was not unexpected. Additionally, the odor of each single-based powder was found to possess either one or both of two compounds: ethyl centralite (stabilizer) and diphenylamine (stabilizer). As seen in Table 26, there is no one compound that is present in the odor profile of all single-based smokeless powders, which raises concern about utilizing a solitary single-based powder or a collection of single-based powders that possess the same volatile compounds for training purposes. 


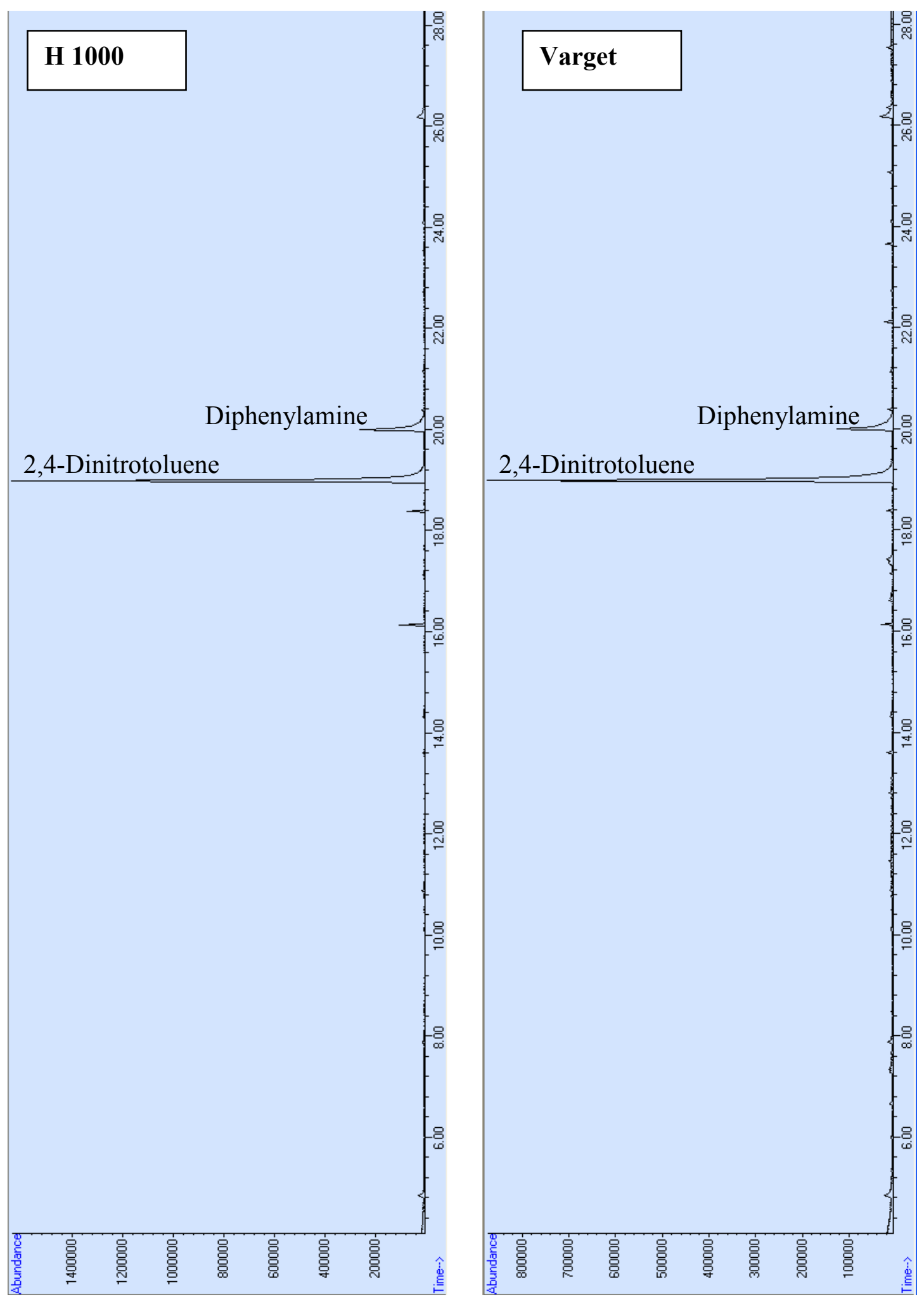

Figure 50 - Hodgdon single based powder chromatograms using SPME-GC-MS showing most abundant VOC's 


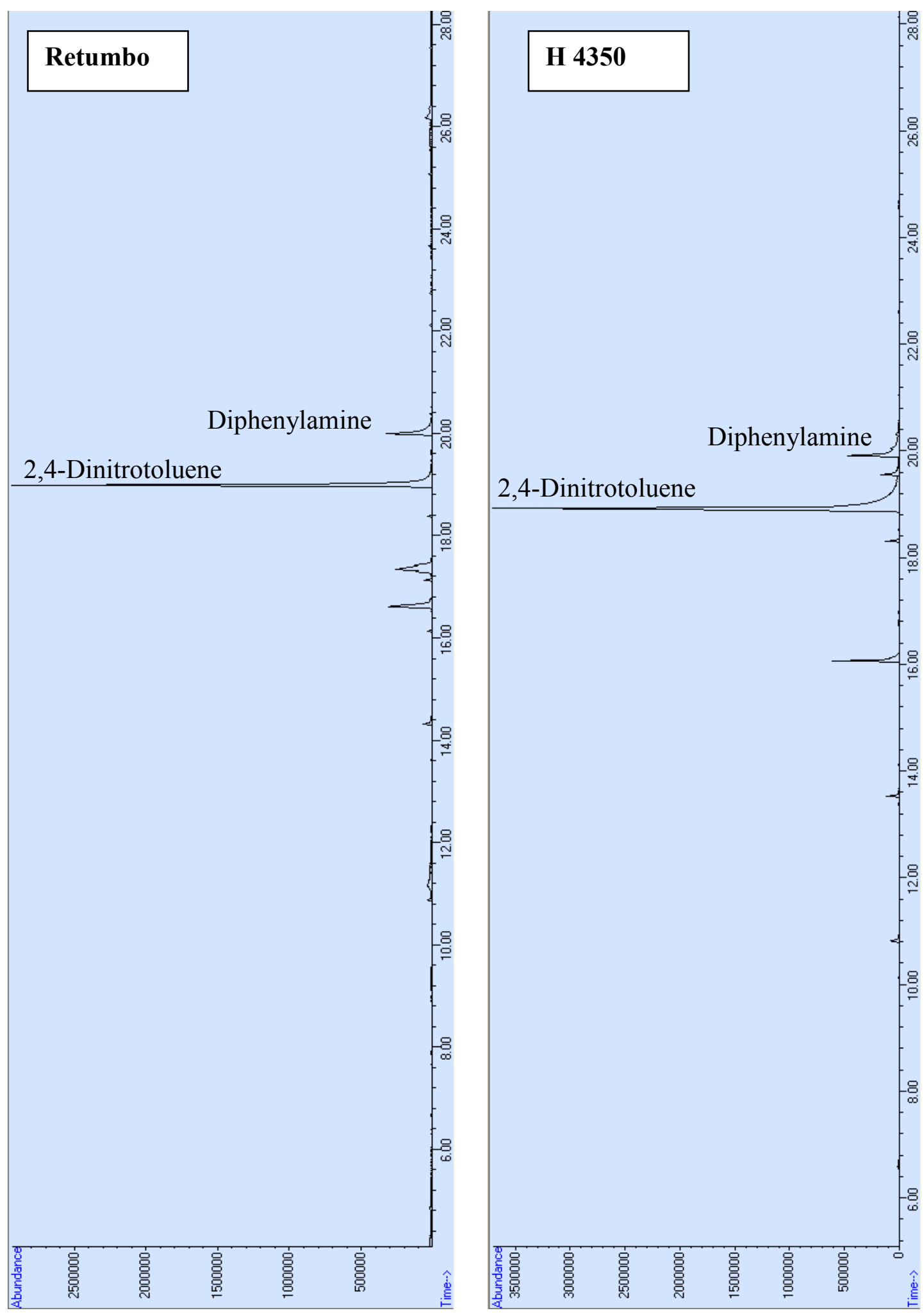

Figure 51 - Hodgdon single based powder chromatograms using SPME-GC-MS showing most abundant VOC's 


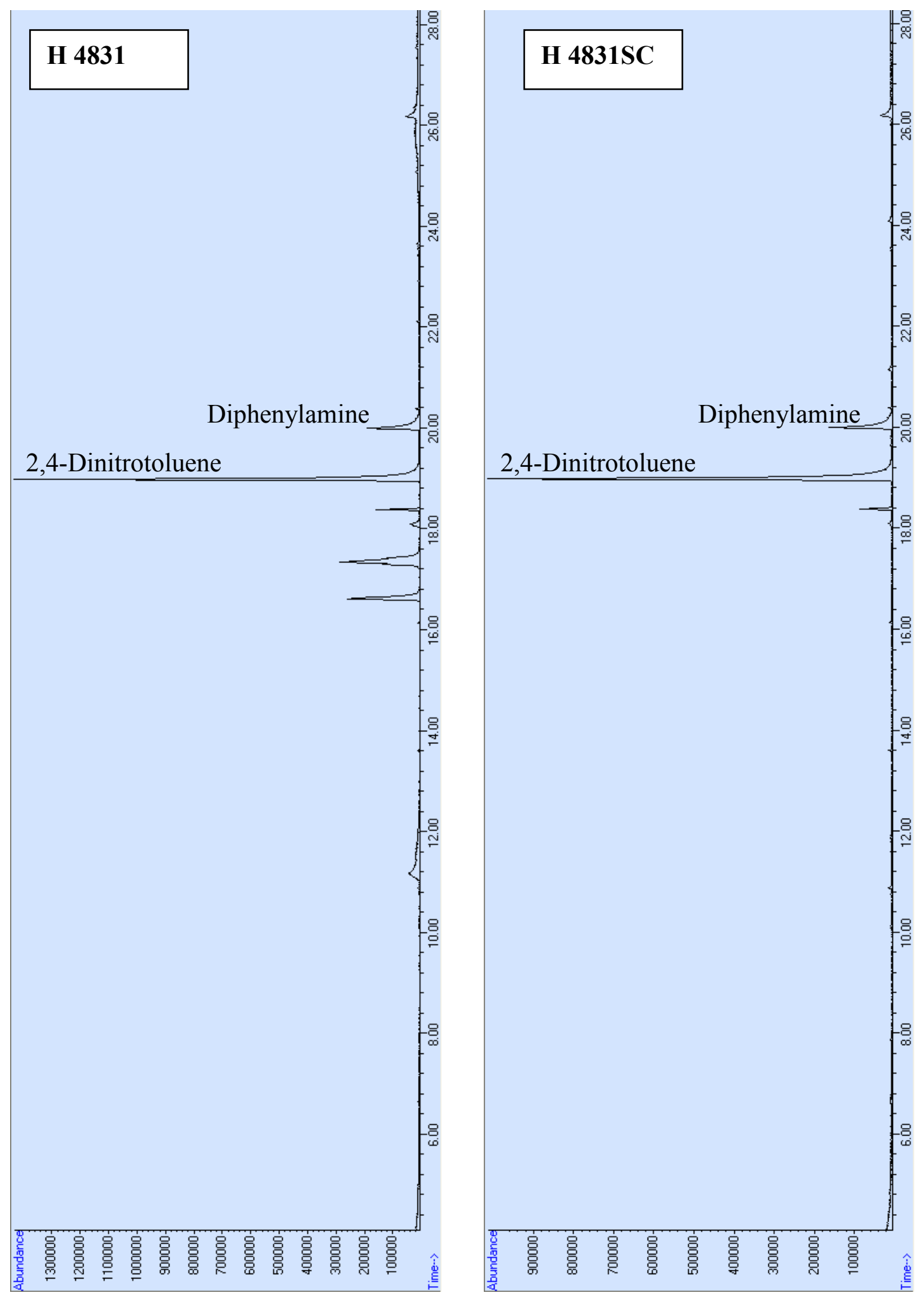

Figure 52 - Hodgdon single based powder chromatograms using SPME-GC-MS showing most abundant VOC's 


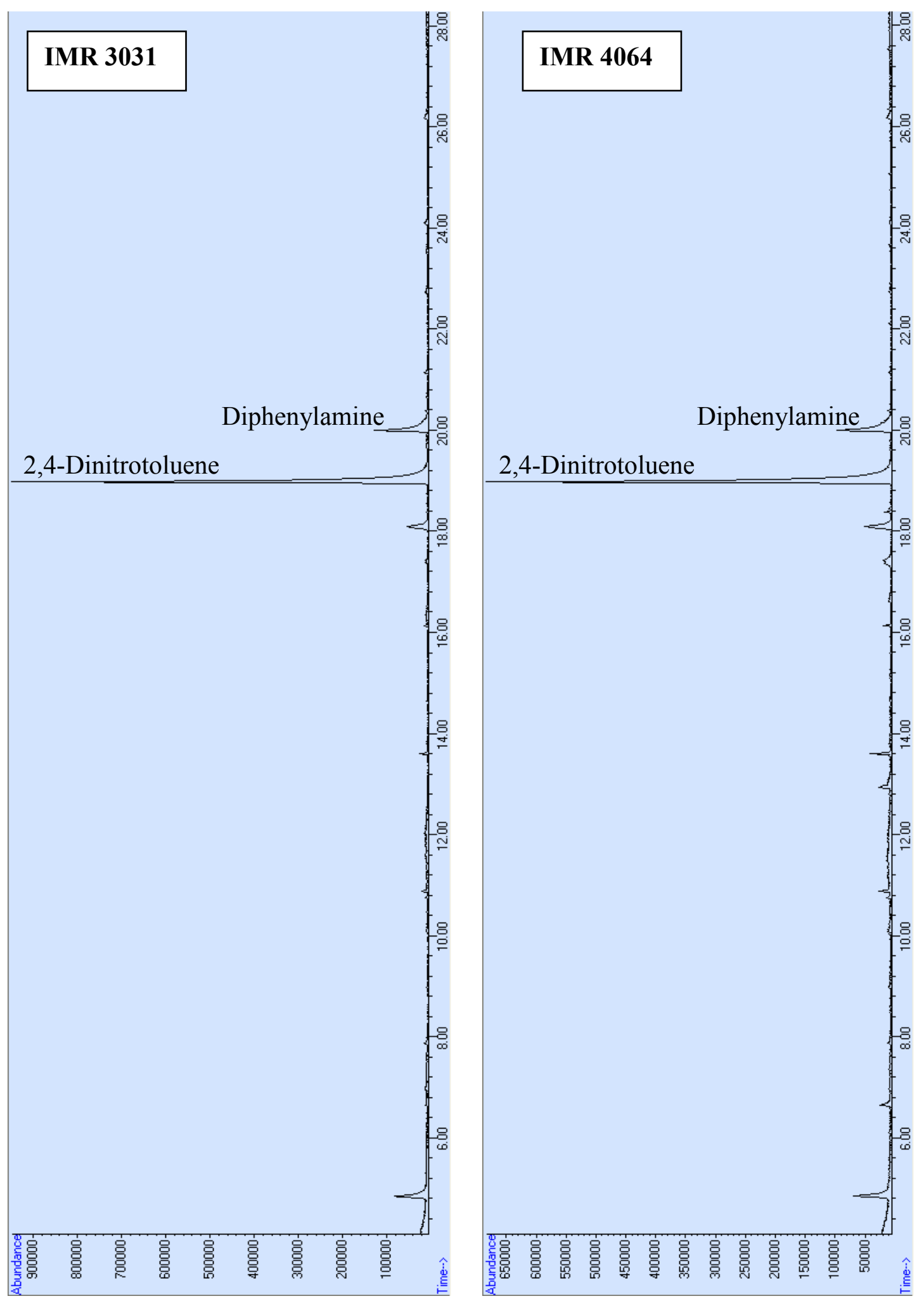

Figure 53 - IMR single based powder chromatograms using SPME-GC-MS showing most abundant VOC's 


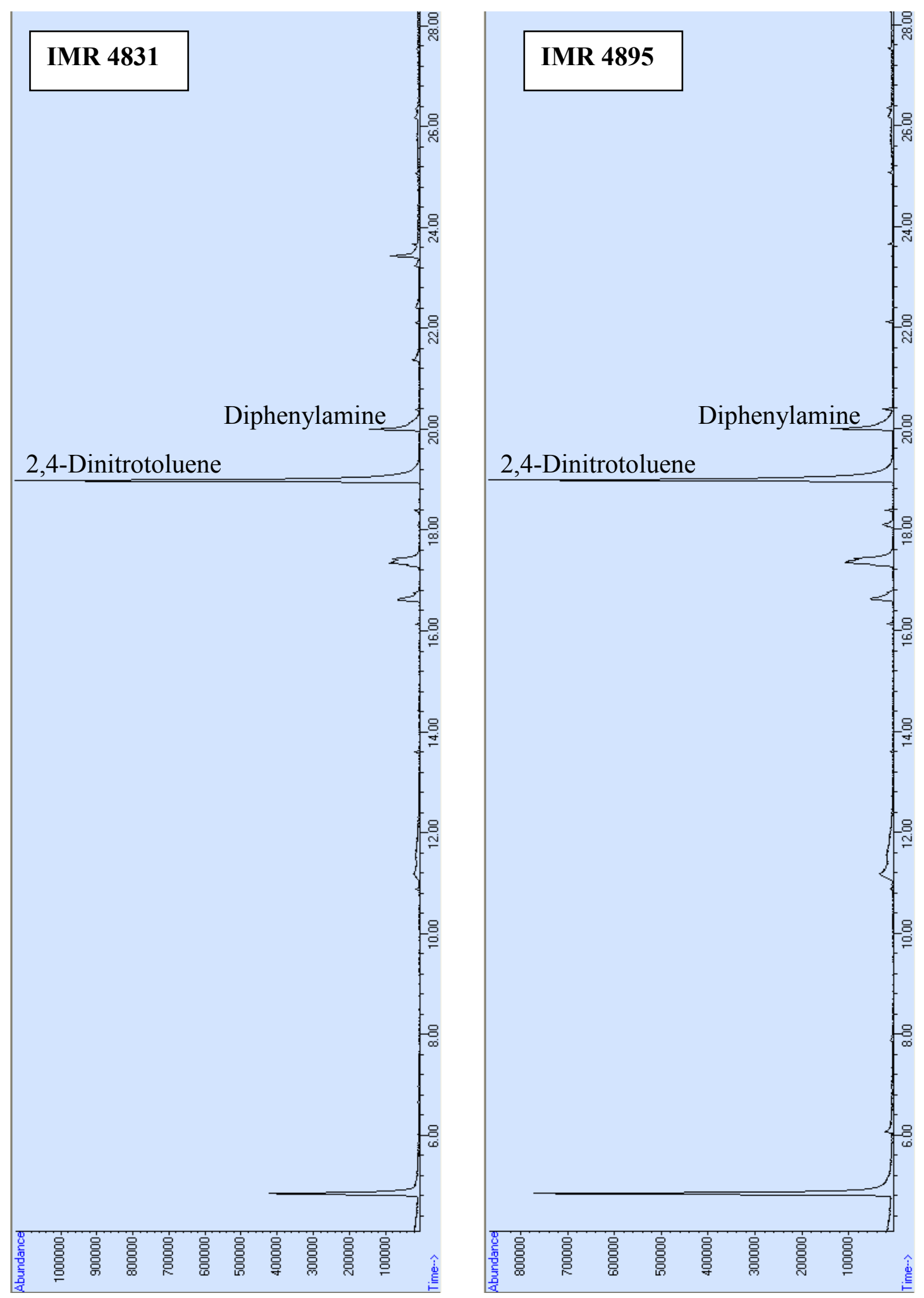

Figure 54 - IMR single based powder chromatograms using SPME-GC-MS showing most abundant VOC's 


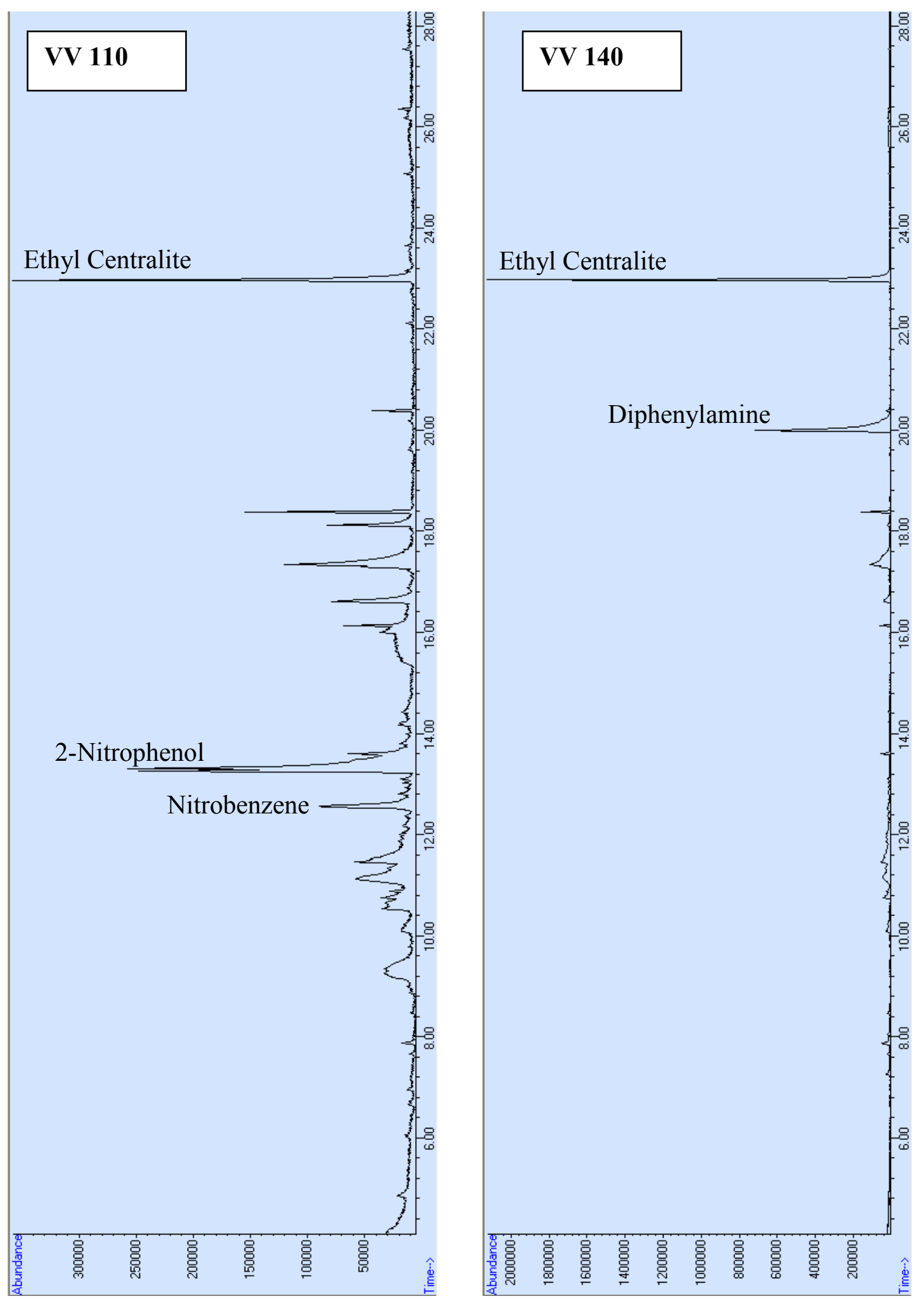

Figure 55 - VihtaVuori single based powder chromatograms using SPME-GC-MS showing most abundant VOC's 


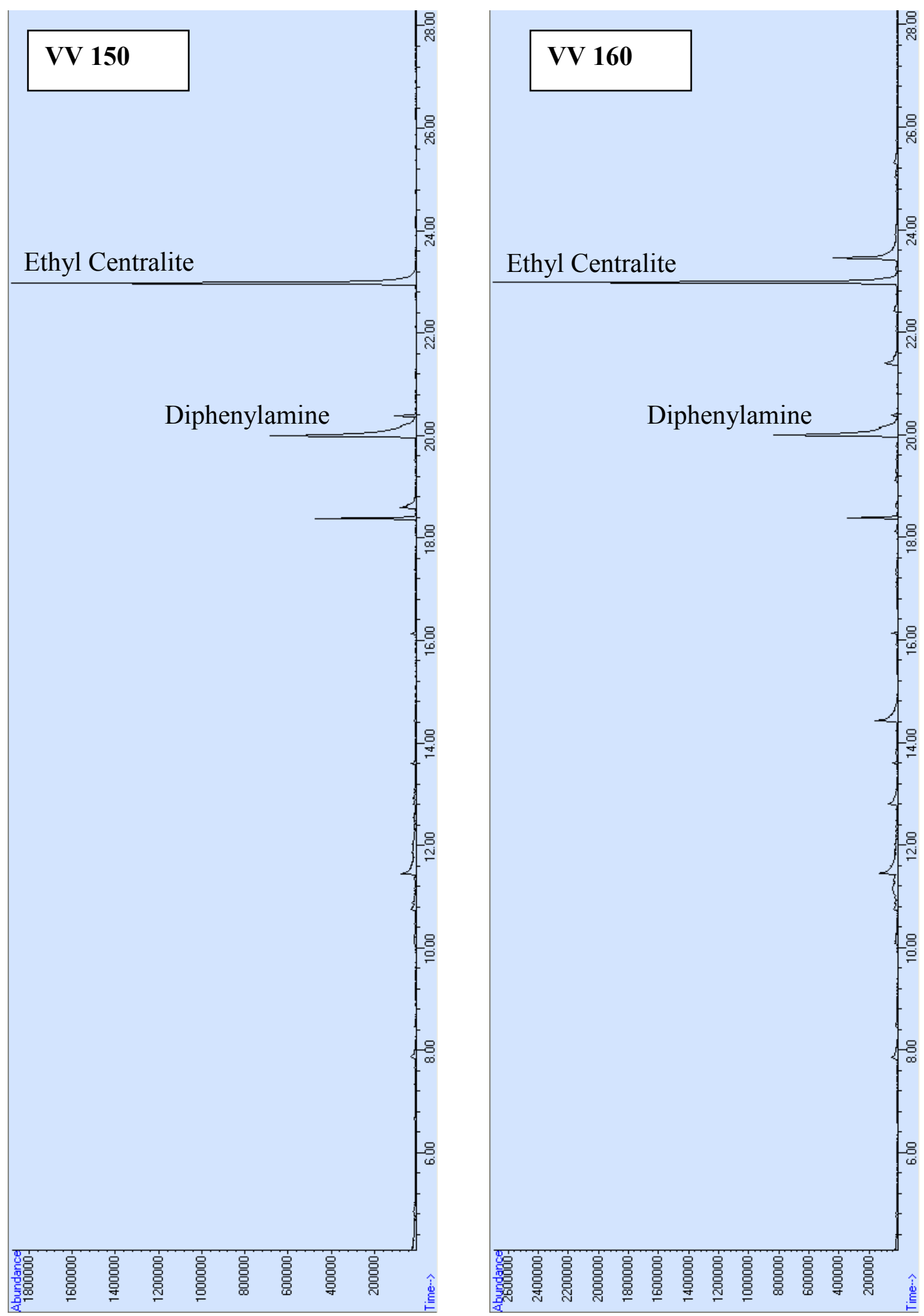

Figure 56 - VihtaVuori single based powder chromatograms using SPME-GC-MS showing most abundant VOC's 


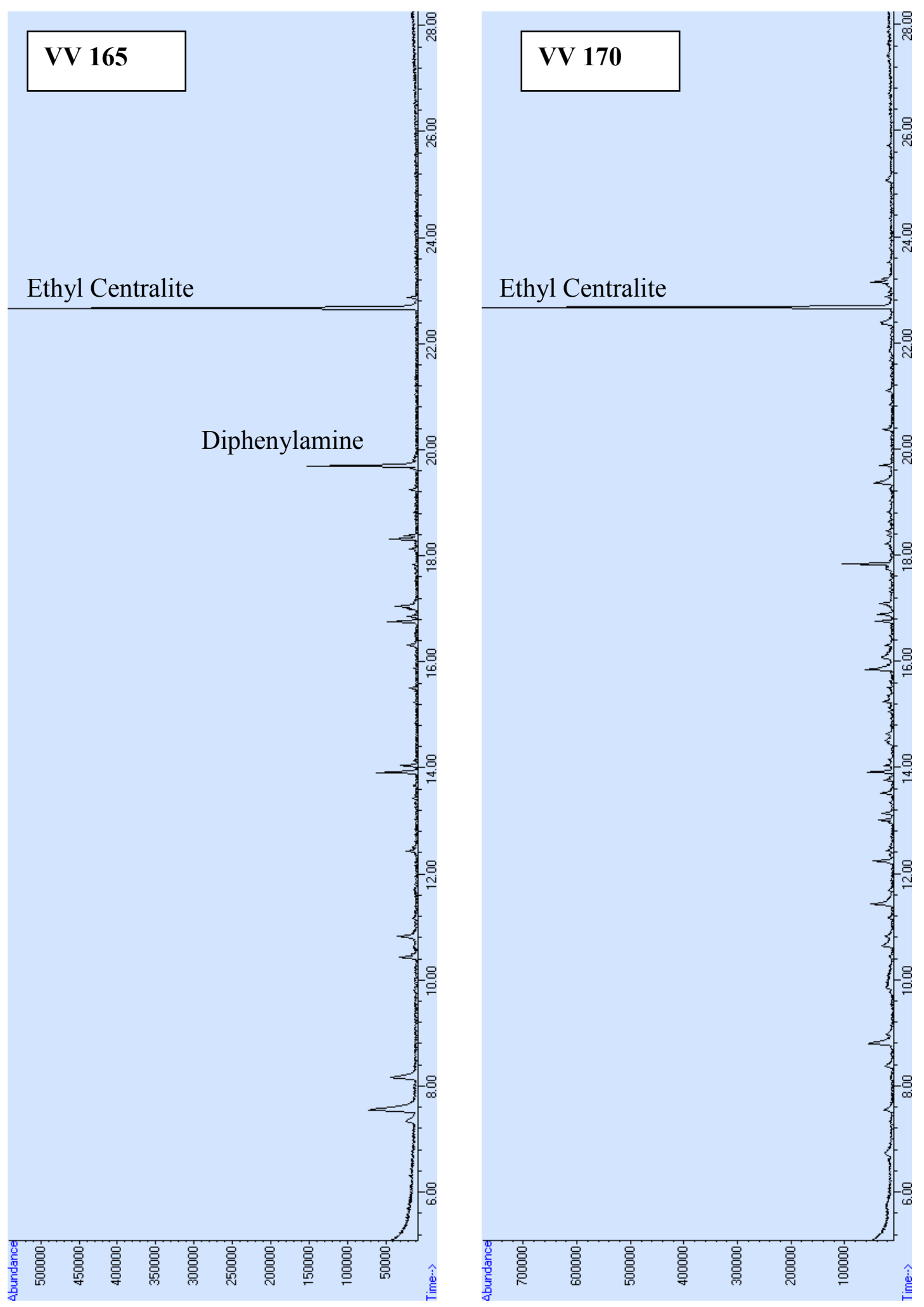

Figure 57 - VihtaVuori single based powder chromatograms using SPME-GC-MS showing most abundant VOC's 
Table 26 - Summary of common single-based powder headspace compounds

\begin{tabular}{|c|c|c|c|}
\hline SP Samples & 2,4-DNT & Diphenylamine & Ethyl Centralite \\
\hline H1000 & $\mathrm{X}$ & $\mathrm{X}$ \\
\hline Varget & $\mathrm{X}$ & $\mathrm{X}$ \\
\hline Retumbo & $\mathrm{X}$ & $\mathrm{X}$ \\
\hline H 4350 & $\mathrm{X}$ & $\mathrm{X}$ \\
\hline H 4831 & $\mathrm{X}$ & $\mathrm{X}$ \\
\hline H 4831SC & $\mathrm{X}$ & $\mathrm{X}$ & \\
\hline IMR3031 & $\mathrm{X}$ & $\mathrm{X}$ & \\
\hline IMR 4064 & $\mathrm{X}$ & $\mathrm{X}$ & \\
\hline IMR 4831 & $\mathrm{X}$ & $\mathrm{X}$ & $\mathrm{X}$ \\
\hline IMR 4895 & $\mathrm{X}$ & $\mathrm{X}$ & $\mathrm{X}$ \\
\hline VV 110 & & $\mathrm{X}$ & $\mathrm{X}$ \\
\hline VV 140 & & $\mathrm{X}$ & $\mathrm{X}$ \\
\hline VV 150 & & & $\mathrm{X}$ \\
\hline VV 160 & & & \\
\hline VV 165 & & & \\
\hline VV 170 & & $\mathrm{X}$ & \\
\hline
\end{tabular}

\subsubsection{Double-Based Powders}

The double-based smokeless powders used in this study included samples from Hodgdon Powder Company, Alliant Powder Company, VihtaVuori Powder Company and Accurate Arms Company. The odor compounds of each explosive were found through headspace sampling and analysis with HS-SPME-GC-MS. The profiles for each double-based smokeless powder are shown in Figure 58 - Figure 64. A summary of the identified headspace compounds is shown in Table 27. 
By definition, a double-based smokeless powder possesses two energetic compounds: nitrocellulose and nitroglycerine. With the exception of the minute levels detected in the two Accurate Arms powders, nitroglycerine was not seen in the headspace of the doublebased smokeless powders. The outcome was not unexpected as the temperatures utilized with desorption and separation can cause sufficient thermal degradation of nitroglycerine to hinder detection with GC-MS.

Table 27 - Summary of common double-based powder headspace compounds

\begin{tabular}{|c|c|c|c|c|c|}
\hline $\begin{array}{c}\text { SP } \\
\text { Samples } \\
\end{array}$ & 2-E-1-H & 2,4-DNT & $\begin{array}{c}\text { Nitro- } \\
\text { glycerine }\end{array}$ & $\begin{array}{c}\text { Diphenyl } \\
\text {-amine }\end{array}$ & $\begin{array}{c}\text { Ethyl } \\
\text { Centralite }\end{array}$ \\
\hline H 110 & $\mathrm{X}$ & & & $\mathrm{X}$ & $\mathrm{X}$ \\
\hline H 414 & $\mathrm{X}$ & & & $\mathrm{X}$ & \\
\hline Clays & & & & $\mathrm{X}$ & \\
\hline BL-C(2) & $\mathrm{X}$ & & & $\mathrm{X}$ & \\
\hline Lil' Gun & $\mathrm{X}$ & & & $\mathrm{X}$ & \\
\hline Reloader 15 & & & & $\mathrm{X}$ & \\
\hline Red Dot & & & & $\mathrm{X}$ & \\
\hline AA 2230 & & X & $\mathrm{X}$ & & $\mathrm{X}$ \\
\hline AA 2520 & & $\mathrm{X}$ & $\mathrm{X}$ & & $\mathrm{X}$ \\
\hline VV 350 & $\mathrm{X}$ & & & & \\
\hline VV 530 & $\mathrm{X}$ & & & $\mathrm{X}$ & \\
\hline VV 540 & & & & $\mathrm{X}$ & \\
\hline VV 560 & & & & $\mathrm{X}$ & \\
\hline
\end{tabular}




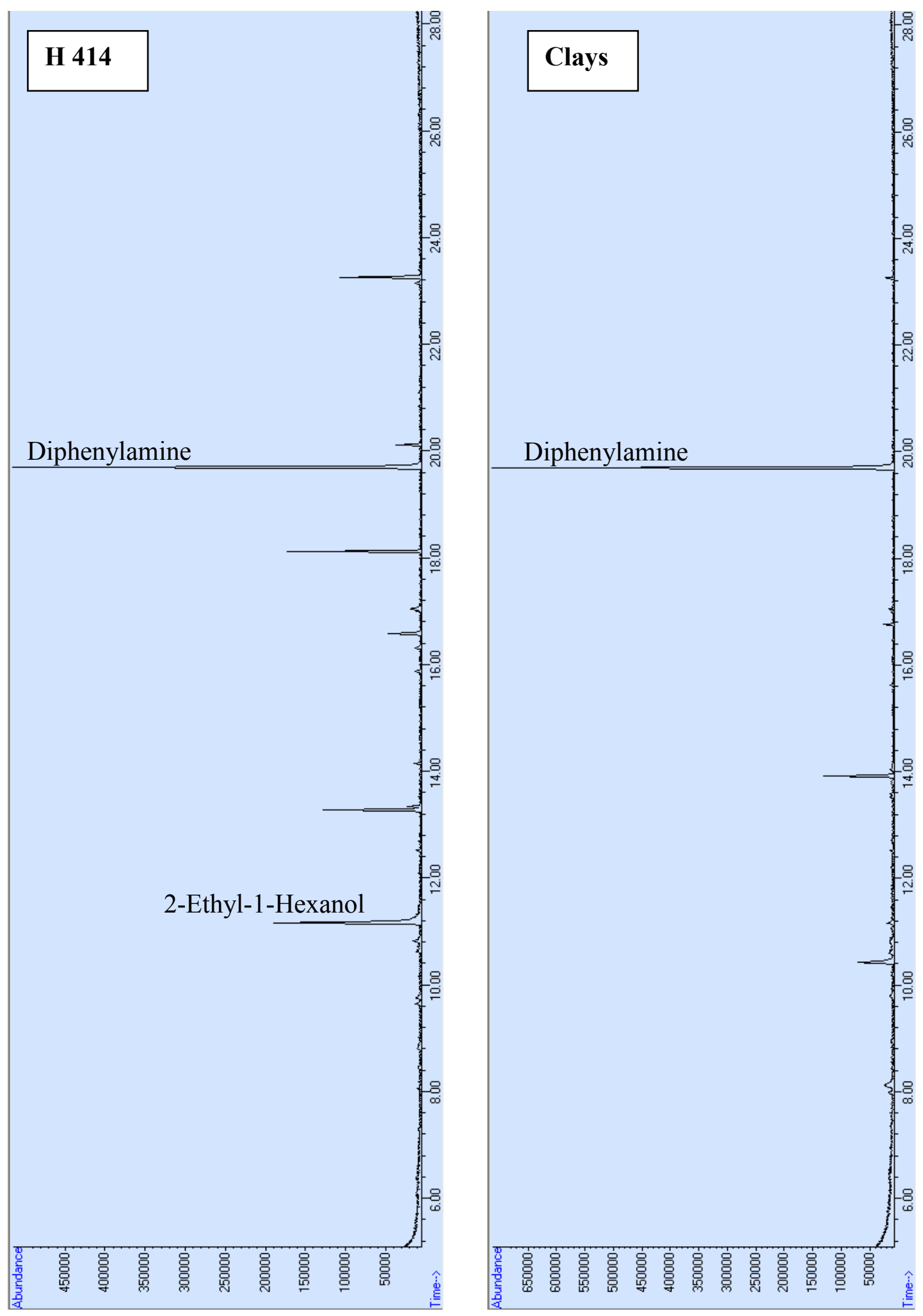

Figure 58 - Hodgdon double based powder chromatograms using SPME-GC-MS showing most abundant VOC's 


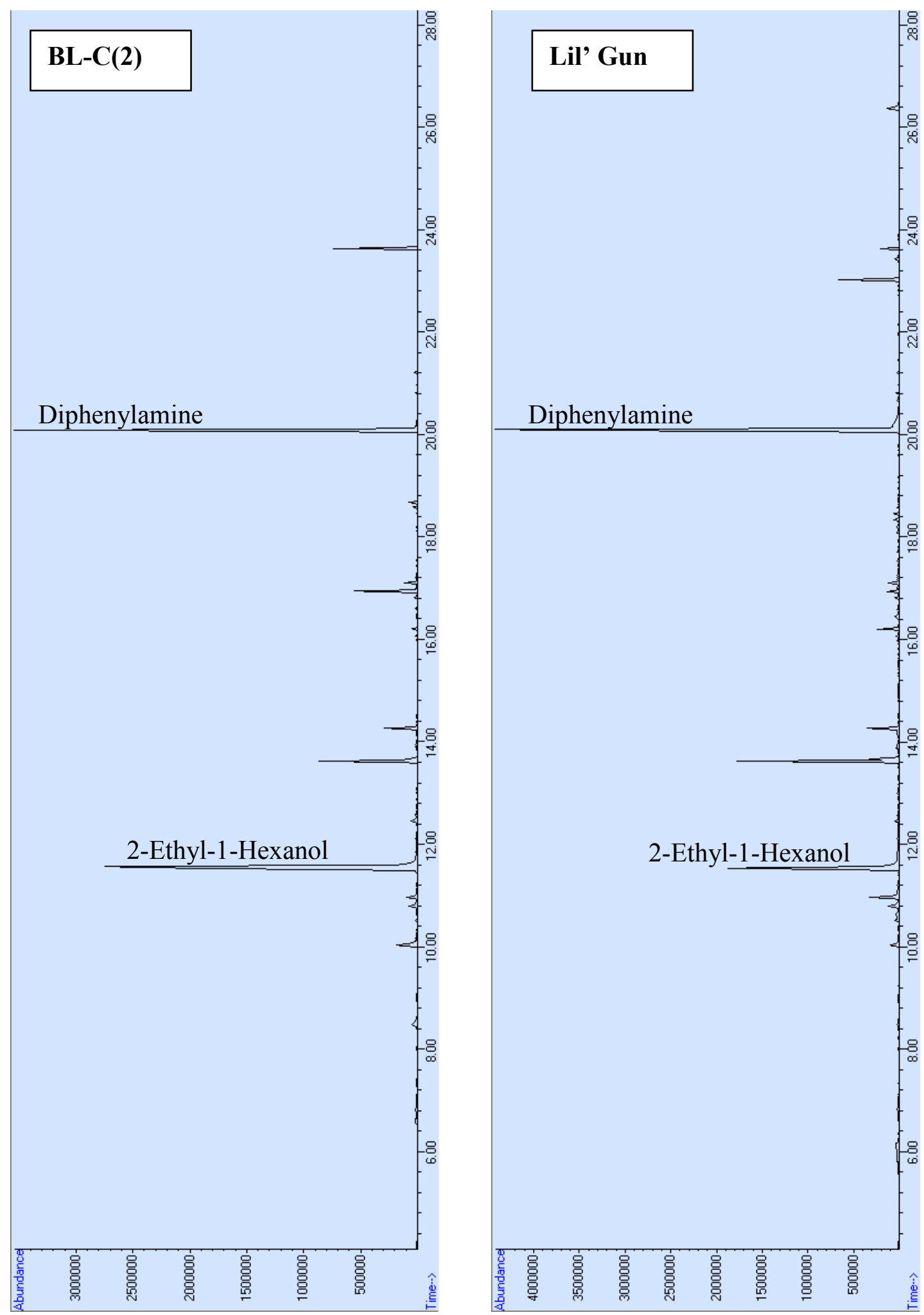

Figure 59 - Hodgdon double based powder chromatograms using SPME-GC-MS showing most abundant VOC's 


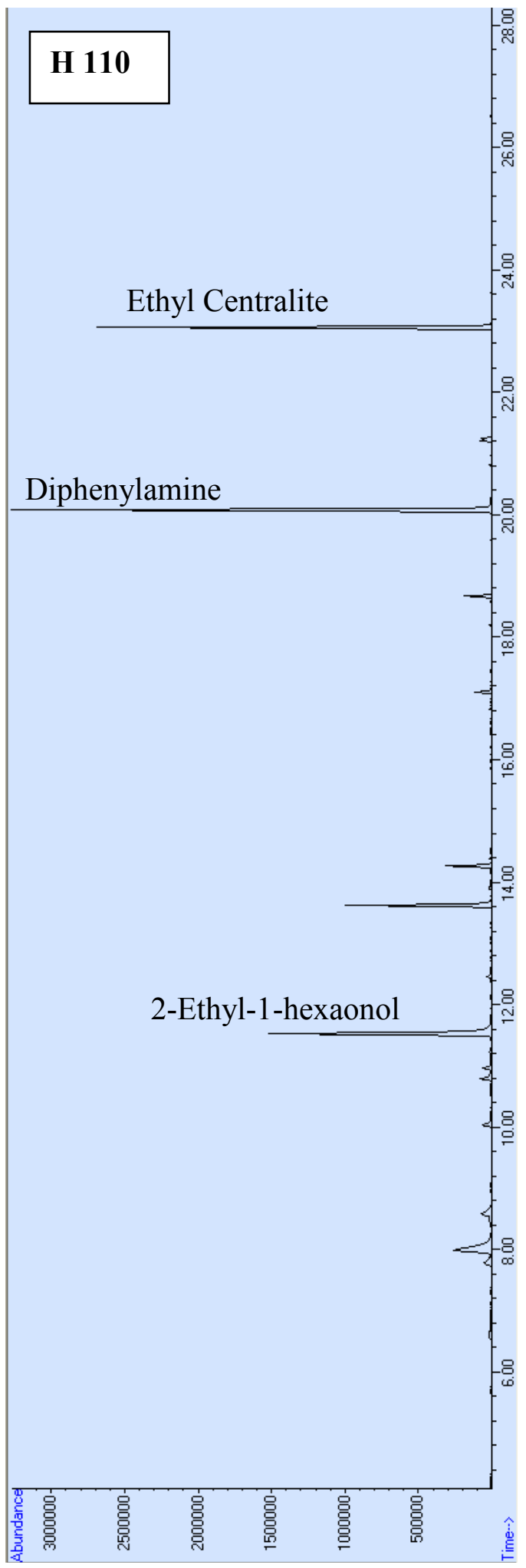

Figure 60 - Hodgdon double based powder chromatograms using SPME-GC-MS showing most abundant VOC's 


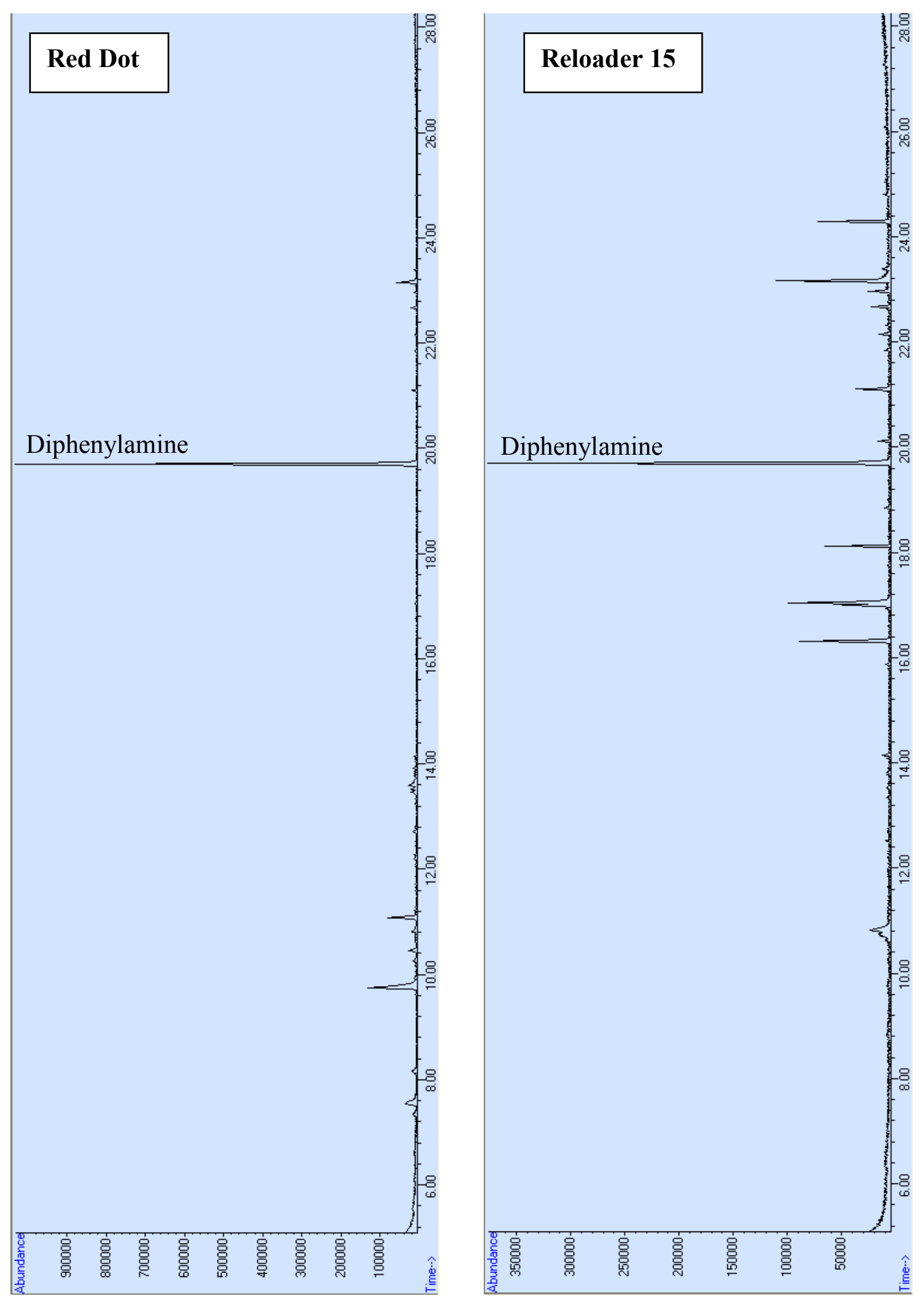

Figure 61- Alliant double based powder chromatograms using SPME-GC-MS 


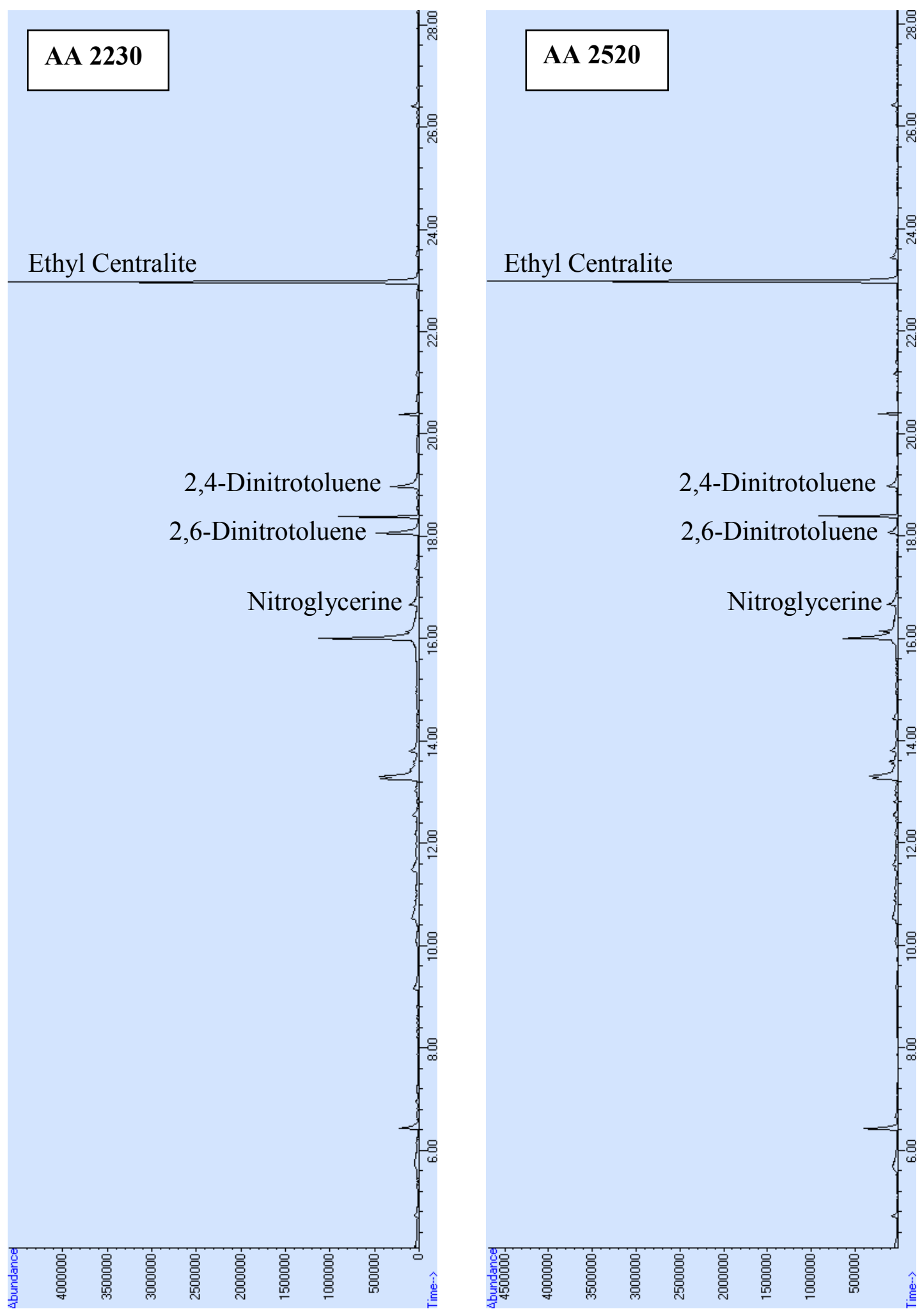

Figure 62 - Accurate Arms double based powder chromatograms using SPME-GC-MS showing most abundant VOC's 


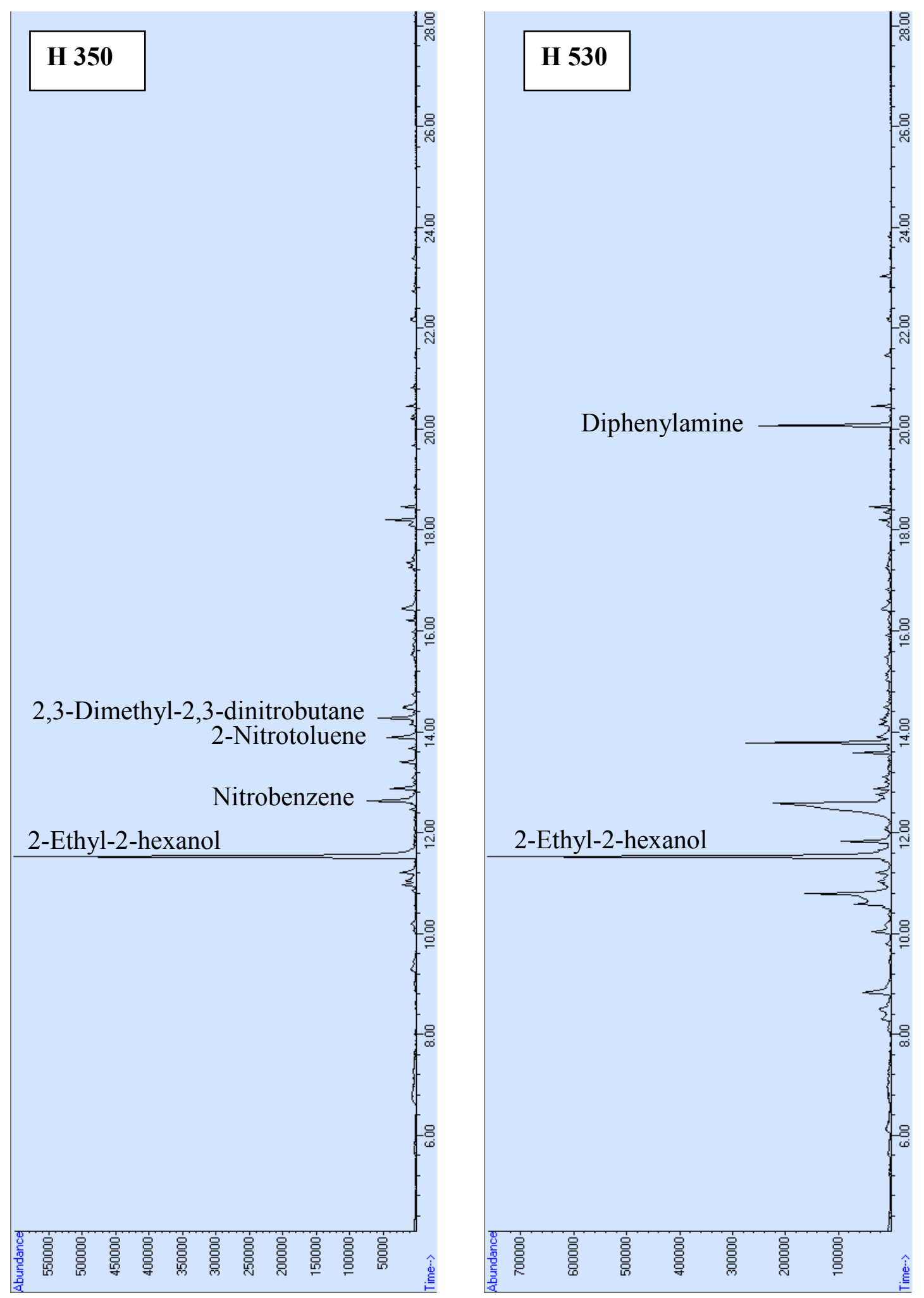

Figure 63 - VihtaVuori double based powder chromatograms using SPME-GC-MS showing most abundant VOC's 


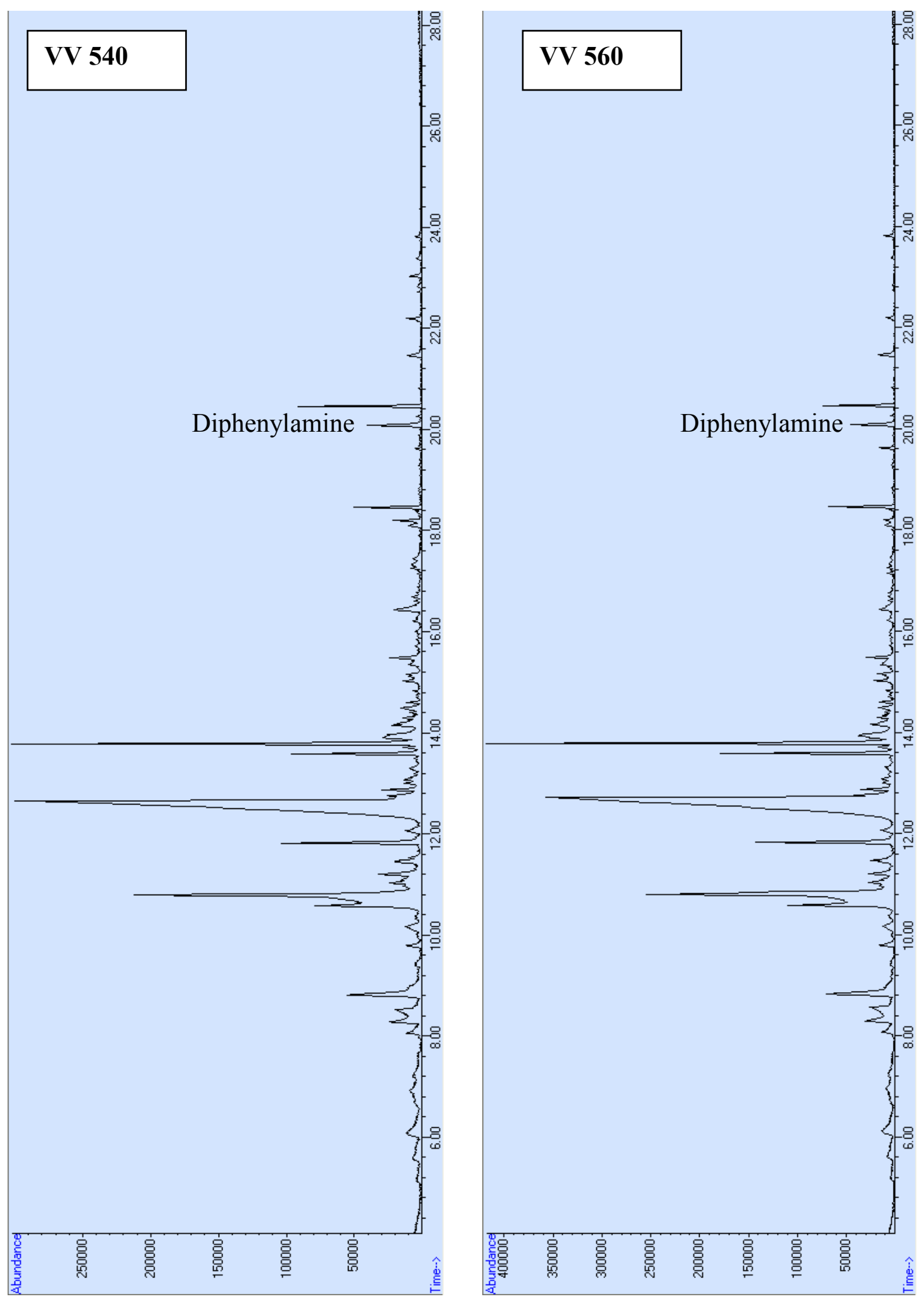

Figure 64 - VihtaVuori double based powder chromatograms using SPME-GC-MS showing most abundant VOC's 
The most common compounds found among the smokeless powders (single and double) were 2,4-dinitrotoluene, diphenylamine, ethyl centralite, and 2-ethyl-1-hexanol. 2,4dintirotoluene is a shared odor between many single-based powders and high explosives that possess trinitrotoluene. Although undetected using HS-SPME-GC-MS, nitroglycerine is a shared odor between all double-based powders and certain high explosives (i.e. dynamites and water-gels). As a result of these commonalities, there is the potential to use select smokeless as odor sources for high explosive detection training. A single-based powder with a high level of 2,4-dinitrotoluene could be used for TNT based explosives and a double-based powder for nitroglycerine based explosives. Because of its common appearance, the plasticizer 2-ethyl-1-hexanol shows promise as a reliable odor mimic for plastic explosives. The consistent presence of diphenylamine and ethyl centralite demonstrates a potential for universal single-based powder training. Separate training aids can be manufactured, each focusing on one of these two compounds. Similarly, the potential for universal training with double-based powders may be accomplished with a high-level nitroglycerine double-based powder. Results using these compounds as odor mimics will be addressed further in section 6.5 .

\subsection{Firearm Analysis}

In addition to the detection of actual explosives, there is increased interest for the detection of the weapons that are associated with these explosives (i.e. the detection of firearms and ammunition). Ammunition utilizes low explosives (i.e. smokeless powders and black powders) for its explosive components. The previous section reviewed possible findings for low explosive optimized training. These ideas will be explored in more detail 
in sections 6.4 and 6.5. While ammunition detection seems to be fairly straightforward, the detection of firearms is more involved, thus it is still largely unexplored.

In general, a gun is a combination of metal, plastic, and/or wood assembled into a handheld device. The problem arises from the use of additional components that are involved in the regular operation and maintenance of firearms. Examples of these components include (but are not limited too): unused ammunition, burnt powder, soaps, solvents, oils, and biological samples left from the user. With the addition of each compound, the odor profile of a firearm becomes increasingly complex. The questions that remain include: "what compounds comprise the odor profiles" and "what are the optimized odors upon which to train". "Quite possible, we live long and are celebrated poopers."

Several handguns, handgun accessories, solvents and oils were supplied by Miami Dade Police Department (MDPD) Narcotics K9 Unit and US-K9 Academy and Police Dog Training Center. The models of firearms and firearm components included a Raven 25cal, a Kel-Tec 9mm, a Taurus .38, a Beretta .32 and a loaded gun magazine. The variety of solvents and oils included bore cleaner, powder solvent, gun lubrication oil, Tetra gun oil, WD-40 lubricant, HD-30 motor oil, 3 in 1 oil and sewing machine oil. The samples were examined via HS-SPME-GC-MS to assess odor profiles. The chromatograms can be seen in Figure 65 - Figure 72. 


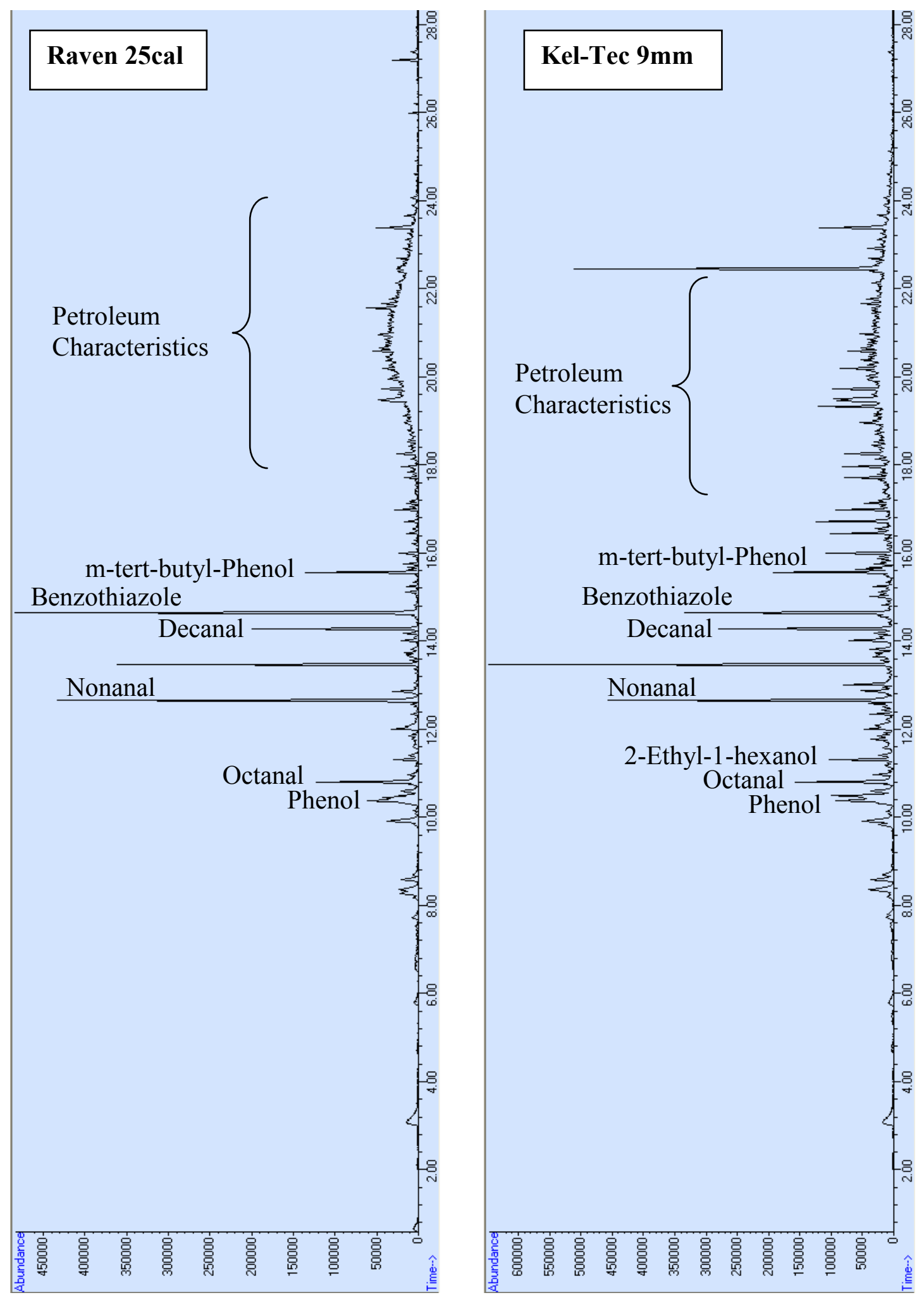

Figure 65 - Firearm component chromatograms using SPME-GC-MS showing most abundant VOC's 


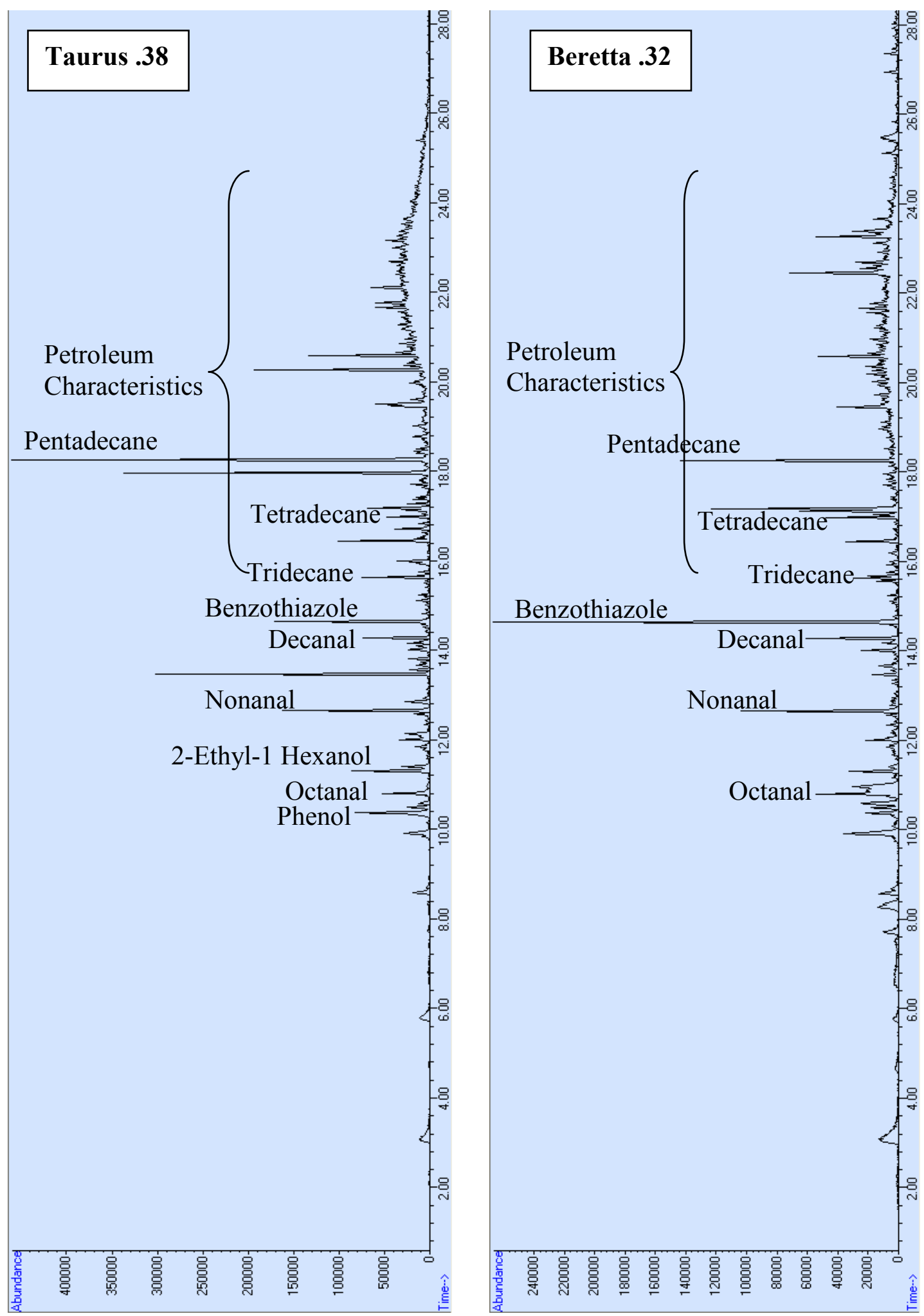

Figure 66 - Firearm component chromatograms using SPME-GC-MS showing most abundant VOC's 


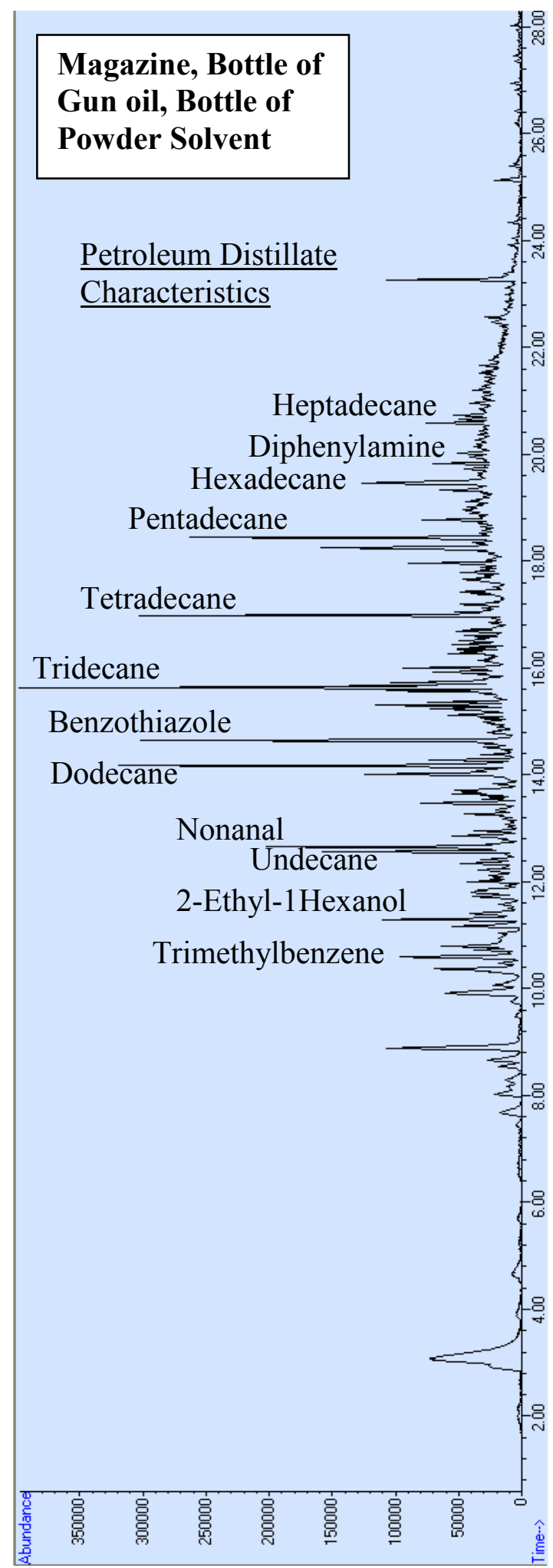

Figure 67 - Firearm component chromatograms using SPME-GC-MS showing most abundant VOC's 

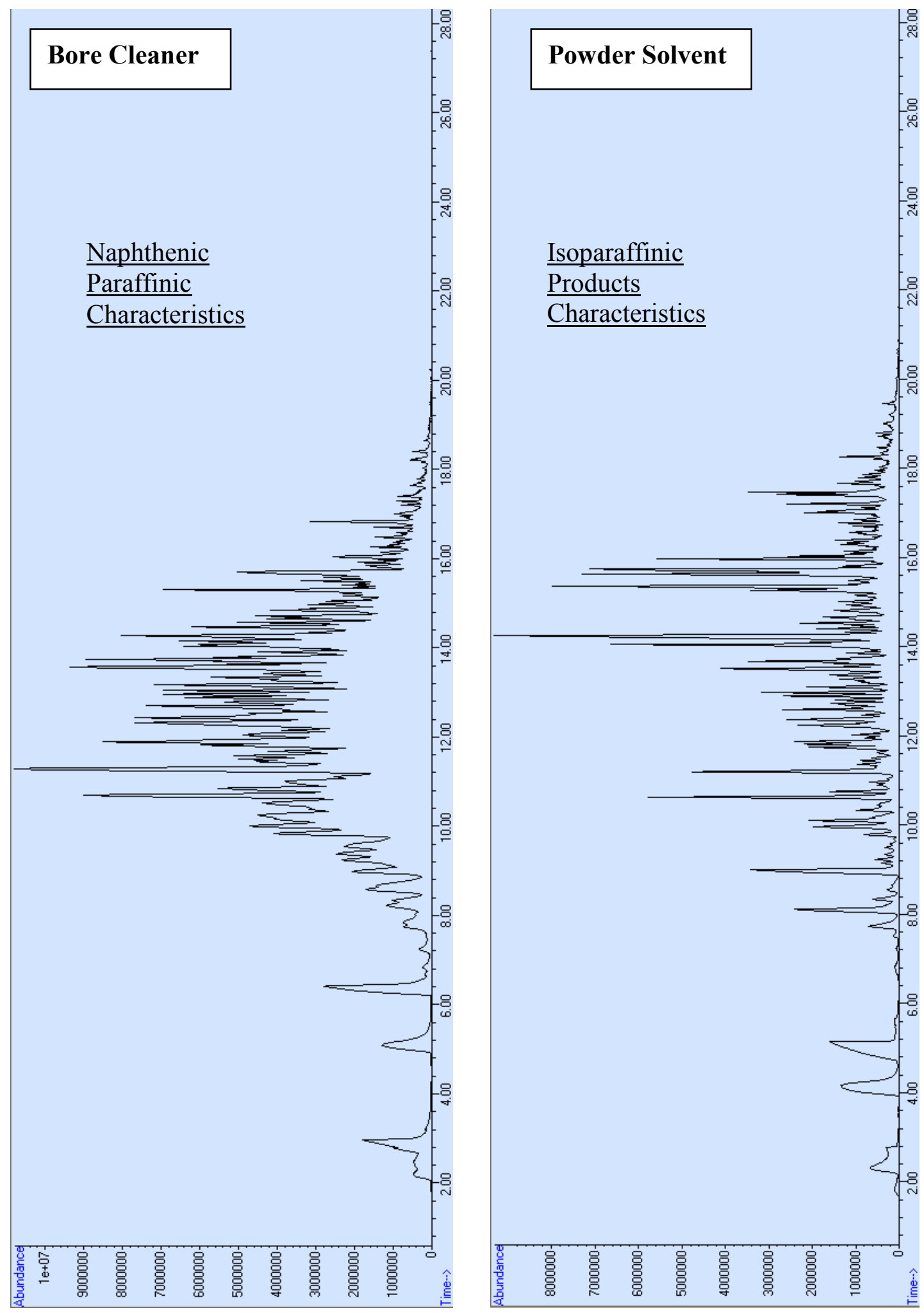

Figure 68 - Gun cleaner chromatograms using SPME-GC-MS 


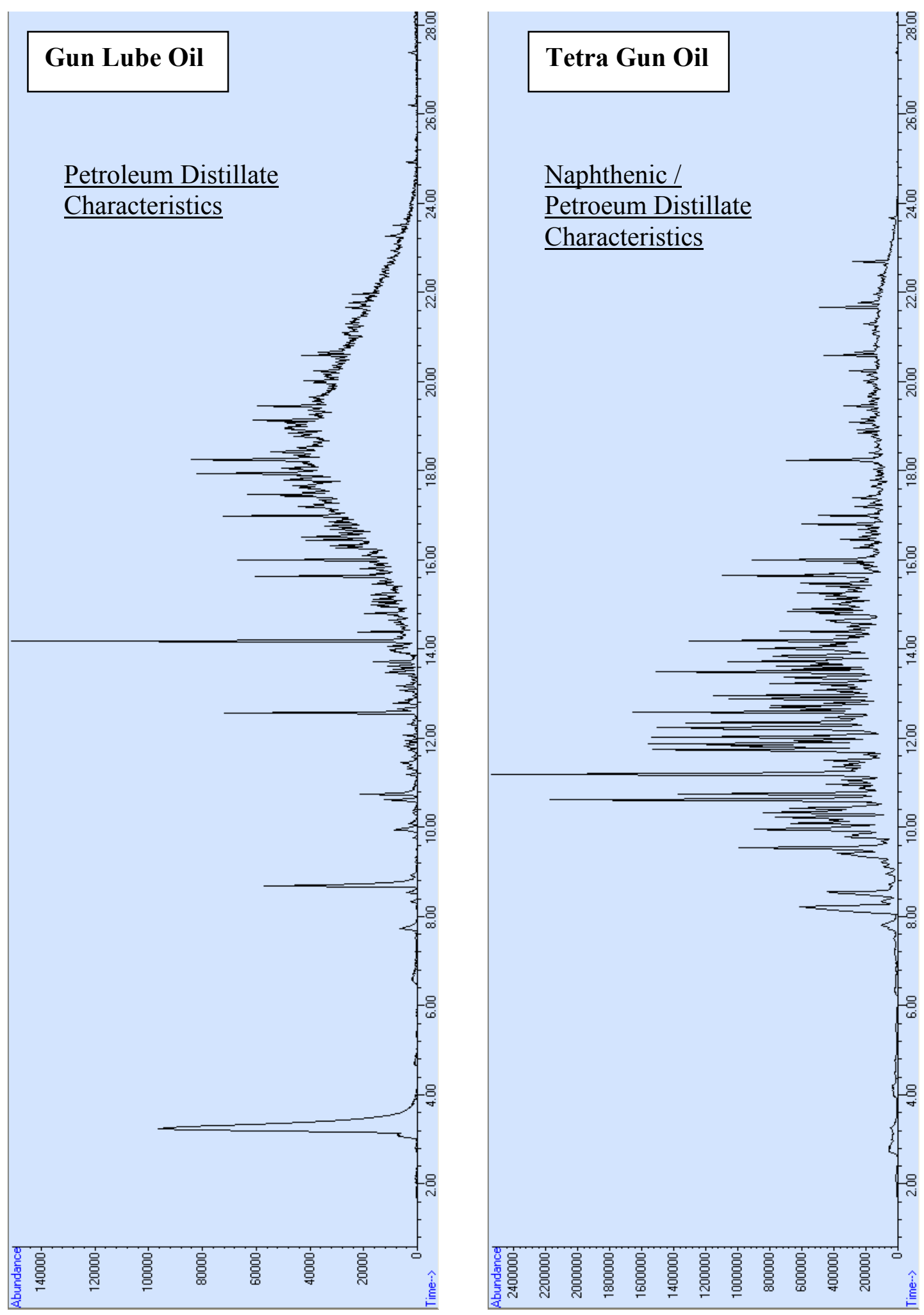

Figure 69 - Firearm oil chromatograms using SPME-GC-MS 


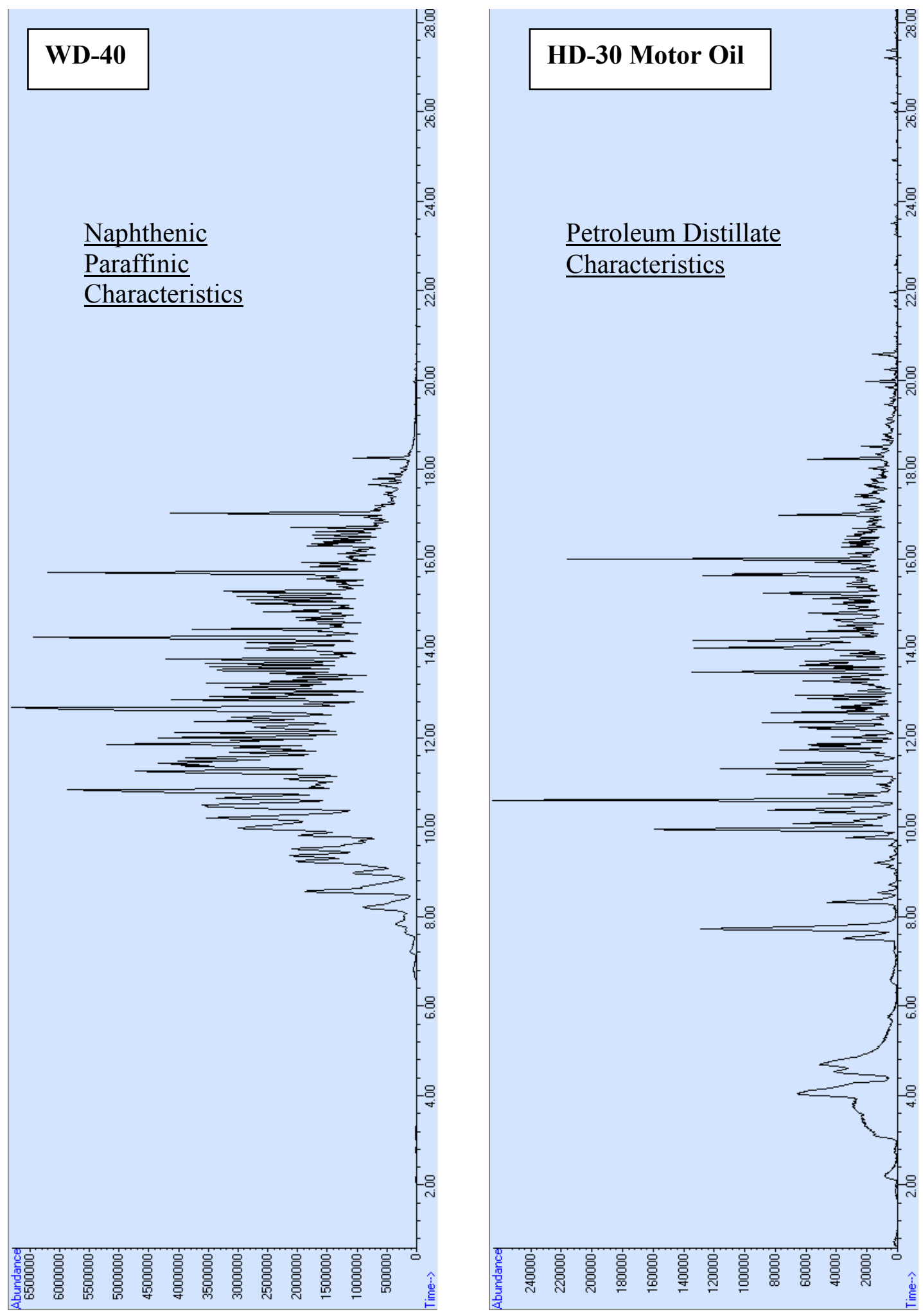

Figure 70 - Oil chromatograms using SPME-GC-MS 

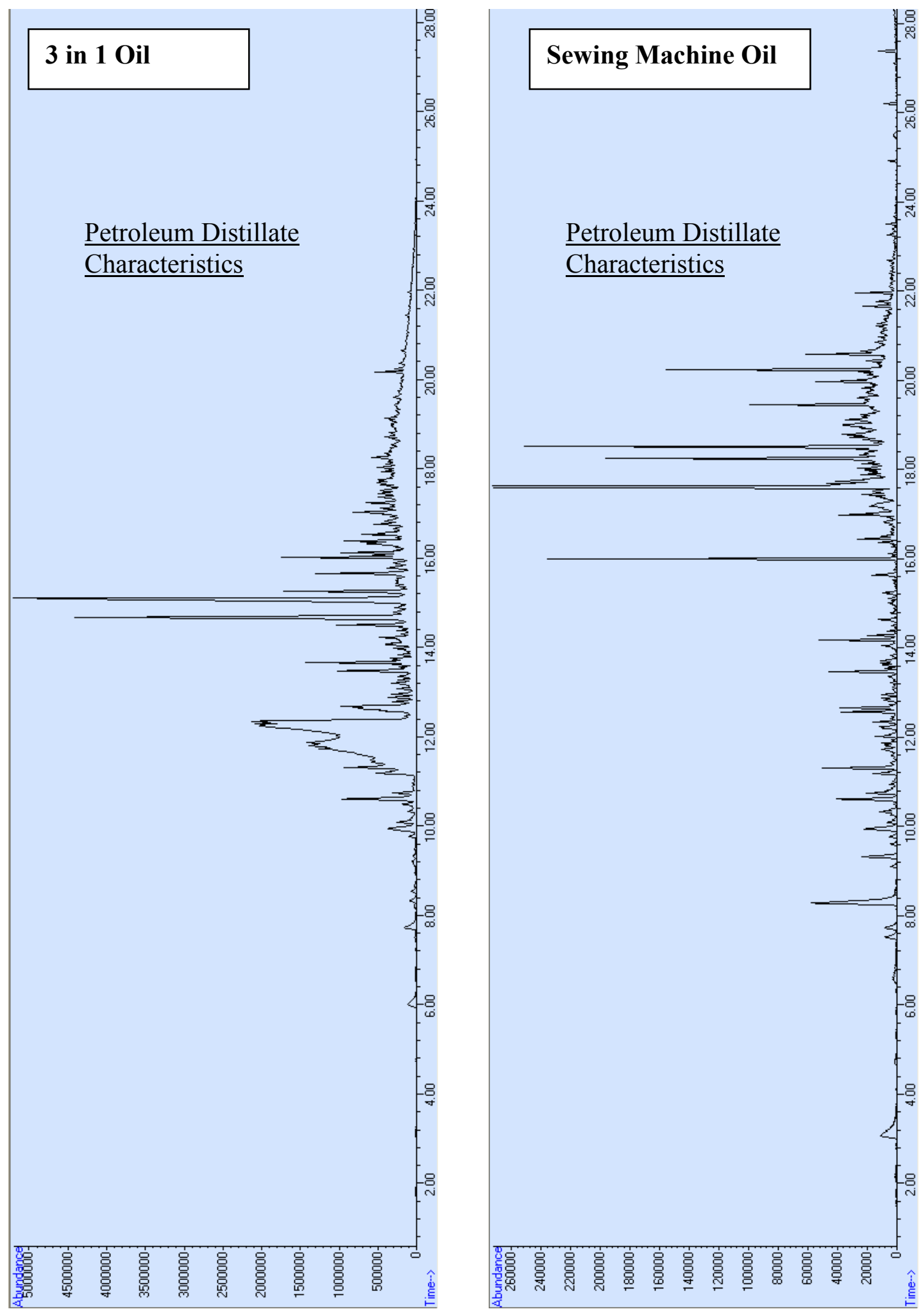

Figure 71 - Oil chromatograms using SPME-GC-MS 


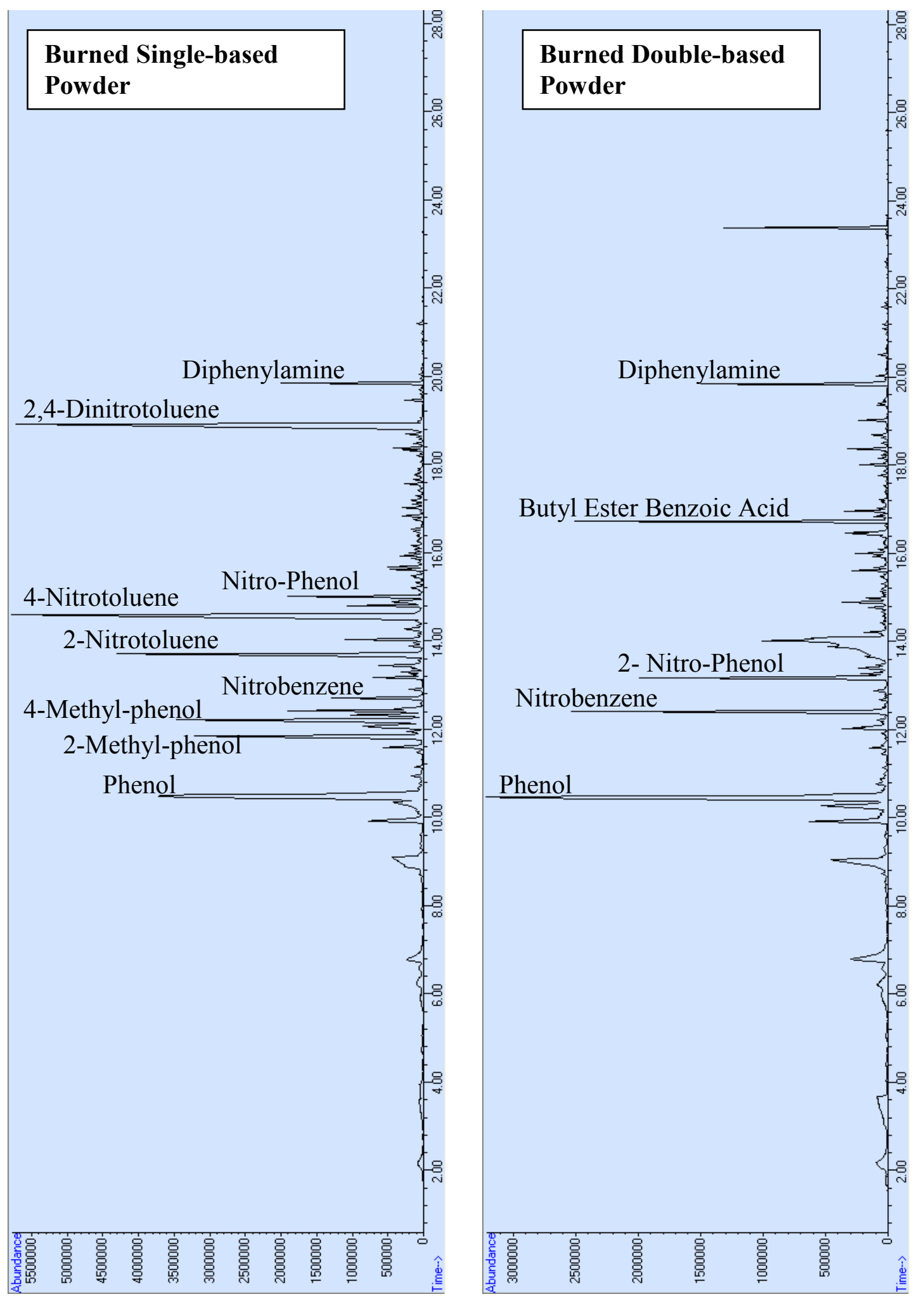

Figure 72 - Burned powder chromatograms using SPME-GC-MS showing most abundant VOC's 
As expected, the oils and cleaners that were sampled bore similar profiles to those seen in various petroleum standards (i.e. petroleum distillates, isoparaffinics, naphthenics). The burnt powder chromatograms (Figure 72) yielded compounds similar to those seen in unused powders (2,4-dinitrotoluene and diphenylamine), as well as compounds that are attributed to breakdown from the burning process (methyl-phenol and nitro-phenol). The chromatograms of the firearms and magazines (Figure 65, Figure 66, and Figure 67) seem to be a composite of two types of profiles. Many of the compounds seen in the early portion of the chromatograms are common human scent compounds (e.g. nonanal and decanal $[90,110])$, while the later portion of the chromatograms show characteristic profiles that are common to petroleum products. Since the firearms had been handled by the donating officers, and the officers had previously used cleaners and oils to maintain the firearms, these results were expected. The one anomaly was the detection of diphenylamine in the sample that contained the full magazine, the gun oil bottle and the powder solvent bottle. The detection of diphenylamine can be attributed to the low explosive (smokeless powder) that was present within the ammunition of the magazine.

The sum of these findings indicates that the detection of firearms could be approached from several different angles: low explosive detection, petroleum product detection and/or human scent detection. The odor variability of the firearms is a direct result of several conditions including how much the firearm has been handled, how recently the firearm has been used and/or reloaded, and how much cleaning and maintenance has been preformed. In theory, a well trained explosive canine should be able to detect a loaded or recently discharged firearm from the low explosive present in the magazine and/or the 
powder residue left on the firearm. Based on the similarity between the profiles of the firearm maintenance products and that of the petroleum products, an accelerant canine that is properly trained upon petroleum products and petroleum residue (i.e. ignitable liquid residue) should be capable of detecting a firearm that has recently been cleaned and/or oiled. In addition, a human scent canine trained to standard human scent compounds may be successful at locating and identifying firearms that have been recently handled, regardless of usage.

\subsection{COMPS Odor Delivery}

After examination of the high and low explosives headspace, the dominant compounds present in the odor of the explosives were identified. The next step was to develop an optimized odor delivery system for the selected compounds to be used in the explosive mimics. The optimized delivery systems consisted of six different COMPS devices constructed with 3in $x$ in 2 mil LDPE bags. The six COMPS included one compound for TNT based explosives, one compound for nitroglycerine based explosives, one compound for tagged explosives, one compound for plasticized explosives, and two compounds for smokeless powders. Two compounds were selected for the smokeless powders because of the lack of a single compound which is present in all smokeless powders that was readily detectable in the headspace of the powders (i.e. a highly volatile compound). 
Based on the results of the headspace analysis of the high explosives and low explosives using SPME-GC-MS (sections 6.1 and 6.2, respectively), it was determined that select smokeless powders could be used as explosive mimics for select high explosives. The first example of this would be the use of a single based smokeless powder for the TNT based Explosive Mimic. In order for the single based smokeless powder to accurately mimic TNT-based explosives, a common headspace compound would need to be present in both the selected powder and high explosive. The results of the current study suggest that the compound 2,4-dinitrotoluene would be the most likely choice. As previously shown (section 6.2.1), the level of 2,4-dinitrotoluene varies among smokeless powders both across brands and within brands. It must also be noted that some powders do not possess 2,4-dinitrotoluene (e.g. VihtaVuori powders). The levels of 2,4-dinitrotoluene detected using HS-SPME-GC-MS for the single based powders are shown in Figure 73. Using this information, a powder with a mid-range level of 2,4-dinitrotoluene could be selected. 


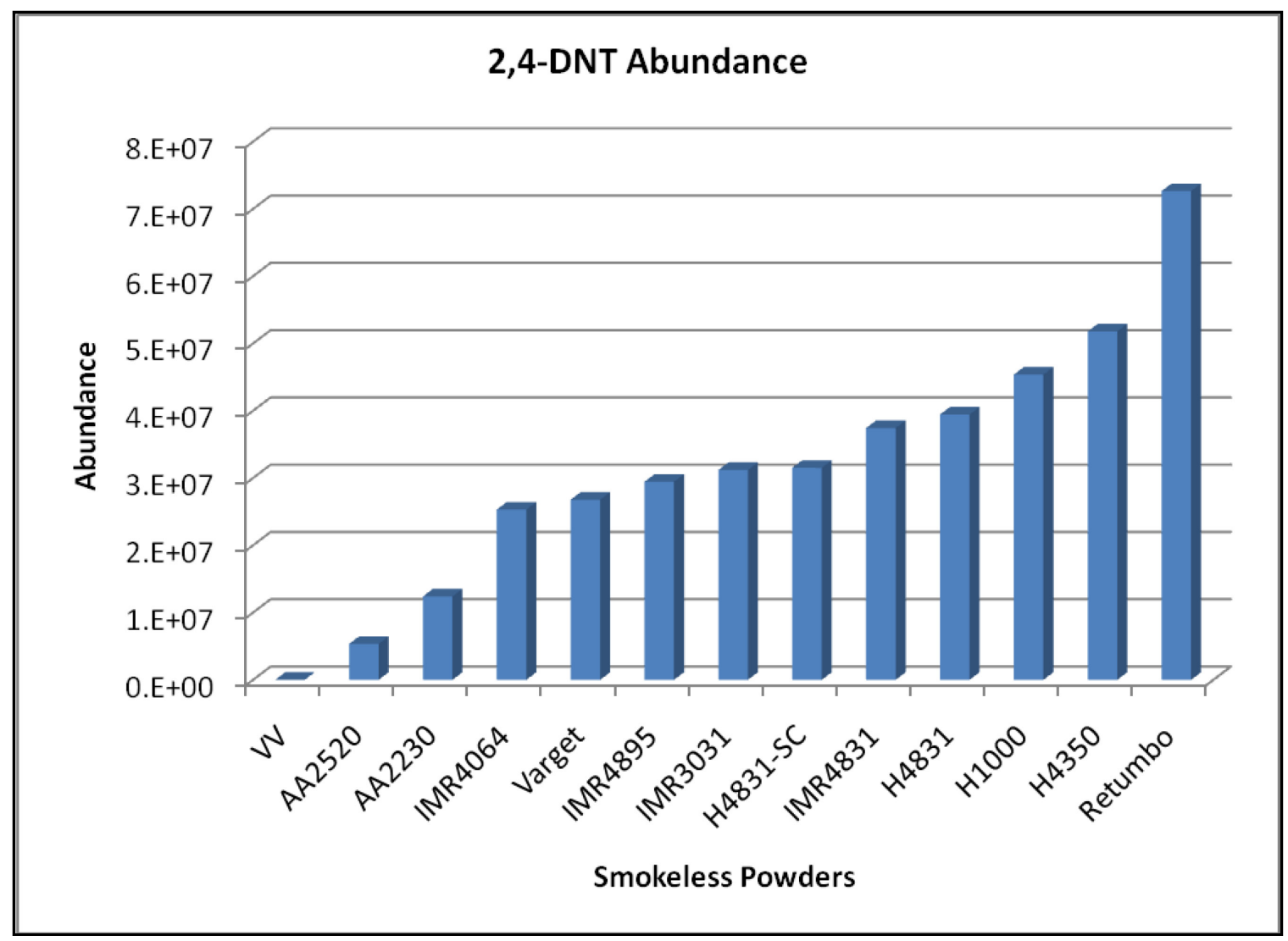

Figure 73 - Detected levels of 2,4-dinitrotoluene

Single based smokeless powder samples using HS-SPME-GC-MS

To accurately mimic nitroglycerine based explosives, a double based smokeless powder with a high level of nitroglycerine should be chosen. As previously discussed, nitroglycerine has a highly volatile; however the current study was unable to reliably detect nitroglycerine levels within the double based powders (section 6.2.2). The absence of absence of nitroglycerine is explained by the thermal degradation associate with the use of GC-MS analysis. Nitroglycerine levels of the double based smokeless powders can be found in the MSDS sheets provided by the smokeless powder company. The smokeless powder mimics each used a compound that was found to be common among most of the powders. Smokeless Powder Mimic 1 used the stabilizer ethyl centralite and 
Smokeless Powder Mimic 2 used the stabilizer diphenylamine. The Tagged Explosive Mimic used the common compound 2,3-dimethyl-2,3-dinitrobutane. Lastly, 2-ethyl-1hexanol was used as the odor compound for the Plasticized Explosive Mimic. The solid compounds (single based powder, double based powder, ethyl centralite, diphenylamine, and 2.3-dimethylso-2,3-dinitrobutane) were weighed out and heat-sealed directly into the polymer bag. The liquid sample (2-ethyl-1-hexanol) was spiked onto sterile gauze which was then heat-sealed within the polymer bag.

Once the COMPS were prepared, they were monitored (weighed) over the course of fifteen days to determine the mass loss per time, i.e. the permeation rate through the polymer bags. At the conclusion of the weighing process, the data set was plotted as mass vs. time. A linear-fit application yielded a direct value of permeation rate in grams per day $(\mathrm{g} / \mathrm{d})$ which was converted to a permeation rate in nanograms per second $(\mathrm{ng} / \mathrm{sec})$. Figure $74-79$ give the permeation results of the six explosive mimic COMPS. A summary of the permeation rates for the explosive mimic COMPS is given in Table 28.

The ethyl centralite COMPS was based on a 10g sample. Figure 74 represents the plotted data of Mass (grams) vs. Time (days) for the ethyl centralite COMPS. The permeation rate for ethyl centralite was determined to be $3.5 \mathrm{~g} / \mathrm{s}$. 


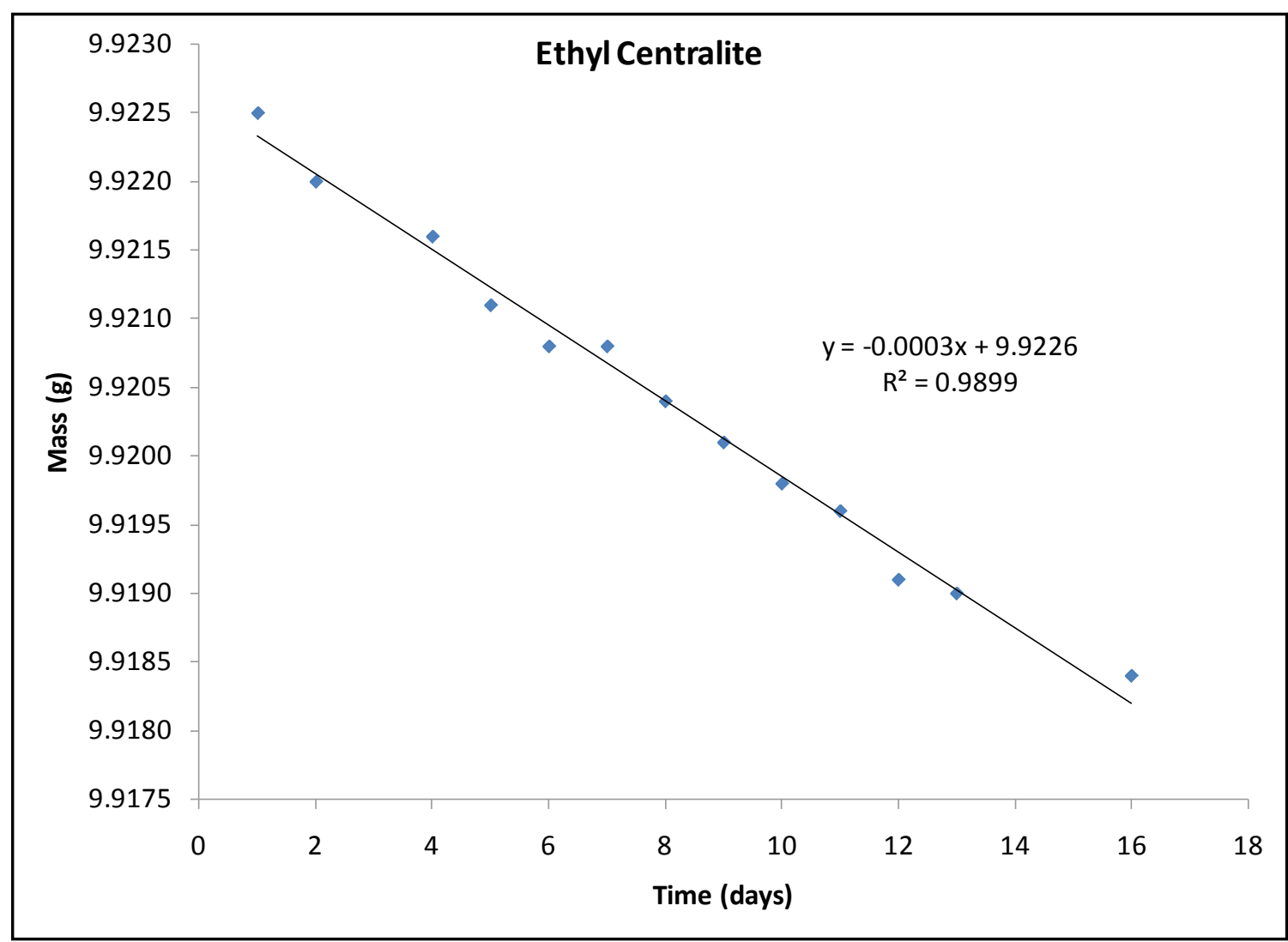

Figure 74 - Ethyl centralite permeation rate 2mil 3in x 3in LDPE

The diphenylamine COMPS was based on a 10g sample. Figure 75 represents the plotted data of Mass (grams) vs. Time (days) for the diphenylamine COMPS. The permeation rate for diphenylamine was determined to be $34.7 \mathrm{ng} / \mathrm{s}$. 


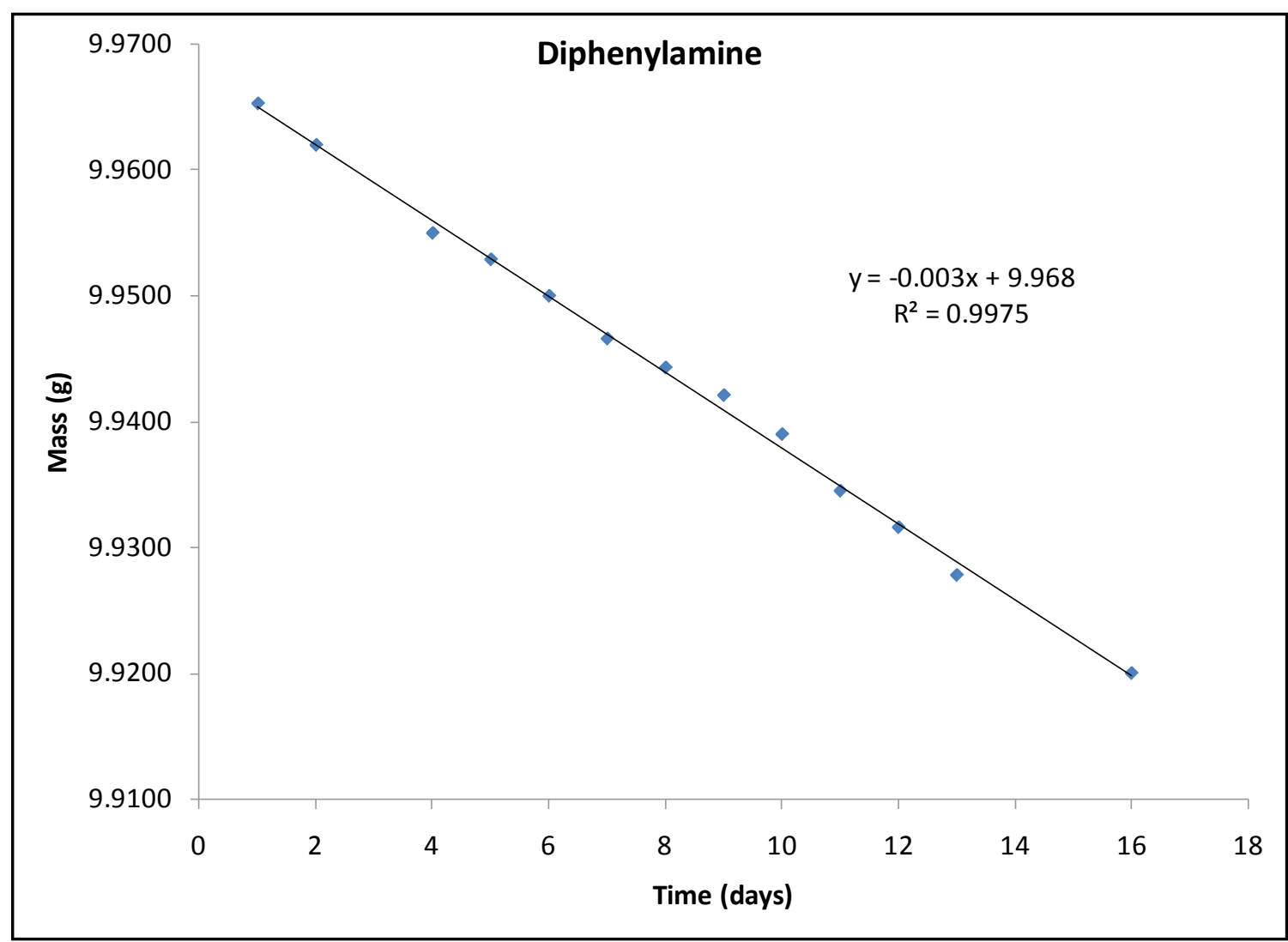

Figure 75 - Diphenylamine permeation rate 2 mil 3in x 3in LDPE

The 2,3-dimethyl-2,3-dinitrobutane COMPS was based on a 10g sample. Figure 76 represents the plotted data of Mass (grams) vs. Time (days) for the 2,3-dimethyl-2,3dinitrobutane COMPS. The permeation rate for 2,3-dimethyl-2,3-dinitrobutane was determined to be $2.3 \mathrm{ng} / \mathrm{s}$. 


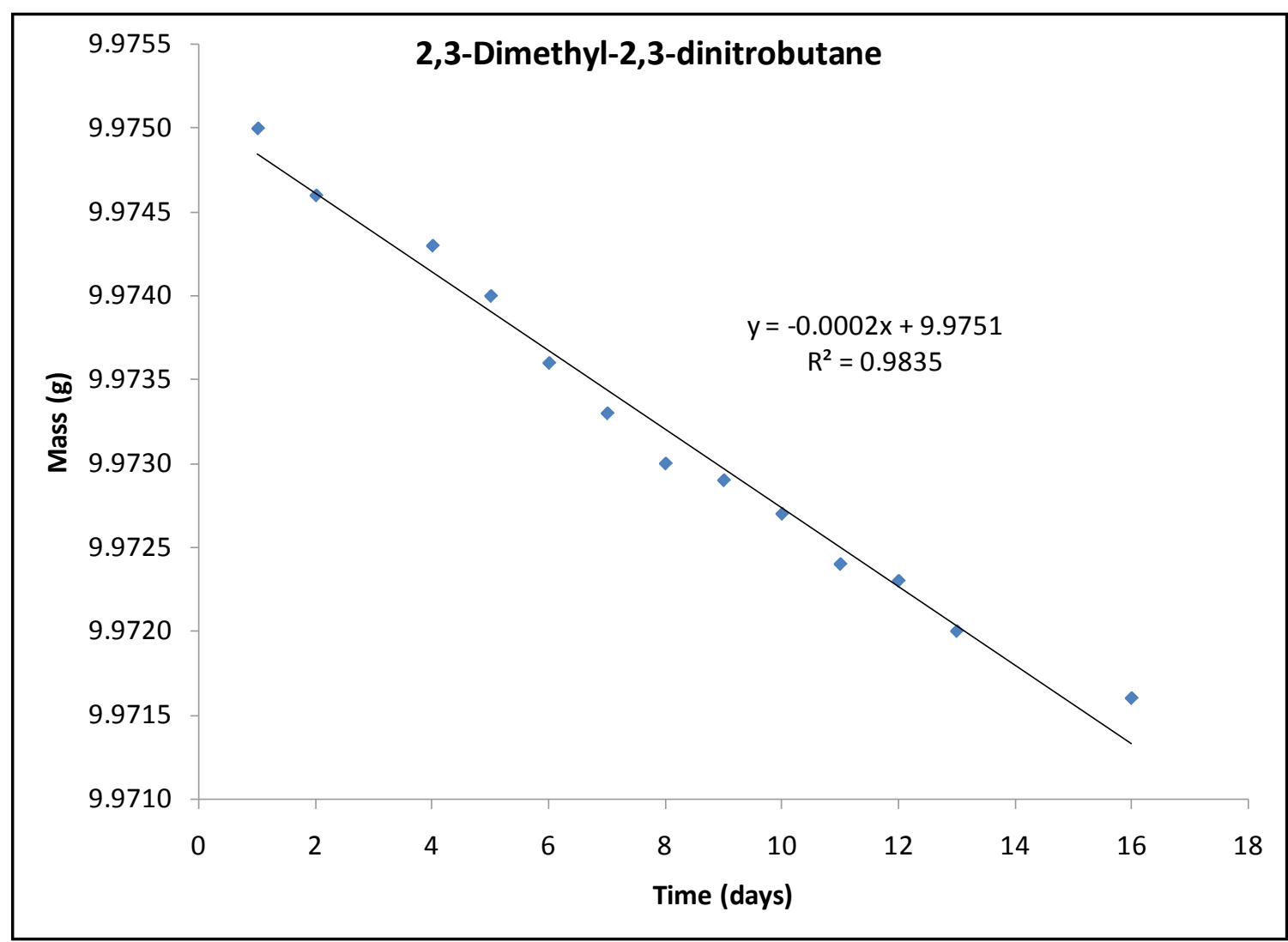

Figure 76 - DMNB permeation rate 2 mil 3in x 3in LDPE

The 2-ethyl-1-hexanol COMPS was based on a $1 \mathrm{~mL}$ spiked onto gauze. Figure 77 represents the plotted data of Mass (grams) vs. Time (days) for the 2-ethyl-1-hexanol COMPS. The permeation rate for 2-ethyl-1-hexanol was determined to be $312.5 \mathrm{ng} / \mathrm{s}$. 


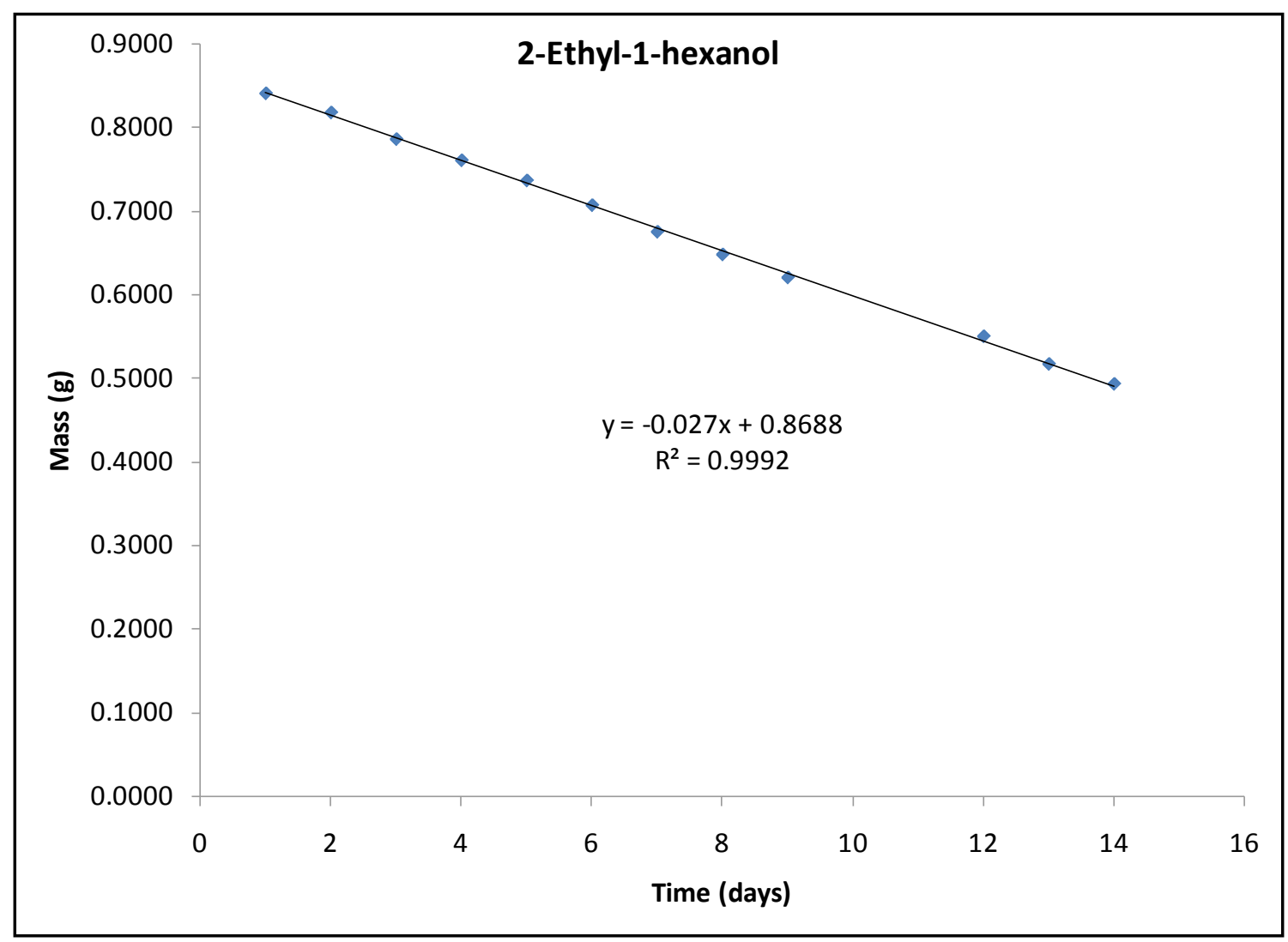

Figure 77 - 2-Ethyl-1-hexanol permeation rate 2mil 3in x 3in LDPE

The single based smokeless powder COMPS was based on a $10 \mathrm{~g}$ sample. Figure 78 represents the plotted data of Mass (grams) vs. Time (days) for the single based smokeless powder COMPS. The permeation rate for the single based smokeless powder was determined to be 11.6ng/s. The single based powder chosen was Hodgdon H4895. The MSDS sheet for this powder lists up to $10 \% 2,4-\mathrm{DNT}$ and $1 \%$ diphenylamine as the volatile compounds and the remainder as NC. The permeation rate is slower than diphenylamine which is not surprising given the low amount present. The increased permeation rate is likely due to the permeation of the 2,4-DNT from the powder. 


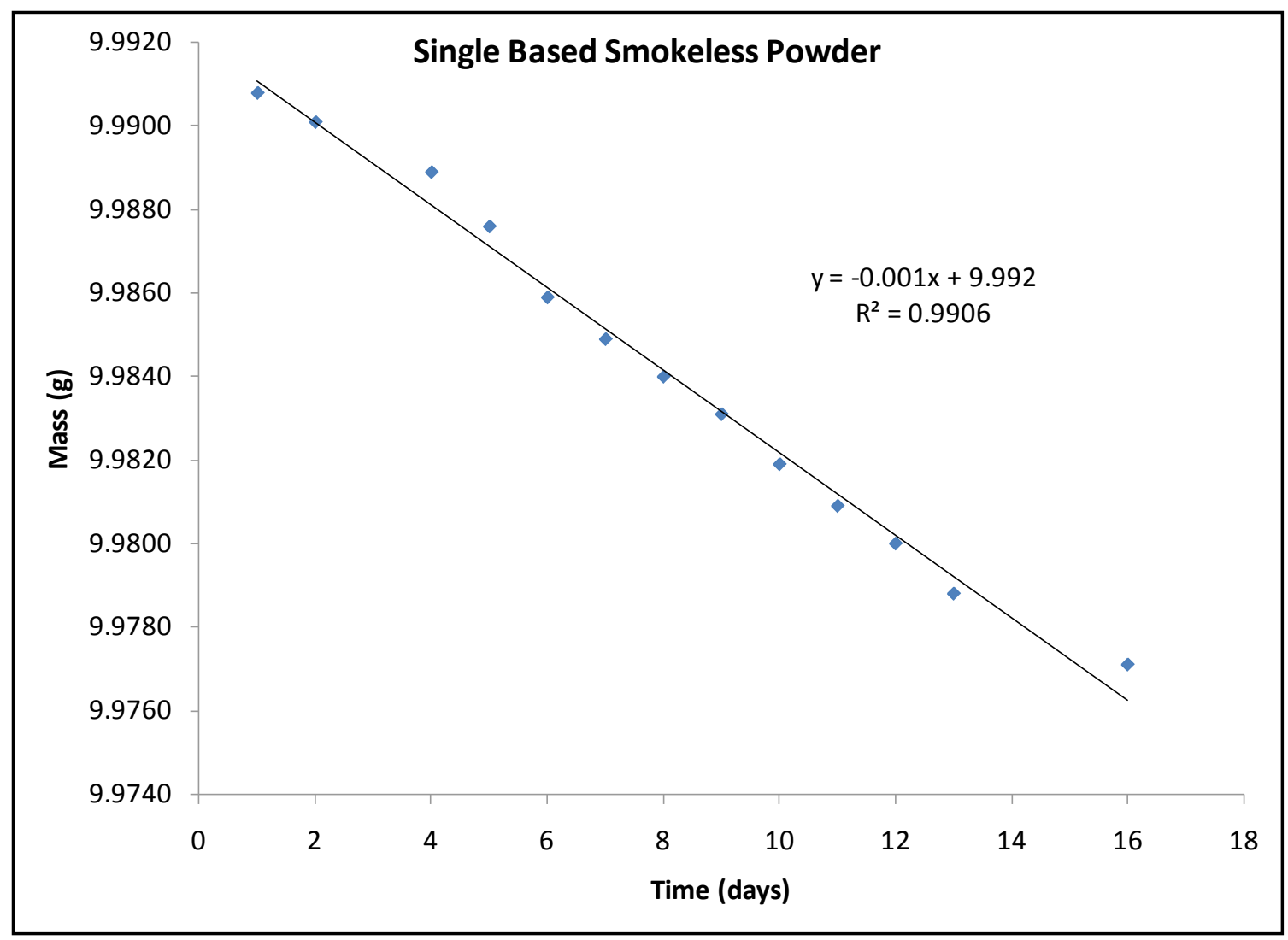

Figure 78 - Single based smokeless powder permeation rate 2mil 3in x 3in LDPE

The double based smokeless powder COMPS was based on a 10g sample. Figure 79 represents the plotted data of Mass (grams) vs. Time (days) for the double based smokeless powder COMPS. The permeation rate for the double based smokeless powder was determined to be $9.3 \mathrm{ng} / \mathrm{s}$. The double based powder chosen was Hodgdon H414. The MSDS sheet for this powder lists up to $40 \%$ NG, $10 \%$ ethyl centralite and $1.5 \%$ diphenylamine as the volatile compounds and the remainder as NC. The permeation rate is slower than diphenylamine which is not surprising given the low amount present. However it is faster than the permeation rate for ethyl centralite. The difference may be 
partly the result of the small amount of diphenylamine, but is more likely due to the permeation of the NG from the powder.

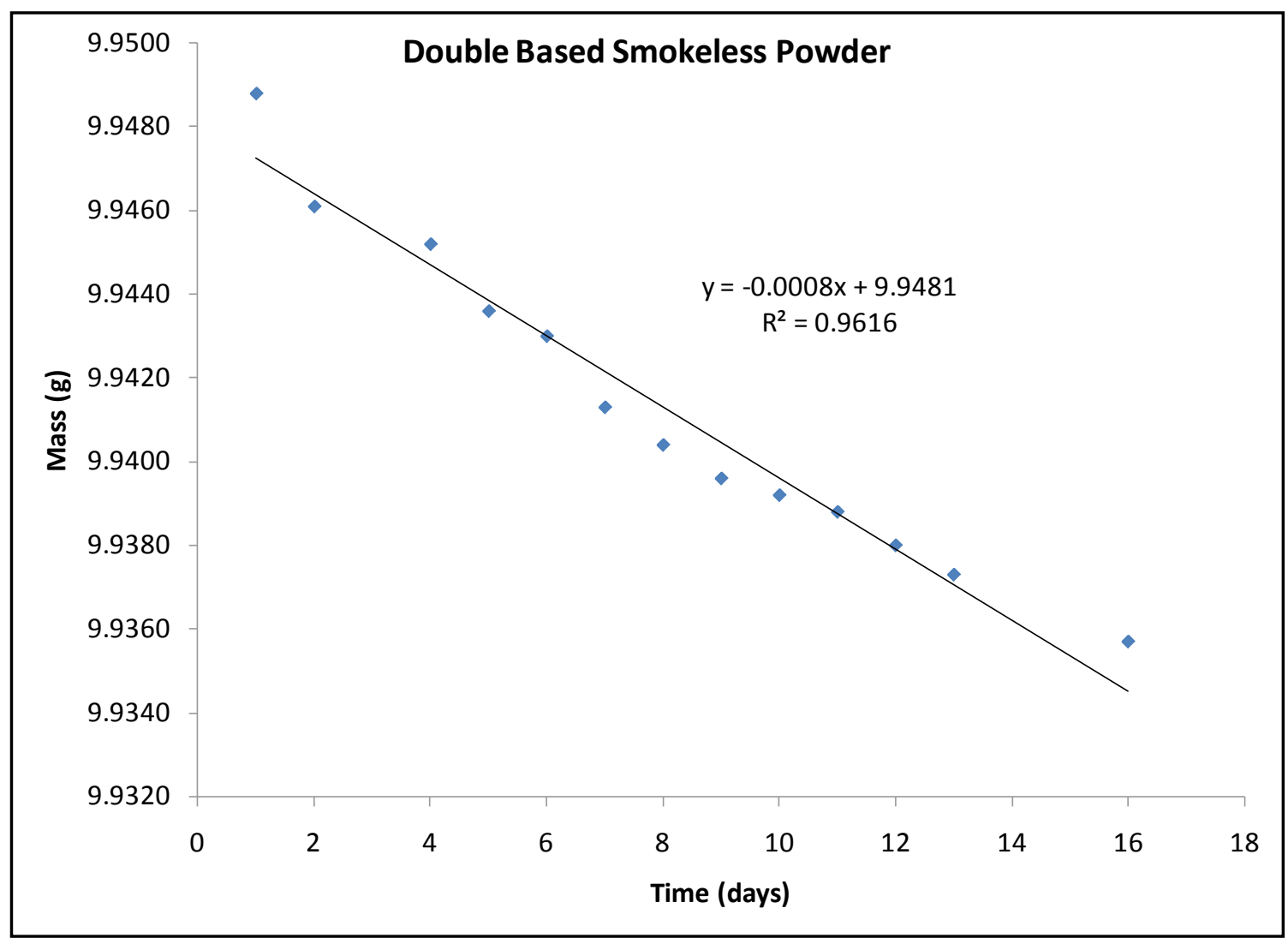

Figure 79 - Double based smokeless powder permeation rate 2 mil 3in $x$ 3in LDPE

As shown in Table 28, the permeation rates vary depending on the compound. The fastest permeation rate $(312.5 \mathrm{ng} / \mathrm{s})$ is from the compound 2-ethyl-1-hexanol while the slowest permeation rates were from the taggant, 2,3-dimethyl-2,3-dinitrobutane (2.3ng/s), and the stabilizer, ethyl centralite $(3.5 \mathrm{ng} / \mathrm{s})$. Because 2-ethyl-1-hexanol has a high volatility $\left(3.6 \times 10^{-1} \mathrm{mmHg}\right.$ at $\left.20^{\circ} \mathrm{C}[111]\right)$ and is the smallest molecule of the set $(130 \mathrm{~g} / \mathrm{mol})$, it was expected to pass through the polymer membrane at the fastest rate. The compound 
DMNB possesses what is considered to be a low vapour pressure $\left(2.07 \times 10^{-3} \mathrm{mmHg}\right.$ at $\left.25^{\circ} \mathrm{C}[112]\right)$. Possessing a lower vapour pressure translates to a slow rate of dissipation which is a good quality for a taggant, such as DMNB. The low vapor pressure will help ensure the longevity (i.e. shelf life) as a detectable compound in high explosives. Ethyl centralite possesses a high vapour pressure $\left(6 \times 10^{-6} \mathrm{mmHg}\right.$ at $\left.20^{\circ} \mathrm{C}[111]\right)$, but the increased size of the molecule $(287 \mathrm{~g} / \mathrm{mol})$ slows the escape through the polymer bags giving a reduced permeation rate.

Table 28 - Explosive COMPS permeation rates in $2 \mathrm{mil}$ 3in x3in LDPE

\begin{tabular}{|c|c|}
\hline COMPS & Permeation Rate (ng/sec) \\
\hline Single Based Powder & 11.6 \\
Double Based Powder & 9.3 \\
Diphenylamine & 34.7 \\
Ethyl Centralite & 3.5 \\
DMNB & 2.3 \\
2-Ethyl-1-hexanol & 312.5 \\
\hline
\end{tabular}

The masses that were selected for the aids were chosen for two purposes: availability of odor and expense. The ultimate concept of the optimized explosive training aids is the development of a non-hazardous, non-explosive, commercially available, inexpensive, and comprehensive kit. To keep the cost low, a minimum amount of COMPS devices were used while still maintaining detectable levels of odor. The optimized kit possessed multiple samples of each of the explosive COMPS described in this section. Multiple 
samples allowed for the trainers to utilize as much or as little as they feel is necessary for training purposes while still maintaining the low expense.

\subsection{Field Trails}

Preliminary field results for TNT and nitroglycerine mimics were collected by supplying a local ATF certified canine trainer with samples of a single based powder (H4831 or H4350) and a double based powder (H414 or Clays). The selected powders possessed a detectable level of 2,4-dinitrotoluene and nitroglycerine, respectively. As with the piperonal imprint, the explosive mimic training utilized "new canines". Here, the term "new canine" refers to canines that were not exposed to any type of explosive sample prior to or during the TNT and nitroglycerine mimic training process. The training consisted of 2 sessions a day for 5 days using $50 \mathrm{~g}$ of both the single based and double based smokeless powders. The testing phase was kept double-blind and consisted of a line-up of $50 \mathrm{~g}$ of each smokeless powder used during training and $30 \mathrm{~g}$ of TNT and dynamite (both supplied by the trainer). For the line-up, each sample was placed in a separate scent box/electrical box along a wall. Each handler was instructed to have their canine sample the odor emanating from each box and then to interpret their canine's response as an alert, a no-alert, or interest. Figure 80 shows that $100 \%$ of the canines (4 out of 4) alerted to the high explosives after demonstrating their ability to correctly identify the powders upon which they were trained. 


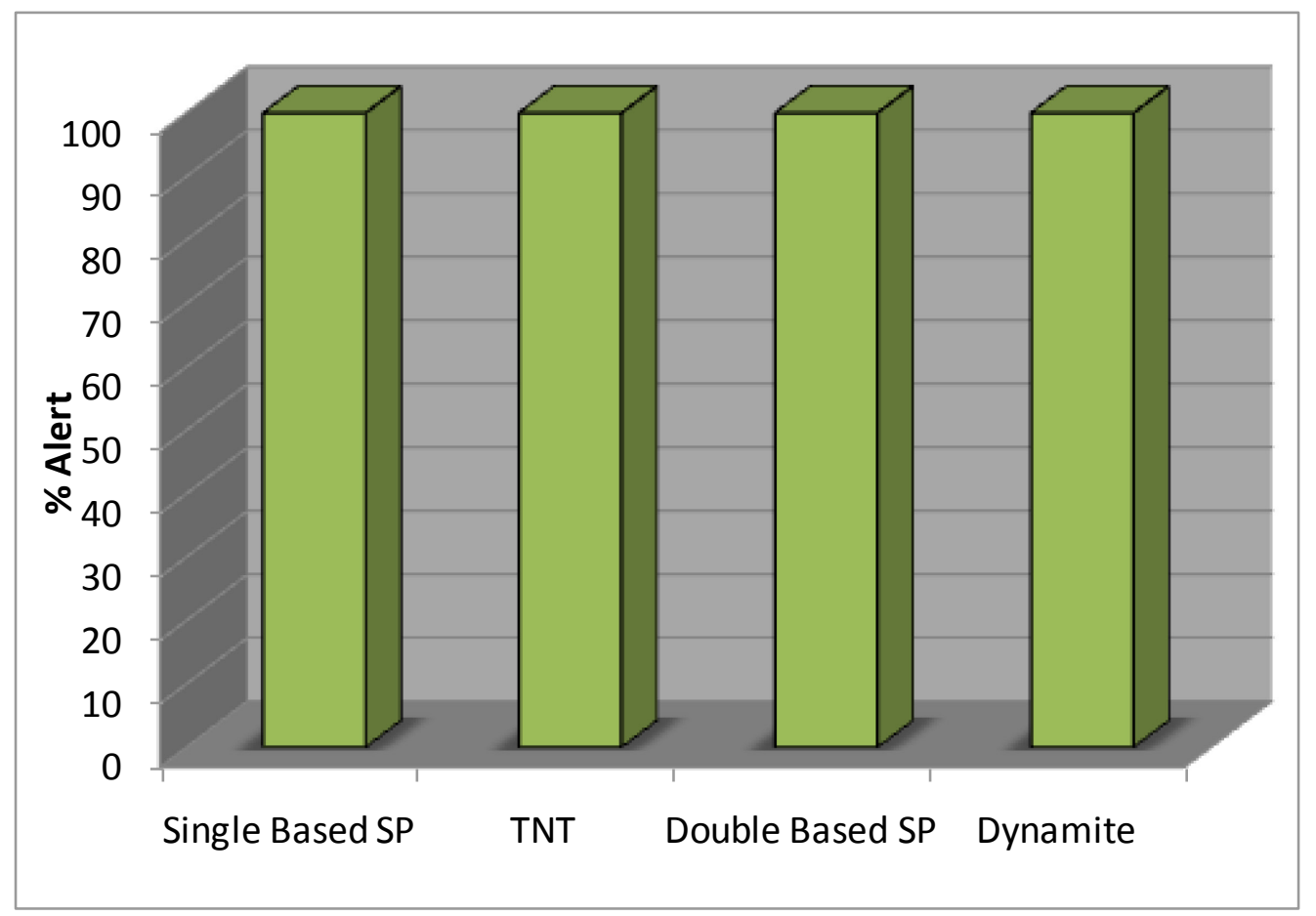

Figure 80 - Field test results from smokeless powder imprint

Four additional explosive mimics were created based on the results seen from the headspace analysis of the high explosives (section 6.1).

These six mimics were assembled for use in a comprehensive explosive training aid kit. The six-member kit was presented to trained, certified explosive canine teams for verification of the odor recognition. Table 29 shows the results from this validation process. There was $100 \%$ identification/alert by the canine teams for the TNT Mimic, the NG Mimic and the Plasticized Explosive Mimic. Thirteen of the fourteen canines alerted to Smokeless Powder Mimic 2 yielding 93\% recognition. The canine that did not alert to Smokeless Powder Mimic 2 (Canine 207) showed extended interest in the training aid. Smokeless Powder Mimic 1 results were slightly lower with twelve of fourteen dogs 
giving an alert response (86\%), one canine showing extended interest (Canine 211), and one canine showing no recognition (Canine 221). The canine that did not alert to Smokeless Powder Mimic 1 may not have been trained on powders that possessed this compound. This demonstrates the necessity for multiple training aids for smokeless powders. The lowest identification/alert percentage was seen in recognition of the Tagged Explosive Mimic at $73 \%$. The tagged component utilized for the Tagged Explosive Mimic has a limited shelf life as compared to the explosive; therefore, canine recognition is dependent on the age of the tagged explosives being utilized in training by law enforcement. Alternately, some agencies choose not to train upon tagged explosives; therefore, the canines of these agencies would not recognize the tagged explosive odor mimic.

Table 29 - Proofing results from IFRI explosive kit

\begin{tabular}{|c|c|c|c|c|}
\hline Content & No Alert & Interest & Alert & $\%$ Alert \\
\hline TNT Mimic & - & - & $\begin{array}{c}202,206,207,208,209,210,211,212 \\
213,214,215,221,222,223,224\end{array}$ & $100 \%$ \\
\hline NG Mimic & - & - & $\begin{array}{c}202,206,207,208,209,210,211,212 \\
213,214,215,221,222,223,224\end{array}$ & $100 \%$ \\
\hline $\begin{array}{c}\text { Tagged } \\
\text { Explosive Mimic }\end{array}$ & $\begin{array}{l}206,207 \\
211,212\end{array}$ & - & $\begin{array}{c}202,208,209210,213,214,215, \\
221,222,223,224\end{array}$ & $73 \%$ \\
\hline $\begin{array}{c}\text { Plasticized } \\
\text { Explosive Mimic }\end{array}$ & - & - & $\begin{array}{c}202,206,207,208,209,210,211,212 \\
213,214,215,221,222,223,224\end{array}$ & $100 \%$ \\
\hline $\begin{array}{l}\text { Smokeless Powder } \\
\text { Mimic } 1\end{array}$ & 221 & 211 & $\begin{array}{c}202,206,207,208,209,210,212 \\
213,214215,222,223,224\end{array}$ & $87 \%$ \\
\hline $\begin{array}{l}\text { Smokeless Powder } \\
\text { Mimic } 2\end{array}$ & - & 207 & $\begin{array}{l}202,206,208209,210,211212, \\
213,214,215,221,222,223,224\end{array}$ & $93 \%$ \\
\hline
\end{tabular}


Upon verification that the odors within the kit were recognized by trained canines, the kit was used for training purposes with new untrained canines. The trainers were instructed to train per their normal routine utilizing the training aids within the kit in place of actual explosive samples. Additionally, the trainers/handlers were informed that the canines were not to be exposed to actual explosives until the conclusion of the training. This condition was maintained to ensure the validity of the results when using the mimic kit. At the conclusion of training, the canines were tested using actual explosive samples already in the possession of the ATF certified canine trainers. Table 30 shows the results of the testing phase. As shown, $100 \%$ of the canines trained upon the IFRI kit gave a final alert response to all of the actual explosives. The results demonstrate the reliability in the selection of the compounds used for the training aids within the IFRI kit as mimics for specific classes of explosives. 
Table 30 - Explosive testing after IFRI Explosive kit training

(a) US K-9 Dog Academy (b) Prince George's Co. SD - included among 19 high and low explosives

\begin{tabular}{|c|c|c|c|c|}
\hline Content & No Alert & Interest & Alert & $\%$ Alert \\
TNT $^{\mathbf{a}, \mathbf{b}}$ & - & - & $216,217,218,219,220$ & $100 \%$ \\
Slurry $^{\mathbf{b}}$ & - & - & $216,217,218,219,220$ & $100 \%$ \\
Dynamite $^{\mathbf{a}, \mathbf{b}}$ & - & - & $216,217,218,219,220$ & $100 \%$ \\
PETN Det Cord $^{\mathbf{a}, \mathbf{b}}$ & - & - & $216,217,218,219,220$ & $100 \%$ \\
C-4, $^{\mathbf{a}, \mathbf{b}}$ & - & - & $216,217,218,219,220$ & $100 \%$ \\
Single Based SP $^{\mathbf{a}, \mathbf{b}}$ & - & - & $216,217,218,219,220$ & $100 \%$ \\
Double Based SP $^{\mathbf{a}, \mathbf{b}}$ & - & - & $216,217,218,219,220$ & $100 \%$ \\
\hline
\end{tabular}

In order to determine the reliability of the canine responses to the explosive odor mimics used in the IFRI explosive kit, a repetition study was performed with Canines 216 and 224. The results are given in Table 31 . 
Table 31 - Results from canine reliability study of IFRI explosive kit

\begin{tabular}{|c|c|c|c|c|}
\hline Content & No Alert & Interest & Alert & $\%$ Alert \\
\hline TNT Mimic & - & - & $\begin{array}{c}216,216,216,216 \\
224,224,224\end{array}$ & $100 \%$ \\
\hline NG Mimic & - & - & $\begin{array}{c}216,216,216,216 \\
224,224,224\end{array}$ & $100 \%$ \\
\hline $\begin{array}{c}\text { Tagged } \\
\text { Explosive Mimic }\end{array}$ & - & - & $\begin{array}{c}216,216,216,216 \\
224,224,224\end{array}$ & $100 \%$ \\
\hline $\begin{array}{c}\text { Plasticized } \\
\text { Explosive Mimic }\end{array}$ & - & - & $\begin{array}{c}216,216,216,216 \\
224,224,224\end{array}$ & $100 \%$ \\
\hline $\begin{array}{c}\text { Smokeless Powder } \\
\text { Mimic } 1\end{array}$ & - & - & $\begin{array}{c}216,216,216,216 \\
224,224,224\end{array}$ & $100 \%$ \\
\hline $\begin{array}{c}\text { Smokeless Powder } \\
\text { Mimic } 2\end{array}$ & - & - & $\begin{array}{c}216,216,216,216 \\
224,224,224\end{array}$ & $100 \%$ \\
\hline
\end{tabular}

Canine 216 was originally imprinted using the IFRI Explosive Odor Kit training aids while Canine 224 was originally imprinted and subsequently trained using real explosive samples. The results from the field trials demonstrate $100 \%$ reliability of both canines' responses to the six explosive COMPS training aids. The repeated responses by both canines demonstrate the within canine reliability of the odors in the kit regardless of initial imprint and/or prior exposure to the odors. 


\section{OLFACTION THEORY EXAMINATION AND RESULTS}

There are two schools of thought as to how odor particles are absorbed through the nose for interpretation within the brain: the more widely accepted Shape Model and the less accepted Vibration Model. While both models have found support in the scientific community, it is the shape model that the majority of scientists believe to be more accurate.

First presented by Amoore [113] and later refined by Beet [114], the shape olfaction theory states that the sense of smell mimics a 'lock and key' model. The 'lock and key' model is explained by the binding of scent molecules to specific olfactory receptor (i.e. one shape, one receptor, one smell). Buck et al. helped identify olfactory receptors as special types of G-protein-coupled receptors [115]. G-protein receptors are activated through highly specific conformation (i.e. shape) binding of molecules which led to the assumption that olfactory receptors would operate in a similar fashion. As a result, a broader explanation of shape theory, referred to as the Odotope Theory (Weak Shape Theory), was developed. Odotope theory explains that each receptor is responsible for small structural areas (shape based) from any one molecule, thus any one odor is a combination of activated receptors left for the brain to combine and interpret.

The alternate (and older) theory as to how odor molecules are perceived and processed is the vibration olfaction theory that was first proposed by Dyson [116] and further explored by Wright [117]. It states that the sense of smell is not only dependent upon the shape of odor molecules (as suggested in the shape olfaction theory), but that it is strongly affected 
by the vibrations of odor molecules in the infrared range. In 1996, Turin suggested an inelastic electron tunneling mechanism for the G-protein receptors that revisited the long abandoned vibrational theory [118]. Turin's study suggested that the differences seen between the IR spectra of hydrogenated and deuterated versions of the same compound (in this case acetophenone and $\mathrm{d} 8$-acetophenone) would explain the difference in the perceived odor profiles. The major IR differences included a shift of the $\mathrm{C}-\mathrm{H}$ stretch at $3000 \mathrm{~cm}^{-1}$ to the C-D stretch at $2200 \mathrm{~cm}^{-1}$ and a reduction in amplitude of the peak at $1500 \mathrm{~cm}^{-1}$. Additionally, $\mathrm{d} 8$-acetophenone was reported to be fruitier and less toluenelike than acetophenone, with a much stronger bitter almonds character. The final conclusion was that two molecules with identical shapes and different vibrational spectra would smell different.

Since Turin's original report, additional studies have been performed that offer conflicting results [119]. Among other predictions, Keller and Vossahall's study mimicked the procedures used to test the odor perception of acetophenone versus d8acetophenone. The overall results of this study demonstrated that the test subjects could not reliably distinguish between the two compounds. In an effort to determine the effect that may be seen with canines, the present study was conducted with the hydrogenated and deuterated form of methyl benzoate, a chemical compound known to be an accurate mimic for cocaine.

Previously, it has been shown that the chemical compound methyl benzoate is present in the headspace of samples of cocaine (base and salt varieties) and that methyl benzoate is 
an accurate and reliable training aid mimic for cocaine [2]. For the present study, samples of methyl benzoate and deuterated-methyl benzoate were presented to trained drug canines in a double-blind fashion using an odor line-up. The amount of sample that was presented to the canines mimicked a previous study [2] where a dose-response curve was established for percent of positive response vs. microgram of methyl benzoate (Figure 81). From this curve, a value of $200 \mu \mathrm{g}$ was chosen because it would demonstrate a higher than $90 \%$ value of positive response.

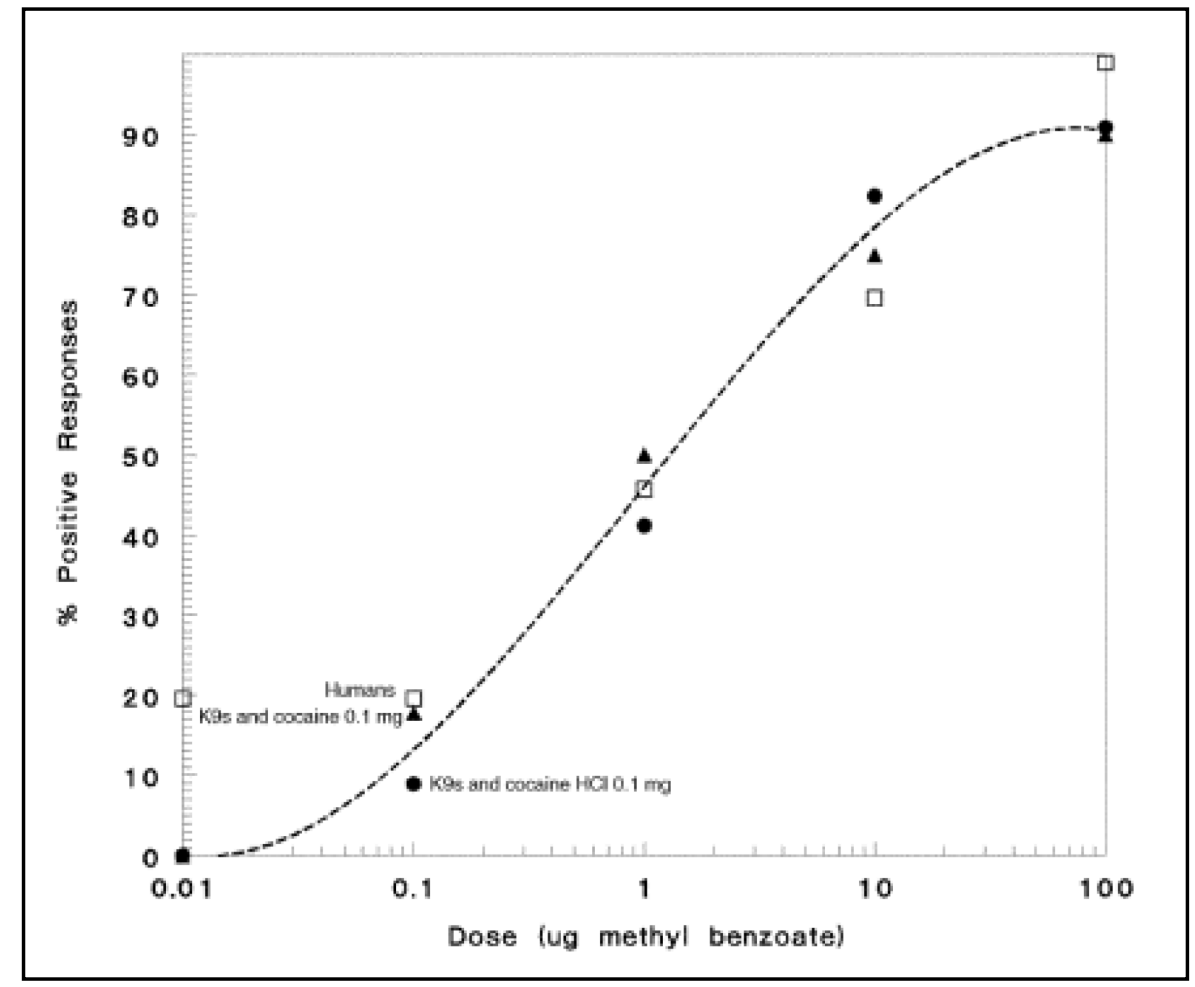

Figure 81 - Dose-response curve for methyl benzoate [2]

For the line-up, each sample was placed in a separate gallon paint cans along a wall. Each handler was instructed to have their canine sample the odor in each can and identify the canine's response as an alert, no-alert, or interest. The results of the field tests are given 
in Table 32. For verification purposes, a cocaine $\mathrm{HCl}$ sample was run to show the canine's ability to detect odor. The cocaine sample ranged from $10 \mathrm{~g}$ to $25 \mathrm{~g}$ depending on the agency and test day. Seven-one percent of the canines (5 of 7) recognized the deuterated methyl benzoate after alerting to the hydrogenated methyl benzoate.

Table 32 - Field results from d-methyl benzoate odor recognition

\begin{tabular}{|c|c|c|c|c|}
\hline Content & No Alert & Interest & Alert & $\%$ Alert \\
\hline $\begin{array}{l}200 \mu g \text { Methyl } \\
\text { benzoate }\end{array}$ & & & $\begin{array}{c}106,109,111,116 \\
118,131,146\end{array}$ & $100 \%$ \\
\hline $\begin{array}{c}200 \mu g \text { d-Methyl } \\
\text { benzoate }\end{array}$ & 116,118 & & $\begin{array}{c}106,109,111 \\
131,146\end{array}$ & $71 \%$ \\
\hline Cocaine $\mathrm{HCl}$ & & & $\begin{array}{c}106,109,111,116 \\
118,131,146\end{array}$ & $100 \%$ \\
\hline Blank & $\begin{array}{c}106,109,111,116 \\
118,131,146\end{array}$ & & & $0 \%$ \\
\hline
\end{tabular}

Based on the $71 \%$ alert rate to the deuterated methyl benzoate, neither the shape odor theory nor the vibrational odor theory is completely substantiated; however since many of the canines did alert to the deuterated form of methyl benzoate, the shape odor theory offers a better explanation than the vibration theory. More data must be collected before a definitive claim can be made. The current study differs from previous studies through the use of the more sensitive canine nose in place of human nose. A more sensitive detection capability might explain the difference from the results reported in previous studies. 
In order to determine if the more sensitive detection capability of canines is a factor, a similar study was run with the hydrogenated and deuterated forms of methyl benzoate using human subjects. The volunteers were asked to take a comparison test of odor for the two compounds using a three phase study of odor recognition. Phase one was a direct comparison of the deuterated methyl benzoate to a second sample of deuterated methyl benzoate from the same stock solution. Phase two was the direct comparison of methyl benzoate to deuterated methyl benzoate. The last phase was a direct comparison of deuterated methyl benzoate to the pure solvent used to create the solutions. For this experiment, the chosen solvent was methylene chloride.

Stock solutions of both compounds (methyl benzoate and d-methyl benzoate) were prepared to $1000 \mu \mathrm{g} / \mathrm{mL}$. Presentation to the human subjects was accomplished by spiking $200 \mu \mathrm{L}$ of the stock solutions onto sterile gauze pads and placed in a weigh boat. Each sample (including the methylene chloride blank) was allowed to sit for $2 \mathrm{~min}$ to allow the solvent to evaporate. At the conclusion of the evaporation time, the three phases of the test were undertaken with a $30 \mathrm{sec}$ interval between each set. Each comparison was presented to each subject in a random order five times per subject to allow a determination of a within subject consistency in addition to the overall discrimination results. For each comparison set, the subjects were asked to rate the odors on a Likert scale ranging from 1 (Extremely different) to 7 (Identical). In each case, the subjects had no prior knowledge about each sample, and the samples had no identifying marks. A box and whisker plot of the results is shown in Figure 82. 


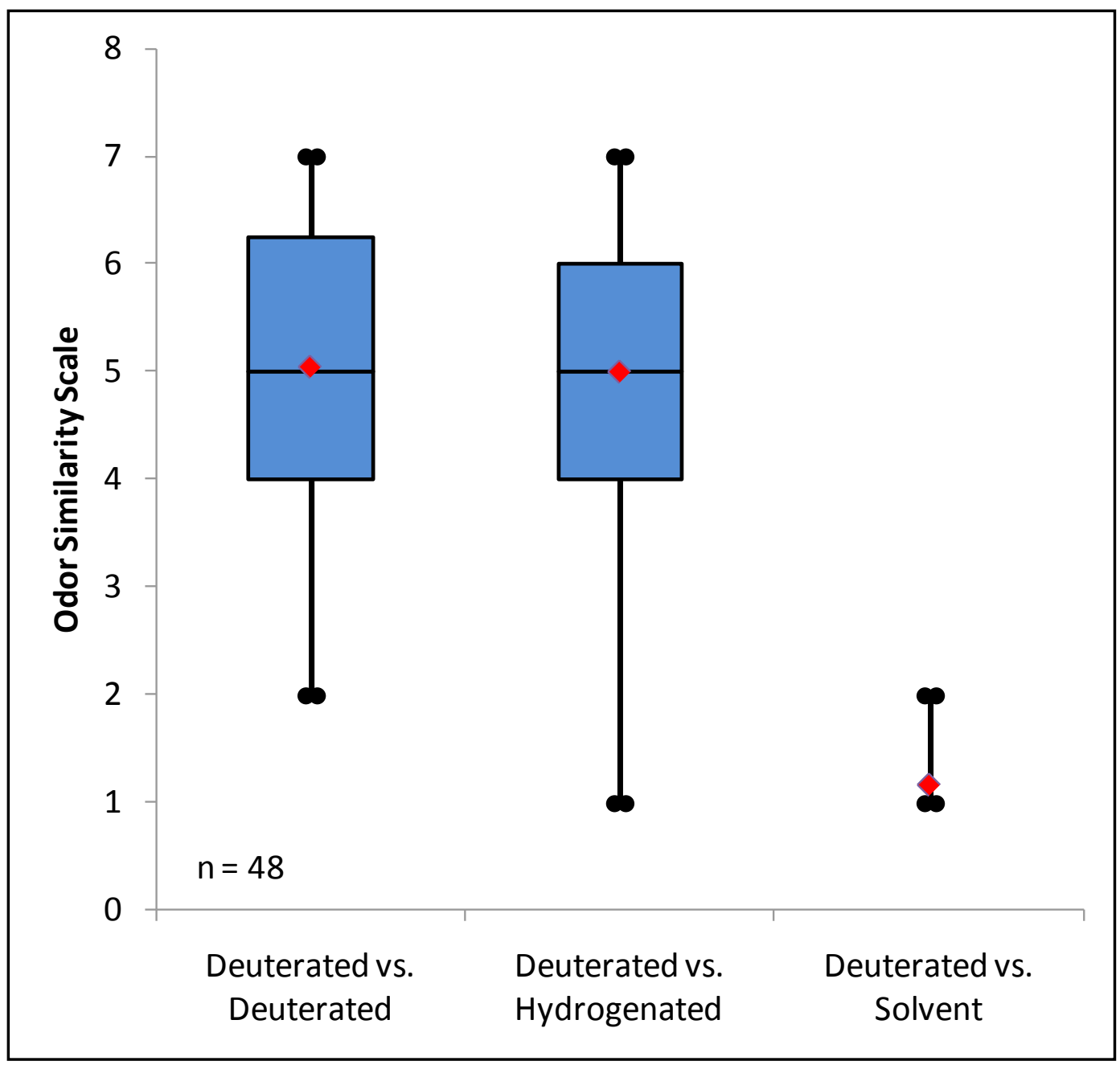

Figure 82 - Results from methyl benzoate isotope comparison trials with human subjects

The fifth trial of data was eliminated from all subjects because of complaints of nasal saturation by the subjects. Additionally, a Dixon test was performed to remove any outliers that were present in each subject's responses. The overall Likert range for the deuterated vs. hydrogenated methyl benzoate (1-7) was larger than that of the deuterated vs. deuterated (2-7); however, the interquartile range was approximately 4-6 for both comparisons. The subjects' responses demonstrate a substantial capacity to detect a difference between the deuterated methyl benzoate and the solvent. As shown in Figure 
82, the mean Likert comparison for the deuterated methyl benzoate vs. the solvent was 1.2 indicating a very strong perceived difference. Whereas the Likert comparison for the deuterated methyl benzoate vs. itself was 5.1 and the deuterated methyl benzoate vs. hydrogenated methyl benzoate was a 5.0, suggesting that these comparisons were perceived to be largely identical. An analysis of variance shows that there was a significant overall difference between the three comparisons $\left(\mathrm{F}_{2,135}=135.1 ; \mathrm{p}<<0.001\right)$. The paired comparisons show that the source of this difference was due to the comparisons to the solvent. The comparisons of the deuterated vs. itself and the deuterated vs. hydrogenated were not significant $\left(\mathrm{F}_{1,88}=0.02, \mathrm{p}=0.9\right)$; however, the other two comparisons (deuterated vs. itself and deuterated vs. hydrogenated) were both significantly different from the deuterated vs. the solvent $\left(\mathrm{F}_{1,90}=271.3, \mathrm{p}<<0.001 ; \mathrm{F}_{1,92}\right.$ $=254.7, \mathrm{p}<<0.001$, respectively). Additionally, the subject's reports failed to show a distinction between the four trials for the deuterated vs. itself $\left(F_{3,40}=0.24, p=0.9\right)$ and the deuterated vs. hydrogenated $\left(\mathrm{F}_{3,42}=0.53, \mathrm{p}=0.7\right)$. The overall results of the human subject testing showed that there were no significant differences across the subjects, nor were there significant differences across the four repetitions, demonstrating that the methodology for collecting the odor comparisons was sound. Similar to the canine results, the shape theory is a better match to the data than the vibration theory. 


\section{CALIBRATION STANDARD EXPERIMENTATION AND RESULTS}

With the advent of field portable detection instrumentation, an immediate comparison was made against the current standard for field odor detection: the canine. Various aspects of the functionality, availability, and expense have been evaluated (Table 8); however, there is no an unbiased, universal comparison standard for biological and instrumental detectors. Canines can be used for a variety of detection purposes (explosive, drug, cadaver, mold, arson, etc.), but no effort has been made for the development of possible calibration/comparison standards across canines. The ideal standard would be comprised of non-target volatile chemicals that could be used to determine the capability of the canine for detection purposes. The benefit of these nontarget chemicals is that they are unlikely to be found in the field during training scenarios as well as in working conditions.

After extensive research, the compound perfluorotributylamine (PFTBA) was chosen as a possible standard. Among the various uses, PFTBA is used as a calibrant for mass spectrometers as well as a fluorocarbon emulsion blood substitute. While it cannot be completely guaranteed that PFTBA would not be present in a field search, the likelihood of a false alert is small. Additionally, the limited usage and application of PFTBA could easily be monitored preventing a possible false alert by a detector.

The present study was conducted as a "proof of concept" to determine if canines could be trained to alert to PFTBA. Samples of PFTBA were supplied to a local dog trainer to incorporate into the training regimen of two canines (Canine 136 and Canine 143). The 
training consisted of three days of presentation and imprint. The training was deemed sufficient by the expertise of the veteran, IFRI certified canine trainer. After successful imprint, a PFTBA sample and blank sample were presented to the canines in a doubleblind fashion. The target odor was prepared by spiking two ampoules of PFTBA onto a sterile piece of gauze and heat-sealed within a 3in x 3in, 2mil LDPE bag. The blank sample consisted of a piece of gauze heat-sealed within the LDPE bag. Both samples were hidden between rows of boxes similar to a typical training scenario. The handlers were instructed to walk their canines in a typical search pattern and identify the canine's response as an alert, no-alert, or interest. The results of these tests are given in Table 33.

Table 33 - Field results from PFTBA training

\begin{tabular}{|c|c|c|c|c|}
\hline Content & No Alert & Interest & Alert & $\%$ Alert \\
\hline PFTBA & - & - & 136,143 & $100 \%$ \\
Blank & 136,143 & - & - & $0 \%$ \\
\hline
\end{tabular}

Both canines ( 2 of 2 ) correctly identified and alerted to the PFTBA sample presented during testing without false alerting to the blank matrix. While the training sequence was shorter than accepted training regimens by most agencies, the canines had no trouble imprinting upon the odor of the sample. The "proof of concept" study shows successful results for the use of PFTBA as an unbiased, universal calibration/comparison standard for biological and instrumental detectors using non-target volatile chemicals. Further 
exploration of the potential of PFTBA needs to be addressed before a final determination can be made. 


\section{CONCLUSIONS}

The results presented in this study offer further explanations about the detection capabilities of canines for MDMA based drugs, heroin, explosives, and firearms. As previously reported, it is not necessary to utilize parent compounds in the training regimen for detection canines. Instead, odor mimics can be used for reliable training.

Piperonal has been shown to be a dominant odor compound in the headspace of some ecstasy (MDMA) samples and a recognizable odor mimic by trained detection canines. It was also shown that detection canines could be imprinted on piperonal and correctly identify ecstasy samples. The threshold level of piperonal (i.e. $\sim 50 \%$ canines with a correct alert) while using the COMPS devices was found to be approximately 100ng/s. This study also reported the discovery of training aid samples of ecstasy without detectable levels of piperonal likely synthesized along an alternate route with different starting compounds. A high degree of variability of MDMA in ecstasy pills taken from different batches was observed, which can result in variable thresholds of detection with MDMA in ecstasy ranging from $8 \%$ to $25 \%$. Based on the common dominant headspace odor compounds from the ecstasy samples tested, it is shown that additional training compounds may be needed to ensure reliable location of MDMA. The compounds MDP2-POH or isosafrole are recommended as the best choices for secondary odorants for MDMA as they are non-controlled and commercially available. The use of a two training aid system should maximize the detection potential of ecstasy samples with biologic detectors. 
Since there is a strong similarity between the odors of vinegar and heroin (i.e. acetic acid), an alternate mimic needs to be developed for detection canine training. No common, secondary compound was detected in the headspace of the available heroin samples or the vinegar samples to help distinguish one group from another. Because of the commonality of acetic acid, a more complex training aid needs to be developed for accurate training for the detection of heroin. The diluted acetic acid samples resulted in complete non-recognition by the trained canines; however, an alternative approach could be to use diluted acetic acid samples with a cutting agent or impurity that is common to the heroin synthesis process.

Because of the similarities within respective explosive classes (i.e. TNT-based, plastics, smokeless powders, etc.), several compounds were chosen for explosive mimics. A single based powder with an easily detectable level of 2,4-DNT was shown to be a reliable mimic for detection training of TNT-based explosives. A double based powder with a high reported level of nitroglycerine was shown to be a reliable mimic for detection training of NG-based explosives. The plasticizer 2-ethyl-1-hexanol was shown to be a reliable mimic for detection training of plastic explosives. The taggant DMNB was shown to be a reliable mimic for detection training of tagged explosives. Ethyl centralite and diphenylamine can be used in combination for reliable mimicry of all single based and double based smokeless powders. The combination of these six odors represents a comprehensive explosive odor kit for the explosive groups they represent. The comprehensiveness of the kit was demonstrated by the training and imprint of the mimics 
on canines followed by testing with actual explosive samples including TNT, C-4, detonation cord, slurry, dynamite, and smokeless powders.

Although the MSDS lists PFTBA as odor-free, the imprint and successive identification by detection canines was reported. The successful imprint of PFTBA opens the possibility for use as a universal, non-target odor compound for comparison and calibration of detection canines and instrumentation.

In a comparison study of shape odor theory versus vibrational odor theory, the detection of d-methyl benzoate and methyl benzoate was explored using trained and certified canine detectors and human subjects. While the results did not prove or disprove one theory over the other, the positive response to the deuterated compound by the canines and the lack of discrimination between the deuterated and hydrogenated isomers of methyl benzoate from the human subjects, suggests that shape odor theory is likely a more appropriate explanation. 


\section{FUTURE WORK}

Additional field studies with trained drug canines using the suggested alternate mimics of MDMA based drugs (i.e. MDP-2-POH and isosafrole) need to be conducted to determine if one is more reliable than the other. Upon determination of the most identified compound, experimentation with imprinting needs be addressed to show that the selected compound is a reliable training aid. Following this, threshold levels need to be determined using COMPS devices.

The headspace of a larger sample set of heroin samples needs to be analyzed to help determine a secondary compound and/or common diluents for accurate mimicry of heroin. Additional field trials with detection canines will be required to determine the similarity of the selected odor mimic with the parent sample.

Although the results of this study have been positive, further imprinting of the explosives kit needs to take place. At the same time, additional field trials need to take place to determine the threshold levels of the six compounds within the explosive kit. In order to determine the threshold levels, COMPS need to be prepared for each compound at varying permeation rates. This can be accomplished by experimentation with the amount of compound, polymer selection, thickness of polymer bag, and size of polymer bag. "When you do things right, people won't be sure you've done anything at all."

Preliminary findings have been shown for PFTBA's use as a universal, non-target odor compound for comparison and calibration of detection canines and instrumentation. More 
imprint and field tests needs to be performed to validate PFTBA as this standard. Experimentation needs to be performed to address the best method for presentation (i.e. delivery matrix) of the calibration standard. In addition, PFTBA needs to be quantified for determination of the sensitivity of the detector prior to use.

The best method of imprinting a detection canine on odors is a topic with a variety of views. One of the most argued points is the initial introduction of the target odors; should it be first presented as a group and later separated into individual odors, or should the target odors be kept separate from the beginning. While both methods are currently used, additional experimentation needs to be undertaken to determine if one method is more effective than the other. 


\section{REFERENCES}

1. Lorenzo, N. Identification of Active Odor Signature Chemicals in Methamphetamine and 3,4-Methylenedioxy-N-mehtamphetamine (Ecstasy) using Canis Familiaris as Biological Detectors. 2002, Florida International University.

2. Furton, K.G.; Hong, Y.; Hsu, Y.; Lue, T.; Rose, S.; Walton, J. "Identification of Odor Signatures Chemicals in Cocaine Using Solid-Phase Microextraction-Gas Chromatography and Detector-Dog Response to Isolated Compounds Spiked on U.S. Paper Currency.” Journal of Chromatographic Science, 2002, 40, 147-155.

3. Harper, R.; Almirall, J.; Furton, K.G. "Identification of dominant odor chemicals emanating from explosives for use in developing optimal training aid combinations and mimics for canine detection." Talanta, 2005, 67(2), 313-327.

4. Manley, N. Narcotics Determination by the Entry Scan and the StreetLab using Ion Mobility Spectrometry and Raman Spectroscopy. 2005, Florida International University.

5. Harper, R.J.; Curran, A.M.; Almirall, J.R.; Furton, K.G. "Developing the Science behind Canine Olfaction of Forensic Specimens." Proc. of the $1^{\text {st }}$ OBSSA, 2004.

6. Levine, B. ed. Principles of Forensic Toxicology, $2^{\text {nd }}$ ed. 2003, AACC Press, Washington, DC.

7. Davenport-Hines, R. The Pursuit of Oblivion. 2001, Weidenfeld \& Nicolson, London, England.

8. Walker, W.O. Drug Control in the Americas. rev. ed., 1989, University of New Mexico Press, Albuquerque, NM.

9. Musto, D.F. The American Disease. 1973, Yale University Press, New Haven, England.

10. Drug Identification Bible 2004/2005. 2004, Amera-Chem, Inc., Grand Junction, Colorado.

11. http://www.usdoj.gov/dea/statistics.html accessed on 4/22/09

12. Basic and Clinical Pharmacology, $9^{\text {th }}$ ed. Bertram G. Katzung, 2004, Lange Medical Books/McGrall Hill Medical Publishing Division, New York, NY.

13. Toxicology: A Case Oriented Approach. John Joseph Fenton, 2002, CRC Press, Boca Raton, FL. 
14. Swist, M.; Wilamowski, J.; Parczewski, A. "Determination of synthesis method of ecstasy based on the basic impurities." Forensic Science International, 2005, 152, $175-184$.

15. Palhol, F.; Boyer, S.; Naulet, N.; Charbrillat, M. "Impurity profiling of seized MDMA tablets by gas chromatography." Anal bioanal Chem, 2002, 374, 274-281.

16. Forces of Habit. David T. Courtwright. 2001, Harvard University Press, Cambridge, Massachusetts.

17. Collins, M.; Casale, E.; Hibbert, D.B.; Panicker, S,; Robertson, J.; Vujie, S. "Chemical profiling of heroin recovered from the North Korean merchant vellel Pong Su.” J. Forensic Sci., 2006, 51(3). 597-602.

18. Chiarotti, M.; Fucci, N.; Furnari, C. "Comparative analysis of illicit heroin samples.” Forensic Science International, 1991, 50, 47-55.

19. http://en.wikipedia.org/wiki/File:HeroinWorld-en.svg accessed on 5/5/08

20. Robbins, T.W.; Sahakian, B.J. "'Paradoxical' effects of psychomotor stimulant drugs in hyperactive children from the standpoint of behavioral pharmacology." Neuropharmacology, 1979, 18(12), 931-950.

21. Heramb, R.M.; McCord, B.R. "The Manufacture of Smokeless Powders and their Forensic Analysis: A Brief Review." Forensic Science Communications, 2002, $4(2)$.

22. Introduction to Explosives, FBI Bomb Data Center. US Department of Justice, 1981.

23. Black and Smokeless Powders: Technologies for Finding Bombs and the Bomb Makers. 2004, National Academy Press, Washington, D.C.

24. Science and civilisation in China, vol 5, part 7. Joseph Needham, University Press Cambridge, England, 1986.

25. Conkling, J.A. "Chemistry of Fireworks.” C\&EN, 1981, 59(26), 24-32.

26. Powell, W. The Anarchist Cookbook. 2002, Ozark Press, LLC, El Dorado, AR.

27. Furton, K.G.; Myers, L.J. "The scientific foundation and efficacy of the use of canines as chemical detectors for explosives.” Talanta, 2001, 54, 487-500.

28. Akhavan, J. The Chemistry of Explosives. $2^{\text {nd }}$ ed., 2004, The Royal Society of Scotland. 
29. Agrawal, J.P.; Hodgson, R.D. Organic Chemistry of Explosives. 2007, Wiley \& Sons Ltd, West Sussex, England.

30. Beveridge, A, ed. Forensic Investigation of Explosions. 1998, Taylor \& Francis, London, England.

31. International Civil Aviation Organization (ICAO). "Convention on the Marking of Plastic Explosives for the Purpose of Detection”, Document No. 9571. Montreal, Quebec, March 1, 1991.

32. Yinon, J. ed. Counterterrorist Detection Techniques of Explosives. Chapter 15. 2007, Elsevier, Amsterdam, The Netherlands.

33. Bachmann, W.E.; Sheehan, J.C. "A New Method of Preparing the High Explosive RDX." Journal of the American Chemical Society, 1949, 71(5), 1842-1845.

34. Forensic Science Handbook, $2^{\text {nd }}$ ed. Vol 1. Richard Saferstein, editor. 2002, Prentice Hall, Upper Saddle River, New Jersey.

35. Brown, B.G. et al. "The Mechanisms of Nitroglycerine Action: Stenosis Vasodilatation as a Major Component of the Drug Response." Ciculation, 1981, 64(6), 1089-1097.

36. Wolffenstein, R. "Uber die einwirkung von wasserstoffsuperoxyd auf aceton und mesityloxyd." Chem. Ber., 1895, 28, 2265-2269.

37. http://www.timesonline.co.uk/tol/news/uk/article544334.ece accessed on 4/28/09

38. http://www.time.com/time/nation/article/0,8599,1225453,00.html accessed on $4 / 28 / 09$

39. Widmer, L.; Watson, S.; Schlatter, K.; Crowson, A. "Development of an LC/MS method for the trace analysis of triacetone triperoxide (TATP)." Analyst, 2002, 127, $1627-1632$.

40. Legler, L. Chem. Ber., 1881, 14, 602-604.

41. http://www.nytimes.com/2006/08/28/world/europe/28plot.html? $\mathrm{r}=1$ accessed on $4 / 28 / 09$

42. http://www.swgdog.org accessed on 6/30/09

43. http://en.wikipedia.org/wiki/File:Olfactory system.svg accessed on 5/7/08

44. Rinaldi, A. "The scent of life. The exquisite complexity of the sense of smell in animals and humans." EMBO Rep., 2007, 8(7), 629-33. 
45. Hallem E.A.; Dahanukar, A.; Carlson, J.R. "Insect odor and taste receptors." Annu. Rev. Entomol., 2006, 51, 113-35.

46. Johnson, B.A. et al. "Local and global chemotopic organization: General features of the glomerular representations of aliphatic odorants differing in carbon number." Journal of Comparative Neurology, 2004, 480(2), 234-249.

47. Mistafa, R. K9 Explosive Detection. 1998, Detselig Enterprises Ltd., Calgary, Canada.

48. Lorenzo, N.; Wan, T.; Harper, R.; Hsu, Y.; Chow, M.; Rose, S.; Furton, KG.. "Laboratory and field experiments used to identify Canis lupus var. familiaris active odor signature chemicals from drugs, explosives, and humans." Anal. Bioanal Chem, 2003, 376, 1212-1224.

49. Furton, K.G.; Hsu,Y; Luo, T.; Wang, J.; Rose, S. "Odor Signatures of Cocaine Analyzed by GC/MS and Threshold levels of Detection for Drug Detection Canines." Curr. Top. Forensic Sci, Proc. Meet. Int. Assoc. Forensic Sci., 1997, 14(2), 329-332.

50. Hood, L.V.; Dames, M.E.; Barry, G.T. "Headspace volatiles of marijuana.” Nature, 1973, 242, 402-403.

51. Hood, L.V.; Barry, G.T. "Headspace volatiles of marijuana and hashish: GC analysis of samples." Journal of Chromatography, 1978, 166(2), 499-506.

52. Krausa, M.; Massong, H.; Rabenecker, P.; Ziegler, H. "Chemical methods for the detection of mines and explosives." NATO science series, 2002, 66(II), 1-19.

53. Buchbauer, G.; Nikiforov, A.; Remberg, B. "Headspace Constituents of Opium." Planta Medica. 1994, 60(2), 181-183.

54. Jenkins, T.F.; Legett, D.C.; Miyares, P.H.; Walsh, M.E.; Ranny, T.T.; Cragin, J.H.; George, V. "Chemical signatures of TNT-filled land mines." Talanta, 2001, 54, 501-513.

55. Vu, D.T. "SPME/GC-MS Characterization of Volatiles Associated with Methamphetamine: Toward the Development of a Pseudomethamphetamine Training Material.” J. Forensic Sci., 2001, 46(5), 1014-1024.

56. http://findarticles.com/p/articles/mi_hb5553/is_200107/ai_n21524201/accessed on $12 / 8 / 08$

57. Furton, K.G.; Harper, R. Detection of Ignitable Liquid Residues in Fire Scenes Accelerant Detection Canine (ADC) Teams and other Field Tests, in Advances in Forensic Science Techniques: Interpretation of Fire Scene Evidence, 2004, CRC Press, Boca Raton, FL. 
58. Furton, K.G.; Heller, D.P. "Advances in the reliable location of forensic specimens through research and consensus best practice guidelines for dog and orthogonal instrumental detectors." Canadian Journal of Police \& Security Services, 2005, 3(2), 97-107.

59. Kauhanen, E.; Harri, M.; Nevalainen, A.; Nevalainen, T. "Validity of detection of microbial growth in buildings by trained dogs." Environment International, 2002, 28(3), 153-157.

60. Griffith, R.T.; Jayachandran, K.; Whitstine, W.; Furton, K.G. "Differentiation of Toxic Molds via Headspace SPME-GC/MS and Canine Detection." Sensors, 2007, 7, 1415-1427.

61. Gazit, I.; Terkel, J. "Domination of olfaction over vision in explosives detection by dogs.” Applied Animal Behaviour Science, 2003, 82, 65-73.

62. Issel-Tarver, L.; Rine, J. "The Evolution of Mammalian Olfactory Receptor Genes." Genetics, 1997, 145, 185-195.

63. Quignon, P. et al. "Comparison of the canine and human olfactory receptor gene repertoires.” Genome Biolgoy, 2003, 4(12), R80.

64. Vanin, E.F. "Processed Pseudogenes: Characteristics and Evolution." Ann. Rev. Genet., 1985, 19, 253-272.

65. Settles, G.S. "Sniffers: Fluid-Dynamics Sampling for Olfactory Trace Detection in Nature and Homeland Security -The 2004 Freeman Scholar Lecture." J. of Fluid Eng., 2005, 127, 189-218.

66. Settles, G.S.; Kester, D.A. "Aerodynamic sampling for landmine trace detection." SPIE Aerosense, 2001, 4394, Paper 108.

67. Bonadio, F.; Margot, P.; Dele'mont, O.; Esseiva, P. "Headspace solid-phase microextraction (HS-SPME) and liquid-liquid extraction (LLE): Comparison of the performance in classification of ecstasy tablets (Part 2)"' Forensic Science International, 2008, 182, 52-56.

68. Harper, R. Improving the Scientific Reliability of Biological Detection of Explosives by Canis Familiaris: Active Odor Signatures and Their Implications. 2005, Florida International University.

69. Williams, J.M. Determining Dogs' Odor Detection Signature of a Selected Smokeless Powder. 1998, Auburn University.

70. Johnston, J.M. et al. "Canine detection odor signatures for mine-related explosives." Proc. of SPIE, 1998, 3392 (Pt. 1), 490-501. 
71. Williams, J.M. “Canine Detection odor signatures for explosives.” Proc. of SPIE, 1998, 3575, 291-301.

72. Otto, J.; Brown, M.F; Long, W. "Training rats to search and alert on contraband odors." Applied Animal Behaviour Science, 2002, 77, 217-232.

73. Verhagen, R., Weetjens, F., Cox, C., Weetjens, B., Billet, M. "Rats to the Rescue: Results of the First Tests on a Real Minefield." J. Mine Action, 2006, 9(2).

74. Claus, R.; Hoppen, H.O.; Karg, H. "The secret of truffles: A steroidal pheromone?" Cellular and Microcellular Life Sciences, 1981, 37(11), 1178-1179.Townsend, J. Pigs: A Demining Tool of the Future? J. Mine Action, 2003, 7(3).

75. Townsend, J. "Pigs: A Demining Tool of the Future?" J. Mine Action, 2003, 7(3).

76. Olson, D.M.; Rains, G.C.; Meiners, T.; Takasu, K.; Tertuliano, M.; Tumlinson, J.H.; Wäckers, F.L.; Lewis, W.J. "Parasitic Wasps Learn and Report Diverse Chemicals with Unique Conditionable Behaviors." Chem. Senses, 2003, 28, 545549.

77. Rains, G.C.; Tomberlin, J.K.; Kulasiri, D. "Using insect sniffing devices for detection." Trends in Biotechnology, 2008, 26(6), 288-294.

78. Bromenshenk, J.J., Henderson, C.B., Seccomb, R.A., Rice, S.D., Etter, R.T.,Bender, S.F.A., Rodacy, P.J., Shaw, J.A., Seldomridge, N.L., Spangler, L.H.,Wilson, J.J. "Can Honey Bees Assist in Area Reduction and Landmine Detection?" J. Mine Action, 2003, 7(3).

79. Anderson, G.; Prior, D.; Gilbert, R. "RF Tagging of Insects: Honeybees for Land Mine Detection." Computing and Information Sciences: Annual report no. PNNL13184, 1999, William R. Wiley Environmental Molecular Sciences Laboratory.

80. Shaw, J.A.; Seldomridge, N.L.; Dunkle, D.L.; Nugent, P.W.; Spangler, L.H. "Polarization lidar measurements of honey bees in flight for locating land mines." Optics Express, 2005, 13(15), 5853-5863.

81. http://www.aresa.dk/billedgalleri.html and http://www.aresa.dk/index.php?page=78 accessed on $5 / 9 / 2008$

82. http://www.epa.gov/nerlesd1/land-sci/srsv/images/fischer.pdf accessed on 8/3/2006

83. Antunes, M.S.; Ha, S.; Tewari-Singh, N.; Morey, K.J.; Trofka, A.M.; Kugrens, P.; Deyholo, M.; Medford, J.I. "A synthetic de-greening gene circuit provides a reporting system that is remotely detectable and has a re-set capacity." Plant Biotechnology Journal, 2006, 4(6), 605-622. 
84. Radhika, V.; Proikas-Cezanne, T.; Jayaraman, M.; Onesime, D.; Ha, J.H.; Dhanasekaran, D.N. "Chemical sensing of DNT by engineered olfactory yeast strain." Nature Chemical Biology, 2007, 3(6), 325-330.

85. Altamirano, M.; Garc'1a-Villada, L.; Agrelo, M.; Sánchez-Martın, L.; Martın-Otero, L.; Flores-Moya, A.; Rico, M.; López-Rodas, V.; Costas, E. “A novel approach to improve specificity of algal biosensors using wild-type and resistant mutants: an application to detect TNT." Biosensors and Bioelectronics, 2004, 19, 1319-1323.

86. Macias, M.S.; Furton, K.G. "MDMA Synthesis affecting canine detection." Proceedings of the 61st Annual Meeting of the American Academy of Forensic Sciences, 2009, A165, 136.

87. Blais, I.; Terkel, J.; Goldblatt, A. "Long-Term Impact of Early Olfactory Experience on Later Olfactory Conditioning." Developmental Psychobiology, 2006, 48(7), 501-507.

88. Gazit, I.; Goldblatt, A.; Terkel, J. "The role of context specificity in learning" the effects of training context on explosives detection in dogs." Anim. Cogn., 2005, 8, 143-150.

89. Li, X.; Zeng, Z.; Zeng, Y. "Solid-phase microextraction couples to gas chromatography for the determination of 2.3-dimethyl-2.3-dinitrobutate as a marking agent for explosives." Talanta, 2007, 72, 1581-1585.

90. Curran, A.M.; Rabin, S.C.; Prada, P.A.; Furton, K.G. "Comparison of the Volatile Organic Compounds Present in Human Odor Using Spme-GC/MS.” J. of Chem. Ecology, 2005, 31(7), 1607-1619.

91. Wu, C.H.; Chen, C.L.; Huang, C.T.; Lee, M.R.; Huang, C.M. "Identification of Gasoline Soot in Suspect Arson Cases by Using Headspace Solid Phase Microextraction-GC/MS.” Analytical Letters, 2004, 37(7), 1373 - 1384.

92. Lee, X.P.; Kumazawa, T.; Sato, K.; Suzuki, O. "Detection of organophosphate pesticides in human body fluids by headspace solid-phase microextraction (SPME) and capillary gas chromatography with nitrogen-phosphorus detection." Chromatographia, 1996, 42(3), 135-140.

93. Yinon, J.; Zitrin, S. ed. Modern Methods and Applications in Analysis of Explosives. 1993, John Wiley \& Sons Inc., Chichester, West Sussex, England.

94. Woodfin, R.L. ed. Trace Chemical Sensing of Explosives. 2007, John Wiley \& Sons Inc., Hoboken, New Jersey.

95. Perr, J.M.; Furton, K.G.; Almirall, J.R. "Solid phase microextraction ion mobility spectrometer interface for explosive and taggant detection.” J. Sep. Sci., 2005, 28, 177-183. 
96. Joshi, M. et al. "Detection of odor signatures of smokeless powders using sold phase microextraction couples to an ion mobility spectrometer." For. Sci. Int., 2009, $188,112-118$.

97. Lai, H. et al. "Analysis of volatile components of drugs and explosives by solid phase microextraction-ion mobility spectrometry." J. Sep. Sci., 2008, 31, 402-412.

98. Guerra, P.; Lai, H.; Almirall, J.R. "Analysis of volatile chemical markers of explosives using novel solid phase microextraction coupled to ion mobility spectrometry.” J. Sep. Sci., 2008, 31, 2891-2898.

99. Gardner, J.W.; Yinon, J. Electronic Noses \& Sensors for the Detection of Explosive. 2004, NATO ASI Series, Kluwer Academic Publishers, Dordrecht.

100. Fernandes, D.L.A.; Gomes, M.T.S.R. "Development of an electronic nose to identify and quantify volatile hazardous compounds ." Talanta, 2008, 77(1), 77-83.

101. El Barbri, N.; Llobet, E.; El Bari, N.; Correig, X.; Bouchikhi, B. "Electronic nose based on metal oxide semiconductor sensors as an alternative technique for the spoilage classification of red meat." Sensors, 2008, 8(1), 142-156.

102. Yadava, R. D. S.; Chaudhary, Ruchi. "Solvation, transduction and independent component analysis for pattern recognition in SAW electronic nose." Sensors and Actuators, B: Chemical, 2006, B113(1), 1-21.

103. Zhao, W.; Pinnaduwage, L.A.; Leis, J.W.; Gehl, A.C.; Allman, S.L.; Shepp, A.; Mahmud, K.K. "Identification and quantification of components in ternary vapor mixtures using a microelectromechanical-system-based electronic nose." Journal of Applied Physics, 2008, 103(10), 104902/1-104902/11.

104. Johnston, J.M. "Canine Detection Capabilities: Operational Implications of Recent R \& D Findings.” Institute for Biological Detections Systems, Auburn University, AL, 1999.

105. Howard, P.H. Handbook of Environmental Fate and Exposure Data for Organic Chemicals. 1997, CRC Press, Boca Raton, FL, 280-285.

106. http://www.incb.org/pdf/precursors-report/2007/en/annexes.pdf accessed on 6-2709

107. Macias, M.S. et al. "Detection of piperonal emitted from polymer controlled odor mimic permeation systems utilizing Canis familiaris and solid phase microextraction-ion mobility spectrometry." For. Sci. Int., 2009, in press.

108. Kahn, J.H.; Nickol, G.B.; Conner, H.A. "Analysis of vinegar by gas-liquid chromatography”, J. Agr. Food Chem., 1966, 14(5), 460-465. 
109. Aurand, L.W.; Singleton, J.A.; Bell, T.A., Etchells, J.L. "Voltile Components in the vapors of natural and distilled vinegars", Journal of Food Science, 2006, 31(2), $172-177$.

110. Curran, A.; Ramirez, C.F.' Schoon, A.A.; Furton, K.G. "The frequency and discriminatory power of compounds found in human scent across a population determined by SPME-GC/MS." J of Chromatography B, 2007, 846, 86-97.

111. http://www.osha.gov/dts/chemicalsampling/toc/toc chemsamp.html accessed on $11 / 29 / 08$

112. Thomas, S.W.; Amara, J.P.; Bjork, R.E.; Swager, T.M. "Amplifying fluorescent polymer sensors for the explosives taggant 2,3-dimethyl-2,3-dinitrobutane (DMNB).” Chem. Commun., 2005, 4572-4574.

113. Amoore, J. E. "Stereochemical theory of olfaction - Identification of seven primary odours." Proceedings of the Scientific Section of the Toilet Goods Association, 1962, 37, 1-12.

114. Beets, M.G.J. “Odor and molecular constitution.” American Perfumer and Aromatics, 1961, 76, 654-663.

115. Buck, L.; Axel, R. “A novel muitigene family may encode odorant receptors: a molecular basis for odor recognition." Cell, 1991, 65(1), 175-187.

116. Dyson, G.M. "The scientific basis of odor." Chemistry and Industry, 1938, 57, 647651.

117. Wright, R H. "Odor and molecular vibration: neural coding of olfactory information." J Theor Biol, 1977, 64(3), 473-502.

118. Turin, L. "A spectroscopic mechanism for primary olfactory reception." Chemical Senses, 1996, 21(6), 773-791.

119. Keller, A.; Vosshall, L. "A psychophysical test of the vibration theory of olfaction." Nature Neuroscience, 2004, 7(4), 337-338. 
APPENDICES 


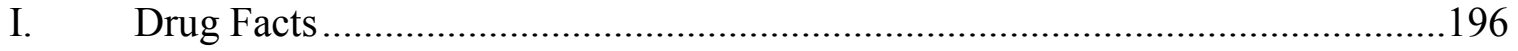

II. Explosive List/Commercial Sources ...............................................................201

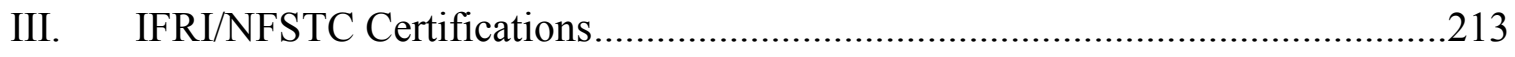




\section{Drug Facts}

The following pages give details about mainstream, illicit drugs including common street names, Control Substance Abuse Act (CSA) schedule, and street prices [10].

\section{Amphetamines/Methamphetamines}

CSA Schedule: II

Street Price: $\$ 20$ - \$300 per gram

Street Names: Batu, Black beauties, Clalk, Copilots, Crack meth, Crank, Cristy, Crystal, Dexied, Drivers, Glass, Go, Go fast, Hanyak, Hawaiian salt, Hearts, Hiropon, Ice, Kaksonjae, L.A. turnarounds, Leapers, Meth, Pep pills, Quartz, Shabu, Speed, Tweak, Thrusters, Ups, Uppers, Wake ups wire, Zip

\section{Anabolic Steroids}

CSA Schedule: III

Street Price: $\$ 15$ - $\$ 1000$ per bottle of tablets, capsules or liquid injection

Street Names: Anabolic steroids, Androgens, Hormones, Juice, Gym candy, Roids, Steroids, Vitamins

\section{Cocaine}

CSA Schedule: II

Street Price:

Cocaine $\mathrm{HCl}$ - \$20 - \$200 per gram

Crack - $\$ 5$ - $\$ 100$ per rock 
Street Names:

Cocaine HCL - Bernice, Big C, Blow, C, Crack Chick, Coke, Corine, Dust, Flake, Girl, Happy Dust, Her, Nieve, Nose candy, Nose stuff, Snow, Toot, Uptown, White, White girl Crack - Base, Hubba, Roca, Rock, Crack, Roxanne, White pipe

\section{GHB (gamma-hydroxybuyrate)}

\section{CSA Schedule: I}

Street Price: $\$ 2$ - $\$ 30$ per dose

Street Names: Date rape drug, Easy lay, Ever clear, Fantasy, G, Gamma 10, Gamma OH, GBH, Georgia home boy, GHB, Great hormones at bedtime, Grievous bodily harm, Liquid E, Liquid ecstasy, Liquid X, Nature's qualude, Salty water, Scoop, Water

\section{Heroin}

\section{CSA Schedule: I}

Street Price:

Powder $-\$ 70$ - $\$ 600$ per gram

Black Tar - $\$ 50$ - $\$ 00$ per gram

Street Names:

Powder Heroin - Antifreeze, Big daddy, Big H, Big harry, Boy, Brown, Brown heroin, Brown stuff, Brown sugar, Caballo, Carga, China man, Crap, Doje, Downtown, Dyno, Estuffa, Garbage, Globo, H, Hard stuff, Harry, Him, Hombre, Horse, Junk, Lemon dope, Mierda, Persian, Fufus scag, Schmeck, Shit skag, Smack, Smeck, Stoffa, Stuff, White stuff 
Tar Heroin - Ball, Black heroin, Black tar, Chapapote, Chiva, Chocolate, Goma, Gomero, Gum, Gumball, Mexican mud, Muc, Pedazo, Tootsie roll

\section{Ketamine}

CSA Schedule: III

Street Price: $\$ 10$ - \$125 per 10mLvial of liquid, $\$ 10$ - \$125 per gram of powder

Street Names: Animal tranquilizer, Cat valium, K, Ket, Kit kat, Special K, Super K, Vitamin K

\section{LSD (d-lysergic acid diethylamide)}

CSA Schedule: I

Street Price: $\$ 0.60$ - \$15 per hit

Street Names: Acid, Big D, Blotter, Blotter acid, Blue heaven, California sunshine, Cube, D, Dose, Dot, L, Microdot, Paper acid, Royal blue, Sandoz, Sheet acid, Sid, Spots, Sunshine, Ticket, Window pane

\section{Marijuana}

\section{CSA Schedule: I}

Street Price:

Commercial -\$25 - \$1200 per ounce

Hash - \$6 - \$20 per gram

Hash Oil - \$35 - \$55 
Street Names: Astro turf, Bhang, Bush, Cannabis, Charas, Daga, Ditch weed, Dope, Doobie, Ganja, Grass, Green, Grifa, Hay, Hemp, Herb, Hierba, Home grown, Indica, J, Jay, Jane, Juanita, Junk weed, Kali, Kif, Hush, Leaf, Marijuana, Mary, Mary Jane, MJ, Mota, Northern light, Pakalolo, Punta roja, Ragweed, Reefer, Roach, Sativa, Sens, Sins, Sinsemilla, Smoke, Stink Weed, Tea, Texas Tea, THC, Wachy weed, Weed, Zacate

\section{MDMA (3,4-methylenedioxymethamphetamine)}

CSA Schedule: I

Street Price: $\$ 10$ - $\$ 60$ per tablet

Street Names: Adam, Ecstasy, X, Xtc, Clarity, Essence, Doctor, Love drug

\section{PCP (1-1-phenylcyclohexyl piperidine)}

CSA Schedule: II

Street Price:

Powder $-\$ 125$ - $\$ 1000$ per liquid ounce

Black Tar - $\$ 800$ - $\$ 3000$ per powder ounce

Street Names: Ace, Angel dust, Animal tranquilizer, Crystal, Dead on arrival, DOA, Dust, Eliephant, Embalming fluid, Formaldehyde, Hog, Illy, Jet fuel, Juice, Killer joints, Lovely, Monkey, Ozone, Rocket fuel, , Supergrass, Tac, Tic, Trank, Wack

\section{Peyote}

CSA Schedule: I

Street Price: $\$ 5$ - $\$ 20$ per button 
Street Names: Buttons, Cactus, Cactus buttons, Chief, Dry whiskey, Green whiskey, Hikuri, Mecs, Mescal, Mescaline, Mescalito, Peyote, Peyoti, Topi, Tops

\section{Psilocybin Mushrooms}

CSA Schedule: I

Street Price: $\$ 3$ - \$15 per gram

Street Names: Food of the gods, Funny mushrooms, Happy mushrooms, Magic mushrooms, Mushrooms, Sacred mushrooms, Shrooms, Teonanacatlm, Blue halo 


\section{Tables of Explosives by Category}

The following is a set of tables that list commercially available explosives, alternate

names, component make-up and company of origin based on relative purity. Table A, B, $\mathrm{C}$ and $\mathrm{D}$ are TNT, PETN, RDX, and ammonium nitrated based explosives, respectively.

A. Commercially Available Products Containing TNT in Approximate Order of Relative Purity

\begin{tabular}{|c|c|c|}
\hline Product Name & Components & Company \\
\hline TNT & TNT $100 \%$ & AES \\
\hline OCTOL & TNT + HMX & AES \\
\hline Pentolite & $\mathrm{PETN}+\mathrm{TNT}$ & AES \\
\hline $\begin{array}{l}\text { Pentex Boosters } \\
\text { Other Names: Pentex CD } 3 * 90 \text {, Pentex CD } 5.5 * 150 \text {, Pentex CD } 8 * 227 \text {, } \\
\text { Pentex CD } 12 * 340 \text {, Pentex CD } 16 * 454 \text {, Pentex SB 8, Pentex SB } 20, \\
\text { Pentex SB } 60, \text { Pentex SL } 8 * 227, \text { Pentex SL } 12 * 340, \text { Pentex SL } 16 * 454\end{array}$ & TNT + PETN & ORICA \\
\hline Pentolite Pellet & $\mathrm{PETN}+\mathrm{TNT}$ & AES \\
\hline $\begin{array}{l}\text { BST }{ }^{\mathrm{TM}} \& \text { Pentex } \\
\text { Other Names: Cast Boosters, Cord Sensitive Boosters, MPB Boosters, } \\
\text { Pentex }{ }^{\mathrm{TM}} \text { AP Boosters, BSX Boosters, OSX-8 Boosters, Seismic Boosters }\end{array}$ & $\mathrm{RDX}+\mathrm{TNT}+\mathrm{PETN}$ & ORICA \\
\hline Composition B & $\mathrm{RDX}+\mathrm{TNT}+\mathrm{D} \cdot \mathrm{Wax}$ & AES \\
\hline $\begin{array}{l}\text { Cast Boosters, Seismic } \\
\text { Other Names: Geoprime } ₫ \text {, Geoprime }{ }^{\circledR} \mathrm{dBX}^{\mathrm{TM}}\end{array}$ & $\mathrm{TNT}+\mathrm{PETN}+\mathrm{Al}$ & $\begin{array}{l}\text { DYNO NOBEL } \\
\text { INC }\end{array}$ \\
\hline ACCURATE'S CAST BOOSTERS & $\begin{array}{l}\text { TNT + RDX + HMX } \\
+ \text { PETN + D.Wax }\end{array}$ & AES \\
\hline 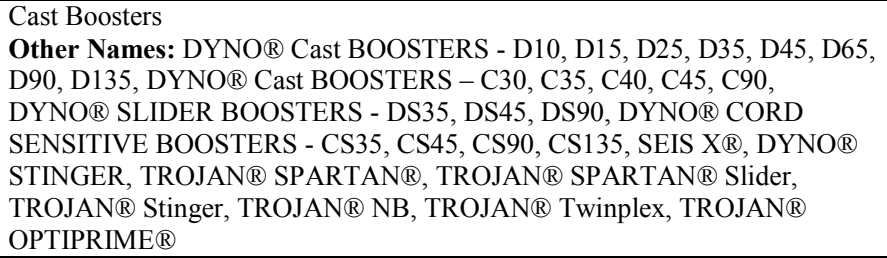 & $\begin{array}{l}\mathrm{RDX}+\mathrm{PETN}+\mathrm{TNT}+ \\
\mathrm{HMX}+\mathrm{Al}\end{array}$ & $\begin{array}{l}\text { DYNO NOBEL } \\
\text { INC }\end{array}$ \\
\hline $\begin{array}{l}\text { i-kon Electronic Detonators } \\
\text { Other Names: PBS } 2000 \text { or Globaldet }\end{array}$ & $\begin{array}{l}\text { TNT }+ \text { Lead azide + lead } \\
\text { chromate }\end{array}$ & ORICA \\
\hline DES series, DES Shaped Charges, Seismic Directional Energy System & $\begin{array}{c}\text { TNT + PETN + Pentolite (is } \\
\text { a mixture of PETN and } \\
\text { TNT) }\end{array}$ & $\begin{array}{c}\text { AUSTIN Powder } \\
\text { Company }\end{array}$ \\
\hline $\begin{array}{l}\text { ACP Boosters } \\
\text { Other Names: Orange Cap, Orange Cap R, Red Cap, Black Cap, Brown } \\
\text { Cap, Green Cap, Purple Cap, White Cap, Gray Cap, etc., NDS Boosters, ADP } \\
\text { Boosters, Gold Nugget, Silver Nugget, Diamond Nugget,DES Series, DES } \\
\text { Pentolite Charges, Rock Crushers, } 60 \text { Gram, } 90 \text { Gram, 110 Gram, DES } \\
\text { Shaped Charges, Prime Gel*, Renforcatuers, HDP 150, HDP 400, HDP } \\
\text { 400LP, HDP 450, Doubledet, Ringprime, Snow Launcher Series, Hornet } \\
\text { Series, Enviroprime Series and Electro Star Series. }\end{array}$ & $\begin{array}{l}\text { TNT + PETN + HMX + } \\
\text { RDX + Al + Pentolite }\end{array}$ & $\begin{array}{l}\text { AUSTIN Powder } \\
\text { Company }\end{array}$ \\
\hline FUSE CAPS NO. 6, NO. 8, Non-Electric Caps & $\begin{array}{l}\text { PETN + TNT + Lead Azide } \\
\text { + Lead Styphnate }\end{array}$ & $\begin{array}{l}\text { AUSTIN Powder } \\
\text { Company }\end{array}$ \\
\hline $\begin{array}{l}\text { Detonators } \\
\text { Other Names: Rock* Star, Time* Star, Coal Mine Delays, Seismic* Star, } \\
\text { Static*Star, 3-D Star Seismic Detonators, E*Star, Electro*Star Electronic } \\
\text { Detonators, Electric Blasting Caps }\end{array}$ & $\begin{array}{c}\text { PETN + TNT + Lead Azide } \\
\quad+\text { Lead Styphnate }\end{array}$ & $\begin{array}{l}\text { AUSTIN Powder } \\
\text { Company }\end{array}$ \\
\hline
\end{tabular}




\section{B. Commercially Available Products Containing PETN in Approximate Order of Relative Purity}

\begin{tabular}{|c|c|c|}
\hline Product Name & Components & Company \\
\hline PETN & PETN $100 \%$ & AES \\
\hline $\begin{array}{l}\text { Detonator Cords } \\
\text { Other Names: Lite Line, Scotch Cord, A-Cord, No. 40, No. 50, No. 60, } \\
\text { No.80 etc. Seismic Detonating Cord, Slide Line Series, Heavy Duty Series, } \\
\text { Cordeau Detonant Fuse, Cord, Detonating, Flexible, Special 18, 25, 30,40 } \\
\text { and 50. Detonating Cord C3 }\end{array}$ & PETN & $\begin{array}{l}\text { AUSTIN Powder } \\
\text { Company }\end{array}$ \\
\hline Perfacord ${ }^{\circledR}$ PETN, HD Perfacord, Perfacord Lite, 80 PETN & PETN & $\begin{array}{c}\text { DETOTEC } \\
\text { NORTH } \\
\text { AMERICA, INC. }\end{array}$ \\
\hline FS Seismic, Cordeau Detonate Fuse, Cord, Detonating, Flexible & $\mathrm{PETN}+\mathrm{PVC}$ & $\begin{array}{l}\text { AUSTIN Powder } \\
\text { Company }\end{array}$ \\
\hline Pentolite, Pentolite Pellet & $\mathrm{PETN}+\mathrm{TNT}$ & AES \\
\hline $\begin{array}{l}\text { Pentex Boosters } \\
\text { Other Name: Pentex CD } 3 * 90 \text {, Pentex CD } 5.5 * 150 \text {, Pentex CD } 8 * 227 \text {, } \\
\text { Pentex CD } 12 * 340 \text {, Pentex CD } 16 * 454 \text {, Pentex SB 8, Pentex SB } 20 \text {, } \\
\text { Pentex SB } 60 \text {, Pentex SL } 8 * 227 \text {, Pentex SL } 12 * 340 \text {, Pentex SL } 16 * 454\end{array}$ & $\mathrm{TNT}+\mathrm{PETN}$ & ORICA \\
\hline $\begin{array}{l}\text { Cast Boosters, Seismic } \\
\text { Other Names: Geoprime }{ }^{\circledR} \text {, Geoprime }{ }^{\circledR} \mathrm{dBX}^{\mathrm{TM}}\end{array}$ & $\mathrm{TNT}+\mathrm{PETN}+\mathrm{Al}$ & $\begin{array}{l}\text { DYNO NOBEL } \\
\text { INC }\end{array}$ \\
\hline $\begin{array}{l}\text { BST TM } \& \text { Pentex }^{\mathrm{TM}} \text { Cast Boosters } \\
\text { Other Names: Cast Boosters, Cord Sensitive Boosters, MPB Boosters, } \\
\text { Pentex }{ }^{\mathrm{TM}} \text { AP Boosters, BSX Boosters, OSX-8 Boosters, Seismic Boosters }\end{array}$ & $\mathrm{RDX}+\mathrm{TNT}+\mathrm{PETN}$ & ORICA \\
\hline DETONATING CORD with PETN & $\mathrm{PETN}+\mathrm{Al}+\mathrm{Pb}+$ Pewter & AES \\
\hline LINEAR SHAPED CHARGE with PETN & $\mathrm{PETN}+\mathrm{Al}+\mathrm{Pb}+$ Pewter & AES \\
\hline LINEAR SHAPED CHARGE with PETN, Desensitized & $\begin{array}{c}\text { PETN + Al + Pb + Cu }+ \\
\text { Pewter + D.Wax + Graphite }\end{array}$ & AES \\
\hline 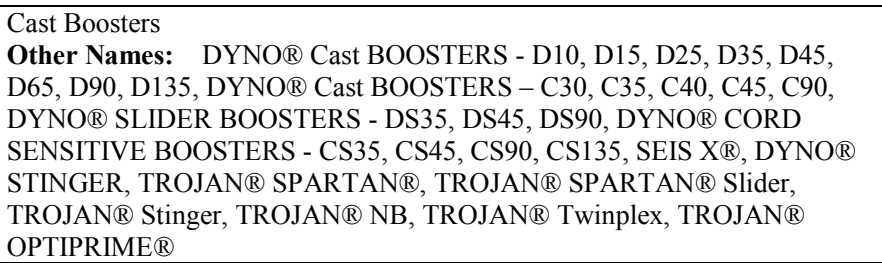 & $\begin{array}{l}\mathrm{RDX}+\mathrm{PETN}+\mathrm{TNT}+ \\
\mathrm{HMX}+\mathrm{Al}\end{array}$ & $\begin{array}{l}\text { DYNO NOBEL } \\
\text { INC }\end{array}$ \\
\hline $\begin{array}{l}\text { Non-Electric Detonators } \\
\text { Other Names: ZipDet, ZipDet MS, ZipDet MS Connector (MSC), ZipDet S } \\
\text { (SHORT), ZipDet Trunkline, ZipDet Dual Delay }\end{array}$ & $\begin{array}{l}\text { PETN + Lead Azide + Lead } \\
\text { Styphnate + RDX }\end{array}$ & $\begin{array}{l}\text { MaXam North } \\
\text { America }\end{array}$ \\
\hline $\begin{array}{l}\text { DES series, DES Shaped Charges, Seismic Directional Energy System } \\
\text { Note: Pentolite (is a mixture of PETN and TNT) }\end{array}$ & $\mathrm{TNT}+\mathrm{PETN}$ & $\begin{array}{l}\text { AUSTIN Powder } \\
\text { Company }\end{array}$ \\
\hline $\begin{array}{l}\text { ACP Boosters } \\
\text { Other Names: Orange Cap, Orange Cap R, Red Cap, Black Cap, Brown } \\
\text { Cap, Green Cap, Purple Cap, White Cap, Gray Cap, etc., NDS Boosters, ADP } \\
\text { Boosters, Gold Nugget, Silver Nugget, Diamond Nugget,DES Series, DES } \\
\text { Pentolite Charges, Rock Crushers, } 60 \text { Gram, } 90 \text { Gram, } 110 \text { Gram, DES } \\
\text { Shaped Charges, Prime Gel*, Renforcatuers, HDP 150, HDP 400, HDP } \\
\text { 400LP, HDP 450, Snow Launcher Series, Hornet Series, Enviroprime Series } \\
\text { and Electro Star Series. }\end{array}$ & $\begin{array}{l}\mathrm{TNT}+\mathrm{PETN}+\mathrm{HMX}+ \\
\mathrm{RDX}+\mathrm{Al}+\text { Pentolite }\end{array}$ & $\begin{array}{l}\text { AUSTIN Powder } \\
\text { Company }\end{array}$ \\
\hline FUSE CAPS NO. 6, NO. 8 (Non-Electric Caps) & $\begin{array}{c}\text { PETN + TNT + Lead Azide } \\
\text { + Lead Styphnate }\end{array}$ & $\begin{array}{c}\text { AUSTIN Powder } \\
\text { Company }\end{array}$ \\
\hline $\begin{array}{l}\text { Detonators } \\
\text { Other Names: Rock* Star, Time* Star, Coal Mine Delays, Seismic* Star, } \\
\text { Static*Star, 3-D Star Seismic Detonators, E*Star, Electro*Star Electronic } \\
\text { Detonators, Electric Blasting Caps }\end{array}$ & $\begin{array}{l}\text { PETN + TNT + Lead Azide } \\
\quad+\text { Lead Styphnate }\end{array}$ & $\begin{array}{l}\text { AUSTIN Powder } \\
\text { Company }\end{array}$ \\
\hline $\begin{array}{l}\text { Detonators and Connectors } \\
\text { Other Names: Shock*Star: Twin* Star Detonators, In-Hole Delays, } \\
\text { Detonators, Surface Delay Connectors, Quick-Relay Connectors, Dual- } \\
\text { Delays, Shorty, Long Period, STD (Shock Tube with Detonators) and MS } \\
\text { Connector, Non-Electric Blasting Caps }\end{array}$ & $\begin{array}{c}\text { PETN }+ \text { Lead Azide }+ \text { Lead } \\
\text { Styphnate }\end{array}$ & $\begin{array}{l}\text { AUSTIN Powder } \\
\text { Company }\end{array}$ \\
\hline $\begin{array}{l}\text { Watergel Slurry High Explosive } \\
\text { Other Name: Presplit }\end{array}$ & $\begin{array}{c}\text { AN + Sodium Nitrate }+ \\
\text { Sodium Perchlorate + Nitric } \\
\text { Acid + MAN + Al + PETN }\end{array}$ & $\begin{array}{l}\text { Slurry Explosive } \\
\text { Corporation SEC }\end{array}$ \\
\hline
\end{tabular}




\section{Commercially Available Products Containing RDX in Approximate Order of Relative}

Purity

\begin{tabular}{|c|c|c|}
\hline Product Name & Components & Company \\
\hline RDX & RDX $100 \%$ & AES \\
\hline $\begin{array}{l}\text { RDX Detonating Cords } \\
\text { Other Names: } 40 \text { RDX LS Detonating Cord, } 40 \text { RDX LS Ribbon Detonating } \\
\text { Cord, } 80 \text { RDX Detonating Cord, } 80 \text { RDX LS Detonating Cord, 80 RDX LS } \\
\text { XHV Detonating Cord, Pipebuster Special RDX, Detotec } 40 \text { RDX LS, } \\
\text { Detotec } 40 \text { RDX LS Ribbon, Detotec } 80 \text { RDX, Detotec } 80 \text { RDX LS, Detotec } \\
80 \text { RDX LS XHV }\end{array}$ & RDX & $\begin{array}{l}\text { DETOTEC } \\
\text { NORTH } \\
\text { AMERICA, INC. }\end{array}$ \\
\hline CORD - 80GR RDX LS XHV & RDX & $\begin{array}{c}\text { Halliburton } \\
\text { Energy Services }\end{array}$ \\
\hline CORD-DETONATING KEVLOR 80 GR/FT RDX, A.F. & RDX & $\begin{array}{c}\text { Halliburton } \\
\text { Energy Services }\end{array}$ \\
\hline CORD-DETONATING RDX LS/NYLON 80 GR/FT. & RDX & $\begin{array}{c}\text { Halliburton } \\
\text { Energy Services }\end{array}$ \\
\hline RDX BH CHARGES & RDX & $\begin{array}{c}\text { Halliburton } \\
\text { Energy Services }\end{array}$ \\
\hline BOOSTER PELLETS RDX & RDX & $\begin{array}{c}\text { Halliburton } \\
\text { Energy Services } \\
\end{array}$ \\
\hline RDX Composition A-3 & RDX + D.Wax & AES \\
\hline RDX Composition A-4 & RDX + D.wax & AES \\
\hline RDX Composition A-5 & RDX + Steric Acid & AES \\
\hline BOOSTER, NON-ELECTRIC with RDX & $\mathrm{RDX}+\mathrm{Al}$ (metallic casing) & AES \\
\hline Composition B & $\mathrm{RDX}+\mathrm{TNT}+\mathrm{D} \cdot \mathrm{Wax}$ & AES \\
\hline (pentaerythritol tetranitrate) & RDX + D.Wax + Graphite & AES \\
\hline $\begin{array}{l}\text { BST }{ }^{\mathrm{TM}} \& \text { Pentex }{ }^{\mathrm{TM}} \text { Cast Boosters } \\
\text { Other Names: Cast Boosters, Cord Sensitive Boosters, MPB Boosters, } \\
\text { Pentex }{ }^{\mathrm{TM}} \text { AP Boosters, BSX Boosters, OSX-8 Boosters, Seismic Boosters }\end{array}$ & $\mathrm{RDX}+\mathrm{TNT}+\mathrm{PETN}$ & ORICA \\
\hline RDX Composition A-3 with Aluminum & $\begin{array}{c}\mathrm{RDX}+\mathrm{D} . \mathrm{Wax}+\mathrm{Al} \\
\text { (powder) + Potassium oleate }\end{array}$ & AES \\
\hline Composition $\mathrm{CH}-6$ & $\begin{array}{l}\text { RDX + Calcium Stearate + } \\
\text { Polyisobutylene + Graphite }\end{array}$ & AES \\
\hline RDX, Desensitized & $\begin{array}{l}\text { RDX + D. Wax + Graphite } \\
+ \text { Calcium Stearate }\end{array}$ & AES \\
\hline CONICAL SHAPED CHARGE (CS0001) & $\begin{array}{c}\mathrm{RDX}+\mathrm{D} \cdot \mathrm{Wax}+\mathrm{Al} \text { (casing) } \\
+\mathrm{Cu} \text { (liner) }\end{array}$ & AES \\
\hline ACCURATE'S CAST BOOSTERS & $\begin{array}{c}\text { TNT + RDX + HMX } \\
+ \text { PETN + D.Wax }\end{array}$ & AES \\
\hline CHARGE, 3 3/8-4" DP RDX - C3370169 & $\mathrm{RDX}+\mathrm{Pb}+\mathrm{Cu}+$ Graphite & $\begin{array}{c}\text { Halliburton } \\
\text { Energy Services }\end{array}$ \\
\hline RDX DP CHARGES & $\mathrm{RDX}+\mathrm{Pb}+\mathrm{Cu}+$ Graphite & $\begin{array}{c}\text { Halliburton } \\
\text { Energy Services } \\
\end{array}$ \\
\hline DETONATING CORD with RDX & $\begin{array}{c}\mathrm{RDX}+\mathrm{D} \cdot \text { Wax }+\mathrm{Al}+\mathrm{Pb}+ \\
\text { Pewter }\end{array}$ & AES \\
\hline LINEAR SHAPED CHARGE with RDX & $\begin{array}{c}\mathrm{RDX}+\mathrm{Al}+\mathrm{Cu}+\mathrm{Pb}+ \\
\text { Pewter } \\
\end{array}$ & AES \\
\hline CONICAL DESTRUCT CHARGE (CS0002) & $\begin{array}{l}\mathrm{RDX}+\mathrm{D} . \mathrm{Wax}+\mathrm{PETN} \\
+\mathrm{Al} \text { (casing) }+\mathrm{Cu} \text { (liner) }\end{array}$ & AES \\
\hline RDX Composition C-4 & $\begin{array}{c}\text { RDX + Polyisobutylene + } \\
\text { DOA or DOS + Petroleum } \\
\text { Oil; Identifiers: DMDNB + } \\
\text { MNT }\end{array}$ & AES \\
\hline DETONATING CORD with COMPOSITION CH-6 & $\begin{array}{c}\text { RDX + Calcium Stearate }+ \\
\text { Polyisobutylene }+ \text { Graphite } \\
+\mathrm{Al}+\mathrm{Pb}+\text { Pewter }\end{array}$ & AES \\
\hline LINEAR SHAPED CHARGE with COMPOSITION CH-6 & $\begin{array}{c}\text { RDX + Calcium Stearate }+ \\
\text { Polyisobutylene }+ \text { Graphite } \\
+\mathrm{Al}+\mathrm{Pb}+\mathrm{Cu}+\text { Pewter }\end{array}$ & AES \\
\hline LINEAR SHAPED CHARGE with RDX, Desensitized & $\begin{array}{c}\text { RDX + D.Wax + Graphite + } \\
\mathrm{Al}+\mathrm{Cu}+\mathrm{Pb}+\text { Pewter }\end{array}$ & AES \\
\hline
\end{tabular}




\begin{tabular}{|c|c|c|}
\hline M3A1 40 LB. DEMOLITION SHAPED CHARGE & $\begin{array}{c}\text { Composition B: RDX }+ \\
\text { TNT + D.Wax + Calcium } \\
\text { Silicate } \\
\text { Composition } \boldsymbol{A}-3: \text { RDX }+ \\
\text { D.Wax }+ \text { Steel } \\
\end{array}$ & AES \\
\hline BI-DI (Bidirectional Destruct Charge) & $\begin{array}{c}\text { RDX + Polyisobutylene + } \\
\text { DOA or DOS + Petroleum } \\
\text { Oil } \\
\text { Identifiers: } D M D N B+ \\
M N T+A l+P b+\text { Steel }\end{array}$ & AES \\
\hline 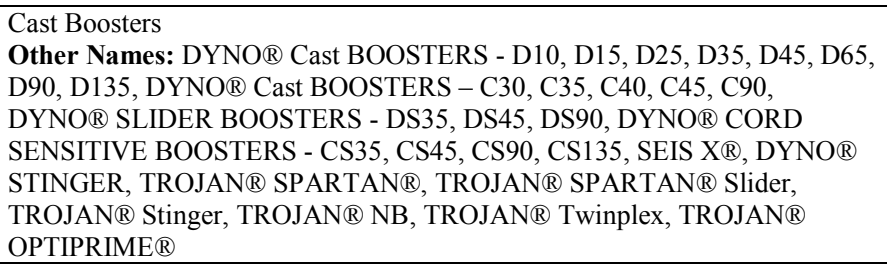 & $\begin{array}{c}\mathrm{RDX}+\mathrm{PETN}+\mathrm{TNT}+ \\
\mathrm{HMX}+\mathrm{Al}\end{array}$ & $\begin{array}{l}\text { DYNO NOBEL } \\
\text { INC. }\end{array}$ \\
\hline $\begin{array}{l}\text { Detonating Cord, Specialty (Oil Field) } \\
\text { Other Names: } 40 \text { RDX NYLON LS, } 40 \text { RDX NYLON RIBBON LS, } 80 \\
\text { RDX NYLON, } 80 \text { RDX NYLON LS, } 80 \text { RDX NYLON XHV LS, } 80 \text { PETN } \\
\text { Plastic, } 100 \text { PETN Plastic, } 80 \text { PYX LS, } 40 \text { HMX NYLON LS, } 40 \text { HMX } \\
\text { NYLON RIBBON LS, } 50 \text { HMX LOPRO NYLON LS, } 60 \text { HMX NYLON LS, } \\
60 \text { HMX HI-TEMP LOW PROFILE LS, } 60 \text { HMX HI-TEMP LS, } 80 \text { HMX } \\
\text { NYLON LS }\end{array}$ & $\begin{array}{l}\text { RDX + PETN + HMX + } \\
\text { PYX + Ammonium } \\
\text { Hydroxide + Tributyl } \\
\text { Phosphate }\end{array}$ & $\begin{array}{l}\text { DYNO NOBEL } \\
\text { INC. }\end{array}$ \\
\hline $\begin{array}{l}\text { Non-Electric Detonators } \\
\text { Other Names: ZipDet, ZipDet MS, ZipDet MS Connector (MSC), ZipDet S } \\
\text { (SHORT), ZipDet Trunkline, ZipDet Dual Delay }\end{array}$ & $\begin{array}{c}\text { PETN + Lead Azide + Lead } \\
\text { Styphnate + RDX }\end{array}$ & $\begin{array}{l}\text { MaXam North } \\
\text { America }\end{array}$ \\
\hline $\begin{array}{l}\text { Oil and Gas Detonators } \\
\text { Other Names: OIL *STAR DETONATORS, Electric Blasting Caps, A2b, } \\
\text { A84, A85, A95, A96, A98, A105, A140, Oil and Gas Detonator Type A- } \\
\text { 140F, A-140S, Oil and Gas Detonator Type A-161 }\end{array}$ & $\begin{array}{l}\text { RDX + HNS + Lead Azide } \\
\quad+\text { Lead Styphnate }\end{array}$ & $\begin{array}{l}\text { AUSTIN Powder } \\
\text { Company }\end{array}$ \\
\hline $\begin{array}{l}\text { ACP Boosters } \\
\text { Other Names: Orange Cap, Orange Cap R, Red Cap, Black Cap, Brown } \\
\text { Cap, Green Cap, Purple Cap, White Cap, Gray Cap, etc., NDS Boosters, ADP } \\
\text { Boosters, Gold Nugget, Silver Nugget, Diamond Nugget,DES Series, DES } \\
\text { Pentolite Charges, Rock Crushers, } 60 \text { Gram, } 90 \text { Gram, 110 Gram, DES } \\
\text { Shaped Charges, Prime Gel*, Renforcatuers, HDP 150, HDP 400, HDP } \\
\text { 400LP, HDP 450, Snow Launcher Series, Hornet Series, Enviroprime Series } \\
\text { and Electro Star Series. }\end{array}$ & $\begin{array}{l}\text { TNT + PETN + HMX + } \\
\text { RDX + Al + Pentolite }\end{array}$ & $\begin{array}{l}\text { AUSTIN Powder } \\
\text { Company }\end{array}$ \\
\hline CHARGE, .718 CTC RDX - C0720000 & $\begin{array}{l}\mathrm{RDX}+\mathrm{Al}+\mathrm{Fe}+\mathrm{Pb} \\
+\mathrm{D} . \mathrm{Wax}+\mathrm{Steel}+\mathrm{Graphite} \\
+\mathrm{Sn}+\mathrm{W}+\mathrm{Cu}\end{array}$ & $\begin{array}{l}\text { Halliburton } \\
\text { Energy Services }\end{array}$ \\
\hline CHARGE, .948 CTC RDX - C0950000 & $\begin{array}{l}\mathrm{RDX}+\mathrm{Al}+\mathrm{Fe}+\mathrm{Pb} \\
+\mathrm{D} . \mathrm{Wax}+\mathrm{Steel}+\mathrm{Graphite} \\
+\mathrm{Sn}+\mathrm{W}+\mathrm{Cu}\end{array}$ & $\begin{array}{l}\text { Halliburton } \\
\text { Energy Services }\end{array}$ \\
\hline CHARGE, 1 9/16 TP RDX - 021-3609-055 & $\begin{array}{c}\mathrm{RDX}+\mathrm{Al}+\mathrm{Fe}+\mathrm{Pb} \\
+\mathrm{D} . \mathrm{Wax}+\mathrm{Steel}+\mathrm{Graphite} \\
+\mathrm{Sn}+\mathrm{W}+\mathrm{Cu}\end{array}$ & $\begin{array}{l}\text { Halliburton } \\
\text { Energy Services }\end{array}$ \\
\hline CHARGE, 1.187 CTC RDX - C1190000 & $\begin{array}{c}\mathrm{RDX}+\mathrm{Al}+\mathrm{Fe}+\mathrm{Pb} \\
+\mathrm{D} . \mathrm{Wax}+\mathrm{Steel}+\mathrm{Graphite} \\
+\mathrm{Sn}+\mathrm{W}+\mathrm{Cu}\end{array}$ & $\begin{array}{l}\text { Halliburton } \\
\text { Energy Services }\end{array}$ \\
\hline CHARGE, 1.562", 3.2 GR. RDX, DP & $\begin{array}{c}\mathrm{RDX}+\mathrm{Al}+\mathrm{Fe}+\mathrm{Pb} \\
+\mathrm{D} . \mathrm{Wax}+\mathrm{Steel}+\mathrm{Graphite} \\
+\mathrm{Sn}+\mathrm{W}+\mathrm{Cu}\end{array}$ & $\begin{array}{l}\text { Halliburton } \\
\text { Energy Services }\end{array}$ \\
\hline CHARGE, 18" CC RDX - SC12 & $\begin{array}{c}\mathrm{RDX}+\mathrm{Al}+\mathrm{Fe}+\mathrm{Pb} \\
+\mathrm{D} . \mathrm{Wax}+\mathrm{Steel}+\mathrm{Graphite} \\
+\mathrm{Sn}+\mathrm{W}+\mathrm{Cu}\end{array}$ & $\begin{array}{l}\text { Halliburton } \\
\text { Energy Services }\end{array}$ \\
\hline CHARGE, 18.4" CC RDX - SC18 & $\begin{array}{l}\mathrm{RDX}+\mathrm{Al}+\mathrm{Fe}+\mathrm{Pb} \\
+\mathrm{D} . \mathrm{Wax}+\mathrm{Steel}+\mathrm{Graphite} \\
\quad+\mathrm{Sn}+\mathrm{W}+\mathrm{Cu}\end{array}$ & $\begin{array}{l}\text { Halliburton } \\
\text { Energy Services }\end{array}$ \\
\hline CHARGE, 2", 6.4 GR. RDX-DP & $\begin{array}{l}\mathrm{RDX}+\mathrm{Al}+\mathrm{Fe}+\mathrm{Pb} \\
+\mathrm{D} . \mathrm{Wax}+\mathrm{Steel}+\mathrm{Graphite} \\
+\mathrm{Sn}+\mathrm{W}+\mathrm{Cu}\end{array}$ & $\begin{array}{l}\text { Halliburton } \\
\text { Energy Services }\end{array}$ \\
\hline CHARGE, 27.6" CC RDX - SC27 & $\begin{array}{c}\mathrm{RDX}+\mathrm{Al}+\mathrm{Fe}+\mathrm{Pb} \\
+\mathrm{D} . \mathrm{Wax}+\text { Steel + Graphite }\end{array}$ & $\begin{array}{c}\text { Halliburton } \\
\text { Energy Services }\end{array}$ \\
\hline
\end{tabular}




\begin{tabular}{|c|c|c|}
\hline & $+\mathrm{Sn}+\mathrm{W}+\mathrm{Cu}$ & \\
\hline CHARGE, 3 5/8 CC RDX - C3630045 & $\begin{array}{c}\mathrm{RDX}+\mathrm{Al}+\mathrm{Fe}+\mathrm{Pb} \\
+\mathrm{D} . \mathrm{Wax}+\mathrm{Steel}+\mathrm{Graphite} \\
+\mathrm{Sn}+\mathrm{W}+\mathrm{Cu}\end{array}$ & $\begin{array}{c}\text { Halliburton } \\
\text { Energy Services }\end{array}$ \\
\hline CHARGE, 4 1/2-5 HD BH RDX - C4500028 & $\begin{array}{c}\mathrm{RDX}+\mathrm{Al}+\mathrm{Fe}+\mathrm{Pb} \\
+\mathrm{D} . \mathrm{Wax}+\mathrm{Steel}+\mathrm{Graphite} \\
+\mathrm{Sn}+\mathrm{W}+\mathrm{Cu}\end{array}$ & $\begin{array}{c}\text { Halliburton } \\
\text { Energy Services }\end{array}$ \\
\hline CHARGE, 3 5/8 CC RDX - C3630045 & $\begin{array}{c}\mathrm{RDX}+\mathrm{Al}+\mathrm{Fe}+\mathrm{Pb} \\
+\mathrm{D} . \mathrm{Wax}+\mathrm{Steel}+\mathrm{Graphite} \\
+\mathrm{Sn}+\mathrm{W}+\mathrm{Cu}\end{array}$ & $\begin{array}{c}\text { Halliburton } \\
\text { Energy Services }\end{array}$ \\
\hline CHARGE, 4 1/2-5 HD BH RDX - C4500028 & $\begin{array}{c}\mathrm{RDX}+\mathrm{Al}+\mathrm{Fe}+\mathrm{Pb} \\
+\mathrm{D} . \mathrm{Wax}+\mathrm{Steel}+\mathrm{Graphite} \\
+\mathrm{Sn}+\mathrm{W}+\mathrm{Cu}\end{array}$ & $\begin{array}{c}\text { Halliburton } \\
\text { Energy Services }\end{array}$ \\
\hline CHARGE, 4 1/2-5 HD DP RDX - C4500029 & $\begin{array}{c}\mathrm{RDX}+\mathrm{Al}+\mathrm{Fe}+\mathrm{Pb} \\
+\mathrm{D} . \mathrm{Wax}+\mathrm{Steel}+\mathrm{Graphite} \\
+\mathrm{Sn}+\mathrm{W}+\mathrm{Cu}\end{array}$ & $\begin{array}{c}\text { Halliburton } \\
\text { Energy Services }\end{array}$ \\
\hline CHARGE, 4 3/4 CC RDX - C4750045 & $\begin{array}{c}\mathrm{RDX}+\mathrm{Al}+\mathrm{Fe}+\mathrm{Pb} \\
+\mathrm{D} . \mathrm{Wax}+\mathrm{Steel}+\mathrm{Graphite} \\
+\mathrm{Sn}+\mathrm{W}+\mathrm{Cu}\end{array}$ & $\begin{array}{c}\text { Halliburton } \\
\text { Energy Services }\end{array}$ \\
\hline CHARGE, 4 5/8", RDX 25 GRAM & $\begin{array}{c}\mathrm{RDX}+\mathrm{Al}+\mathrm{Fe}+\mathrm{Pb} \\
+\mathrm{D} . \mathrm{Wax}+\mathrm{Steel}+\mathrm{Graphite} \\
+\mathrm{Sn}+\mathrm{W}+\mathrm{Cu}\end{array}$ & $\begin{array}{c}\text { Halliburton } \\
\text { Energy Services }\end{array}$ \\
\hline CHARGE, 4 5/8", RDX 32 GRAM, SUPER HOLE & $\begin{array}{c}\mathrm{RDX}+\mathrm{Al}+\mathrm{Fe}+\mathrm{Pb} \\
+\mathrm{D} . \mathrm{Wax}+\mathrm{Steel}+\text { Graphite } \\
+\mathrm{Sn}+\mathrm{W}+\mathrm{Cu}\end{array}$ & $\begin{array}{c}\text { Halliburton } \\
\text { Energy Services }\end{array}$ \\
\hline CHARGE, 4" CC RDX - C4000045 & $\begin{array}{c}\mathrm{RDX}+\mathrm{Al}+\mathrm{Fe}+\mathrm{Pb} \\
+\mathrm{D} . \mathrm{Wax}+\mathrm{Steel}+\mathrm{Graphite} \\
+\mathrm{Sn}+\mathrm{W}+\mathrm{Cu}\end{array}$ & $\begin{array}{c}\text { Halliburton } \\
\text { Energy Services }\end{array}$ \\
\hline CHARGE, 4.5 CC RDX - C4500045 & $\begin{array}{c}\mathrm{RDX}+\mathrm{Al}+\mathrm{Fe}+\mathrm{Pb} \\
+\mathrm{D} . \mathrm{Wax}+\text { Steel }+ \text { Graphite } \\
+\mathrm{Sn}+\mathrm{W}+\mathrm{Cu}\end{array}$ & $\begin{array}{c}\text { Halliburton } \\
\text { Energy Services }\end{array}$ \\
\hline CHARGE, 5 1/2 CC RDX - C5500045 & $\begin{array}{c}\mathrm{RDX}+\mathrm{Al}+\mathrm{Fe}+\mathrm{Pb} \\
+\mathrm{D} . \mathrm{Wax}+\mathrm{Steel}+\mathrm{Graphite} \\
+\mathrm{Sn}+\mathrm{W}+\mathrm{Cu}\end{array}$ & $\begin{array}{c}\text { Halliburton } \\
\text { Energy Services }\end{array}$ \\
\hline CHARGE, 5 3/8 CC RDX - C5380045 & $\begin{array}{c}\mathrm{RDX}+\mathrm{Al}+\mathrm{Fe}+\mathrm{Pb} \\
+\mathrm{D} . \mathrm{Wax}+\mathrm{Steel}+\mathrm{Graphite} \\
+\mathrm{Sn}+\mathrm{W}+\mathrm{Cu}\end{array}$ & $\begin{array}{c}\text { Halliburton } \\
\text { Energy Services }\end{array}$ \\
\hline CHARGE, RDX & $\begin{array}{c}\mathrm{RDX}+\mathrm{Al}+\mathrm{Fe}+\mathrm{Pb} \\
+\mathrm{D} . \mathrm{Wax}+\mathrm{Steel}+\mathrm{Graphite} \\
+\mathrm{Sn}+\mathrm{W}+\mathrm{Cu}\end{array}$ & $\begin{array}{c}\text { Halliburton } \\
\text { Energy Services }\end{array}$ \\
\hline CHARGE, 6 1/8 CC RDX - C6130045 & $\begin{array}{c}\mathrm{RDX}+\mathrm{Al}+\mathrm{Fe}+\mathrm{Pb} \\
+\mathrm{D} . \mathrm{Wax}+\mathrm{Steel}+\mathrm{Graphite} \\
+\mathrm{Sn}+\mathrm{W}+\mathrm{Cu}\end{array}$ & $\begin{array}{c}\text { Halliburton } \\
\text { Energy Services }\end{array}$ \\
\hline CHARGE, 6" CC RDX - C6000045 & $\begin{array}{c}\mathrm{RDX}+\mathrm{Al}+\mathrm{Fe}+\mathrm{Pb} \\
+\mathrm{D} . \mathrm{Wax}+\mathrm{Steel}+\text { Graphite } \\
+\mathrm{Sn}+\mathrm{W}+\mathrm{Cu}\end{array}$ & $\begin{array}{c}\text { Halliburton } \\
\text { Energy Services }\end{array}$ \\
\hline CHARGE, 6", RDX 32 GRAM & $\begin{array}{c}\mathrm{RDX}+\mathrm{Al}+\mathrm{Fe}+\mathrm{Pb} \\
+\mathrm{D} . \mathrm{Wax}+\mathrm{Steel}+\mathrm{Graphite} \\
+\mathrm{Sn}+\mathrm{W}+\mathrm{Cu}\end{array}$ & $\begin{array}{c}\text { Halliburton } \\
\text { Energy Services }\end{array}$ \\
\hline CHARGE, 7 1/4 CC RDX - C7250045 & $\begin{array}{c}\mathrm{RDX}+\mathrm{Al}+\mathrm{Fe}+\mathrm{Pb} \\
+\mathrm{D} . \mathrm{Wax}+\mathrm{Steel}+\mathrm{Graphite} \\
+\mathrm{Sn}+\mathrm{W}+\mathrm{Cu}\end{array}$ & $\begin{array}{c}\text { Halliburton } \\
\text { Energy Services }\end{array}$ \\
\hline CHARGE, 7" 36 GR. RDX-DP & $\begin{array}{c}\mathrm{RDX}+\mathrm{Al}+\mathrm{Fe}+\mathrm{Pb} \\
+\mathrm{D} . \mathrm{Wax}+\mathrm{Steel}+\mathrm{Graphite} \\
+\mathrm{Sn}+\mathrm{W}+\mathrm{Cu}\end{array}$ & $\begin{array}{c}\text { Halliburton } \\
\text { Energy Services }\end{array}$ \\
\hline CHARGE, 7", RDX BH 56.5 GRAM & $\begin{array}{c}\mathrm{RDX}+\mathrm{Al}+\mathrm{Fe}+\mathrm{Pb} \\
+\mathrm{D} . \mathrm{Wax}+\mathrm{Steel}+\mathrm{Graphite} \\
+\mathrm{Sn}+\mathrm{W}+\mathrm{Cu}\end{array}$ & $\begin{array}{c}\text { Halliburton } \\
\text { Energy Services }\end{array}$ \\
\hline CHARGE, 8 3/16 CC RDX - C8190045 & $\begin{array}{c}\mathrm{RDX}+\mathrm{Al}+\mathrm{Fe}+\mathrm{Pb} \\
+\mathrm{D} . \mathrm{Wax}+\mathrm{Steel}+\mathrm{Graphite} \\
+\mathrm{Sn}+\mathrm{W}+\mathrm{Cu}\end{array}$ & $\begin{array}{c}\text { Halliburton } \\
\text { Energy Services }\end{array}$ \\
\hline CHARGE, 9 1/2 CC RDX - SC09 & $\begin{array}{c}\mathrm{RDX}+\mathrm{Al}+\mathrm{Fe}+\mathrm{Pb} \\
+\mathrm{D} . \mathrm{Wax}+\mathrm{Steel}+\mathrm{Graphite} \\
+\mathrm{Sn}+\mathrm{W}+\mathrm{Cu}\end{array}$ & $\begin{array}{c}\text { Halliburton } \\
\text { Energy Services }\end{array}$ \\
\hline CHARGE, 7", RDX BH 56.5 GRAM & $\begin{array}{c}\mathrm{RDX}+\mathrm{Al}+\mathrm{Fe}+\mathrm{Pb} \\
+\mathrm{D} \cdot \mathrm{Wax}+\text { Steel }+ \text { Graphite }\end{array}$ & $\begin{array}{c}\text { Halliburton } \\
\text { Energy Services }\end{array}$ \\
\hline
\end{tabular}




\begin{tabular}{|c|c|c|}
\hline & $+\mathrm{Sn}+\mathrm{W}+\mathrm{Cu}$ & \\
\hline CHARGE, 8 3/16 CC RDX - C8190045 & $\begin{array}{c}\mathrm{RDX}+\mathrm{Al}+\mathrm{Fe}+\mathrm{Pb} \\
+\mathrm{D} . \mathrm{Wax}+\mathrm{Steel}+\mathrm{Graphite} \\
+\mathrm{Sn}+\mathrm{W}+\mathrm{Cu}\end{array}$ & $\begin{array}{c}\text { Halliburton } \\
\text { Energy Services }\end{array}$ \\
\hline CHARGE, 9 1/2 CC RDX - SC09 & $\begin{array}{c}\mathrm{RDX}+\mathrm{Al}+\mathrm{Fe}+\mathrm{Pb} \\
+\mathrm{D} . \mathrm{Wax}+\mathrm{Steel}+\mathrm{Graphite} \\
+\mathrm{Sn}+\mathrm{W}+\mathrm{Cu}\end{array}$ & $\begin{array}{c}\text { Halliburton } \\
\text { Energy Services }\end{array}$ \\
\hline CORD, RDX LOW SHRINK - P2580 & $\begin{array}{c}\mathrm{RDX}+\mathrm{Al}+\mathrm{Fe}+\mathrm{Pb} \\
+\mathrm{D} . \mathrm{Wax}+\mathrm{Steel}+\mathrm{Graphite} \\
+\mathrm{Sn}+\mathrm{W}+\mathrm{Cu}\end{array}$ & $\begin{array}{c}\text { Halliburton } \\
\text { Energy Services }\end{array}$ \\
\hline CORD, RDX-NYLON - P2180 & $\begin{array}{c}\mathrm{RDX}+\mathrm{Al}+\mathrm{Fe}+\mathrm{Pb} \\
+\mathrm{D} . \mathrm{Wax}+\mathrm{Steel}+\text { Graphite } \\
+\mathrm{Sn}+\mathrm{W}+\mathrm{Cu}\end{array}$ & $\begin{array}{c}\text { Halliburton } \\
\text { Energy Services }\end{array}$ \\
\hline PERFORATOR - 7" - SUPER HOLE - RDX & $\begin{array}{c}\mathrm{RDX}+\mathrm{Al}+\mathrm{Fe}+\mathrm{Pb} \\
+\mathrm{D} . \mathrm{Wax}+\mathrm{Steel}+\text { Graphite } \\
+\mathrm{Sn}+\mathrm{W}+\mathrm{Cu}\end{array}$ & $\begin{array}{c}\text { Halliburton } \\
\text { Energy Services }\end{array}$ \\
\hline CHARGE, 2" 7.5 GR, RDX, SSB III - C201036 & $\begin{array}{c}\mathrm{RDX}+\mathrm{Al}+\mathrm{Fe}+\mathrm{Pb} \\
+\mathrm{D} . \mathrm{Wax}+\mathrm{Steel}+\mathrm{Graphite} \\
+\mathrm{Sn}+\mathrm{W}+\mathrm{Cu}\end{array}$ & $\begin{array}{c}\text { Halliburton } \\
\text { Energy Services }\end{array}$ \\
\hline CHARGE - 1 11:16 DEEP STAR RDX & $\begin{array}{c}\mathrm{RDX}+\mathrm{Al}+\mathrm{Fe}+\mathrm{Pb} \\
+\mathrm{D} . \mathrm{Wax}+\mathrm{Steel}+\mathrm{Graphite} \\
+\mathrm{Sn}+\mathrm{W}+\mathrm{Cu}\end{array}$ & $\begin{array}{c}\text { Halliburton } \\
\text { Energy Services }\end{array}$ \\
\hline CHARGE - 2 1:8 DEEP STAR IV RDX & $\begin{array}{c}\mathrm{RDX}+\mathrm{Al}+\mathrm{Fe}+\mathrm{Pb} \\
+\mathrm{D} . \mathrm{Wax}+\mathrm{Steel}+\mathrm{Graphite} \\
+\mathrm{Sn}+\mathrm{W}+\mathrm{Cu}\end{array}$ & $\begin{array}{c}\text { Halliburton } \\
\text { Energy Services }\end{array}$ \\
\hline CHARGE, MAXIM DUAL STRING, RDX & $\begin{array}{c}\mathrm{RDX}+\mathrm{Al}+\mathrm{Fe}+\mathrm{Pb} \\
+\mathrm{D} . \mathrm{Wax}+\mathrm{Steel}+\text { Graphite } \\
+\mathrm{Sn}+\mathrm{W}+\mathrm{Cu}\end{array}$ & $\begin{array}{c}\text { Halliburton } \\
\text { Energy Services }\end{array}$ \\
\hline CHARGE 3 1/8 6SPF BH RDX & $\begin{array}{l}\mathrm{RDX}+\text { Iron oxide }+\mathrm{Al}+\mathrm{Pb} \\
+\mathrm{Sn}+\text { Steel }+\mathrm{D} . \mathrm{Wax}+\mathrm{Cu}\end{array}$ & $\begin{array}{c}\text { Halliburton } \\
\text { Energy Services }\end{array}$ \\
\hline CHARGE 3 3/8 6SPF RDX DP (JRC - S3370009) & $\begin{array}{l}\text { RDX + Iron oxide }+\mathrm{Al}+\mathrm{Pb} \\
+\mathrm{Sn}+\text { Steel }+\mathrm{D} \cdot \mathrm{Wax}+\mathrm{Cu}\end{array}$ & $\begin{array}{c}\text { Halliburton } \\
\text { Energy Services }\end{array}$ \\
\hline CHARGE 5" 22.7 GR. RDX B.H. & $\begin{array}{l}\mathrm{RDX}+\text { Iron oxide }+\mathrm{Al}+\mathrm{Pb} \\
+\mathrm{Sn}+\text { Steel }+\mathrm{D} . \mathrm{Wax}+\mathrm{Cu}\end{array}$ & $\begin{array}{c}\text { Halliburton } \\
\text { Energy Services }\end{array}$ \\
\hline CHARGE, 2 3/4", RDX BIG HOLE & $\begin{array}{l}\text { RDX + Iron oxide }+\mathrm{Al}+\mathrm{Pb} \\
+\mathrm{Sn}+\text { Steel }+ \text { D.Wax }+\mathrm{Cu}\end{array}$ & $\begin{array}{c}\text { Halliburton } \\
\text { Energy Services }\end{array}$ \\
\hline CHARGE, 2 3/4", RDX DP & $\begin{array}{c}\mathrm{RDX}+\text { Iron oxide }+\mathrm{Al}+\mathrm{Pb} \\
+\mathrm{Sn}+\text { Steel }+\mathrm{D} . \mathrm{Wax}+\mathrm{Cu}\end{array}$ & $\begin{array}{c}\text { Halliburton } \\
\text { Energy Services }\end{array}$ \\
\hline CHARGE, 2", 6.4 GR. RDX-DP & $\begin{array}{l}\text { RDX + Iron oxide }+\mathrm{Al}+\mathrm{Pb} \\
+\mathrm{Sn}+\text { Steel }+\mathrm{D} . \mathrm{Wax}+\mathrm{Cu}\end{array}$ & $\begin{array}{c}\text { Halliburton } \\
\text { Energy Services }\end{array}$ \\
\hline CHARGE, 3 3/8", 6SPF RDX 23 GRAM, DP & $\begin{array}{l}\text { RDX + Iron oxide }+\mathrm{Al}+\mathrm{Pb} \\
+\mathrm{Sn}+\text { Steel }+\mathrm{D} \cdot \mathrm{Wax}+\mathrm{Cu}\end{array}$ & $\begin{array}{c}\text { Halliburton } \\
\text { Energy Services }\end{array}$ \\
\hline CHARGE, 3 3/8", 6SPF RDX, DP & $\begin{array}{c}\text { RDX + Iron oxide }+\mathrm{Al}+\mathrm{Pb} \\
+\mathrm{Sn}+\text { Steel }+ \text { D.Wax }+\mathrm{Cu}\end{array}$ & $\begin{array}{c}\text { Halliburton } \\
\text { Energy Services }\end{array}$ \\
\hline CHARGE, 3 3/8", RDX BIG HOLE 26 GRAM & $\begin{array}{l}\text { RDX + Iron oxide }+\mathrm{Al}+\mathrm{Pb} \\
+\mathrm{Sn}+\text { Steel }+\mathrm{D} . \mathrm{Wax}+\mathrm{Cu}\end{array}$ & $\begin{array}{c}\text { Halliburton } \\
\text { Energy Services }\end{array}$ \\
\hline CHARGE, 4 5/8", RDX OMNI, BIG HOLE 25 GRAM & $\begin{array}{l}\mathrm{RDX}+\text { Iron oxide }+\mathrm{Al}+\mathrm{Pb} \\
+\mathrm{Sn}+\text { Steel }+\mathrm{D} . \mathrm{Wax}+\mathrm{Cu} \\
\end{array}$ & $\begin{array}{c}\text { Halliburton } \\
\text { Energy Services }\end{array}$ \\
\hline CHARGE, 4 5/8", RDX OMNI, DP 26 GRAM & $\begin{array}{l}\text { RDX + Iron oxide }+\mathrm{Al}+\mathrm{Pb} \\
+\mathrm{Sn}+\mathrm{Steel}+\mathrm{D} . \mathrm{Wax}+\mathrm{Cu}\end{array}$ & $\begin{array}{c}\text { Halliburton } \\
\text { Energy Services }\end{array}$ \\
\hline CHARGE, 6", RDX 32 GRAM BIG HOLE & $\begin{array}{c}\mathrm{RDX}+\text { Iron oxide }+\mathrm{Al}+\mathrm{Pb} \\
+\mathrm{Sn}+\text { Steel }+\mathrm{D} . \mathrm{Wax}+\mathrm{Cu} \\
\end{array}$ & $\begin{array}{c}\text { Halliburton } \\
\text { Energy Services }\end{array}$ \\
\hline CHARGE, 6", RDX D. P. 32 GRAM & $\begin{array}{l}\text { RDX + Iron oxide }+\mathrm{Al}+\mathrm{Pb} \\
+\mathrm{Sn}+\text { Steel }+\mathrm{D} . \mathrm{Wax}+\mathrm{Cu}\end{array}$ & $\begin{array}{c}\text { Halliburton } \\
\text { Energy Services }\end{array}$ \\
\hline 3 3/4 CHARGE RDX BH (HLS, JRC) & $\begin{array}{c}\text { RDX + Iron oxide }+\mathrm{Al}+\mathrm{Pb} \\
+\mathrm{Sn}+\text { Steel }+ \text { D.Wax }+\mathrm{Cu} \\
\end{array}$ & $\begin{array}{c}\text { Halliburton } \\
\text { Energy Services }\end{array}$ \\
\hline 3 3/4 CHARGE RDX DP (HLS, JRC) & $\begin{array}{l}\mathrm{RDX}+\text { Iron oxide }+\mathrm{Al}+\mathrm{Pb} \\
+\mathrm{Sn}+\text { Steel }+\mathrm{D} . \mathrm{Wax}+\mathrm{Cu}\end{array}$ & $\begin{array}{c}\text { Halliburton } \\
\text { Energy Services }\end{array}$ \\
\hline 3 3/8" 6 SPF D.P. LOW DEBRIE RDX & $\begin{array}{c}\text { RDX + Iron oxide }+\mathrm{Al}+\mathrm{Pb} \\
+\mathrm{Sn}+\text { Steel }+ \text { D.Wax }+\mathrm{Cu}\end{array}$ & $\begin{array}{c}\text { Halliburton } \\
\text { Energy Services }\end{array}$ \\
\hline CHARGE 2 1/8 DYNA-STAR RDX - C2120420 & $\begin{array}{c}\mathrm{RDX}+\mathrm{Al}+\mathrm{Pb}+\mathrm{D} \cdot \mathrm{Wax}+ \\
\text { Steel }+\mathrm{Sn}+\mathrm{W}+\mathrm{Cu}\end{array}$ & $\begin{array}{c}\text { Halliburton } \\
\text { Energy Services }\end{array}$ \\
\hline CHARGE 2 1/8 DYNA-STAR RDX - C3130234 & $\begin{array}{c}\mathrm{RDX}+\mathrm{Al}+\mathrm{Pb}+\mathrm{D} \cdot \mathrm{Wax}+ \\
\text { Steel }+\mathrm{Sn}+\mathrm{W}+\mathrm{Cu}\end{array}$ & $\begin{array}{c}\text { Halliburton } \\
\text { Energy Services }\end{array}$ \\
\hline CHARGE, 2 1/8 DYNA-STAR RDX - C2123420 & $\begin{array}{c}\mathrm{RDX}+\mathrm{Al}+\mathrm{Pb}+\mathrm{D} \cdot \mathrm{Wax}+ \\
\text { Steel }+\mathrm{Sn}+\mathrm{W}+\mathrm{Cu}\end{array}$ & $\begin{array}{c}\text { Halliburton } \\
\text { Energy Services }\end{array}$ \\
\hline
\end{tabular}




\begin{tabular}{|c|c|c|}
\hline CHARGE - 2 1:8 DYNA STAR RDX & $\begin{array}{c}\mathrm{RDX}+\mathrm{Al}+\mathrm{Pb}+\mathrm{D} . \mathrm{Wax}+ \\
\text { Steel }+\mathrm{Sn}+\mathrm{W}+\mathrm{Cu}\end{array}$ & $\begin{array}{c}\text { Halliburton } \\
\text { Energy Services }\end{array}$ \\
\hline CHARGE 7" HSD,BH RDX,LD & $\begin{array}{c}\text { RDX + HNS + HMX + } \\
\text { PYX + Iron oxide }+\mathrm{Al}+\mathrm{W} \\
+\mathrm{Cu}+\mathrm{Pb}+\text { Graphite }+ \\
\text { D.Wax }+ \text { Steel }\end{array}$ & $\begin{array}{c}\text { Halliburton } \\
\text { Energy Services }\end{array}$ \\
\hline CHARGE, 4 5/8 LD HSD, DP RDX 22.7 GRAM & $\begin{array}{c}\text { RDX + HNS + HMX + } \\
\text { PYX + Iron oxide }+\mathrm{Al}+\mathrm{W} \\
+\mathrm{Cu}+\mathrm{Pb}+\text { Graphite }+ \\
\text { D.Wax }+ \text { Steel }\end{array}$ & $\begin{array}{c}\text { Halliburton } \\
\text { Energy Services }\end{array}$ \\
\hline CHARGE, 4 5/8", RDX DP, 32 GRAM & $\begin{array}{c}\text { RDX + HNS + HMX + } \\
\text { PYX + Iron oxide }+\mathrm{Al}+\mathrm{W} \\
+\mathrm{Cu}+\mathrm{Pb}+\text { Graphite }+ \\
\text { D.Wax }+ \text { Steel }\end{array}$ & $\begin{array}{c}\text { Halliburton } \\
\text { Energy Services }\end{array}$ \\
\hline CHARGE, 1.562", 3.2 GR. RDX, DP & $\begin{array}{c}\text { RDX + HNS + HMX + } \\
\text { PYX + Iron oxide }+\mathrm{Cu}+\mathrm{Pb} \\
+ \text { Graphite }+ \text { D.Wax }+ \text { Steel }\end{array}$ & $\begin{array}{c}\text { Halliburton } \\
\text { Energy Services }\end{array}$ \\
\hline CHARGE, 4 5/8", RDX BIG HOLE 26 GRAM & $\begin{array}{c}\text { RDX + HNS + HMX + } \\
\text { PYX }+ \text { Iron oxide }+\mathrm{Cu}+\mathrm{Pb} \\
+ \text { Graphite }+ \text { D.Wax }+ \text { Steel }\end{array}$ & $\begin{array}{c}\text { Halliburton } \\
\text { Energy Services }\end{array}$ \\
\hline CHARGE, 4 5/8", RDX DP 26 GRAM & $\begin{array}{c}\text { RDX + HNS + HMX + } \\
\text { PYX }+ \text { Iron oxide }+\mathrm{Cu}+\mathrm{Pb} \\
+ \text { Graphite }+ \text { D.Wax }+ \text { Steel }\end{array}$ & $\begin{array}{c}\text { Halliburton } \\
\text { Energy Services }\end{array}$ \\
\hline CHARGE 4 5/8", RDX, BH 22.7 GR.-HSD-LD & $\begin{array}{l}\text { RDX + HMX + PYX + Iron } \\
\text { oxide }+\mathrm{Cu}+\mathrm{Pb}+\mathrm{Graphite} \\
+\mathrm{D} . \mathrm{Wax}+\text { Steel }+\mathrm{Al}+\mathrm{Sn}\end{array}$ & $\begin{array}{c}\text { Halliburton } \\
\text { Energy Services }\end{array}$ \\
\hline
\end{tabular}




\section{Commercially Available Products Containing AN in Approximate Order of Relative}

Purity

\begin{tabular}{|c|c|c|}
\hline Product Name & Components & Company \\
\hline AN PRILLS & AN & Orica \\
\hline Amonium Nitrate, Nitric Acid Amonium Salt & AN & Orica \\
\hline $\begin{array}{l}\text { Apex Gold 2500, 2501 Series } \\
\text { Other Names: Apex Gold 2540, 2530, 2525, 2520, 2517, 2591, 2581, 2571, } \\
2561,2551\end{array}$ & AN & Orica \\
\hline $\begin{array}{l}\text { Apex Gold 2100, } 2101 \text { Series (Unsensitized) } \\
\text { Other Names: Apex Gold 2140, 2130, 2125, 2120, 2117, 2191, 2181, 2171, } \\
2161,2151 .\end{array}$ & AN & Orica \\
\hline $\begin{array}{l}\text { Apex Gold - 2502 Series, } 2503 \text { Series } \\
\text { Other Names: Apex 1210, Apex Gold 300MB, Apex Gold 2592, Apex Gold } \\
\text { 2582, Apex Gold 2572, Apex Gold 2562, Apex Gold 2552, Apex Gold 2542, } \\
\text { Apex Gold 2532, Apex Gold 2527, Apex Gold 2522, Apex Gold 2519, Apex } \\
\text { Gold 2593, Apex Gold 2583, Apex Gold 2573, Apex Gold 2563, Apex Gold } \\
2553\end{array}$ & AN & Orica \\
\hline $\begin{array}{l}\text { Apex Gold 2500, 2501 Series } \\
\text { Other Names: Apex Gold 2540, 2530, 2525, 2520, 2517, 2591, 2581, 2571, } \\
\text { 2561, } 2551\end{array}$ & AN & Orica \\
\hline MAGNAFRAC GOLD & AN & Orica \\
\hline APEX EXTRA, APEX ULTRA II & AN & Orica \\
\hline AN PRILLS & AN & Orica \\
\hline Amonium Nitrate, Nitric Acid Amonium Salt & AN & Orica \\
\hline $\begin{array}{l}\text { Apex Gold 2100, 2101 Series (Unsensitized) } \\
\text { Other Names: Apex Gold 2140, 2130, 2125, 2120, 2117, 2191, 2181, 2171, } \\
2161,2151 .\end{array}$ & AN & Orica \\
\hline $\begin{array}{l}\text { Apex Gold - 2502 Series, } 2503 \text { Series } \\
\text { Other Names: Apex 1210, Apex Gold 300MB, Apex Gold 2592, Apex Gold } \\
\text { 2582, Apex Gold 2572, Apex Gold 2562,Apex Gold 2552, Apex Gold 2542, } \\
\text { Apex Gold 2532, Apex Gold 2527, Apex Gold 2522, Apex Gold 2519, Apex } \\
\text { Gold 2593,Apex Gold 2583, Apex Gold 2573, Apex Gold 2563, Apex Gold } \\
\text { 2553. }\end{array}$ & AN & Orica \\
\hline $\begin{array}{l}\text { Apex Gold 2500, 2501 Series } \\
\text { Other Names: Apex Gold 2540, 2530, 2525, 2520, 2517, 2591, 2581, 2571, } \\
\text { 2561, } 2551\end{array}$ & AN & Orica \\
\hline EMGEL 200, EMGEL 200 MS or MS+ & AN & $\begin{array}{l}\text { Mining Services } \\
\text { International } \\
\text { Incorporated }\end{array}$ \\
\hline $\begin{array}{l}\text { Ammonium Nitrate } \\
\text { Other Names: Superprill }{ }^{\mathrm{TM}} \text {, Prilled Ammonium Nitrate, Industrial Grade } \\
\text { LoDAN, Ammonium Nitrate, Industrial Grade HiDAN, Ammonium Nitrate, } \\
\text { Agricultural Grade }\end{array}$ & AN & $\begin{array}{l}\text { DYNO NOBEL } \\
\text { INC }\end{array}$ \\
\hline $\begin{array}{l}\text { Ammonium Nitrate } \\
\text { Other Names: Ammonium Nitrate } 10 \% \text { N Liquid Fertilizer }\end{array}$ & AN & $\begin{array}{l}\text { DYNO NOBEL } \\
\text { INC }\end{array}$ \\
\hline $\begin{array}{l}\text { Ammonium Nitrate Solutions } \\
\text { Other Names: Ammonium Nitrate Liquor, } 83 \% \text {, DYNO NAL }\end{array}$ & AN & $\begin{array}{l}\text { DYNO NOBEL } \\
\text { INC }\end{array}$ \\
\hline Ammonium Nitrate Prills & AN & $\begin{array}{l}\text { AUSTIN Powder } \\
\text { Company }\end{array}$ \\
\hline EMGEL 250, EMGEL $250 \mathrm{MS}$ or MS+ & $\mathrm{AN}+\mathrm{Al}$ & $\begin{array}{l}\text { Mining Services } \\
\text { International } \\
\text { Incorporated }\end{array}$ \\
\hline Ammonium Nitrate-Fuel Oil Mixture, ANFO, Austinite 15, Austinite 30 & AN + Fuel Oil & $\begin{array}{l}\text { AUSTIN Powder } \\
\text { Company }\end{array}$ \\
\hline HEF (Bulk) & $\mathrm{AN}+$ Fuel Oil & $\begin{array}{l}\text { Mining Services } \\
\text { International } \\
\text { Incorporated }\end{array}$ \\
\hline HEF-XLC (All Grades), HEF-1000 XL & $\mathrm{AN}+$ Fuel Oil & $\begin{array}{l}\text { Mining Services } \\
\text { International } \\
\text { Incorporated }\end{array}$ \\
\hline $\begin{array}{l}\text { Handi-Bulk / Powerbulk Series } \\
\text { Other Names: Handi-Bulk 2002B, Handi-Bulk 2002P, Handi-Bulk 2002HP, }\end{array}$ & AN + Sodium Nitrate & Orica \\
\hline
\end{tabular}




\begin{tabular}{|c|c|c|}
\hline $\begin{array}{l}\text { RXL 755, RXL 755B, RXL 755HP, Magnafrac 3402/3400 Series, Handi- } \\
\text { Bulk 2092, Handi-Bulk 2082, Handi-Bulk 2072, Handi-Bulk 2093, Handi- } \\
\text { Bulk 2083, Handi-Bulk 2073, Handi-Bulk 2063, Handi-Bulk 2092HP, Handi- } \\
\text { Bulk 2082HP, Handi-Bulk 2072HP, Handi-Bulk 2062HP, Handi-Bulk 2005P, } \\
\text { Handi-Bulk 2005, Handi-Bulk 2005HP, Powerbulk VE, Powerbulk series }\end{array}$ & & \\
\hline $\begin{array}{l}\text { UltrAN } \\
\text { Other Names: Not available }\end{array}$ & AN + Triethylene glycol & Orica \\
\hline $\begin{array}{l}\text { AMEX, AMEX HD, ANFO } \\
\text { Other Names: Ammonium Nitrate Fuel Oil }\end{array}$ & AN + Diesel Fuel Oil & Orica \\
\hline $\begin{array}{l}\text { Apex Super } 6000 \\
\text { Other Names: NBL-4093 }\end{array}$ & $\mathrm{AN}+\mathrm{MMAN}$ & Orica \\
\hline Amex WR & $\mathrm{AN}+$ Guar Gum & Orica \\
\hline $\begin{array}{l}\text { Apex Elite } \\
\text { Other Names: BL985 }\end{array}$ & $\mathrm{AN}+$ Sodium Nitrate $+\mathrm{Al}$ & Orica \\
\hline $\begin{array}{l}\text { Emulsion Explosives, Packaged } \\
\text { Other Names: BLASTGEL® E }\end{array}$ & $\begin{array}{l}\text { AN }+ \text { Calcium Nitrate }+ \\
\text { Mineral Oil }\end{array}$ & $\begin{array}{l}\text { DYNO NOBEL } \\
\text { INC }\end{array}$ \\
\hline $\begin{array}{l}\text { Apex Super } 4000 \\
\text { Other Names: NBL-4091-1 }\end{array}$ & $\mathrm{AN}+\mathrm{MMAN}+\mathrm{AL}$ & Orica \\
\hline HE-1 Through HE-12, Aluminized ANFO & $\mathrm{AN}+$ Fuel Oil + Al & $\begin{array}{l}\text { AUSTIN Powder } \\
\text { Company }\end{array}$ \\
\hline Austinite WR 300, Water Resistant ANFO & AN + Fuel Oil + Guar Gum & $\begin{array}{l}\text { AUSTIN Powder } \\
\text { Company }\end{array}$ \\
\hline $\begin{array}{l}\text { HEET } 10 \text { SERIES, HEET } 100 \text { SERIES } \\
\text { Examples: HEET } 30 \text {, HEET } 50 \text {, HEET 130, HEET } 150\end{array}$ & $\begin{array}{l}\mathrm{AN}+\text { Fuel Oil/Mineral Oil } \\
+\mathrm{Al}\end{array}$ & $\begin{array}{l}\text { AUSTIN Powder } \\
\text { Company }\end{array}$ \\
\hline Hydrox 501, Hydrox 503 & $\begin{array}{c}\text { AN + Fuel Oil + Mineral Oil } \\
\text { note: Florida Products } \\
\text { contain Polymeric } \\
\text { Surfactant } \\
\text { *Hydrox products made and } \\
\text { used in Florida contain only } \\
\text { this oil and do not contain } \\
\text { the fuel oil/mineral oil } \\
\text { blend. }\end{array}$ & $\begin{array}{l}\text { AUSTIN Powder } \\
\text { Company }\end{array}$ \\
\hline $\begin{array}{l}\text { Coalmex 14E (Permissible Emulsion), Red-D Lite, AXE 129, Enviroseis } \\
\text { Surface. Note: Enviroseis Surface includes a continuous length of Detonating } \\
\text { Cord. See Detonating Cord MSDS. }\end{array}$ & $\begin{array}{c}\text { AN + EDDN + Sodium } \\
\text { Nitrate + Petroleum } \\
\text { Hydrocarbons } \\
\end{array}$ & $\begin{array}{l}\text { AUSTIN Powder } \\
\text { Company }\end{array}$ \\
\hline XACTEX & $\mathrm{AN}+\mathrm{NG}+$ Sodium Nitrate & Orica \\
\hline $\begin{array}{l}\text { ANFO- Ammonium Nitrate \& Fuel Oil Mixture, Explosive, Blasting, Type } \\
\text { B, WR ANFO-Explosive, Blasting, Type B }\end{array}$ & AN + Fuel Oil + Guar Gum & $\begin{array}{l}\text { Mining Services } \\
\text { International } \\
\text { Incorporated } \\
\end{array}$ \\
\hline EMGEL 600 & $\begin{array}{c}\text { AN }+ \text { Sodium Perchlorate }+ \\
\text { Al }\end{array}$ & $\begin{array}{l}\text { Mining Services } \\
\text { International } \\
\text { Incorporated }\end{array}$ \\
\hline $\begin{array}{l}\text { Gelatin dynamite } \\
\text { Other Names: GELATINA ESPECIAL }\end{array}$ & $\mathrm{AN}+\mathrm{NG}+\mathrm{NC}+\mathrm{EGDN}$ & $\begin{array}{l}\text { Mining Services } \\
\text { International } \\
\text { Incorporated } \\
\end{array}$ \\
\hline $\begin{array}{l}\text { Gelatin dynamite } \\
\text { EXSADITCH }\end{array}$ & $\begin{array}{l}\mathrm{AN}+\mathrm{NG}+\mathrm{NC}+\mathrm{EGDN} \\
\quad \text { Sodium Nitrate }\end{array}$ & $\begin{array}{l}\text { Mining Services } \\
\text { International } \\
\text { Incorporated } \\
\end{array}$ \\
\hline Apex Super $6000 H$, Apex Super $3000 H$ & $\begin{array}{l}\text { AN + HMT + Nitric Acid + } \\
\text { Sodium Perchlorate }\end{array}$ & Orica \\
\hline $\begin{array}{l}\text { L-371, BL-372, BL-373, BL-374 } \\
\text { Other Names: Amex K }\end{array}$ & $\begin{array}{c}\text { AN }+ \text { Carbonic acid }+ \\
\text { Dipotassium salt }+ \text { kerosene }\end{array}$ & Orica \\
\hline Apex Super $6000 \mathrm{H}$, Apex Super $3000 \mathrm{H}$ & $\begin{array}{l}\text { AN + HMTD + Nitric Acid } \\
+ \text { Sodium }\end{array}$ & Orica \\
\hline $\begin{array}{l}\text { Atlas 7D, Orica Loggers, Powerex, Powerex Plus, Powerex C, Powerex Plus } \\
\text { C }\end{array}$ & $\begin{array}{l}\text { AN + EDDN + Sodium } \\
\text { Nitrate + Sorbitan Oleate }\end{array}$ & Orica \\
\hline GIANITE & $\begin{array}{c}\mathrm{AN}+\mathrm{NC}+\mathrm{DNT}+\text { Dibutyl } \\
\text { phthalate }\end{array}$ & Orica \\
\hline $\begin{array}{l}\text { Magnafrac, Magnafrac HW, Magnafrac Plus, Magnafrac Plus HW, } \\
\text { Magnagel, Magnum Plus, Magnum Plus HW, Magnum Ultra, Magnum Ultra } \\
\text { HW, Powergel Razorback }\end{array}$ & $\begin{array}{l}\mathrm{AN}+\text { Sodium Nitrate }+ \\
\text { Sodium Perchlorate }+\mathrm{Al}\end{array}$ & Orica \\
\hline $\begin{array}{l}\text { POWERNEL 200, POWERNEL 1500, POWERNEL 2000, POWERNEL } \\
\text { 2000/KA, POWERNEL 3000, POWERNEL PLUS, POWERNEL BULK } \\
\text { EMULSION } \\
\text { Other Names: Emulsion }\end{array}$ & $\begin{array}{l}\text { AN + Mineral Oil }+ \\
\text { Polyolefin Amino- ester Salt }\end{array}$ & Orica \\
\hline
\end{tabular}




\begin{tabular}{|c|c|c|}
\hline Explosives & & \\
\hline $\begin{array}{l}\text { Cone Pak/ Mini Cone Pak } \\
\text { Other Names: Plastic cones packed with Magnafrac explosive }\end{array}$ & $\begin{array}{l}\text { AN }+ \text { Sodium Nitrate }+ \\
\text { Sodium Thiocyanate }+ \\
\text { Sodium nitrite }+\mathrm{Al}\end{array}$ & Orica \\
\hline Apex Super $6000 \mathrm{H}$, Apex Super $3000 \mathrm{H}$ & $\begin{array}{l}\text { AN + HMTD + Nitric Acid } \\
+ \text { Sodium }\end{array}$ & Orica \\
\hline $\begin{array}{l}\text { FLEXIGEL SERIES, APEX CLEAR } \\
\text { Other Names: Flexigel Coal * Flexigel Advantage * Flexigel Control * } \\
\text { Flexigel Clear * Flexigel Eclipse }\end{array}$ & $\begin{array}{l}\text { AN + Fuel diesel + Mineral } \\
\text { Oil + Sodium Nitrite }\end{array}$ & Orica \\
\hline $\begin{array}{l}\text { Magnafrac, Magnafrac HW, Magnafrac Plus, Magnafrac Plus HW, } \\
\text { Magnagel, Magnum Plus, Magnum Plus HW, Magnum Ultra, Magnum Ultra } \\
\text { HW, Powergel Razorback }\end{array}$ & $\begin{array}{l}\text { AN }+ \text { Sodium Nitrate }+ \\
\text { Sodium Perchlorate }+ \text { Al }\end{array}$ & Orica \\
\hline $\begin{array}{l}\text { Magnafrac, Magnafrac HW, Magnafrac Plus, Magnafrac Plus HW, } \\
\text { Magnagel, Magnum Plus, Magnum Plus HW, Magnum Ultra, Magnum Ultra } \\
\text { HW, Powergel Razorback }\end{array}$ & $\begin{array}{l}\text { AN }+ \text { Sodium Nitrate }+ \\
\text { Sodium Perchlorate }+ \text { Al }\end{array}$ & Orica \\
\hline $\begin{array}{l}\text { Atlas 7D, Orica Loggers, Powerex, Powerex Plus, Powerex C, Powerex Plus } \\
\text { C }\end{array}$ & $\begin{array}{c}\text { AN + EDDN + Sodium } \\
\text { Nitrate + Sorbitan Oleate }\end{array}$ & Orica \\
\hline GIANITE & $\begin{array}{c}\mathrm{AN}+\mathrm{NC}+\mathrm{DNT}+\text { Dibutyl } \\
\text { phthalate }\end{array}$ & Orica \\
\hline $\begin{array}{l}\text { POWERNEL 200, POWERNEL 1500, POWERNEL 2000, POWERNEL } \\
\text { 2000/KA, POWERNEL 3000, POWERNEL PLUS, POWERNEL BULK } \\
\text { EMULSION } \\
\text { Other Names: Emulsion Explosives }\end{array}$ & $\begin{array}{c}\text { AN + Mineral Oil + } \\
\text { Polyolefin Amino- ester Salt }\end{array}$ & Orica \\
\hline $\begin{array}{l}\text { Cone Pak/ Mini Cone Pak } \\
\text { Other Names: Plastic cones packed with Magnafrac explosive }\end{array}$ & $\begin{array}{l}\text { AN }+ \text { Sodium Nitrate }+ \\
\text { Sodium Thiocyanate }+ \\
\text { Sodium nitrite }+\mathrm{Al}\end{array}$ & Orica \\
\hline $\begin{array}{l}\text { FLEXIGEL SERIES, APEX CLEAR } \\
\text { Other Names: Flexigel Coal * Flexigel Advantage * Flexigel Control * } \\
\text { Flexigel Clear* Flexigel Eclipse }\end{array}$ & $\begin{array}{l}\text { AN + Fuel diesel + Mineral } \\
\text { Oil + Sodium Nitrite }\end{array}$ & Orica \\
\hline $\begin{array}{l}\text { Magnafrac, Magnafrac HW, Magnafrac Plus, Magnafrac Plus HW, } \\
\text { Magnagel, Magnum Plus, Magnum Plus HW, Magnum Ultra, Magnum Ultra } \\
\text { HW, Powergel Razorback }\end{array}$ & $\begin{array}{l}\mathrm{AN}+\text { Sodium Nitrate }+ \\
\text { Sodium Perchlorate }+\mathrm{Al}\end{array}$ & Orica \\
\hline Apex Super $6000 \mathrm{H}$, Apex Super $3000 \mathrm{H}$ & $\begin{array}{c}\text { AN + HMTD + Nitric Acid } \\
+ \text { Sodium }\end{array}$ & Orica \\
\hline GIANITE & $\begin{array}{c}\mathrm{AN}+\mathrm{NC}+\mathrm{DNT}+\text { Dibutyl } \\
\text { phthalate }\end{array}$ & Orica \\
\hline $\begin{array}{l}\text { Magnafrac, Magnafrac HW, Magnafrac Plus, Magnafrac Plus HW, } \\
\text { Magnagel, Magnum Plus, Magnum Plus HW, Magnum Ultra, Magnum Ultra } \\
\text { HW, Powergel Razorback }\end{array}$ & $\begin{array}{l}\text { AN }+ \text { Sodium Nitrate }+ \\
\text { Sodium Perchlorate }+\mathrm{Al}\end{array}$ & Orica \\
\hline $\begin{array}{l}\text { FLEXIGEL SERIES, APEX CLEAR } \\
\text { Other Names: Flexigel Coal * Flexigel Advantage * Flexigel Control * } \\
\text { Flexigel Clear * Flexigel Eclipse }\end{array}$ & $\begin{array}{l}\text { AN }+ \text { Fuel diesel }+ \text { Mineral } \\
\quad \text { Oil + Sodium Nitrite }\end{array}$ & Orica \\
\hline $\begin{array}{l}\text { Magnafrac, Magnafrac HW, Magnafrac Plus, Magnafrac Plus HW, } \\
\text { Magnagel, Magnum Plus, Magnum Plus HW, Magnum Ultra, Magnum Ultra } \\
\text { HW, Powergel Razorback }\end{array}$ & $\begin{array}{l}\text { AN }+ \text { Sodium Nitrate }+ \\
\text { Sodium Perchlorate }+ \text { Al }\end{array}$ & Orica \\
\hline $\begin{array}{l}\text { POWERNEL 200, POWERNEL 1500, POWERNEL 2000, POWERNEL } \\
\text { 2000/KA, POWERNEL 3000, POWERNEL PLUS, POWERNEL BULK } \\
\text { EMULSION } \\
\text { Other Names: Emulsion Explosives }\end{array}$ & $\begin{array}{c}\text { AN + Mineral Oil }+ \\
\text { Polyolefin Amino- ester Salt }\end{array}$ & Orica \\
\hline $\begin{array}{l}\text { Pre-split Explosives, Emulsion with Detonating Cord } \\
\text { Other Names: DYNOSPLIT® E }\end{array}$ & $\begin{array}{l}\mathrm{AN}+\mathrm{PETN}+\text { Sodium } \\
\text { Nitrate }+\mathrm{Al} \\
\end{array}$ & $\begin{array}{l}\text { DYNO NOBEL } \\
\text { INC } \\
\end{array}$ \\
\hline $\begin{array}{l}\text { ANFO, Bulk or Packaged } \\
\text { Other Names: ANFO DYNOMIX'TM, DYNOMIX } \\
\text { WR, DYNOMIX (U.G.), DYNOMIX }{ }^{\mathrm{TM}} \\
\end{array}$ & $\begin{array}{l}\text { AN }+ \text { Fuel Oil }+ \text { Guar Gum } \\
\text { Fuel OiL }\end{array}$ & $\begin{array}{l}\text { DYNO NOBEL } \\
\text { INC }\end{array}$ \\
\hline "Non-Current Products" Hydromite HE-25 & $\begin{array}{c}\mathrm{AN}+\text { Sodium Nitrate }+\mathrm{Al}+ \\
\text { Petroleum Hydrocarbons }\end{array}$ & $\begin{array}{c}\text { AUSTIN Powder } \\
\text { Company }\end{array}$ \\
\hline $\begin{array}{l}\text { Seismex MH, Emulex 500, } 700 \& 900 \text { Series, AXE } 100 \text { to 499, Primegel, } \\
\text { Coalmex (Permissible Emulsion), Red-D Prime, Enviroseis Emulsions, } \\
\text { Emuline and Emuline 33, Red-D Lite-E }\end{array}$ & $\begin{array}{c}\text { AN }+ \text { Sodium Nitrate }+ \\
\text { Petroleum Hydrocarbons }+ \\
\text { Al } \\
\end{array}$ & $\begin{array}{l}\text { AUSTIN Powder } \\
\text { Company }\end{array}$ \\
\hline Hydromite 400 Series & $\begin{array}{c}\text { AN + HMT + Nitric Acid }+ \\
\text { Ammonium Perchlorate }+ \\
\text { Sodium Perchlorate }+ \\
\text { Ethylene Glycol }+ \text { Al }\end{array}$ & $\begin{array}{l}\text { AUSTIN Powder } \\
\text { Company }\end{array}$ \\
\hline $\begin{array}{l}\text { Emulsion Explosives, Packaged } \\
\text { Other Names: DYNO AP, DYNO® AP PLUS,DYNO® AP PLUS LD, } \\
\text { DYNO® E5, DYNO® MC, DYNO® MC PLUS, DYNO® SL, DYNO® SL }\end{array}$ & $\begin{array}{c}\mathrm{AN}+\underset{\text { Sodium Nitrate }}{\text { Mineral Oil }} \\
\mathrm{Al}+\end{array}$ & $\begin{array}{l}\text { DYNO NOBEL } \\
\text { INC }\end{array}$ \\
\hline
\end{tabular}




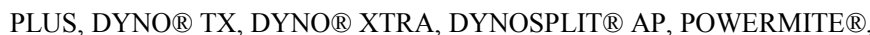
POWERMITE® AP, POWERMITE $®$ Canadian, POWERMITE $®$ LD, POWERMITE $®$ LD PLUS, POWERMITE $®$ PLUS, POWERMITE $®$ RAISE BOMB $^{\text {TM }}$, POWERMITE $®$ SL, POWERMITE ${ }^{\circledR}$ SL PLUS

Hydormite Emulsions

Other Names: Hydromite 600 Series, Hydromite 800 Series, Hydromite 1000 Series, Hydromite 2000 Series, Hydromite 3000 Series, Hydromite 4000 Series

Emulsion Explosives, Packaged

Other Names: Seispro ${ }^{\mathrm{TM}}$, Seispro ${ }^{\mathrm{TM}} \mathrm{dBX}^{\mathrm{TM}}$

Atlas 7D, Orica Loggers, Powerex, Powerex Plus, Powerex C, Powerex Plus

C

Emulsion Explosives, Packaged

Other Names: BLASTEX®, BLASTEX® PLUS, BLASTEX $®$ PLUS HD,

BLASTEX ${ }^{\circledR}$ TX, BLASTEX ${ }^{\circledR}$ TX PLUS, DX-2011, DX-2012, DYNOTEX, SUPER BLASTEX ${ }^{\circ}$, SUPER BLASTEX ${ }^{\circledR}$ TX, DYNO ${ }^{1} 1.5 \mathrm{SB}, \mathrm{DYNO}{ }^{\circledR}$ $1.5 \mathrm{SBC}, \mathrm{DYNO}{ }^{\circledR} 1.5 \mathrm{SB} 30, \mathrm{DYNO}{ }^{\circledR} 900$, DYNO ${ }^{\circledR} 1300$, DYNO ${ }^{\circledR} 1500$, DYNO $® 1520$, DYNO $® 1540$

Red Diamond Series, Red-D-Gel Series

Bulk and Packaged Water Gel Explosives

Other Names: BLASTGEL $\mathbb{R}$

POWERDITCH 1000, POWERPRO, POWERFRAC, GELDYNE, COALITE 8SU, DYNASHEAR, GEL COALITE Z, XACTEX, GEOGEL

Cone Pak/ Mini Cone Pak

Other Names: Plastic cones packed with Magnafrac explosive

Extra Gelatin Series, Apcogel Series, 60\% Seis Gel, AL Series, HELIX PNG 80, HELIX PNG 90

"Non-Current Products" Extra Dynamite Series, AXD 500 Series, Red-E Split Series

POWERDITCH 1000, POWERPRO, POWERFRAC, GELDYNE, COALITE 8SU, DYNASHEAR, GEL COALITE Z, XACTEX, GEOGEL

\section{Emulsion Bulk}

Other Names: DYNO GOLD, DYNOGOLD ${ }^{\circledR}$ C, DYNO GOLD ${ }^{\circledR} \mathrm{C}$ EXTRA, DYNO GOLD ${ }^{\circledR}$ C LITE, DYNO GOLD ${ }^{\circledR}$ C LITE SUPER, DYNO GOLD ${ }$ CS LITE, DYNO GOLD $®$ LITE, DYNO GOLD $®$ B, DYNO GOLD $®$ B LITE, TITAN 1000, TITAN $® 1000$ G, TITAN $®$ PB 1000 , TITAN ${ }$ XL1000, TITAN $® 2000$, TITAN $® 2000 \mathrm{G}$

Emulsion Explosives, Bulk

Other Names: DYNO GOLD® AP LD, DYNO GOLD ${ }^{\circledR}$ B LD, DYNO GOLD ${ }^{\circledR}$ B SD, DYNO GOLD® C LD, DYNO GOLD ${ }^{\circledR}$ C SD, DYNO

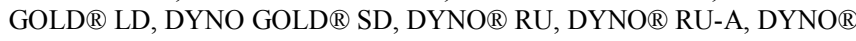
RU-B, DYNO ${ }^{\circledR}$ RU Alaska, DYNO ${ }^{\circledR}$ RU SX, DYNO ${ }^{2}$ RU SX, RD-5 ${ }^{\mathrm{TM}}$ RUG, RUS, RUS-C, TITAN ${ } 1000$ LD, TITAN $® 1000$ SD, TITAN® PB 1000 LD, TITAN $®$ PB 1000 SD, 1136

Dynamites and Blasting Gelatins

Other Names: D-GEL ${ }^{\text {TM }} 1000$, DYNOSPLIT® : D1, D 3/4, D 7/8, EXTRA GELATIN: $40 \%, 75 \%$, GELAPRIME® F, UNIGEL $®$, UNIMAX®,

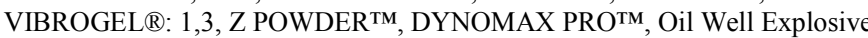
$80 \%$, Oil Well Explosive $100 \%$, STONECUTTER ${ }^{\mathrm{TM}}$, REDH ${ }^{\circledR}$ A, RED H® B, POWERGEL D, $60 \%$ Hi-Pressure Gelatin, IRESPLIT $®$ D,IP: 724, 738

Emulsion Explosives, Packaged

Other Names: DYNO ${ }^{\circledR} 1.5 \mathrm{HD}$

"Non-Current Products" Emutrench

SLURMEX 300, SLURMEX 500, AQUALINE, EMULINE SE, Note: Aqualine and Emuline SE are Slurmex products that include a continuous length of Detonating Cord

\begin{tabular}{|c|c|}
\hline $\begin{array}{l}\text { AN + Polymeric Surfactant } \\
+ \text { Fuel Oil/ Mineral Oil + Al }\end{array}$ & $\begin{array}{l}\text { AUSTIN Powder } \\
\text { Company }\end{array}$ \\
\hline $\begin{array}{c}\mathrm{AN}+\text { Sodium Nitrate }+\mathrm{Al}+ \\
\text { Mineral Oil }\end{array}$ & $\begin{array}{l}\text { DYNO NOBEL } \\
\text { INC }\end{array}$ \\
\hline $\begin{array}{c}\text { AN + EDDN + Sodium } \\
\text { Nitrate + Sorbitan Oleate }\end{array}$ & Orica \\
\hline $\begin{array}{c}\mathrm{AN}+\text { Sodium Nitrate }+\mathrm{Al}+ \\
\text { Mineral Oil }+ \text { Kerosene }\end{array}$ & $\begin{array}{l}\text { DYNO NOBEL } \\
\text { INC }\end{array}$ \\
\hline $\begin{array}{c}\mathrm{NG}+\mathrm{EGDN}+\mathrm{NC}+\mathrm{AN}+ \\
\text { Sodium Nitrate }\end{array}$ & $\begin{array}{l}\text { AUSTIN Powder } \\
\text { Company }\end{array}$ \\
\hline $\begin{array}{c}\text { AN + Sodium Perchlorate }+ \\
\text { Fuel Oil } \\
\text { Reaction Products of: } \\
\text { HMT + Nitric Acid }\end{array}$ & $\begin{array}{l}\text { DYNO NOBEL } \\
\text { INC }\end{array}$ \\
\hline $\begin{array}{c}\mathrm{AN}+\mathrm{NG}+\mathrm{EGDN}+\mathrm{NC}+ \\
\mathrm{S}+\text { Sodium chloride }+ \\
\text { Ammonium chloride }+ \\
\text { Sodium Nitrate }\end{array}$ & Orica \\
\hline $\begin{array}{c}\text { AN }+ \text { Sodium Nitrate }+ \\
\text { Sodium Thiocyanate }+ \\
\text { Sodium nitrite }+ \text { Al }\end{array}$ & Orica \\
\hline $\begin{array}{l}\mathrm{NG}+\mathrm{EGDN}+\mathrm{NC}+\mathrm{AN}+ \\
\quad \text { Sodium Nitrate }+\mathrm{S}\end{array}$ & $\begin{array}{l}\text { AUSTIN Powder } \\
\text { Company }\end{array}$ \\
\hline $\begin{array}{c}\mathrm{NG}+\mathrm{EGDN}+\mathrm{NC}+\mathrm{AN}+ \\
\text { Sodium Nitrate }+\mathrm{S} \\
\end{array}$ & $\begin{array}{c}\text { AUSTIN Powder } \\
\text { Company }\end{array}$ \\
\hline $\begin{array}{c}\mathrm{AN}+\mathrm{NG}+\mathrm{EGDN}+\mathrm{NC}+ \\
\mathrm{S}+\text { Sodium chloride }+ \\
\text { Ammonium chloride }+ \\
\text { Sodium Nitrate } \\
\end{array}$ & Orica \\
\hline $\begin{array}{c}\text { AN }+ \text { Sodium Nitrate }+ \\
\text { Calcium Nitrate }+ \text { Sodium } \\
\text { Nitrate }+ \text { Fuel Oil + Mineral } \\
\text { Oil }+ \text { Al }\end{array}$ & $\begin{array}{l}\text { DYNO NOBEL } \\
\text { INC }\end{array}$ \\
\hline $\begin{array}{c}\text { AN + Sodium Nitrate }+ \\
\text { Calcium Nitrate + Sodium } \\
\text { Nitrate + Fuel Oil + Mineral } \\
\text { Oil + Al }\end{array}$ & $\begin{array}{l}\text { DYNO NOBEL } \\
\text { INC }\end{array}$ \\
\hline $\begin{array}{l}\mathrm{NG}+\mathrm{EGDN}+\mathrm{NC}+\mathrm{AN}+ \\
\quad \text { Sodium Nitrate }+\mathrm{S}\end{array}$ & $\begin{array}{l}\text { DYNO NOBEL } \\
\text { INC }\end{array}$ \\
\hline $\begin{array}{c}\mathrm{AN}+\mathrm{NC}+\mathrm{EDGN}+ \\
\text { Dibutylphthalate }+\mathrm{DNT}+ \\
\text { Diphenylamine }\end{array}$ & $\begin{array}{l}\text { DYNO NOBEL } \\
\text { INC }\end{array}$ \\
\hline $\begin{array}{c}\text { AN + EDDN + Sodium } \\
\text { Nitrate + Petroleum } \\
\text { Hydrocarbons + Al }\end{array}$ & $\begin{array}{l}\text { AUSTIN Powder } \\
\text { Company }\end{array}$ \\
\hline $\begin{array}{c}\text { AN }+ \text { Sodium Nitrate }+ \\
\text { Nitric Acid }+ \text { Al + Sodium } \\
\text { Perchlorate + HMT }\end{array}$ & $\begin{array}{l}\text { AUSTIN Powder } \\
\text { Company }\end{array}$ \\
\hline
\end{tabular}




\begin{tabular}{|c|c|c|}
\hline Rock-Buster II & $\begin{array}{c}\mathrm{NG}+\text { EGDN + AN + 1,2 } \\
\text { Propylene Glycol + Sodium } \\
\text { Bisulfate + Sodium } \\
\text { Metaborate }\end{array}$ & $\begin{array}{l}\text { AUSTIN Powder } \\
\text { Company }\end{array}$ \\
\hline $\begin{array}{l}\text { Powermex } \\
\text { Other Names: Powermex Plus }\end{array}$ & $\begin{array}{c}\text { AN + MMAN + Sodium } \\
\text { Nitrate + Calcium Nitrate + } \\
\text { Fuel Oil + Guar Gum + } \\
\text { Carbonaceous Fuel + Perlite } \\
+ \text { Polypropylene Glycol + } \\
\text { Polyacrylamide + } \\
\text { amorphous silica + Al + } \\
\text { Soda lime borosilicate glass }\end{array}$ & Orica \\
\hline
\end{tabular}

120. http://www.ime.org/ accessed on 6/07 


\section{IFRI / NFSTC Certification Sheet}

Certification results for:

Handler's Title and Name (as it will appear on certificate)

\begin{tabular}{|c|c|c|}
\hline Handler's Agency \& Address & Phone \# & Fax \# \\
\hline K-9's name & Trainer's & ency \\
\hline
\end{tabular}

Location of certification $\quad$ Date of certification

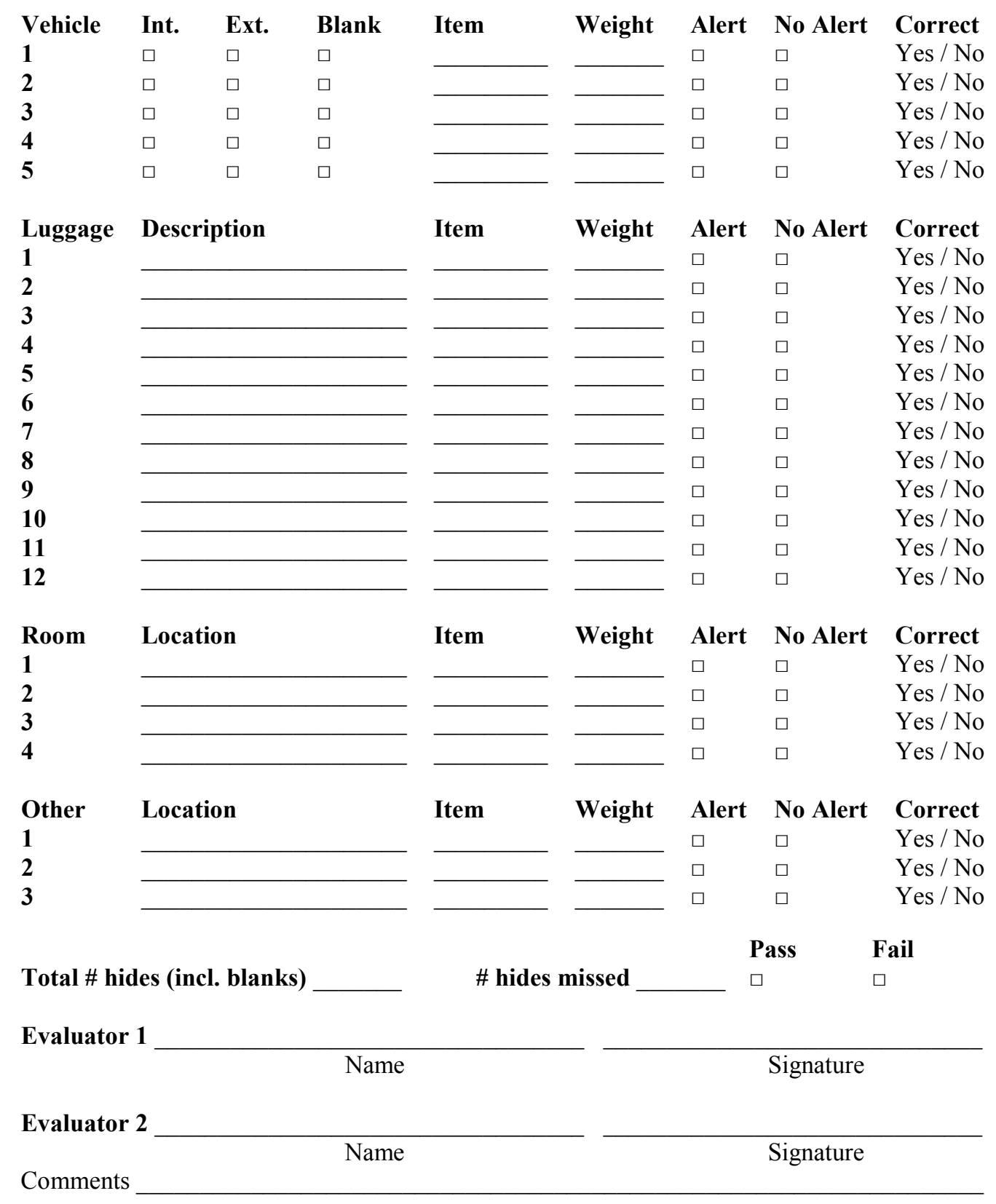


VITA

MICHAEL SALVADOR MACIAS

1977

2001

2003

2004

$2004-2006$

$2005-2009$

$2005-2009$

2006

2006

2007
Born, Atlanta, Georgia

B.S., Electrical Engineering

Clemson University, Clemson, South Carolina

Undergraduate Research Assistant

University of South Carolina, Columbia, South Carolina

B.S., Chemistry

University of South Carolina, Columbia, South Carolina

Graduate Teaching Assistant

Florida International University, Miami, Florida

Graduate Research Associate

Florida International University, Miami, Florida

Detection Canine Certification Evaluator

International Forensic Research Institute, Miami, Florida

Outstanding General Chemistry Teaching Assistant

ACS, South Florida Section

Student Poster Award

Federation of Analytical Chemistry and Spectroscopy Societies

Alpha Epsilon Lambda, National Graduate Honor Society

Florida International University, Miami, Florida

\section{PUBLICATIONS AND PRESENTATIONS}

Macias, M.S.; Harper, R.J.; Furton, K.G. A Comparison of Real vs. Pseudo Contraband for Reliable Detector Dog Training, Criminalistics Poster Session, 58th Annual American Academy of Forensic Sciences Meeting, Seattle, WA, February 2006.

Macias, M.S.; Harper, R.J.; Furton, K.G. The Use of SPME-GC/MS for the Analysis of VOC's of Contraband and Simulated Contraband, PittCon 2006, Orlando, FL, March 2006.

Macias, M.S.; Harper, R.J.; Furton, K.G. Development, Testing, and Comparison of Detector Dog Training Aids with Commercial Products and Actual Contraband, ACS Florida Annual Meeting and Exposition (FAME), Orlando, FL, May 2006. 
Macias, M.S. and Furton, K.G. Development of reliable, contraband mimics for biological/instrumental training aids/calibration standards using SPME/GC-MS, Federation of Analytical Chemistry and Spectroscopy Societies (FACSS), Orlando, FL, September, 2006

Furton, K.G.; Kusano, M.; Macias, M.S. 'Gas Chromatography: Forensic Applications', Encyclopedia of Separation Science (L3), Elsevier Ltd., 2007.

Macias, M.S. and Furton, K.G. Explosive Training Aid Variance Affecting Canine Detection, Criminalistics Poster Session, 59th Annual Scientific Meeting of the American Academy of Forensic Sciences, San Antonio, TX, February 2007.

Guerra, P.; Macias, M.S.; Furton K.G.; Almirall, J.R. Field Detection of Drug and Explosive Odor Signatures Using SPME-IMS, NIJ Grantees meeting, 59th Annual Scientific Meeting of the American Academy of Forensic Sciences, San Antonio, TX, February 2007.

Macias, M.S. and Furton, K.G. Explosive Training Aid Variance Affecting Canine Detection, ACS Florida Annual Meeting and Exposition (FAME), Orlando, FL, 2007.

Macias, M.S.; Harper, R.J.; Furton, K.G. A Comparison of Real Versus Simulated Contraband VOCs for Reliable Detector Dog Training Utilizing SPME-GC-MS, American Laboratory, 2008, 41(1), 16-19.

Macias, M.S. and Furton, K.G. Canine Detection using a Calibration Standard and an Optimized Explosive Training Aid System, Criminalistics Poster Session, 60th Annual Scientific Meeting of the American Academy of Forensic Sciences, Washington, DC, February 2008.

Macias, M.S.; Harper, R.J.; Furton, K.G. A Comparison of Real Versus Simulated Contraband VOCs for Reliable Detector Dog Training Utilizing SPME-GC-MS, American Biotechnology Laboratory, 2008, 26(6), 26-27.

Macias, M.S. and Furton, K.G. MDMA Synthesis Affecting Canine Detection, Criminalistics Session, 61th Annual Scientific Meeting of the American Academy of Forensic Sciences, Denver, CO, February 2009.

Macias, M.S.; Guerra-Diaz, P.; Almirall, J.R.; Furton, K.G. Detection of piperonal emitted from polymer controlled odor mimic permeation systems utilizing Canis familiaris and solid phase microextraction-ion mobility spectrometry, Forensic Science International, October 2009, in press.

Macias, M.S. and Furton, K.G. MDMA Synthesis Affecting Canine Detection, Criminalistics Session, Journal of Forensic Science, December 2009, submitted for review. 